\begin{tabular}{l|l|l} 
Universidad & Campus \\
Politécnica & de Excelencia \\
de Cartagena & Internacional
\end{tabular}

\title{
Effect of Micro-Encapsulated Phase Change Materials on the Mechanical Properties of Concrete
}

A thesis submitted for the degree of Doctor of Philosophy (PhD)

by

SHIMA PILEHVAR

Supervisors:

Prof. Ramón Pamies

Prof. Anna-Lena Kjøniksen

Cartagena, July 2018 


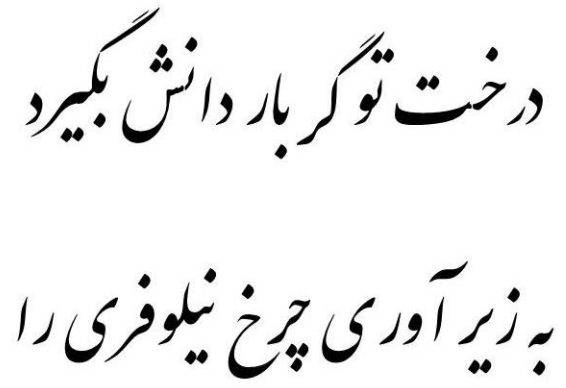

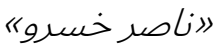

\section{Dedicated to}

all women in my homeland, Iran, who struggle for equality and emancipation particularly

\section{$M Y M O M$}

for raising me to believe that everything is possible for a woman even making concrete 


\section{Acknowledgements}

This thesis has been developed into the framework of an ambitious research project granted to the research group of Prof. Anna-Lena Kjøniksen at Østfold University College by the Research Council of Norway (project number 238198) and has been carried out in collaboration with the research group of Prof. Ramón Pamies in the facilities of the Department of Materials Engineering and Manufacturing, Technical University of Cartagena.

I wish to express my thanks to my advisors Prof. Anna-Lena Kjøniksen and Prof. Ramón Pamies for their constant guidance, encouragement, inspiration and support throughout this project. It was a privilege to be a student of them. They have given me plenty of opportunities to communicate the outcomes of the research in many ways.

I would like to acknowledge the valuable comments and advices that I received in different stages of my research work from Prof. Luca Valentini.

I am also hugely appreciative to Prof. Marcos Lanzón for his supporting during my experiments in his lab in spite of all mess I did there.

I sincerely acknowledge the unconditional help and support of Dr. Matteo Magistri and Dr. Davide Salvioni from MAPEI, Italy.

Thank you so much Susi for being my partner to create all funny stories during this time. I can never ever forget Kahoot, Sun Sun, leaving the mobile phone at the gym and our Friday lunch in my life. Ania, you are one of the nicest girls I have ever met in my life. I hope you forgive us for asking you to produce more than $100 \mathrm{~kg}$ microcapsules while we needed only $15 \mathrm{~kg}$.

I thank Vinh, Inge, Sikander, and Trond for the stimulating discussions and help with my research work in the last three years. 
My sincere thanks go to my Spanish friends Maria and Rosi for all café con leche and entertainments. I am grateful to Prof. José Ginés Hernandez for all adventures during my stay. I felt in Spain like at home.

Last but not the least, I am grateful to my family, my Mom, Atena, Sami, and Danial, for their constant support, prayers, and love for me. Baba, it hurts too much to think I never see you again, but I know you are with me and helping me through my life. 


\section{Table of Contents}

Resumen $\mathrm{XV}$

Summary xix

Thesis structure xxi

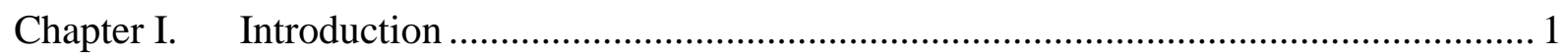

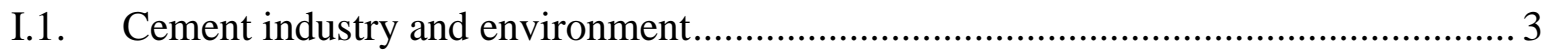

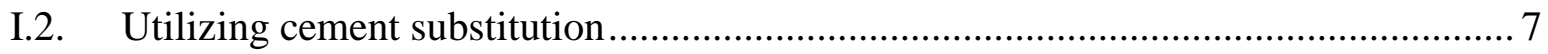

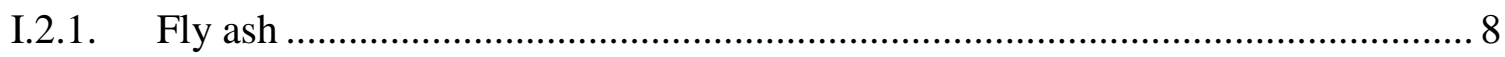

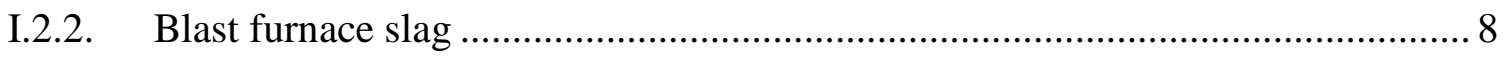

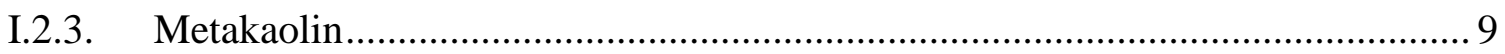

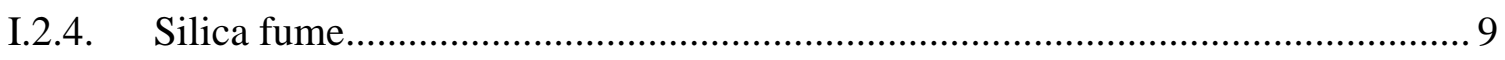

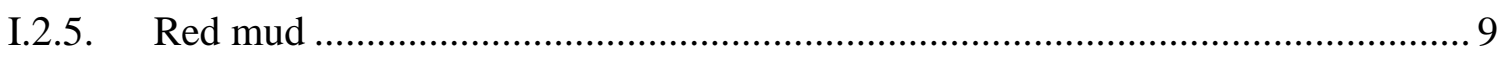

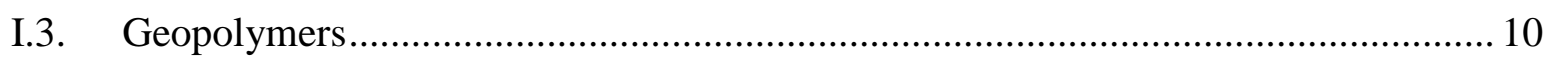

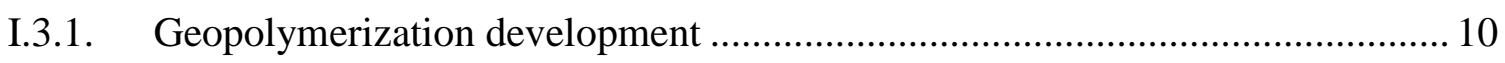

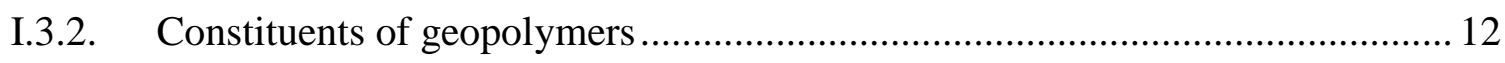

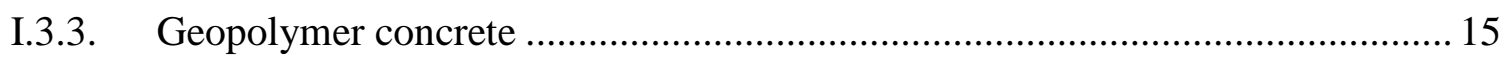

I.4. Micro-encapsulated phase change materials .................................................. 15

I.4.1. Micro-encapsulated phase change materials for passive buildings systems ...... 18

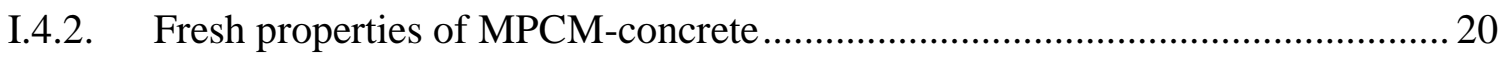

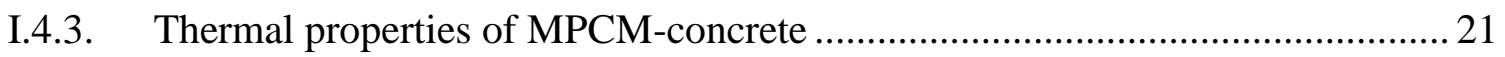

I.4.4. Mechanical properties of MPCM-concrete ….................................................. 21 


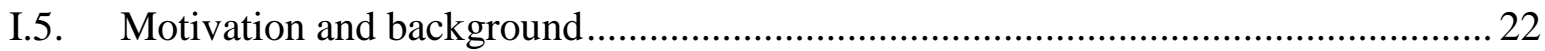

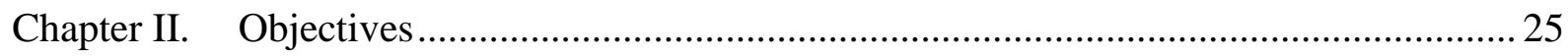

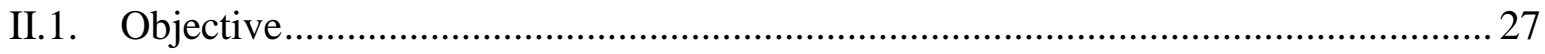

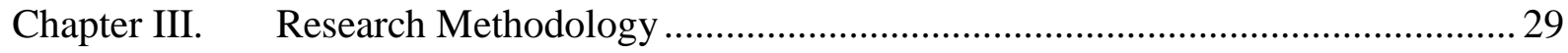

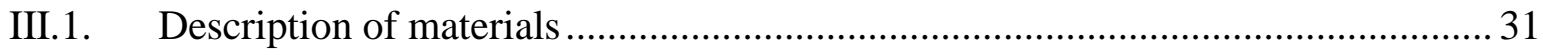

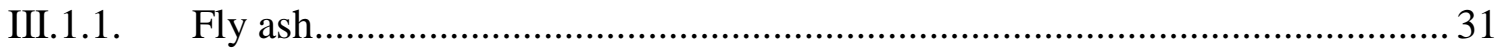

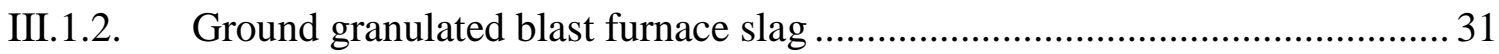

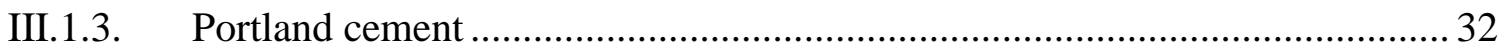

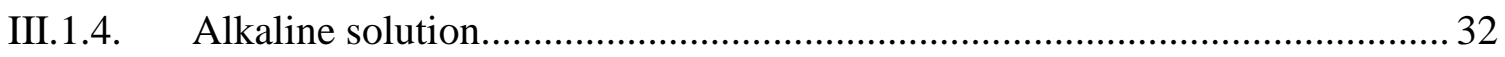

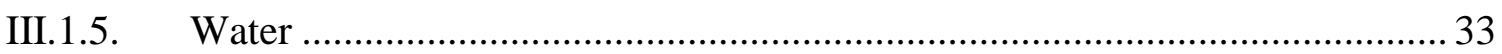

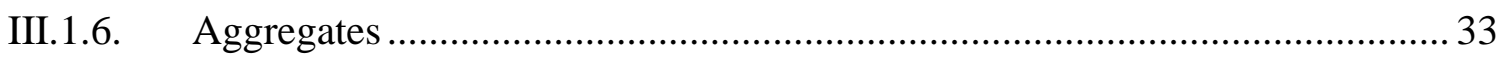

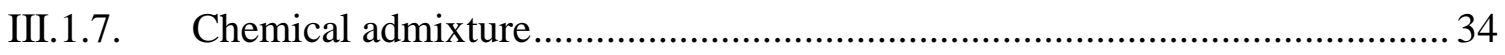

III.1.8. Micro-encapsulated phase change materials .............................................. 34

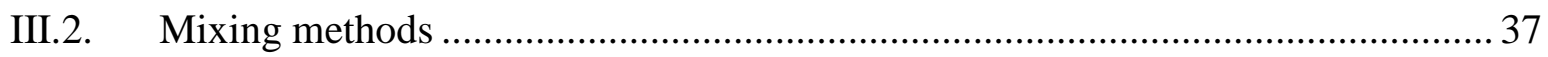

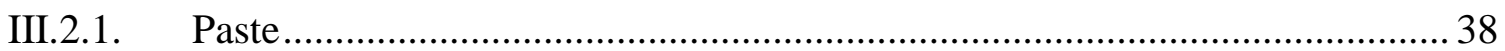

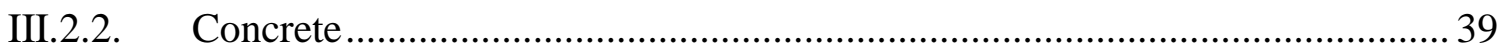

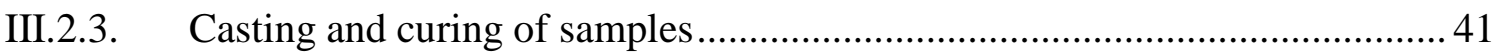

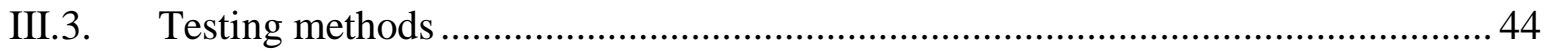

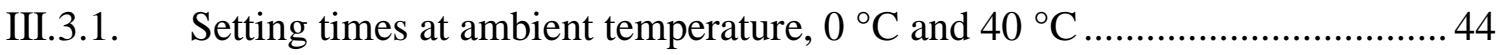

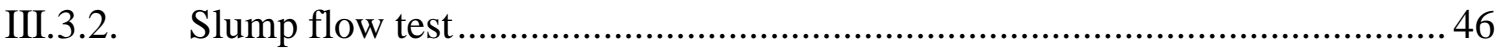

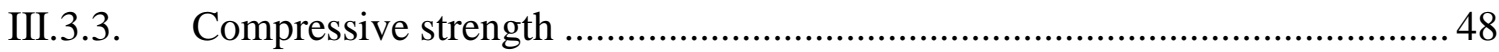


III.3.4. X-ray micro-tomography analysis

III.3.5. Scanning electron microscopy (SEM) imaging ....................................... 54

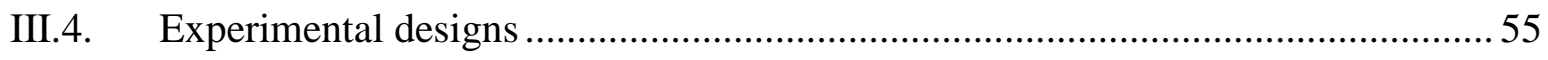

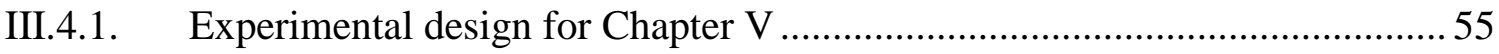

III.4.2. Experimental design for Chapter VI....................................................... 57

III.4.3. Experimental design for Chapter VII ...................................................... 58

III.4.4. Experimental design for Chapter VIII and Chapter IX …...........................6 60

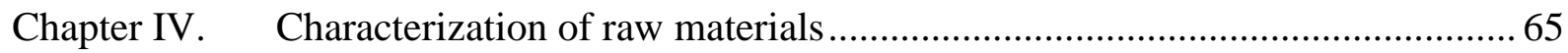

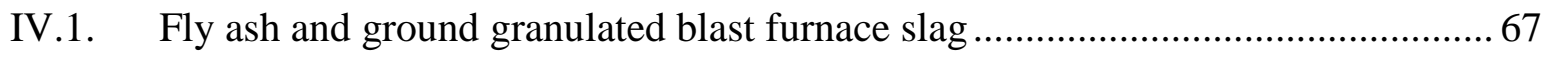

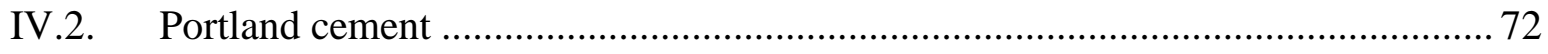

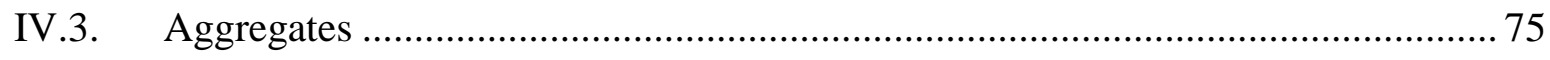

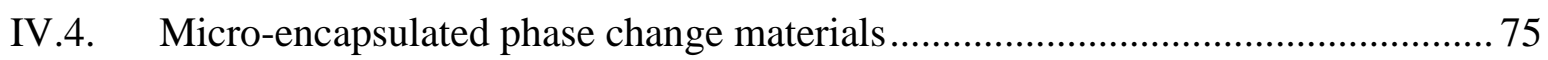

Chapter V. Effect of micro-encapsulated phase change materials on the mechanical properties and microscale changes of geopolymer concrete and Portland cement concrete at

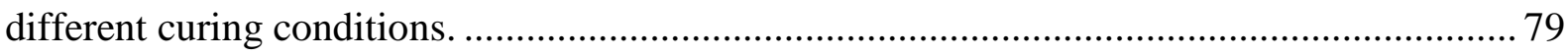

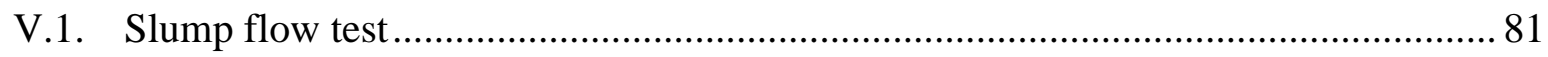

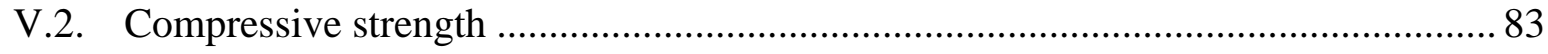

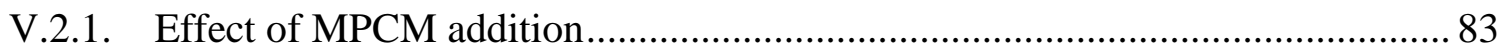

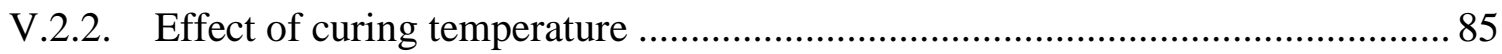

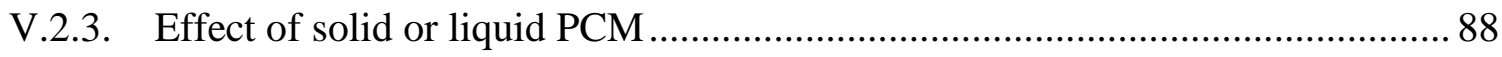

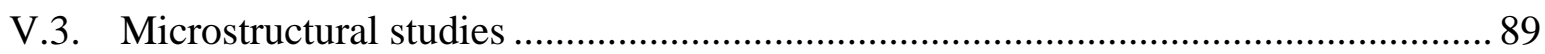

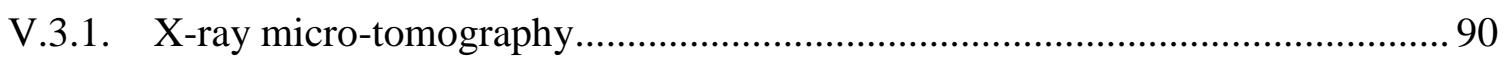


V.3.2. SEM analysis

Chapter VI. Mix design and compressive strength of fly ash/slag geopolymer concrete containing micro-encapsulated phase change materials. .99

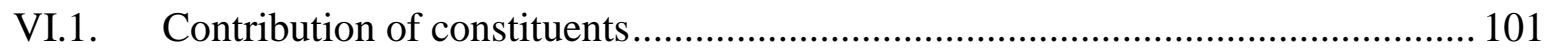

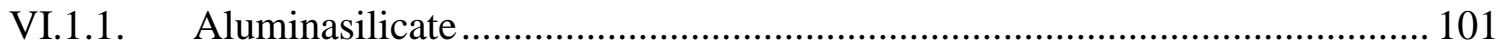

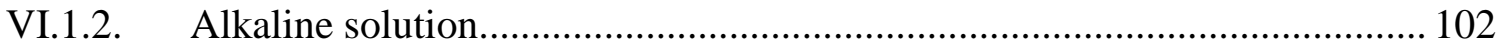

VI.1.3. Micro-encapsulated phase change materials ............................................... 102

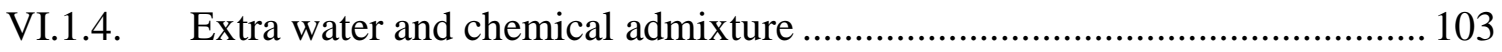

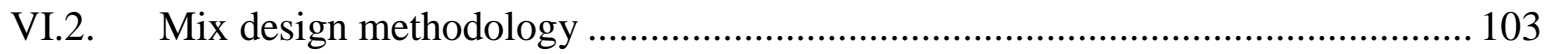

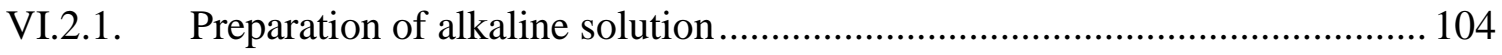

VI.2.2. Liquids to geopolymer binder (L/GB) ..................................................... 104

VI.2.3. Determination of geopolymer binder (GB) .......................................... 105

VI.2.4. Determination of required sand and gravel ............................................. 105

VI.2.5. Calculation of water and superplasticizing admixture ............................... 107

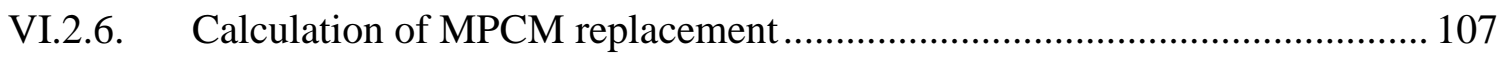

VI.2.7. Validation of compressive strength with proposed mix design................... 108

VI.3. Verification of the mix design by using experimental data .............................. 110

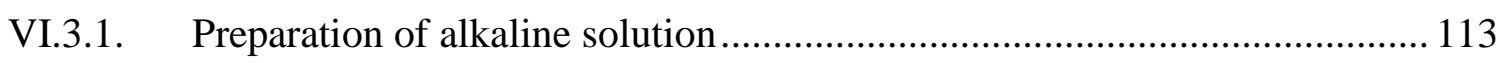

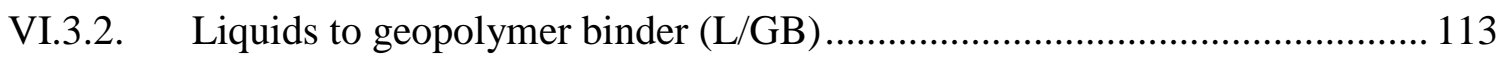

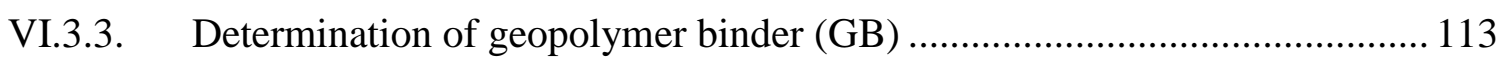

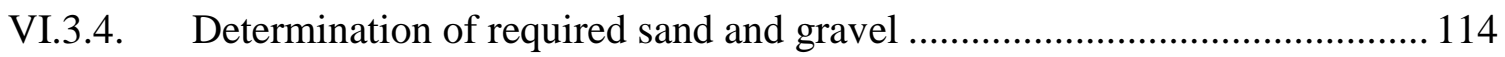

VI.3.5. Calculation of water and superplasticizing admixture ............................... 115 
VI.3.6. Adjustment of proposed mix design for 1 liter

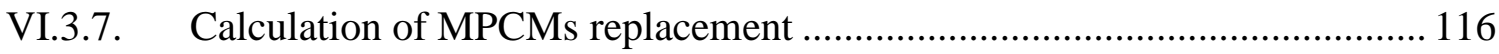

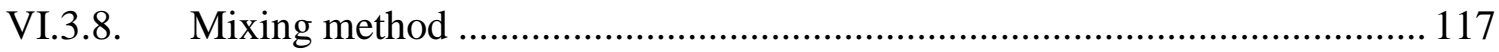

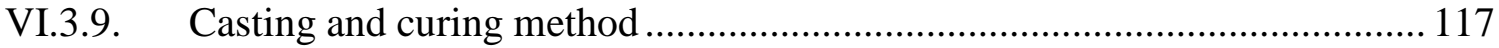

VI.3.10. Validation of Achieved Strength ............................................................ 117

Chapter VII. Physical and mechanical properties of proposed fly ash/slag geopolymer concrete containing different types of micro-encapsulated phase change materials.

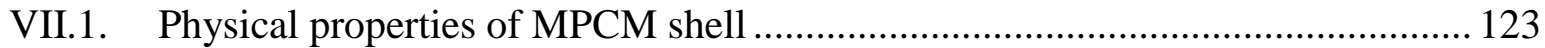

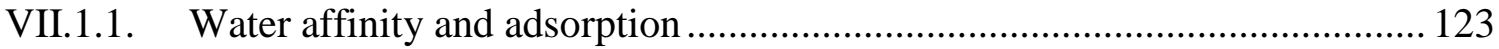

VII.1.2. Resistance against alkaline solution and mixing process ........................... 125

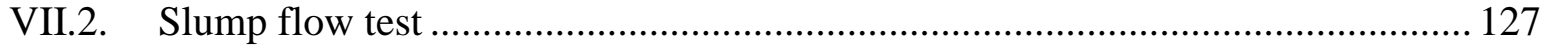

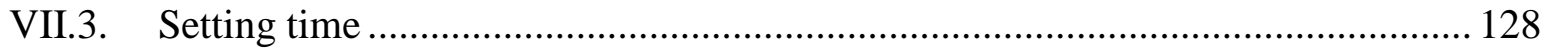

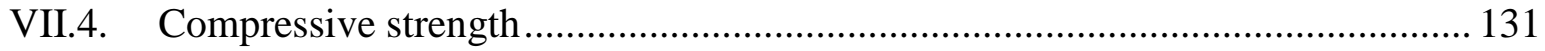

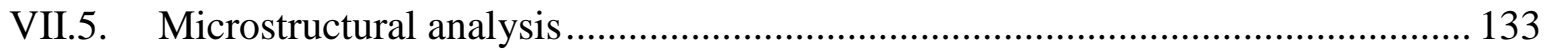

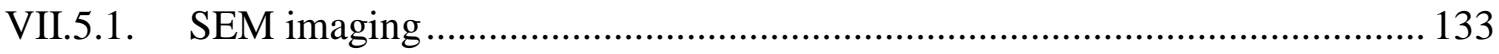

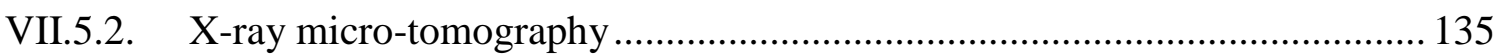

Chapter VIII. Effect of freeze-thaw cycles on the physical and mechanical behaviors of geopolymer concrete and Portland cement concrete containing different types of microencapsulated phase change materials.

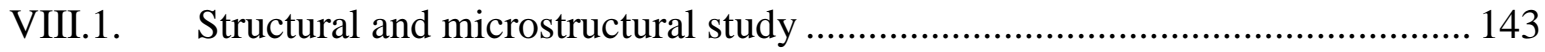

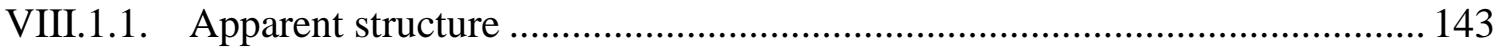

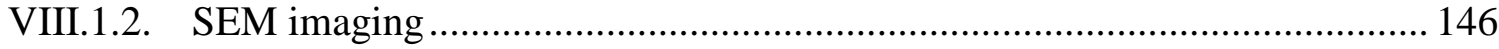


VIII.1.3. X-ray micro-tomography 150

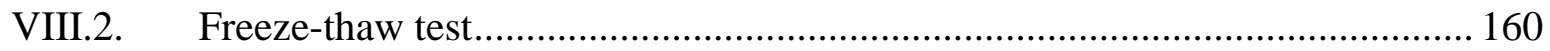

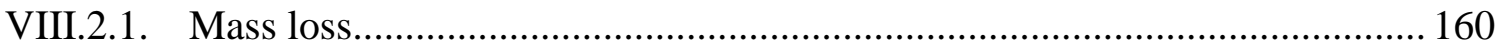

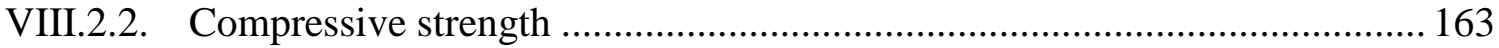

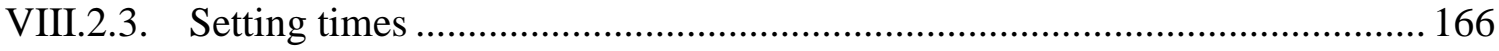

Chapter IX. Effect of different types of micro-encapsulated phase change materials in liquid state on the mechanical properties of geopolymer concrete 169

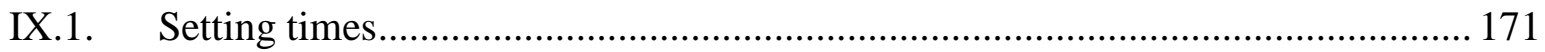

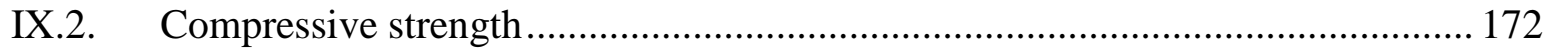

IX.2.1. Effect of curing time and temperature ................................................... 172

IX.2.2. Effect of MPCM type and state …........................................................ 174

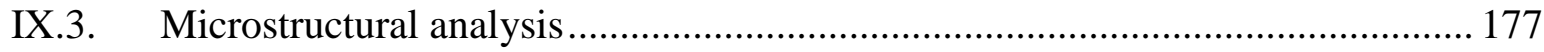

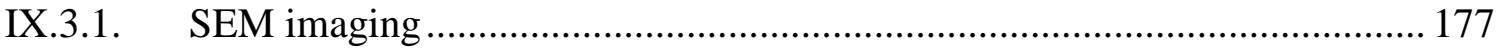

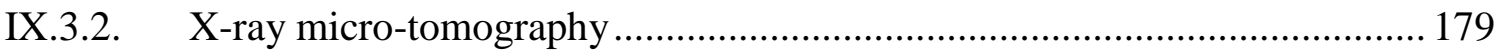

Chapter X. Conclusions, publications, conferences and future work ................................ 183

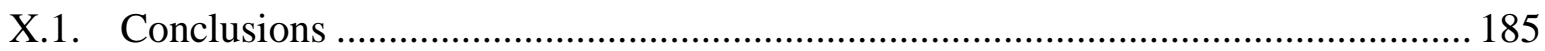

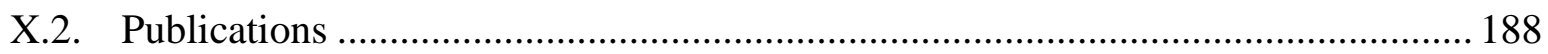

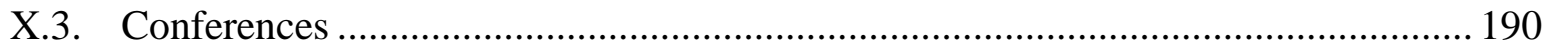

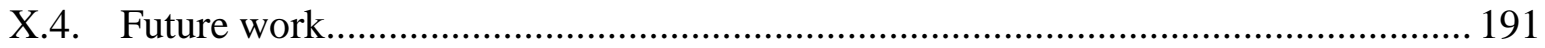

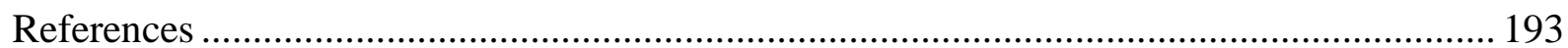

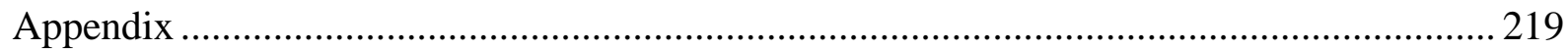

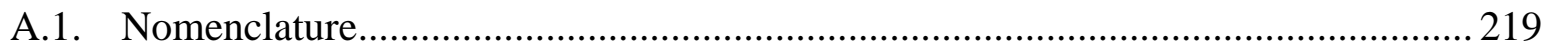


A.1.1. Abbreviations

A.1.2. Symbols.

A.2. History of the development of alkali-activated cement and composites.

A.3. Results from Chapter V 226

A.4. Results from Chapter VII

A.5. Results from Chapter VIII 235

A.6. Results from Chapter IX 237 


\section{Resumen}

Esta tesis doctoral está centrada en el estudio de las propiedades mecánicas de materiales de construcción basados en geopolímeros compuestos por cenizas volantes y escoria a los que se le incorporan materiales de cambios de fase microencapsulados (MPCM por sus siglas en inglés). Las investigaciones realizadas se enmarcan en un proyecto financiado por el Consejo de Investigación de Noruega.

Se ha evaluado el efecto de estas microcápsulas tanto en estado sólido como líquido en las propiedades mecánicas y la microestructura de estos hormigones basados en geopolímeros (GPC, por sus siglas en inglés) y cemento Portland (PCC, por sus siglas en inglés). Se prepararon muestras de GPC y PCC con diferentes cantidades de MPCM, realizando curados a 20 y $40^{\circ} \mathrm{C}$. Se registró un descenso de la resistencia a la compresión en ambos materiales, pero manteniendo valores suficientemente elevados para su uso como materiales de construcción. Las propiedades mecánicas de GPC no se vieron afectadas por la adición de MPCM ni en estado sólido $\left(20^{\circ} \mathrm{C}\right)$, ni líquido $\left(40^{\circ} \mathrm{C}\right)$; aunque en el caso del cemento Portland se pudo observar que las microcápsulas fundidas sí que provocaban un gran descenso en la resistencia mecánica. Se empleó la técnica de tomografía de rayos X para determinar el efecto de la porosidad de las microcápsulas tanto en las muestras de GPC como PCC. Mediante microscopía electrónica de barrido se pudo observar la formación de oquedades de aire entre las microcápsulas y la matriz de hormigón.

Por otro lado, se ha desarrollado un método de diseño para las mezclas de GPC con el objetivo de maximizar la resistencia a la compresión tras la adición de MPCM. Se han utilizado dos tipos diferentes de microcápsulas para una mejor evaluación de su efecto en las propiedades de GPC. Se ha podido observar que el tiempo de fraguado de las pastas basadas en geopolímero depende tanto de la cantidad de agua adsorbida en la superficie de las microcápsulas, como de 
la viscosidad de las muestras, y posiblemente también de su calor latente. Al aumentar la concentración de MPCM se pudo observar que el tiempo inicial de fraguado aumentaba mientras que el tiempo final disminuía. Además, la adición de MPCM resultó disminuir tanto la trabajabilidadcomo la resistencia a la compresión de GPC. Estos efectos eran más pronunciados para el caso de MPCM con estructuras aglomeradas y que presentan en su superficiegrupos polares que en el caso de microcápsulas con menor cantidad de aglomeración, una estructura más esférica y una superficie completamente hidrofóbica. Aunque la adición de MPCM reduce la resistencia a la compresión de GPC, después de 28 días de curado, el desempeño mecánico fue mayor que en el caso del cemento Portland. Los estudios de SEM y tomografía de rayos $\mathrm{X}$ sugieren que la aglomeración de microcápsulas, los espacios vacíos generados con la matriz de hormigón, el incremento de aire ocluido y la rotura de microcápsulas al aplicar esfuerzos provocan la disminución de la resistencia a la compresión de GPC.

También se ha realizado un estudio del efecto de las condiciones de congelación en las propiedades mecánicas de GPC y PCC con diferentes contenidos de MPCM. Cuando las microcápsulas se añaden al hormigón, el porcentaje de pérdida de masa tras los ciclos de congelación y descongelación se ve incrementado. La adición de MPCM proporciona una excelente durabilidad a la acción de estos ciclos con una mínima repercusión en la resistencia a la compresión. Se han realizado una serie de estudios microestructurales que han revelado que estos ciclos térmicos provocan un deterioro que se puede atribuir a la aparición de microgrietas en las zonas de interfase entre la pasta/agregados y la pasta/MPCM, y también a la formación de cristales de etringita. El efecto de la temperatura en el tiempo de fraguado de estas pastas también ha sido evaluado. A $0{ }^{\circ} \mathrm{C}$, el tiempo inicial de fraguado de las pastas basadas en cemento Portland se ven retrasados debido a la acción de la baja temperatura y la elevada viscosidad de MPCM. Sin embargo, las pastas de geopolímero muestran un tiempo inicial más corto debido a la separación de fases de la solución alcalina a bajas temperaturas. 
El tiempo final disminuye con la concentración de MPCM tanto para las pastas de GPC como para las de cemento Portland.

Se ha evaluado también el efecto de dos tipos diferentes de MPCM en estado líquido $\left(40^{\circ} \mathrm{C}\right)$ en las propiedades mecánicas y la microestructura de GPC y PCC. A esta temperatura, tanto el tiempo final como inicial de fraguado disminuyen hasta valores muy bajos debido a la aceleración de la reacción de geopolimerización. A $40{ }^{\circ} \mathrm{C}$, la resistencia a la compresión de ambos materiales es lo suficientemente elevada como para mantener sus aplicaciones hormigón estructural con la adición de las microcápsulas. El estudio de la microestructura reveló un aumento de los huecos de aire presentes en GPC y PCC cuando la temperatura de curado aumenta de 20 a $40{ }^{\circ} \mathrm{C}$ debido a la aceleración de la reacción. 


\section{Summary}

This $\mathrm{PhD}$ Thesis focuses on the details of development of the mechanical properties of fly ash/slag geopolymer concrete incorporated with microcapsules for construction applications in the framework of a wide research program funded by the Research Council of Norway.

The effect of MPCM in solid and liquid states on the mechanical properties and microstructure of geopolymer concrete (GPC) and Portland cement concrete (PCC) was investigated. GPC and PCC containing different amounts of MPCM were prepared and cured at both $20{ }^{\circ} \mathrm{C}$ and $40{ }^{\circ} \mathrm{C}$. While the compressive strength of both GPC and PCC was found to decrease with the addition of MPCM, it is still sufficiently high for construction purposes. Whether the PCM is in solid $\left(20{ }^{\circ} \mathrm{C}\right)$ or liquid $\left(40{ }^{\circ} \mathrm{C}\right)$ state did not significantly affect the mechanical properties of GPC, while melting the PCM were found to reduce the strength of PCC. X-ray tomography imaging was utilized to examine the effect of MPCM on the porosity of the samples. SEM imaging revealed that air gaps were formed between the microcapsules and the surrounding concrete matrix.

A mix design procedure for GPC was developed in order to maintain a high compressive strength after adding MPCM. Two types of MPCM were used for a better understanding the effect of different MPCMs on the properties of the GPC. The setting time of geopolymer pastes was found to depend on both the amount of water adsorbed by the microcapsules, the viscosities of the samples, and possibly the latent heat. Accordingly, the initial setting time increased and the final setting time decreased with MPCM concentration. The addition of MPCM was found to reduce both the slump and the compressive strength of GPC. These effects were more pronounced for the MPCM that form agglomerated structures and has a surface containing some polar groups, than for the more spherically shaped and less agglomerated MPCM with a hydrophobic surface. Although the addition of MPCM reduced the compressive strength of 
GPC, the mechanical performance was higher than that of PCC after 28 days of curing. A combination of SEM imaging and X-ray-tomography suggested that MPCM agglomeration, gaps between MPCM and the concrete matrix, an increased amount of entrapped air, and microcapsules that break under stress might contribute to the reduced compressive strength of GPC.

The effect of frost conditions on the physical and mechanical properties of GPC and PCC containing different MPCM was examined. When MPCM was added to concrete, the percentage of mass loss after the freeze-thaw cycles increased. The addition of MPCM provided an excellent resistance against freeze-thaw cycles with a minor reduction of the compressive strength. Microstructural studies revealed that the freeze-thaw induced concrete deterioration could be contributed to microcracks appearing in the poor interfacial transition zones between paste/aggregate and paste/MPCM, and to the formation of ettringite crystals. The effect of temperature on the setting times of the corresponding pastes was also evaluated. At $0{ }^{\circ} \mathrm{C}$, the initial setting time of Portland cement pastes had a delay due to the low temperature and the high viscosity of MPCM. However, for geopolymer pastes, the initial setting time became shorter due to phase separation of the alkaline solution at low temperatures. The final setting time decreased with MPCM concentration for both geopolymer and Portland cement pastes.

The effect of two different MPCMs in the liquid state (at $40{ }^{\circ} \mathrm{C}$ ) on the mechanical properties and microstructure of GPC and PCC was studied. At $40{ }^{\circ} \mathrm{C}$, the initial and final setting times were very fast due to the acceleration of the geopolymerization reaction. At $40{ }^{\circ} \mathrm{C}$, the compressive strength of both GPC and PCC with MPCM addition is sufficiently high for building applications. Microstructural studies showed that a higher number of air voids were present in GPC and PCC samples cured at $40{ }^{\circ} \mathrm{C}$ than at $20{ }^{\circ} \mathrm{C}$. This is due to acceleration of the reaction rates. 


\section{Thesis structure}

The thesis is divided into 10 chapters. Chapter I provides an introduction to the research field including a review of the recent developments of supplementary cementitious materials and geopolymerization development. Special attention is given to the application of microencapsulated phase change materials for passive buildings systems. This chapter explains the fresh properties, mechanical properties and stability of concrete incorporated with microencapsulated phase change materials.

Chapter II gives a general overview of the work performed in the project, highlighting the motivation and main objectives.

Chapter III provides details regarding description of materials, mixing methods, testing methods, and experimental designs used in the project.

Chapter IV is devoted to the characterization of the raw materials utilized in this project.

The results have been divided in 5 chapters. Chapter $\boldsymbol{V}$ is focused on the experimental results of one type of micro-encapsulated phase change material in solid and liquid states on the mechanical properties and microstructure of GPC and PCC.

Due to the lack of a proper GPC mix design for samples containing MPCM, a rational mix design procedure for fly ash/slag GPC is developed in Chapter VI in order to maintain a high compressive strength after adding MPCM.

In Chapter VII, the experimental results of different MPCMs on the fresh and mechanical properties of the proposed GPC are discussed. The properties of microcapsule shells including water affinity and retaining properties, resistance against alkaline solution and mixing process are shown in this chapter. 
Chapter VIII covers the experimental results of freeze-thaw cycles on the properties of the geopolymer and Portland cement composites containing different types of MPCMs.

Chapter IX describes the effect of different types of micro-encapsulated phase change materials in liquid state on the mechanical properties of geopolymer composites.

The thesis finishes in Chapter $\boldsymbol{X}$, which concludes the research work by describing the most important outcomes and provides recommendations for future work. 
Chapter I.

Introduction 



\section{I.1. Cement industry and environment}

With the rapid population growth in recent years, the demand for construction materials has increased considerably. Concrete is the most widely used building material and will be in demand for construction purposes far into the future [1]. Its versatility and durability give rise for applications such as for highways, streets, bridges, dams, and buildings. Ordinary Portland cement is considered as a vital ingredient for producing concrete. The estimated yearly production of cement exceeded 4 billion ton in 2017 [2], and as global population rises and urbanization grows this figure is expected to rise to more than 5 billion ton by 2030 [3]. Figure I.1 presents the trend of global cement production since 1990. The main production increase belongs to China, who are responsible for $58 \%$ of global cement production $[2,3]$.

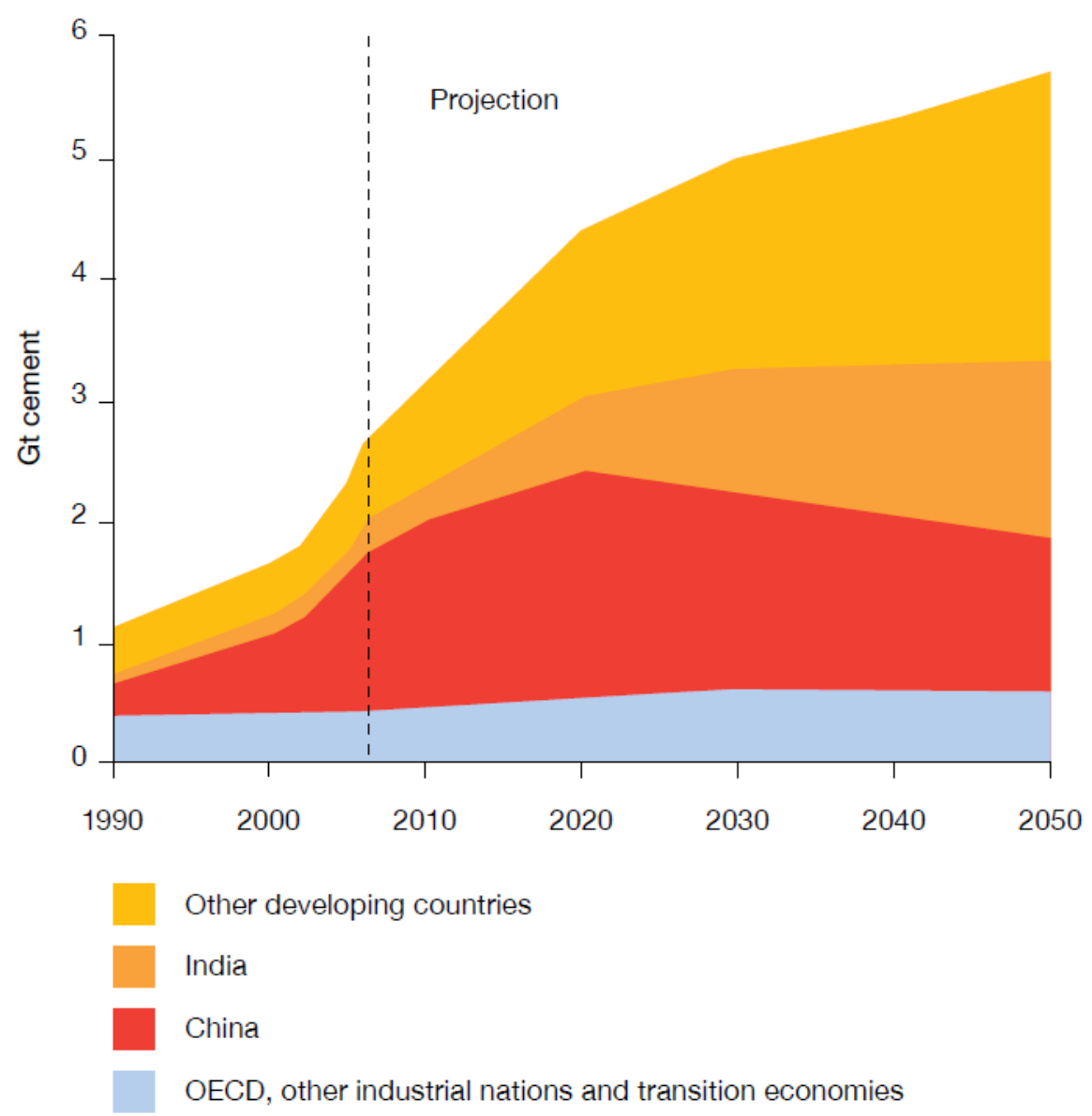

Figure I.1. Cement production in industrialized and developing countries [3]. 


\section{Chapter I}

It is generally accepted that global warming is threating our planet. The emission of greenhouse gasses from human activities is believed to be the main contribution to global warming [4]. The tropospheric concentration and lifetime of the most common greenhouse gasses are shown in Table I.1 [5]. Among the greenhouse gases, carbon dioxide $\left(\mathrm{CO}_{2}\right)$ has the highest contribution to the global warming.

Table I.1. The highest tropospheric concentrations and lifetime of greenhouse gases (adapted from CDIAC, 2016) [5].

Pre-1750

Gas
Recent tropospheric

concentration
Atmospheric lifetime

(years)

\begin{tabular}{lccc}
\hline \multicolumn{2}{l}{ Concentrations in parts per million (ppm) } & & \\
\hline Carbon dioxide $\left(\mathrm{CO}_{2}\right)$ & $\sim 280$ & 399.5 & $100-300$ \\
\hline Concentrations in parts per billion (ppb) & & \\
\hline Methane $\left(\mathrm{CH}_{4}\right)$ & 722 & 1834 & 12.4 \\
Nitrous oxide $\left(\mathrm{N}_{2} \mathrm{O}\right)$ & 328 & 121 \\
& 270 & & hours-days
\end{tabular}

Portland cement production has a significant impact on the environment as a major contributor to $\mathrm{CO}_{2}$ emissions by two main sources: the conversion of $\mathrm{CaCO}_{3}$ to $\mathrm{CaO}$ and $\mathrm{CO}_{2}$ in the cement clinker production (about 55\%) and emissions from combustion of huge amounts of fossil fuels to provide the required thermal energy for this reaction (around 45\%) [4]. The cement industry is the third largest source of carbon dioxide emission with about $8 \%$ of total emissions from 
fossil fuels [6]. Figure I.2 depicts the cement emission forecast versus mitigation path. The mitigation involves human interventions to reduce the emissions of greenhouse gases or enhance their removal from the atmosphere. According to Figure I.2, emissions related to the cement industry are expected to increase by $260 \%$ from 1990 to 2050 , despite the noticeable improvements in efficiency [3].

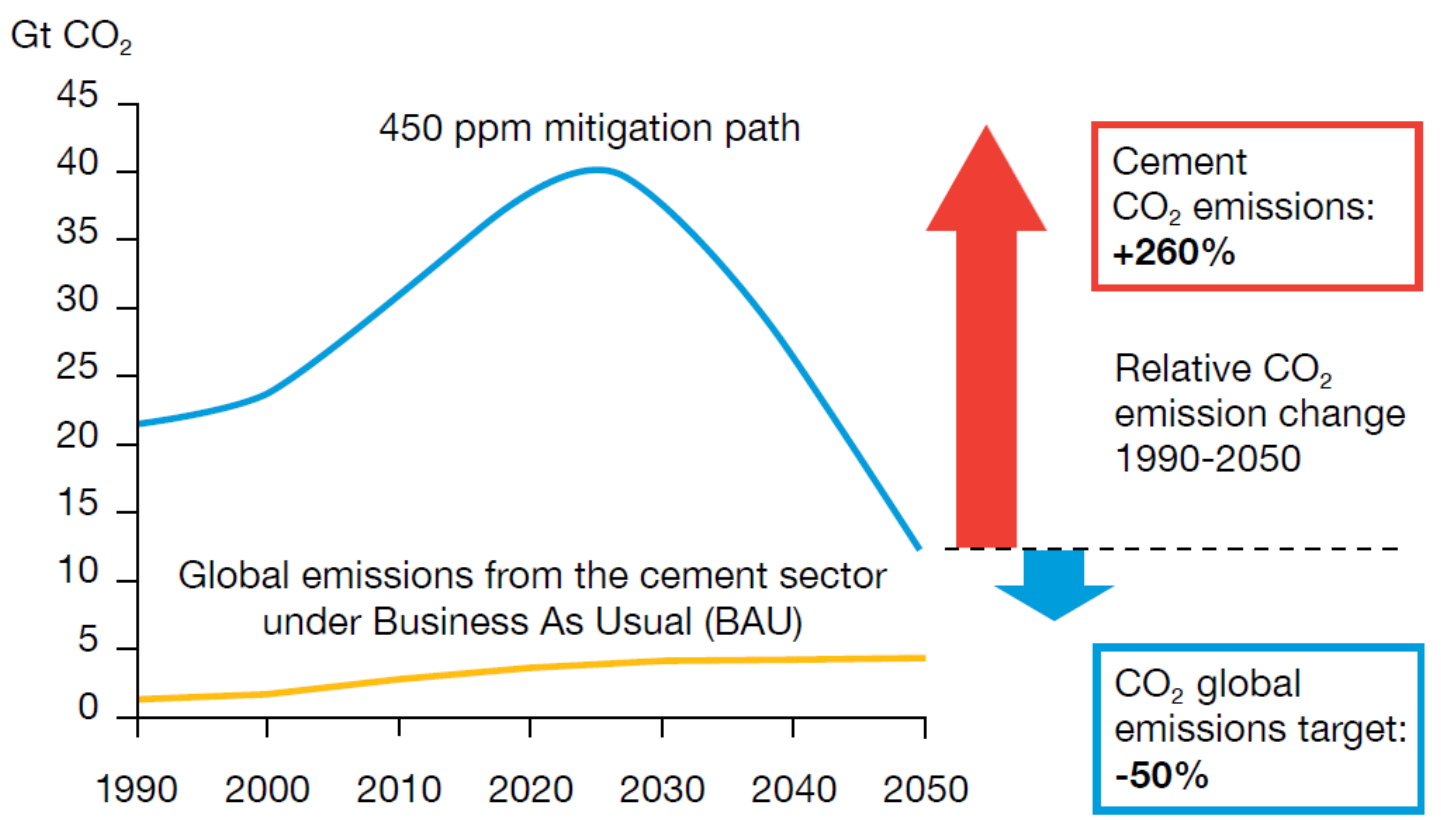

Figure I.2. Cement emission forecast vs. mitigation path [3].

One of the main problems discussed over the last decades is a high and quickly growing energy demand. This can result in supply difficulties, depletion of resources and destructive environmental impact such as climate change, global warming, and ozone depletion. It is predicted that the world energy consumption will rise with $28 \%$ between 2015 and 2040 [7]. Energy-intensive industries is expected to account for about $65 \%$ of total industrial energy consumption throughout the projection period of 2017 to 2050 [8]. The cement industry is facing the challenges relating to energy resources. Figure I.3 illustrates that the cement and lime industry is the most energy-intensive industry both in the present and the future. The cost of energy is unavoidably rising due to depletion of universal fuel sources. The fuel consumption 
for producing cement is around $25-30 \%$ of the total cement production cost [3]. Consequently, the cost of both the final products and its market is increasing. If the emissions are not limited, green taxes should be taken into account as an additional cost. This might lead to a double cement price by 2030 [9].

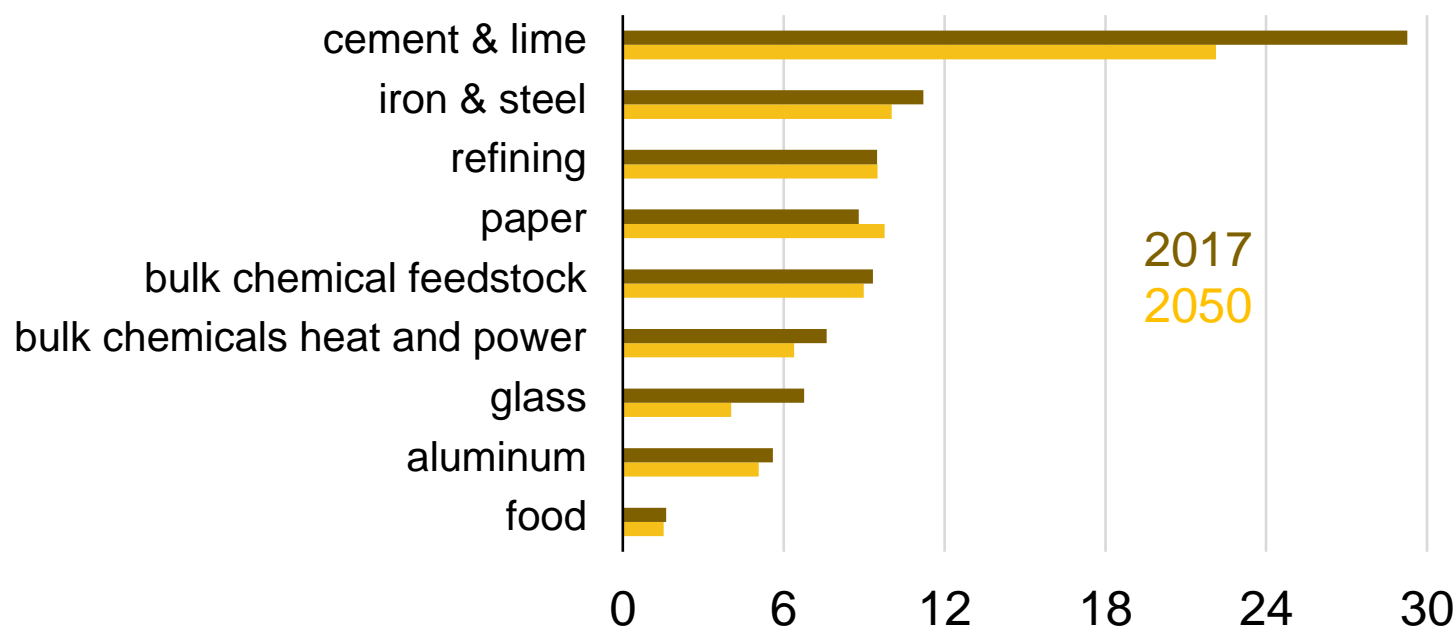

Figure I.3. Energy-intensive industries (trillion British thermal units per billion 2009 of shipments) [8].

In order to curb $\mathrm{CO}_{2}$ emissions and decrease the thermal energy consumption in cement plants, three main strategies have been studied in recent years $[4,9]$ :

1. Alternative fuels and energy efficiency.

2. Carbon capture and storage.

3. Utilizing alternative cementitious materials. 


\section{I.2. Utilizing cement substitution}

Concrete is usually considered as a mixture of paste (around 25 to $40 \%$ of the total volume of concrete), fine aggregates (from 63 microns to $10 \mathrm{~mm}$ ), and coarse aggregates (usually from 5 $\mathrm{mm}$ to $20 \mathrm{~mm}$ ). The paste components are basically cementitious materials like Portland cement, water and entrapped air [10]. The binding quality of concrete is due to the chemical reaction (hydration) between the cement and water. A low dosage of a chemical admixture can be used to reduce the amount of water, adjust setting or hardening time, increase the workability of fresh concrete, and intentionally entrain air [10].

To reduce the environmental impact of the concrete industry, short term and long-term approaches have been discussed [11]. In the long term, sustainable development will occur only if we are able to make dramatic improvements to our resource efficiency. Unfortunately, the rate of concrete consumption is unlikely to be reduced the next 50 years. In the short-term, it is possible to recycle the waste products of one industry by utilizing them as raw materials of another industry, thereby reducing the environmental impact. By reducing the use of Portland cement and utilizing waste resources, an environmentally friendly concrete industry might be achieved [12].

Utilizing industrial by-products, which are low or negative in $\mathrm{CO}_{2}$ emission, is considered as the most promising solution for the cement industry. By using waste materials, the accumulation of industrial waste and landfills can be reduced. In addition, the waste materials can be a substitute for cement and improve the properties of the final products. A very wide range of industrial by-product waste materials and natural materials which are rich in aluminosilicates such as fly ash [13, 14], blast furnace slag $[15,16]$, metakaolin $[17,18]$, red mud $[19,20]$, and silica fume $[21,22]$ can be utilized as cement substitute. The most common supplementary cementitious materials are reviewed below. 


\section{I.2.1. Flyash}

Fly ash (FA) is obtained by electrostatic or mechanical precipitation of dust-like particles from the flue gases of furnaces fired with pulverized coal [23]. The chemical composition is mainly composed of the oxides of silicon $\left(\mathrm{SiO}_{2}\right)$, aluminium $\left(\mathrm{Al}_{2} \mathrm{O}_{3}\right)$, iron $\left(\mathrm{Fe}_{2} \mathrm{O}_{3}\right)$, and calcium $(\mathrm{CaO})$, whereas magnesium, potassium, sodium, titanium, and sulphur are also present in lesser amounts. In accordance with ASTM C618, FA is classified as Class C and class F fly ash. Class C fly ash originates from burning of low-rank coals (lignites or sub-bituminous coals) and have cementitious properties due to a high calcium content (self-hardening when reacted with water) [24]. The low-calcium Class $\mathrm{F}$ fly ash is obtained from burning of higher-rank coals (bituminous coals or anthracites) that are pozzolanic in nature and high in silica $\left(\mathrm{SiO}_{2}\right)$ and alumina $\left(\mathrm{Al}_{2} \mathrm{O}_{3}\right)$ (hardening when reacted with $\mathrm{Ca}(\mathrm{OH})_{2}$ and water) [24].

\section{I.2.2. Blast furnace slag}

Blast furnace slag is formed in the processes of iron and steel manufacturing from iron ore, the residue of coke combustion, and the limestone or serpentine and other materials. [25, 26]. If the molten slag, at a temperature in the range between 1400 and $1600{ }^{\circ} \mathrm{C}$, is rapidly cooled by immersing in water, a fine grain glass is formed with a highly cementitious nature [10]. Slag compositions vary depending on the type of smelted ore. Normally ground slag in the presence of water or an activator like $\mathrm{NaOH}$ can set in a similar way to Portland cement, and the differences in reactivity between them are usually due to factors such as the amount of glassy content, fineness, and grain size distribution [27]. 


\section{I.2.3. Metakaolin}

Utilizing calcined clays as a pozzolanic additive for cement or cement substitute has been known since the time of the Romans. Metakaolin is obtained from high-purity kaolin clay by calcination at temperatures between $650-800{ }^{\circ} \mathrm{C}$. The calcination is an endothermic process where kaolinite is subjected to a large amount of heat in order to remove the hydroxyl ions and strain the bonding network [28]. The main uses of metakaolin today is as a component in Portland cement and concrete and due to high contents of silica and alumina in an active form, which interacts with $\mathrm{Ca}(\mathrm{OH})_{2}$ in the presence of water and improve the concrete properties [29].

\section{I.2.4. Silica fume}

Silica fume is a by-product which is utilized as pozzolan. It is a result of the reduction of high purity quartz with coal in an electric arc furnace during the manufacture of silicon or ferrosilicon [10]. Silica fume consists of ultrafine particles with a surface area of about 20,000 $\mathrm{m}^{2} / \mathrm{kg}$, with particles approximately one hundredth the size of the average cement. Because of its extreme fineness and high silica content, silica fume is a very reactive pozzolanic material. Silica fume is added to Portland cement and reacts with $\mathrm{Ca}(\mathrm{OH})_{2}$ in the presence of water to achieve improved properties of cement composites [21].

\section{I.2.5. $\quad$ Red mud}

Red mud is a waste material from the aluminium industry. It generally has a high alkalinity, so its disposal can cause serious environmental problems [30]. Its characteristics depend on the nature of bauxite ore used in the extraction of aluminium, which differ from place to place. The main constituents are oxides of different metals of which iron oxide, is the most prevalent [31]. 
Presence of alumina and iron oxide in red mud compensates the deficiency of the same components in limestone, which is the primary raw material for cement production [32]. In addition to iron, other dominant particles include silica, residual aluminium, and titanium oxide.

\section{I.3. Geopolymers}

\section{I.3.1. Geopolymerization development}

One of the efforts to produce a more environmentally friendly concrete is to develop an inorganic alumino-silicate polymer, called geopolymer. The history of the development of alkali-activated cement and composites compiled by Roy [33] is shown in Appendix A.2. Victor Glukhovsky emphasized the difference between the composition of traditional Portland cements and the basic rock-forming minerals of the earth's crust [34]. He developed new binders from low calcium or calcium-free aluminosilicate (clay) and alkaline metal solutions. The concretes made by that formulation were called "soil silicates". Soil silicates were assumed to be a product of a synthesis of alkaline minerals rich in alumino-silicate like volcanic rocks into zeolites. The soil silicates exhibit excellent durability at low temperature and pressure. In the early 1980s, geopolymers which consist of tri-dimensional alumino-silicate networks, were introduced by Joseph Davidovits to replace ordinary Portland cement [27]. The difference between zeolites and geopolymers is that the geopolymers reveal an amorphous to semicrystalline microstructure due to the short hardening time whereas zeolites exhibit a well crystallized structure [35].

Geopolymerizaion is an exothermic reaction that involves dissolution of silico-aluminates in a $\mathrm{MOH}$ solution (M: alkali metal) and provides an amorphous to semi-crystalline three dimensional structure [27]. Any pozzolanic compound or silica and alumina sources that can 
be quickly dissolved in the alkaline solution, acts as a source of geopolymer binder and leads to geopolymerization [36].

Poly silicon-oxo-aluminate (polysialate) is the term used for the chemical designation of geopolymer based on silico-aluminate [27]. During the geopolymer reaction, aluminum and silica tetrahedra are interlinked alternately by sharing oxygen atoms. A polymeric structure of Al-O-Si bonds is formed, and constitutes the main building blocks of the geopolymeric structure [37]. Due to thermodynamic considerations, Al-O-Al bonds do not preferentially form while it is expected that some $\mathrm{Si}-\mathrm{O}-\mathrm{Si}$ bonding occur. The empirical formula is:

$$
\mathrm{M}_{\mathrm{n}}\left[\left(-\mathrm{SiO}_{2}\right)_{\mathrm{z}}-\mathrm{AlO}_{2}\right]_{\mathrm{n}} \cdot \mathrm{wH}_{2} \mathrm{O}
$$

where " $\mathrm{z}$ " is 1,2 or 3 or higher up to 32 ; $\mathrm{M}$ is a monovalent cation such as sodium or potassium, and $\mathrm{n}$ is the degree of polycondensation [27]. The types of polysialates are shown in Figure I.4.

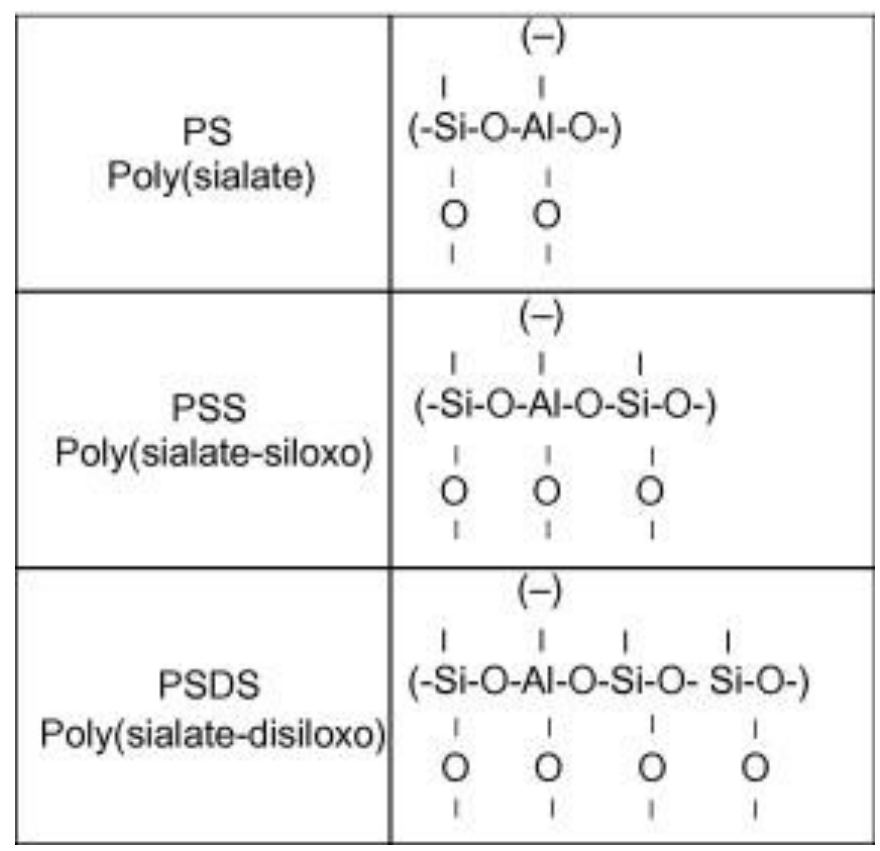

Figure I.4. Chemical structures of polysialates [38]. 
The proposed reaction scheme of geopolymers by polycondensation are described in Figure I.5 $[35,39]$. Accordingly, materials containing silicon $(\mathrm{Si})$ and aluminium $(\mathrm{Al})$ can be processed to make the geopolymer composites.
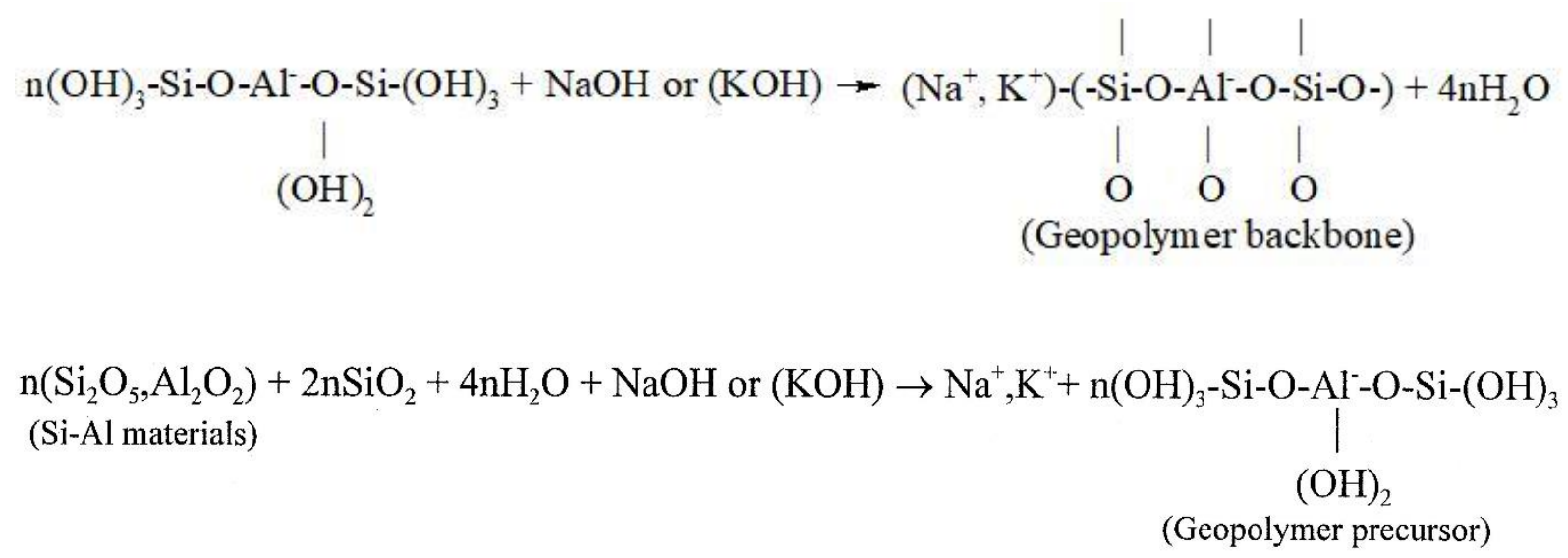

Figure I.5. Schematic formation of geopolymer materials [35].

As can be seen from last term in the second equation, water is released during the chemical reaction when the geopolymers formation occurs. This water, expelled from the geopolymer matrix during curing and further drying periods, leave behind discontinuous nano-pores in the matrix, which provides benefits to the performance of the geopolymers. Therefore, the water in a geopolymer mixture has no role in the chemical reaction (apart from dissolving the reactants), but increases the workability of the mixture during handling. This is in contrast to the chemical reaction of water in a Portland cement concrete during the hydration process [40].

\section{I.3.2. Constituents of geopolymers}

The main materials of the geopolymer binder are the aluminosilicate source materials and the alkaline solution. The source material should be amorphous and the degree of polymerization mainly depends on the degree of amorphosity and fineness of the alumin-osilicate materials. The aluminosilicate sources can be natural minerals, such as kaolinite, metakaolin and clays 
$[18,41]$ or industrial by-products such as fly ash, slag, red mud, and silica fume $[13,15,42]$. The alkaline components used as an alkaline solution is a compound from the elements of the first group in the periodic table. Unlike Portland cement, geopolymers do not form calcium silicate-hydrates (CSHs) for matrix formation and strength, but utilize the polycondensation of aluminosilicates and a high alkaline content to achieve the structural strength, see Figure I.5. The common activators are sodium hydroxide $(\mathrm{NaOH})$, potassium hydroxide $(\mathrm{KOH})$, sodium silicate $\left(\mathrm{Na}_{2} \mathrm{SiO}_{3}\right)$ and potassium silicate $\left(\mathrm{K}_{2} \mathrm{SiO}_{3}\right)$. For the preparation of the alkali solution a single alkali type or a mixture of different alkalis can be used [43, 44]. A sodium hydroxide alkaline solution will dissolve a higher amount of $\mathrm{Al}^{3+}$ and $\mathrm{Si}^{4+}$ ions than a potassium hydroxide solution [45]. Using a combination of sodium hydroxide and sodium silicate results in a better performance than when only sodium hydroxide is used [46] due to a higher formation of calcium silicate hydrate (CSH) in the presence of sodium silicate [46, 47].

Geopolymer composites exhibit an excellent performance in comparison with conventional building materials such as:

- Quick controllable setting and hardening [48, 49]

- High compressive strength $[50,51]$

- Freeze-thaw resistance $[52,53]$

- Excellent durability in sulfate environment and superior resistance to acid and salt attacks $[54,55]$

- High fire resistance and low thermal conductivity [56, 57]

- Small shrinkage [58]

Geopolymers can be classified based on the $\mathrm{Si}: \mathrm{Al}$ ratio [59]. A low ratio of $\mathrm{Si}: \mathrm{Al}$ of 1, 2, or 3 initiates a 3D-network that is very rigid, whereas a $\mathrm{Si}$ :Al ratio higher than 15 provides a 
polymeric character to the geopolymeric materials. Table I.2 illustrates applications from low to high $\mathrm{Si}: \mathrm{Al}$ ratios.

Table I.2. Application of geopolymeric materials [59].

\begin{tabular}{|c|c|}
\hline Si:Al & Applications \\
\hline 1 & $\begin{array}{l}\text { Bricks } \\
\text { Ceramics } \\
\text { Fire protection }\end{array}$ \\
\hline 2 & $\begin{array}{l}\text { Low } \mathrm{CO}_{2} \text { cements and concretes } \\
\text { Radioactive and toxic waste encapsulation }\end{array}$ \\
\hline 3 & $\begin{array}{l}\text { Fire protection fibre glass composite } \\
\text { Foundry equipments } \\
\text { Heat resistant composites, } 200^{\circ} \mathrm{C} \text { to } 1000^{\circ} \mathrm{C} \\
\text { Tooling for aeronautics titanium process }\end{array}$ \\
\hline$>3$ & $\begin{array}{l}\text { Sealants for industry, } 200^{\circ} \mathrm{C} \text { to } 600^{\circ} \mathrm{C} \\
\text { Tooling for aeronautics SPF aluminium }\end{array}$ \\
\hline $20-35$ & Fire resistant and heat resistant fiber composites \\
\hline
\end{tabular}




\section{I.3.3. Geopolymer concrete}

A geopolymer binder with different types of aggregates or additives incorporated can be used as geopolymer mortar and concrete [60]. Various mix proportions of geopolymer concrete with typical properties is shown in Table I.3. When developing geopolymer concrete (GPC) formulations, the type, amount and ratio of the source materials, alkaline solution, curing time and temperature must be taken into account [61-63].

Table I.3. Various proposed mix design for geopolymer concrete.

\begin{tabular}{ccccc}
\hline & Hardjito et al.[64] & Rangan [40] & Jaunaid [65] & Pavithra [66] \\
\hline Source materials & FA & FA & FA & FA \\
Molarity (M) & $8-14$ & 8 & 16 & 16 \\
Slump (mm) & $60-215$ & 100 & Medium-high & $33-110$ \\
Compressive & $17-70$ & $30-60$ & $44-49$ & $33-53$ \\
strength (MPa) & & & & \\
& & & & \\
Curing time & 7 day after 24h & h days after 24 & 7 days after 24, 48, & 28 days \\
& & and $72 \mathrm{~h}$ &
\end{tabular}

$\begin{array}{cccc}\text { Curing } & \text { precuring at } 60{ }^{\circ} \mathrm{C} & \text { steam precuring } & \\ \text { temperature } & \text { at } 60{ }^{\circ} \mathrm{C} & \text { precuring at } 60{ }^{\circ} \mathrm{C}\end{array}$
according to

ACI standard

\section{I.4. Micro-encapsulated phase change materials}

Phase change materials (PCM) are able to absorb, store and release energy during the phase change within a specific temperature range. When the temperature of the environment rises 


\section{Chapter I}

above the temperature of the phase change of the material, the PCM absorbs the heat in and changes from solid to liquid. When the temperature drops below the melting point, the PCM releases its heat of fusion to the environment and return to solid state. During the phase changes the temperature of the PCM remains practically constant. This can be utilized to reduce the use of air conditioning systems or heating when the system is applied in buildings. PCMs are classified as organic compounds, inorganic compounds and eutectics. Organic phase change materials are usually divided into paraffin and non-paraffin systems. Paraffins are obtained from crude oil distillation and constituted of a mixture of different hydrocarbons. They are mainly in liquid or waxy solid state. They are safe, odorless, tasteless, non-toxic and noncorrosive products, chemically stable, with a high heat of fusion (around $200 \mathrm{~kJ} / \mathrm{kg}$ ), low vapor pressure, good compatibility with other materials, and high availability over a large range of melting points (from -10 to $90{ }^{\circ} \mathrm{C}$ ). On the other hand, they are flammable (with flash point between 150 and $200{ }^{\circ} \mathrm{C}$ ), have a relatively large volume change during the phase transition, and have a low thermal conductivity (around $0.2 \mathrm{~W} \mathrm{~m}^{-1} \mathrm{~K}^{-1}$ ) [67-70]. Most studies focus on paraffin-derived compounds such as $N$-octadecane [71-74], $N$-hexadecane [75, 76], tetradecane [77], Rubitherm RT27 [77], Rubitherm RT20 [77], and paraffin wax [78, 79].

Microencapsulation is a process where a thin shell is created around a microscopic droplet of a substance to produce capsules with useful properties. Microencapsulation is interesting for numerous applications such as pharmaceuticals [80-82], food industry [83-85], textiles [86, 87], electrochromic devices and nanoelectronic components [88, 89], sensing and catalysis nanocomponents [90], electrophoretic displays [91], and in the building industry [68, 69, 92]. 
The main reasons for encapsulation of materials applied in the building industry are [93]:

- Avoiding interaction between the core material and the outside environment

- Avoiding the loss of the core material due to volatilization

- Reducing the health risks that non-encapsulated materials may present e.g. toxicity, flammability

- Avoiding unpleasant odors

- Providing a high heat transfer area per unit volume

- Controlling volume changes during the phase change

- Preventing the leakage of the core material during the phase change

- Facilitating the handling of materials for later applications

- The possibility of modifying the physical properties of the microcapsules by shell functionalization

PCMs are therefore often used in encapsulated form in building applications. During the selection of shell material, it is necessary to take into account the compatibility of the shell not only with the PCMs but also with the material where the microcapsules will find the final application [94]. Products containing encapsulated PCMs are classified according to the type of encapsulation, their shape and size, and whether they are embedded in or affixed to the structure [95]. Table I.4 illustrates encapsulation in the form of micro- and macroencapsulation. 


\section{Chapter I}

Table I.4. Types of encapsulation for PCMs used in the building sector [95].

\begin{tabular}{lll}
\hline Encapsulation & Micro-encapsulated & Macro-encapsulated \\
\hline Shape & Spherical or cylindrical & Depending on the container \\
\hline Size & $\varnothing<1 \mathrm{~mm}$ & $\emptyset>1 \mathrm{~cm}$ \\
\hline PCM substances & Paraffin & Organics and inorganics \\
\hline Construction Shape & Embedded & Wall and ceiling linings
\end{tabular}

Size processes

\begin{tabular}{ll}
\hline Examples & - Granulated, Rubitherm \\
- Micronal DS 5008 X & - EPS Ltd Module beam \\
- MPCM-28 wet cake & - Bags (Climator, Dörken) \\
& - Celblock \\
& - Aluminum container
\end{tabular}

\section{I.4.1. Micro-encapsulated phase change materials for passive buildings}

\section{systems}

PCMs are able to decrease the energy demand of cooling and heating systems, stabilizing the indoor temperature fluctuations. Concerning the thermal comfort for humans, the melting point of the PCM should be in the range of 10 to $30{ }^{\circ} \mathrm{C}$. The precise temperature should be chosen based on average day and night temperatures changes and other climatic limitations [96]. The PCM should have a high latent heat per volume unit, i.e., a small volume of PCM can absorb 
or release higher amounts of energy, consequently leading to a lighter building envelope [97]. A large specific heat capacity and high thermal conductivity are required to achieve a fast thermal response [98]. In addition, chemical aspects, chemical stability, and low volume change and little supercooling during the solidification process should be taken into account. It is desired that the PCMs are non-toxic, non-corrosive, non-flammable and non-explosive [96]. In order to achieve a long-term stability, the PCM should be resistant to a number of repeated melting/freezing cycles.

Passive systems are charged and discharged without any mechanical contribution, hence solar radiation, natural convection or temperature difference are used. In this technology, PCMs are integrated into the building envelopes to increase the thermal mass.

In cold climates, buildings require large amounts of insulation to reduce heating loads in the winter. This causes large temperature fluctuations in the summer due to excessive over-heating due to a lack of thermal mass. PCMs which melt during the day and solidify at night prevent rooms from overheating during the day during the warm months, and may also reduce the need for heating during night in the winter $[68,69,99,100]$. Figure I.6 shows the process of melting and solidifying of PCM as a heating and cooling system for a building [101].

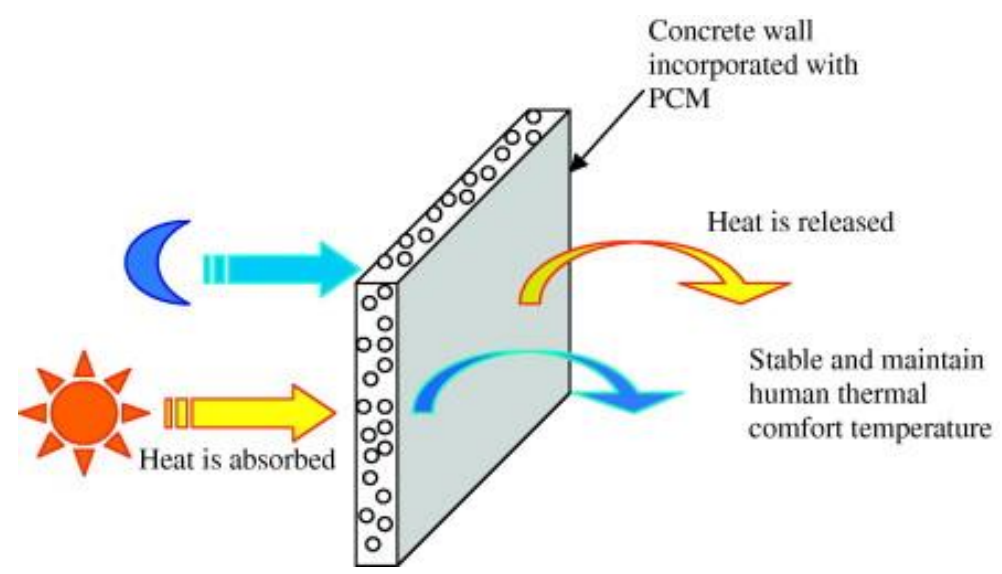

Figure I.6. Heating and cooling function of a concrete wall incorporated with PCM to maintain pleasant human comfort temperature in a room [101]. 
There are two methods to add micro-encapsulated phase change materials (MPCM) to concrete materials, which are called the MPCM replacement method and the MPCM additive method [102]. In the replacement method, MPCM replace a certain percentage of fine aggregate (sand) in the concrete mixture. In the additive method, MPCM is used as an additive in the concrete mixture. In the replacement method, the loss of compressive strength due to the addition of MPCM is not as high as for the additive method [102].

\section{I.4.2. Fresh properties of MPCM-concrete}

The ease of placing, consolidating, and finishing fresh concrete and the resistance of freshly mixed concrete against segregation is called workability [10]. Factors that can influence the workability of concrete are: (1) the method and duration of transportation; (2) quantity and characteristics of source materials; (3) concrete consistency (slump); (4) grading, shape, and surface texture of fine and coarse aggregates; (5) entrained air; (6) water content; (7) concrete and ambient air temperatures; (8) admixtures.

The workability of building material binders is determined by using empirical methods such as slump, V-funnel and J-ring tests. Slump is used as a measure of the consistency or wetness of concrete. A low-slump concrete has a high stiffness. If the consistency of concrete is too dry, the concrete will be difficult to work with and larger aggregates may separate from the mix. However, a more fluid mix is not necessarily more workable. If the mix is too wet, segregation and honeycombing can occur [10].

Hunger et al. [103] measured the effect of MPCM on the workability of self-compacting concrete by testing slump flow, V-funnel time and J-ring. The mixtures with $3 \%$ and $5 \%$ of MPCM exhibited slightly higher viscosity which was contributed to the higher water demand. This hypothesis is in agreement with previous findings [104, 105] claiming that a less rough 
surface, higher particle sizes, and the water absorption on the polymeric wall of the microcapsules affect the workability of mortar and concrete.

\section{I.4.3. Thermal properties of MPCM-concrete}

The main impact of applying of MPCM into the concrete is that it significantly improves the heat storage capacity $[106,107]$. It is possible to achieve complete melting and solidifying of MPCM in concrete through each cycle [107]. Incorporating MPCM in concrete walls can provide improved thermal inertia as well as lower inner temperatures [107]. Increasing the amount of MPCM cause a lower thermal conductivity and an increased heat capacity, and therefore significantly improve the thermal performance of concrete [103]. Increase of the air content and a lower thermal conductivity can contribute to these effects.

\section{I.4.4. Mechanical properties of MPCM-concrete}

The incorporation of MPCM in concrete can improve the thermal energy storage capacity of building structures, but the presence of MPCM decreases the mechanical properties of concrete [103, 108-110]. In spite of reduced concrete compressive strength after adding MPCM, it is still often high enough to be suitable for constructional purposes (acceptable range of compressive strength is between 25 and $40 \mathrm{MPa}$ ).

The microcapsules can be destroyed during the mixing process, and release its paraffin wax filling into the surrounding matrix, which causes a significant loss of concrete strength [103]. Thus, the fragile nature of the paraffin microcapsules should be considered in order to limit capsules breakage [109]. 


\section{I.4.5. Stability of MPCM in concrete}

PCMs hold promise in enhancing the performance of concrete technology in several applications. The alkalinity level of concrete is one of the parameters that should be considered when the PCM is added into concrete. Some PCMs are not suitable for use in high-alkali level concrete because the alkali can degrade them. Utilizing pozzolans at an appropriate level has been suggested to reduce the alkalinity of concrete [111]. Additionally, porous lightweight aggregates can be utilized as the carrier for the PCM when they are added directly or in a microencapsulated form to the concrete to increase the stability of PCMs [112]. Furthermore, the immersion PCM-concrete samples has better resistance to freeze-thaw cycles than specimens without PCM due to water absorbency and lower permeability $[112,113]$.

\section{I.5. Motivation and background}

Ordinary Portland cement is normally considered as the main material for construction purposes. However, the Portland cement production has a severe impact on the environment due to the huge amount of greenhouse gases emitted to the atmosphere and a costly production process. The geopolymer binder synthesized by mixing materials rich in silica and amorphous alumina with a strong alkaline activator are a very interesting concrete alternative, as it improves the performance of construction materials, while utilizing a high proportion of industrial by-products such as fly ash (FA), coal ash and blast furnace slag (GGBFS). Compared with PCC, GPC exhibit excellent properties such as high initial strength and short setting time, excellent durability in sulfate environment and superior resistance to acid attack, high fire resistance and low thermal conductivity, and small shrinkage.

The incorporation of micro-encapsulated phase change materials (MPCM) in building materials, such as mortar and concrete can improve the thermal energy storage capacity of 
building structures, thereby decreasing the energy demand in buildings. However, the MPCM has a negative effect on the mechanical properties of construction materials and the presence of MPCM decreases the workability and mechanical strength of concrete.

So far, only microcapsules containing PCM with a hydrophilic shell were incorporated into the only Portland cement concrete. After incorporation of microencapsulated PCM into the conventional concrete, the mechanical properties such as compressive strength decreases. When the microcapsules are added the compressive strength often become too low to meet the standard requirements of constructive materials. This can be due to a weak microcapsule shell, or the hydrophilic character of the microcapsules which greatly increases the water consumption needed for hydration. 
Chapter I 
Chapter II.

Objectives 



\section{II.1. Objective}

Studies of the mechanical strength of geopolymer concrete with incorporated MPCM have not been reported previously. The main purpose of this study is to examine how incorporation of MPCM influences the mechanical properties of both GPC and PCC at different conditions and to develop an accurate and convenient mix design for fly ash/slag geopolymer concrete with incorporated MPCM.

In order to achieve the aim, the research work was structured into the following specific objectives:

- Examining how incorporation of MPCM influences the mechanical properties of both GPC and PCC at different curing times.

- Designing a GPC mixture with improved mechanical properties and better workability, to compensate for the negative effect of incorporated MPCM on these properties.

- Durability of GPC and PCC with incorporated MPCM against frost conditions.

- Assessment of the behavior of GPC and PCC including MPCMs at higher temperatures. 
Chapter III.

Research Methodology 



\section{III.1. Description of materials}

\section{III.1.1. Flyash}

The fly ash (FA) used in this study was purchased in bulk quantity from Norcem, Germany (reference number/Lot number: not given). When the first batch from 2015 was used up, another batch of FA was supplied in 2016. The fineness index of the FA was determined by air permeability to be $2954 \pm 50 \mathrm{~cm}^{2} / \mathrm{g}$. The fineness determination was conducted by AirPermeability apparatus in accordance with EN 196-6, in Mapei S.p.A., Italy. The specific gravity of the FA was $2.26 \pm 0.02 \mathrm{~g} / \mathrm{cm}^{3}$, determined in accordance with ASTM standard C188 by means of a Le Chatelier flask.

\section{III.1.2. Ground granulated blast furnace slag}

The ground granulated blast furnace slag (GGBFS) was purchased from Cemex, Germany (reference number/Lot number: not given). Two different batches of GGBFS were used; the first batch was obtained in 2015, the second batch arrived in 2016. The blain fineness determined by the air permeability method was $3312 \pm 50 \mathrm{~cm}^{2} / \mathrm{g}$. The fineness determination was done by Air-Permeability apparatus in accordance with EN 196-6, in Mapei S.p.A., Italy. The specific gravity of GGBFS was determined as $2.85 \pm 0.02 \mathrm{~g} / \mathrm{cm}^{3}$ according to ASTM C188 using a Le Chatelier flask.

The chemical composition of the two batches of FA and GGBFS obtained by X-Ray Fluorescence (XRF) analysis was carried out by Alberto Alcolea at Technical University of Cartagena, Spain. X-ray fluorescence spectrometer (S4 PIONEER) was utilized for XRF analysis and the pressed pellet ( $8 \mathrm{~g}$ of sample $+2 \mathrm{~g}$ of a cellulose wax) method was used for sample preparation. 
To identify the phase of FA and GGBFS, X-ray diffraction (XRD) was carried out by a X-Ray

Diffractometer (BRUKER D8 ADVANCE) at the Technical University of Cartagena, Spain.

The particle size distribution of FA and GGBFS was performed by a laser diffraction particle size analyzer (Beckman-Coulter, LS 13320 Series) at the Technical University of Cartagena, Spain.

\section{III.1.3. Portland cement}

In order to obtain data for comparison, experiments have also been conducted on ordinary Portland cement composites in the same way as for geopolymer composites.

Portland cement II mixed with FA (Blain fineness $=4500 \mathrm{~cm}^{2} / \mathrm{g}$, specific gravity= $2.99 \mathrm{~g} / \mathrm{cm}^{3}$ ), was purchased from Norcem, Norway. The XRF and XRD were carried out by X-ray fluorescence spectrometer (S4 PIONEER) and X-Ray Diffractometer (BRUKER D8 ADVANCE) at Technical University of Cartagena, Spain, respectively.

\section{III.1.4. Alkaline solution}

A combination of sodium hydroxide $(\mathrm{NaOH})$ solution and sodium silicate $\left(\mathrm{Na}_{2} \mathrm{SiO}_{3}\right)$ solution was used as alkaline solution.

The solid sodium hydroxide was used in two different forms either as mini-pearls or as pellets. Batch I of sodium hydroxide, in mini pearl form (density $=1.52 \mathrm{~g} / \mathrm{cm}^{3}$ ), was provided by PERMAKEM AS (reference number: 100001). Afterwards, another batch of sodium hydroxide in pellet form (density $=2.13 \mathrm{~g} / \mathrm{cm}^{3}$ ) was purchased from VWR, Norway (reference number: 28245.460). 
Sodium silicate solution (density $=1.93 \mathrm{~g} / \mathrm{cm}^{3}, 35 \mathrm{wt}$. \% solid) was purchased from VWR, Norway (reference number: 28079.460). The ratio of sodium silicate to sodium hydroxide is an important factor which will be discuss in further chapters.

\section{III.1.5. Water}

Normal Norwegian tap water, was used for preparation of Portland cement concrete, $\mathrm{NaOH}$ solution and as extra water in the geopolymer concrete. De-ionized water was used in all pastes, which were made in Cartagena, to avoid any impurities present in the tap water.

\section{III.1.6. Aggregates}

Two different batches of natural sand were used as the prime source of fine aggregate for all concrete specimens. Two batches of natural gravel were used for both GPC and PCC. Both sand (density of $2.7 \mathrm{~g} / \mathrm{cm}^{3}$ ) and gravel (density of $2.6 \mathrm{~g} / \mathrm{cm}^{3}$ ) were provided by Gunnar Holth and Skolt Pukkverk AS, originating from Mysen and Råde, Norway. The particle size distribution (PSD) analysis of batch I and II of sand and gravel carried out by mechanical sieving according to EN 933-1. $500 \mathrm{~g}$ and $1300 \mathrm{~g}$ of sand and gravel were weighed for PSD determination, respectively. A mechanical sieve (mesh size from $63 \mathrm{~mm}$ to $63 \mu \mathrm{m}$ ) was used for shaking aggregates. The time for vibrating sand and gravel was $10 \mathrm{~min}$ and $2 \mathrm{~min}$, respectively. Afterward, the residual on each sieve was weighed and the percentage of cumulative passing was calculated.

For preparation all pastes in this study, CEN-Standard sand EN 196-1 provided by Normensand GmbH, Germany (reference number: 1990408) was utilized. 


\section{III.1.7. Chemical admixture}

FLUBE OS 39 (density of $1.20 \mathrm{~g} / \mathrm{cm}^{3}$ ), a poly-naphthalene sulfonate polymer from Bozzetto Group, Italy (reference number: I1-0000178741), was used as a superplasticizing admixture to improve the workability of GPC and decrease the amount of extra water. This superplasticizer was chosen due to the good effect of naphthalene based superplasticizers on the workability geopolymer concrete containing fly ash class F [27]. Dynamon SR-N (density of $1.1 \mathrm{~g} / \mathrm{cm}^{3}$ ) from MAPEI, Norway (reference number: 73060-171116), was used as a superplasticizing admixture to improve the workability of PCC and decrease the amount of water.

\section{III.1.8. Micro-encapsulated phase change materials}

In order to reduce the effect of the water affinity of the MPCM shell, two MPCMs with hydrophobic shells were utilized. Both MPCMs are provided by University of Castilla, Spain. The core material for both MPCMs is a paraffin wax (Rubitherm ${ }^{\circledR R T 27) . ~ T h e ~ s h e l l ~ f o r ~ t h e ~ f i r s t ~}$ MPCM is a copolymer consisting of low density polyethylene (PE) and ethylvinylacetate (EVA) and the second MPCM has a copolymer shell of styrene (St) and divinylbenzene (DVB) $[114,115]$. In this study, these microcapsules are named PE-EVA-PCM and St-DVB-PCM, respectively. Figure III.1 illustrates the appearance of both MPCMs. 

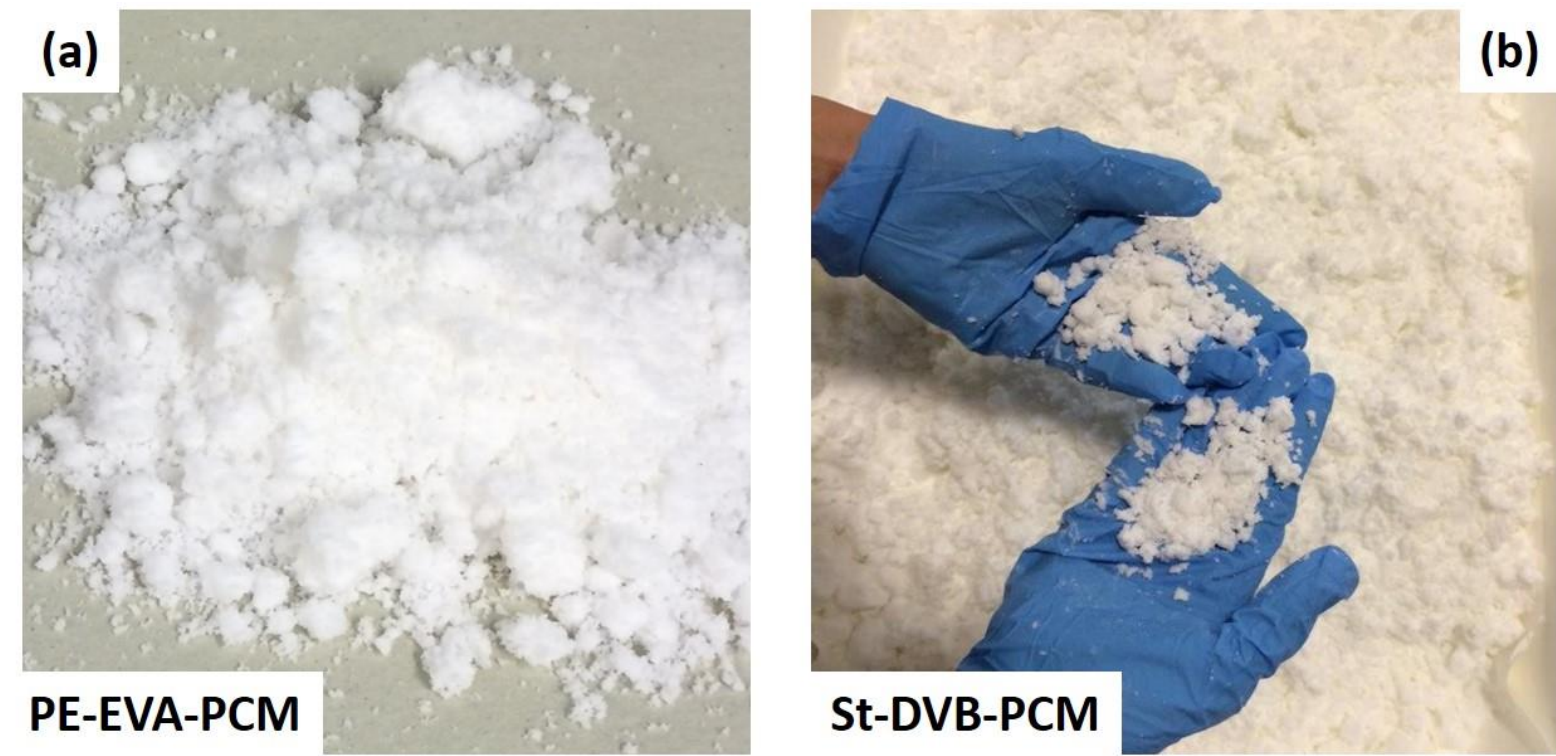

Figure III.1. Illustrative pictures of the appearance of (a) PE-EVA-PCM, (b) St-DVB-PCM.

The general properties of PE-EVA-PCM and St-DVB-PCM are presented in Table III.1. The melting point of MPCM should be approximately three degrees higher than the room temperature [116], and near the average temperature of the hottest summer month [117]. 
Table III.1. Properties of PE-EVA-PCM and St-DVB-PCM [114, 115].

\begin{tabular}{ccc}
\hline General properties & PE-EVA-PCM & St-DVB-PCM \\
\hline Appearance & White powder & White powder \\
Form & Non-spherical & Spherical \\
Synthesizing & & Suspension-like \\
technique & Spray drying & polymerization
\end{tabular}

\begin{tabular}{|c|c|c|}
\hline \multirow{3}{*}{ Shell composition } & Low density polyethylene (50 wt \%) & Styrene (50 wt \%) \\
\hline & & \\
\hline & ethylvinylacetate (50 wt \%) & Divinylbenzene (50 wt \%) \\
\hline \multirow{2}{*}{ Core material } & Paraffin & Paraffin \\
\hline & (Rubitherm®RT27) & (Rubitherm®RT27) \\
\hline Melting point & $28.4 \pm 0.9^{\circ} \mathrm{C}$ & $24.2 \pm 0.9^{\circ} \mathrm{C}$ \\
\hline Specific gravity & $0.9 \mathrm{~g} / \mathrm{cm}^{3}$ & $0.9 \mathrm{~g} / \mathrm{cm}^{3}$ \\
\hline Latent heat & $98.1 \mathrm{~J} / \mathrm{g}$ & $96.1 \mathrm{~J} / \mathrm{g}$ \\
\hline
\end{tabular}

The particle size distribution of MPCMs determined by Low Angle Laser Light Scattering laser diffraction (Malvern Masterizer 2000) at the University of Castilla - La Mancha, Ciudad Real, Spain. 


\section{III.2. Mixing methods}

To prepare $\mathrm{NaOH}$ solutions of different molarities, the desired amount of sodium hydroxide pellets was measured in a glass beaker and added gradually into a plastic container of water. For example, for preparation of a $14 \mathrm{M} \mathrm{NaOH}$ solution, which is commonly used in this study, $14 \mathrm{~mol} / \mathrm{L} \times 40 \mathrm{~g} / \mathrm{mol}=560 \mathrm{~g}$ of sodium hydroxide pellets were dissolved in water until the volume reached to 1 liter where the $40 \mathrm{~g} / \mathrm{mol}$ is molecular weight of $\mathrm{NaOH}$. The mixing of water and $\mathrm{NaOH}$ is an exothermic process. To keep the generated heat down, the plastic container was kept in a bucket surrounded by ice. During storage, the $\mathrm{NaOH}$ solution was hermetically closed to avoid carbonation. For final mixing, desired quantities of sodium silicate solution and $\mathrm{NaOH}$ solution were mixed together. For all geopolymer mixtures, the alkaline solution was prepared 1 day in advance to ensure complete dissolution of the $\mathrm{NaOH}$ pellets and to lose the exothermic reaction heat.

There are two methods for addition of MPCMs to concrete which are called the MPCM replacement method and the MPCM additive method. Pania et al. [102] observed that the strength reduction of concrete was less when the MPCM replaced a certain percentage of sand (MPCM replacement method) than when the MPCM was added to the concrete mixture as an extra additive (MPCM additive method). Based on the MPCM replacement method, different MPCM percentages (in volume) are replaced with the same percentages of sand. However, due to the absence of sand in geopolymer paste, the MPCM was added to the mixture as an extra additive (additive method). It is noteworthy that for both GPC and PCC, the MPCM was added as the last component in order to limit the potential damages to the MPCM during the mixing process [102]. Figure III.2 exhibits comparable pictures of sand and MPCM. 


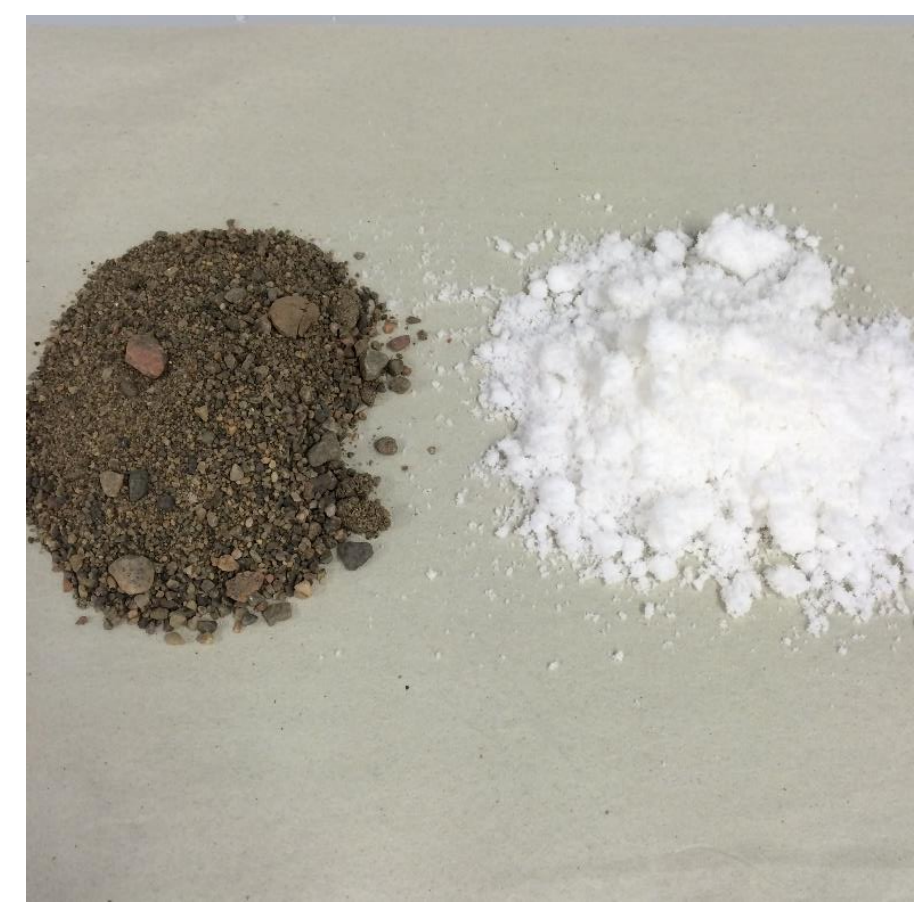

Figure III.2. Illustrative picture of sand and MPCM for replacement method.

\section{III.2.1. Paste}

For all geopolymer paste specimens, an alkaline solution to geopolymer binder (Fly ash + GGBFS) ratio of 0.4 was selected to reach the standard consistency described in EN 196-3. The geopolymer binder and alkaline solution were mixed together for $90 \mathrm{~s}$ with a kitchen mixer in a wet plastic bowl; after which the MPCM was introduced to the mixture and mixed for an additional $90 \mathrm{~s}$ into a homogenous paste. For Portland cement paste, cement and water with a water to cement ratio of 0.35 was mixed for $90 \mathrm{~s}$ to achieve the same consistency as the geopolymer paste. After adding MPCM, the mixing was continued for an additional $90 \mathrm{~s}$. 


\section{III.2.2. Concrete}

\section{III.2.2.1. Geopolymer concrete}

Fly ash, GGBFS and the alkaline solution were mixed together into a homogenous geopolymer paste. The paste was then introduced into the dried sand and mixed for $30 \mathrm{~s}$. Subsequently, gravel was added to the mixture and mixed for 2 minutes. During this 2 minutes mixing, superplasticizer and extra water were added to the mixture separately. Afterwards, the MPCM was added to the mixture and mixing was continued for 2 more minutes. Figure III. 3 shows all the ingredients for preparing geopolymer concrete.

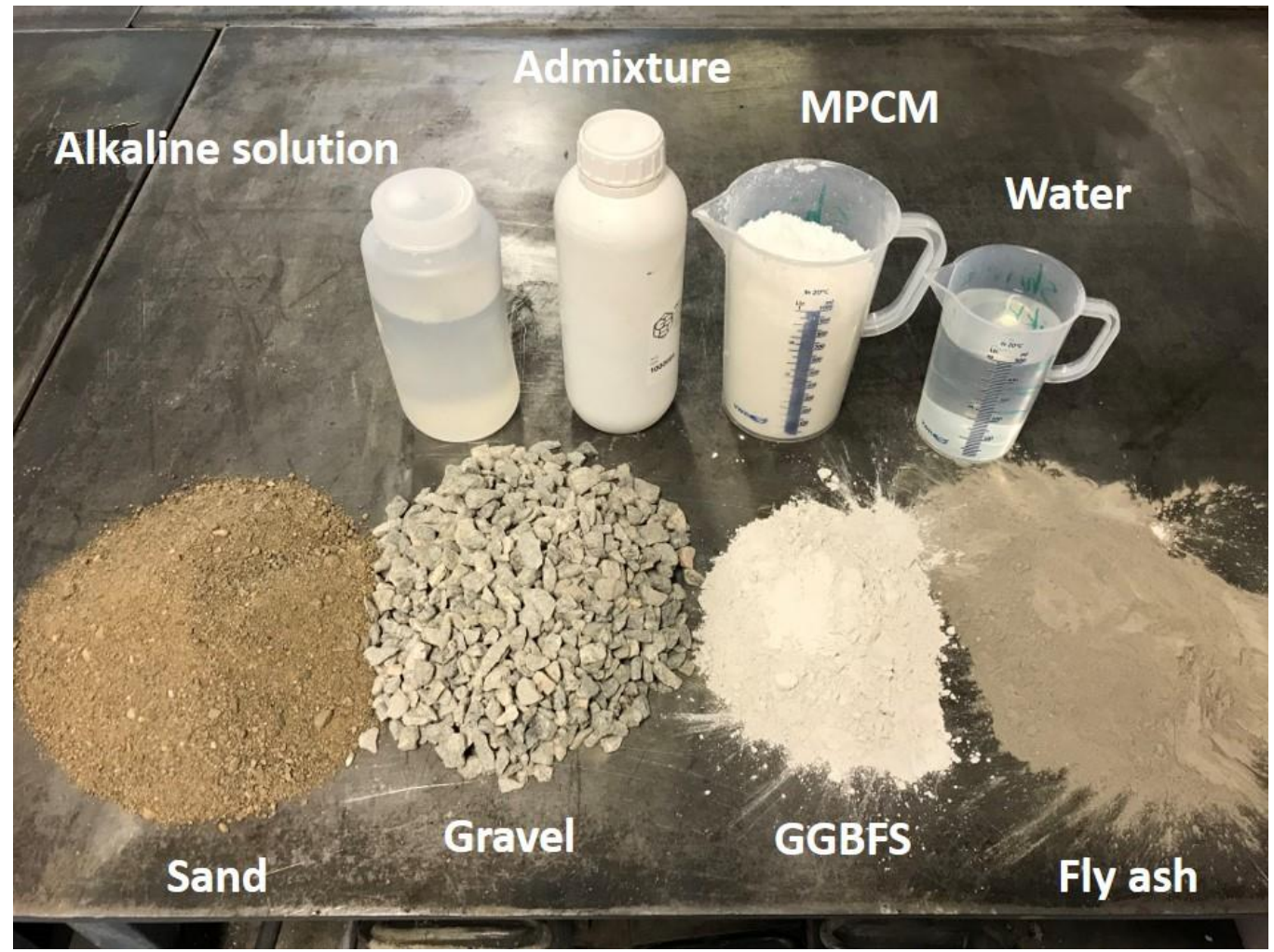

Figure III.3. Ingredients of the geopolymer concrete mixture. 


\section{III.2.2.2. Portland cement concrete}

Cement, sand and gravel were mixed together for 2 minutes. Subsequently, water containing admixture were gradually added and mixed for 1 minute. Finally, the MPCM was added to the concrete mixture and mixing was continued for 2 more minutes. Figure III.4 shows all ingredients for preparing Portland cement concrete.

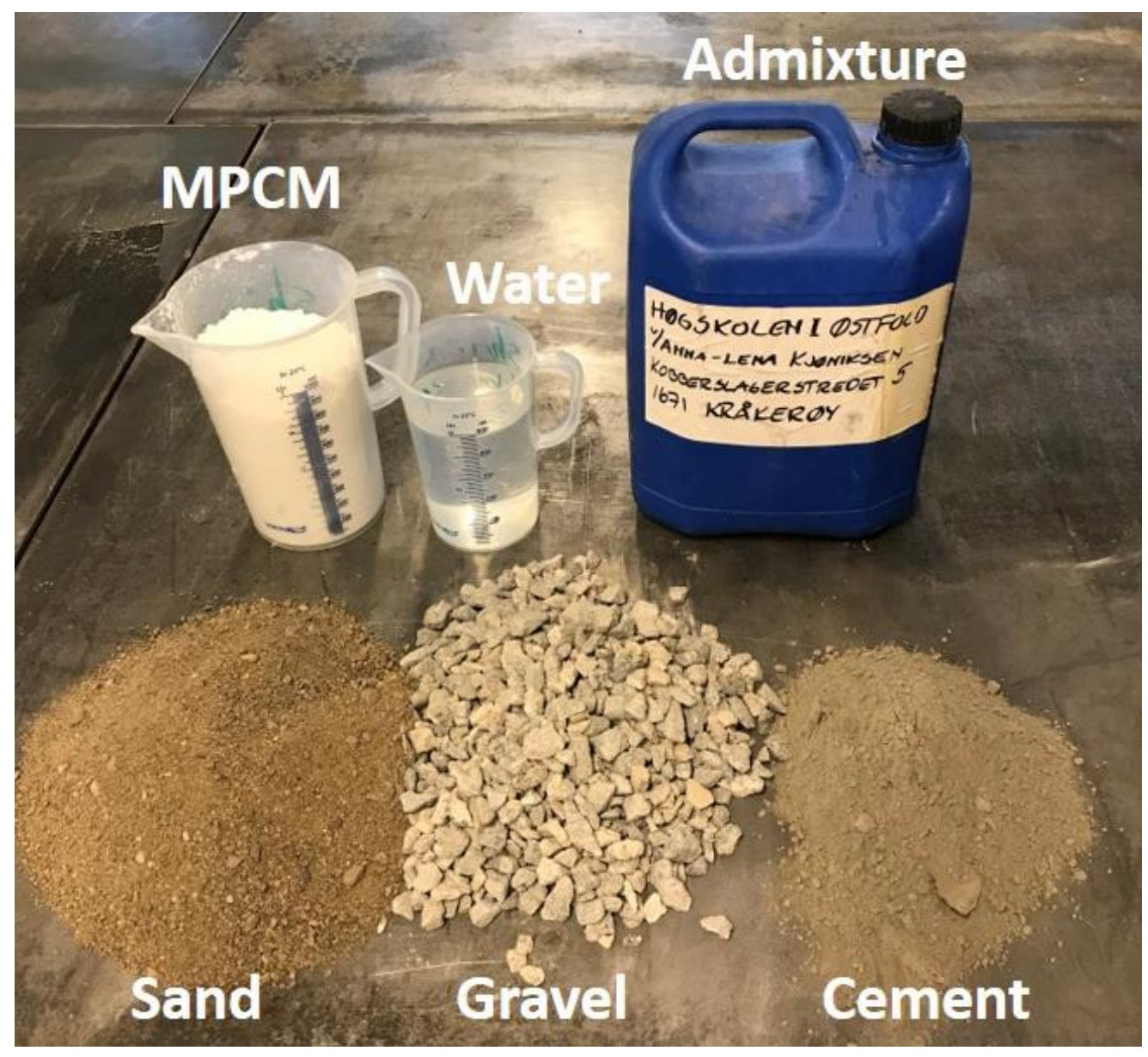

Figure III.4. Ingredients of Portland cement concrete mixture.

\section{III.2.2.3. Concrete mixing procedure}

In order to prepare large quantities of geopolymer paste for making GPC, a manual mixer were used for mixing the binder and alkaline solution (Figure III.5a). The same concrete mixer was used for the final mixing process of both GPC and PCC (Figure III.5b). The mixer was always 
carefully cleaned to remove any material left from the last batch. The inner surface of the mixer was slightly moistened to minimize water absorption by the wall.
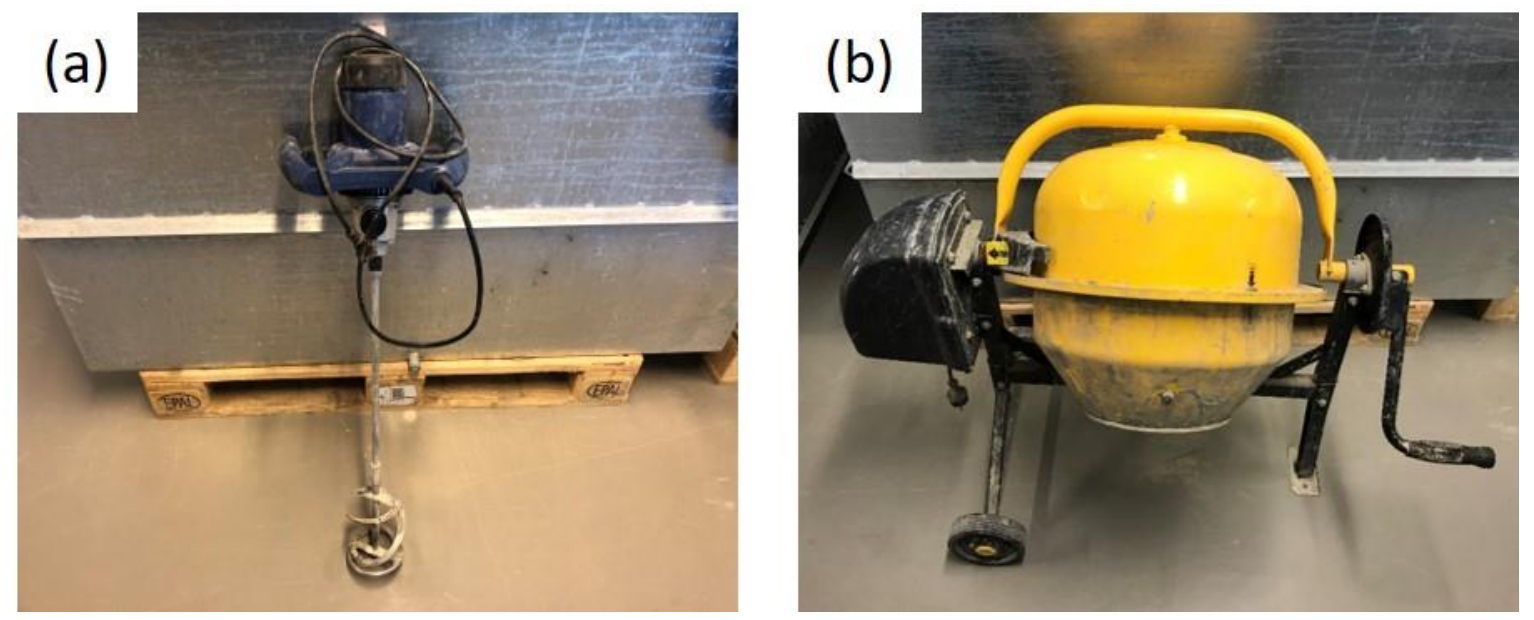

Figure III.5. Mixer used for (a) geopolymer paste in big quantity, (b) final mixing with aggregates.

\section{III.2.3. Casting and curing of samples}

After mixing, GPC and PCC were cast into molds at a size of $10 \times 10 \times 10 \mathrm{~cm}^{3}$. Disposable styrofoam molds and metal molds were used for casting GPC and PCC, respectively (Figure III.6). Due to the short setting time of GPC, a vibration machine was utilized to remove air trapped inside the specimens. The molds were first filled halfway up by fresh GPC and vibrated for $25 \mathrm{~s}$. After this, the molds were filled completely and vibrated for further $25 \mathrm{~s}$. For the PCC, half-filled molds were compacted by means of a steel pestle (25 times) and the same procedure was repeated after the molds were filled all the way up. After casting, both GPC and PCC were pre-cured at ambient temperature with a relatively humidity of $90 \%$ for $24 \mathrm{~h}$, followed by demolding of the samples. 

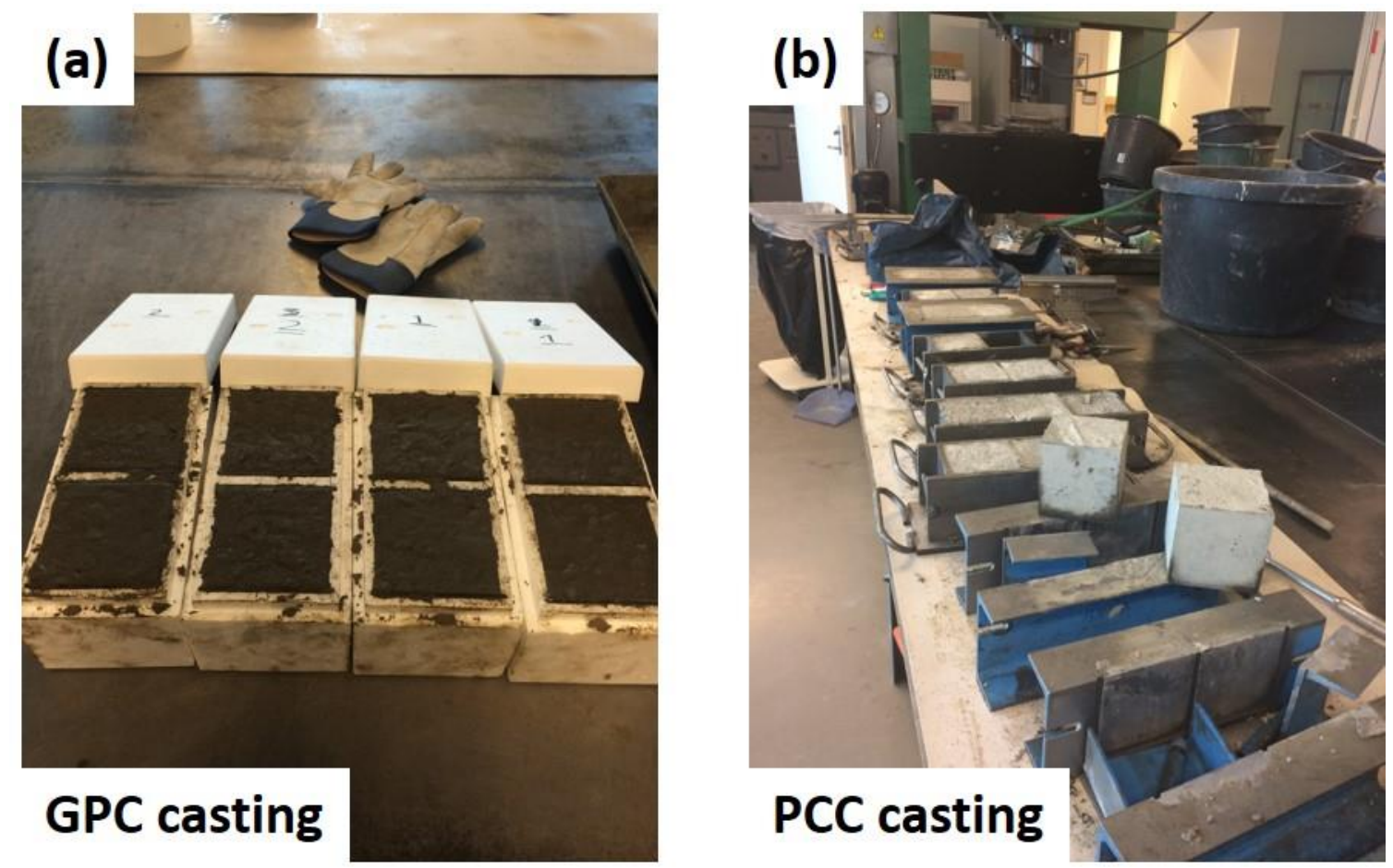

Figure III.6. Casting of (a) GPC and (b) PCC.

\section{III.2.3.1. Curing at $20^{\circ} \mathrm{C}$}

In order to examine how incorporation of MPCM influences the mechanical properties of both GPC and PCC at different curing times, after demolding, the specimens were cured in a tank of water at $20{ }^{\circ} \mathrm{C}$ for desired curing ages (Figure III.7).

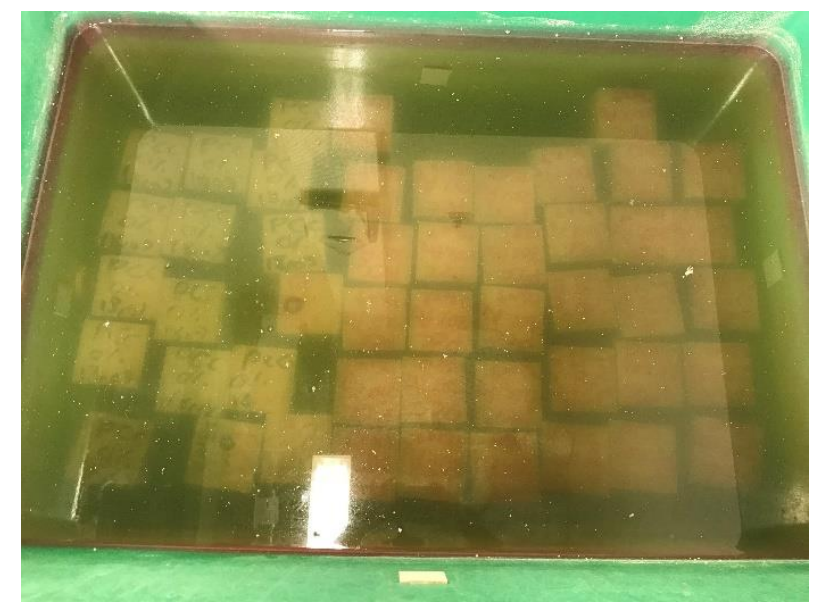

Figure III.7. Curing samples in water at $20^{\circ} \mathrm{C}$. 


\section{III.2.3.2. Curing at $40^{\circ} \mathrm{C}$}

Since the solid or liquid states of the PCM might influence the compressive strength, the systems have been studied both below and above the melting point of the PCM. As mentioned in III.1.8, the MPCMs utilized in this study have melting temperatures of about $28{ }^{\circ} \mathrm{C}$ and 25 ${ }^{\circ} \mathrm{C}$. Thus, GPC and PCC specimens were cured in a tank of water at $40{ }^{\circ} \mathrm{C}$, which is above the melting point of MPCM. An immersion thermostat was set at the centre of the tank and whole tank was covered by a thick plastic to prevent heat loss and keep the temperature of water constant at $40{ }^{\circ} \mathrm{C}$ (Figure III.8). The water temperature was controlled regularly by means of a thermometer.

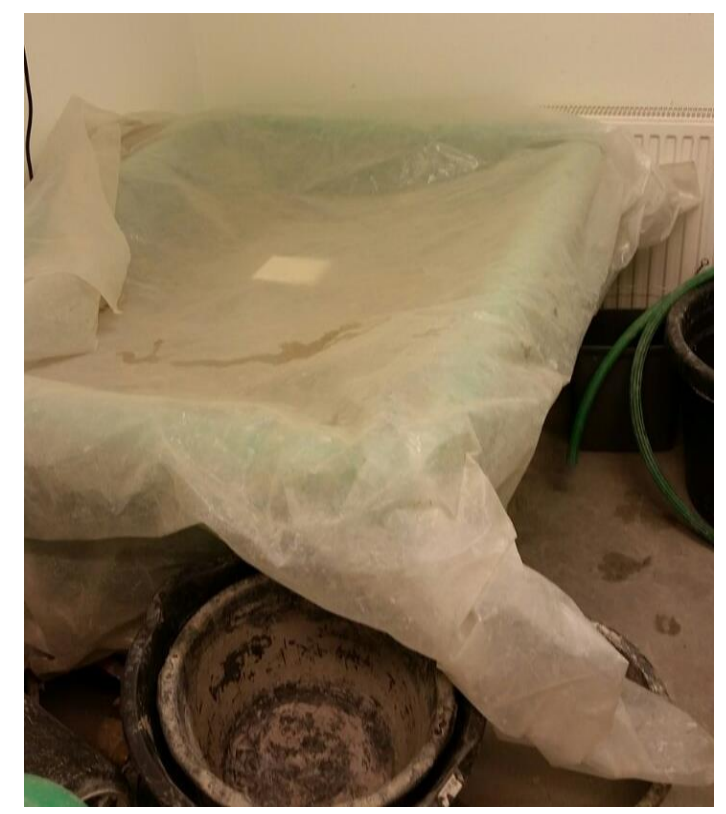

Figure III.8. Curing samples in water at $40{ }^{\circ} \mathrm{C}$.

\section{III.2.3.3. Curing for freeze-thaw cycles}

To prepare samples for freeze-thaw cycles, after 28 days curing in a tank of water at $20{ }^{\circ} \mathrm{C}$, the samples were left in the room for $1 \mathrm{~h}$ (to remove free water from the surfaces), weighed and subjected to freeze-thaw cycles. For each freeze-thaw cycle, a large bucket of tap water was 
placed in a cooling room at $\varnothing$ stfold University College with a temperature of $3 \pm 1{ }^{\circ} \mathrm{C}$. A freezer was placed in a room next to the cooling room to facilitate fast transfer of the samples. The samples were first immersed in tap water at a temperature of $3 \pm 1{ }^{\circ} \mathrm{C}$ for $6 \mathrm{~h}$ (Figure III.9a). Afterwards, the samples were left in a freezer at a temperature of $-20 \pm 1{ }^{\circ} \mathrm{C}$ for $18 \mathrm{~h}$ (Figure III.9b). The transition time between the thawing and freezing phases was less than $10 \mathrm{~min}$. The samples were subjected to $0,7,14$, and 28 freeze-thaw cycles.
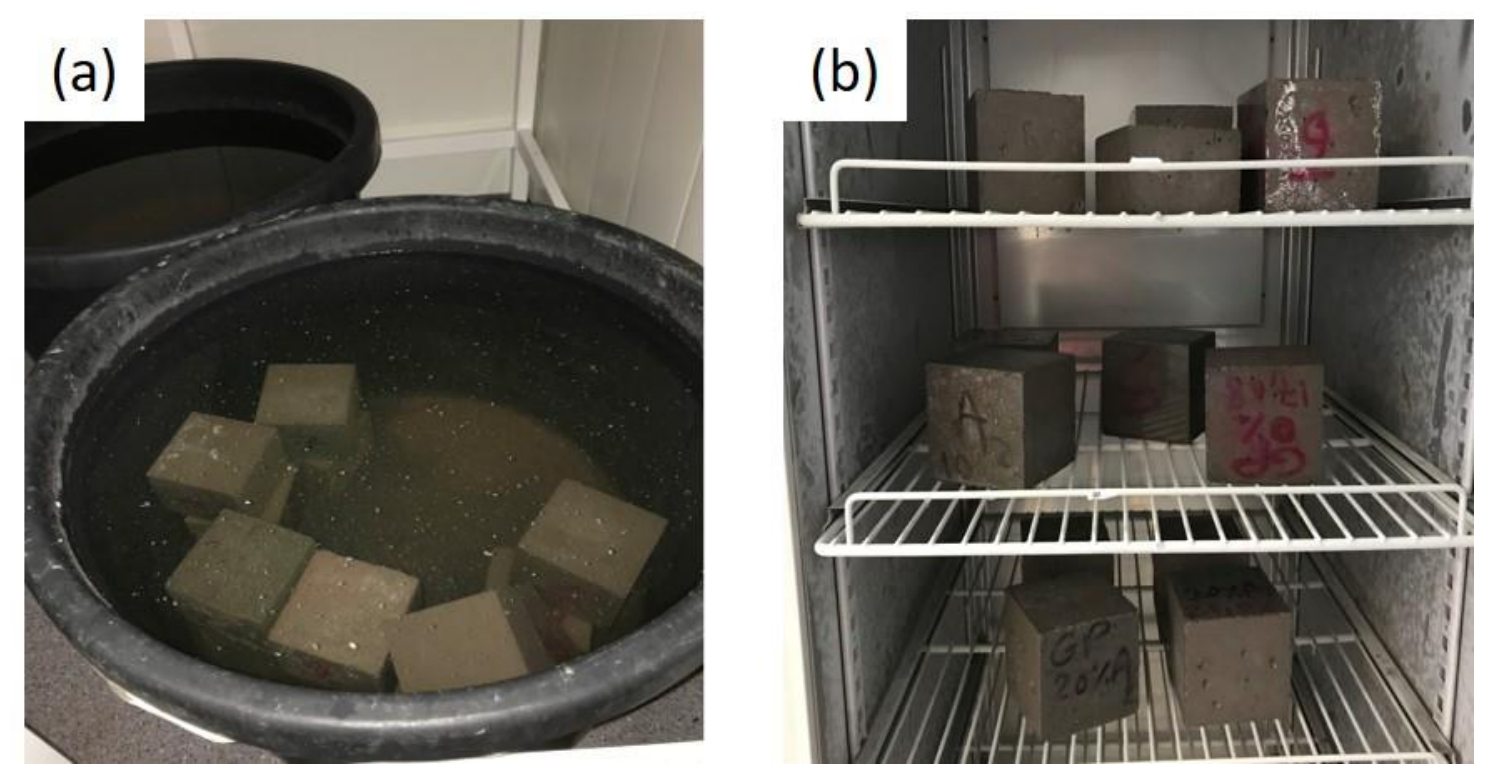

Figure III.9. Specimens in (a) a thawing water, (b) a freezer.

\section{III.3. Testing methods}

\section{III.3.1. Setting times at ambient temperature, $0^{\circ} \mathrm{C}$ and $40{ }^{\circ} \mathrm{C}$}

The initial and final setting times of geopolymer paste and Portland cement paste containing different percentages of PE-EVA-PCM or St-DVB-PCM were performed with a computer controlled Vicat needle apparatus (ToniSET One, Model 7301) in accordance with EN 196-3. The conical metal mold used in the Vicat needle apparatus has a height of $40 \mathrm{~mm}$, and inside diameters at the top and bottom of $70 \mathrm{~mm}$ and $80 \mathrm{~mm}$, respectively (in accordance with EN 
196). A total amount of $400 \mathrm{~g}$ of prepared paste was poured into the mold and placed in the apparatus basin. The setting time measurement was conducted automatically.

The test was carried out in a climate-controlled room to ensure a consistent temperature of 20$22{ }^{\circ} \mathrm{C}$, which is a critical parameter for setting time. The initial setting time was calculated from when the mixing of raw materials was initiated, and continued up to the final setting time with an interval of 2 min and 10 min for geopolymer paste and Portland cement paste, respectively. The initial setting time is the time when the needle penetration is less than $39.5 \mathrm{~mm}$ whereas the final setting time is the moment when the needle penetrates the sample to a depth of 0.5 $\mathrm{mm}$, which is logged and displayed on the screen of the apparatus.

In order to measurement of initial and final setting times of geopolymer and Portland cement pastes including PE-EVA-PCM or St-DVB-PCM at the temperature of $0{ }^{\circ} \mathrm{C}$, the basin was filled with an ice/water mixture and the conical mold was surrounded by ice/water (Figure III.10).

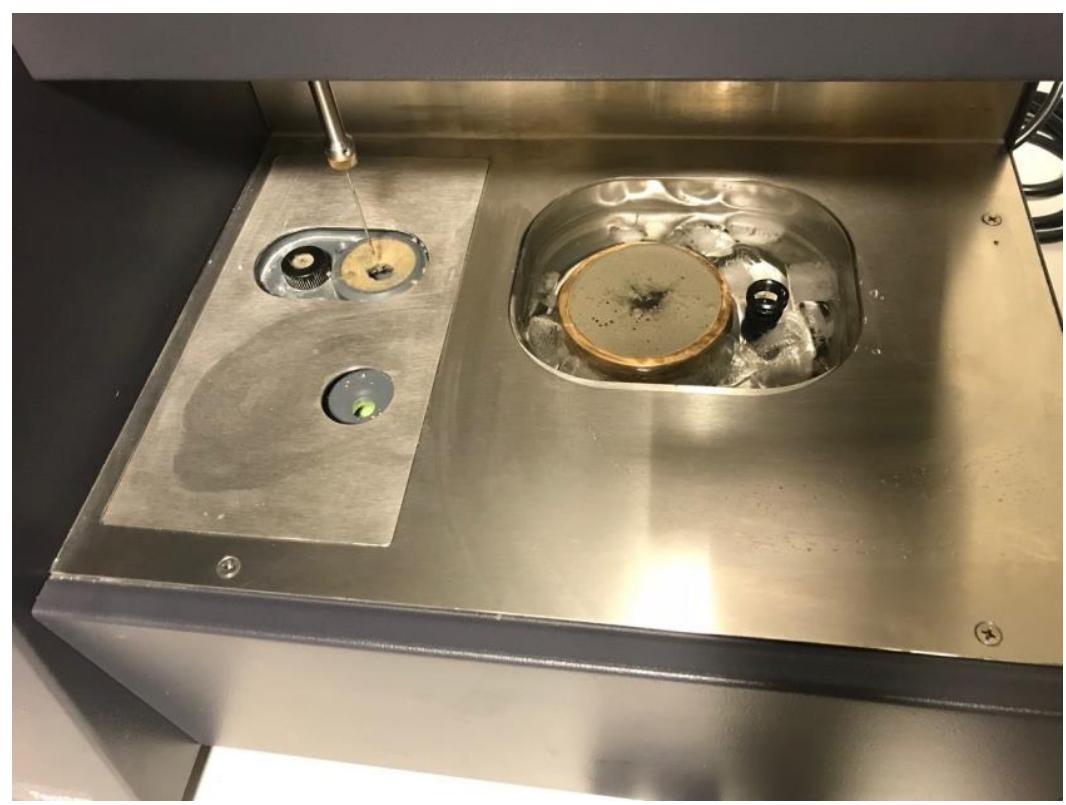

Figure III.10. Setting time measurement at $0{ }^{\circ} \mathrm{C}$. 
In order to measurement of initial and final setting times of geopolymer paste including PEEVA-PCM or St-DVB-PCM at the temperature of $40{ }^{\circ} \mathrm{C}$, the basin was filled with water and the conical mold was kept inside the basin at the temperature of $40^{\circ} \mathrm{C}$ by water circulation through a thermal bath. The water temperature was controlled by means of a digital thermometer (Figure III.11).
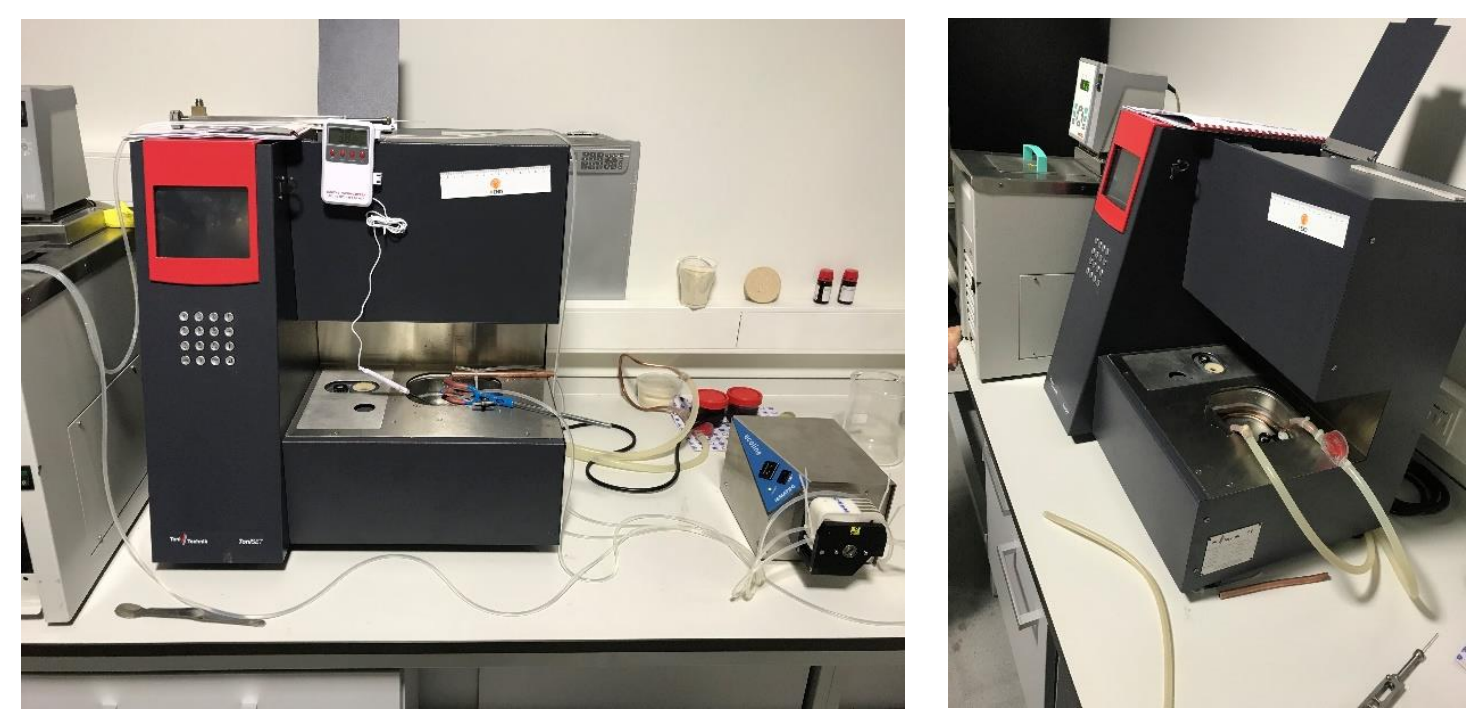

Figure III.11. Setting time measurement at $40^{\circ} \mathrm{C}$.

\section{III.3.2. Slump flow test}

The workability of fresh GPC and PCC mixtures incorporated with different percentages of MPCM, was measured immediately after mixing by a slump test according to EN 12350-2. An Abrams cone was used as the mold. The cone dimensions were $300 \mathrm{~mm}$ in height, and $100 \mathrm{~mm}$ and $200 \mathrm{~mm}$ in diameters at the top and base, respectively. The slump mold, base plate and temping rod were initially moistened. The mold was firmly held by standing it on the two foot pieces on the sides of the mold. Then, the fresh concrete mixture was poured in three equal layers in the mold. Each layer was uniformly compacted with 25 blows of a temping rod. 
After filling the top layer, the extra mixture was removed from the top surface and the mold was then lifted vertically without any displacement. The slump is determined by the vertical distance between the top of the mold and the displaced original center of the top surface of the slumped concrete (h) which is demonstrated in EN 12350-2 (Figure III.12) [118]. Figure III.13a presents the slump test of a fresh PCC mixture, and Figure III.13b depicts the slump test of a too stiff GPC mixture after adding MPCM.

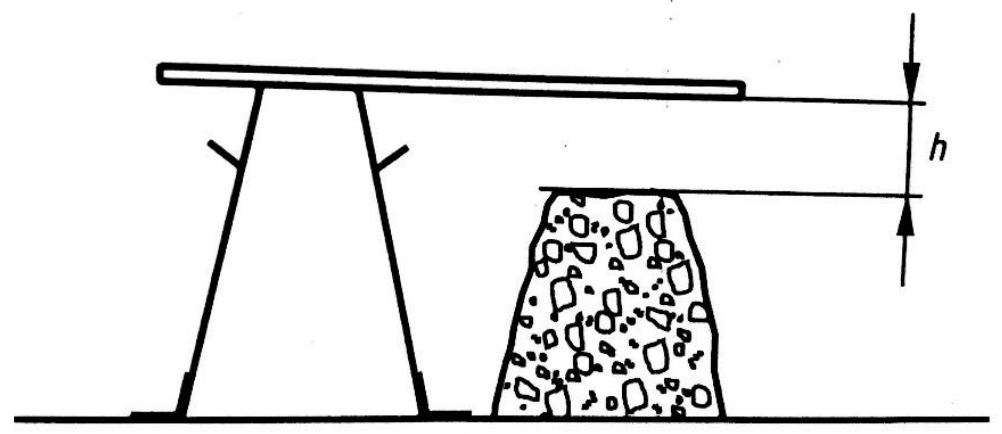

Figure III.12. Determination of slump according to [118].
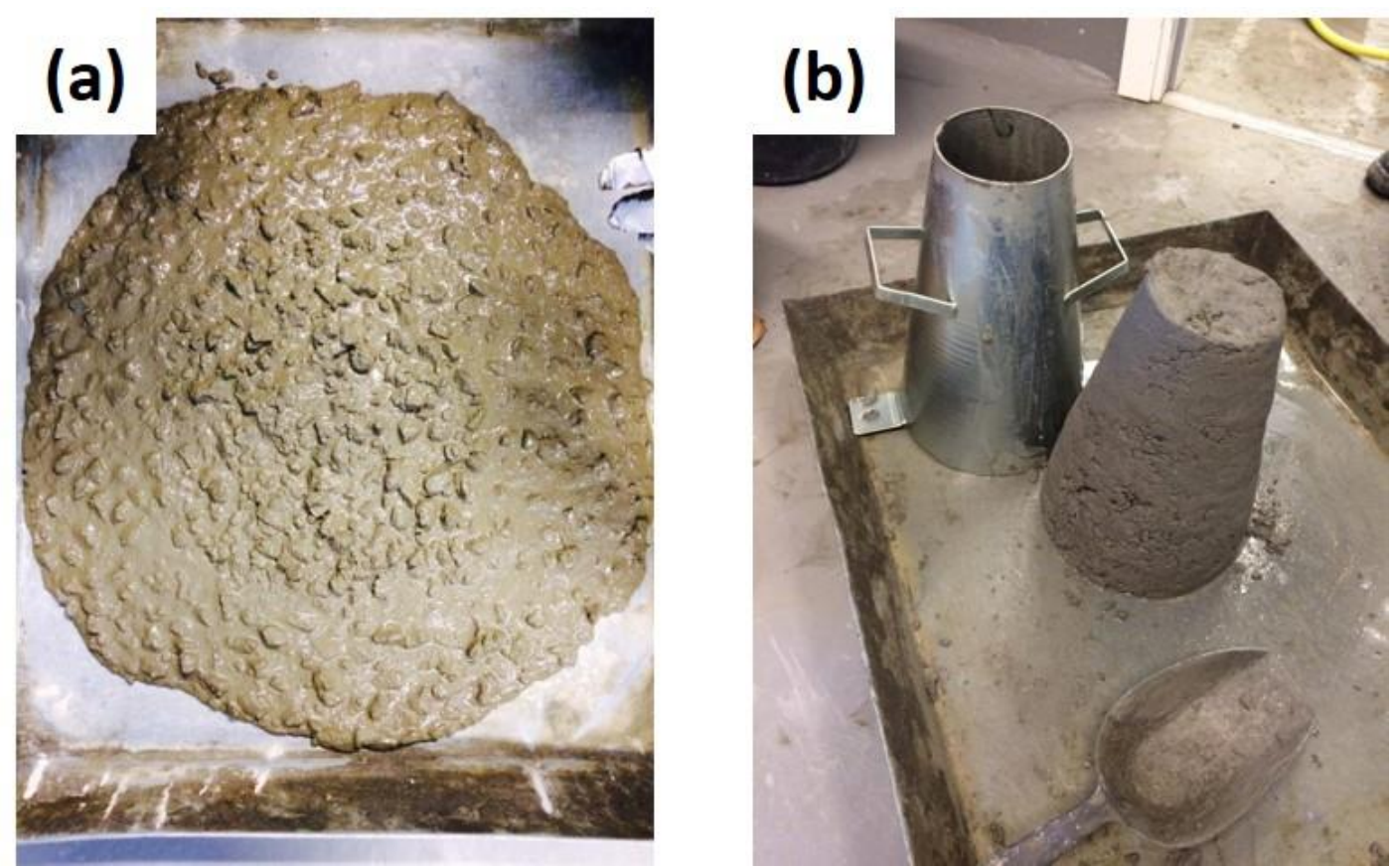

Figure III.13. Slump test of (a) PCC mixture, (b) a failed GPC mixture. 


\section{III.3.3. Compressive strength}

The compressive strength is given by the equation:

$$
f_{c}=\frac{F}{A_{c}}
$$

Where $\mathrm{f}_{\mathrm{c}}$ is the compressive strength in $\mathrm{MPa}\left(\mathrm{N} / \mathrm{mm}^{2}\right) ; \mathrm{F}$ is the maximum load at failure in $\mathrm{N}$; $\mathrm{A}_{\mathrm{c}}$ is the cross-sectional area of the specimen on which the compressive force acts, calculated from the designated size of the specimen in $\mathrm{mm}^{2}$. The compressive strength is expressed to the nearest $0.1 \mathrm{MPa}\left(\mathrm{N} / \mathrm{mm}^{2}\right)$.

Additionally, in this study, the percentage strength reduction of GPC and PCC is calculated as:

$$
\text { Percentage Strength Reduction }=\frac{\left(\sigma_{0}-\sigma_{M P C M}\right)}{\sigma_{0}} \times 100
$$

where $\sigma_{0}$ and $\sigma_{\mathrm{MPCM}}$ are the strength reduction without and with MPCM, respectively.

The percentage mass loss is calculated to examine the effect of freeze-thaw cycles on the concrete degradation:

$$
\text { Percentage mass loss }=\frac{\theta_{0}-\theta_{\text {cycle }}}{\theta_{0}} \times 100
$$

where $\theta_{0}$ and $\theta_{\text {cycle }}$ are the mass of the sample before and after the cycle, respectively.

\section{III.3.3.1. Compressive strength at $20^{\circ} \mathrm{C}$}

The compressive strength tests were performed in accordance with EN 12390-3 on cubic samples $\left(10 \times 10 \times 10 \mathrm{~cm}^{3}\right)$. The compressive strength was determined using a digital compressive strength test machine (Form+ Test Machine) with compression capacity of 3000 
$\mathrm{kN}$ (Figure III.14). Each test cube was exposed to a force at a loading rate of $0.8 \mathrm{kN} / \mathrm{s}$ until it failed. The compressive strength tests were carried out at $20{ }^{\circ} \mathrm{C}$ on $\mathrm{GPC}$ and PCC specimens containing different percentages of PE-EVA-PCM and St-DVB-PCM at selected curing times. For each compression test at $20^{\circ} \mathrm{C}$, three cubes were left in the room for $1 \mathrm{~h}$ (to remove free water from the surfaces), before they were weighed and tested. The reported values are the average of the three cubes. The standard deviations are plotted as error bars.

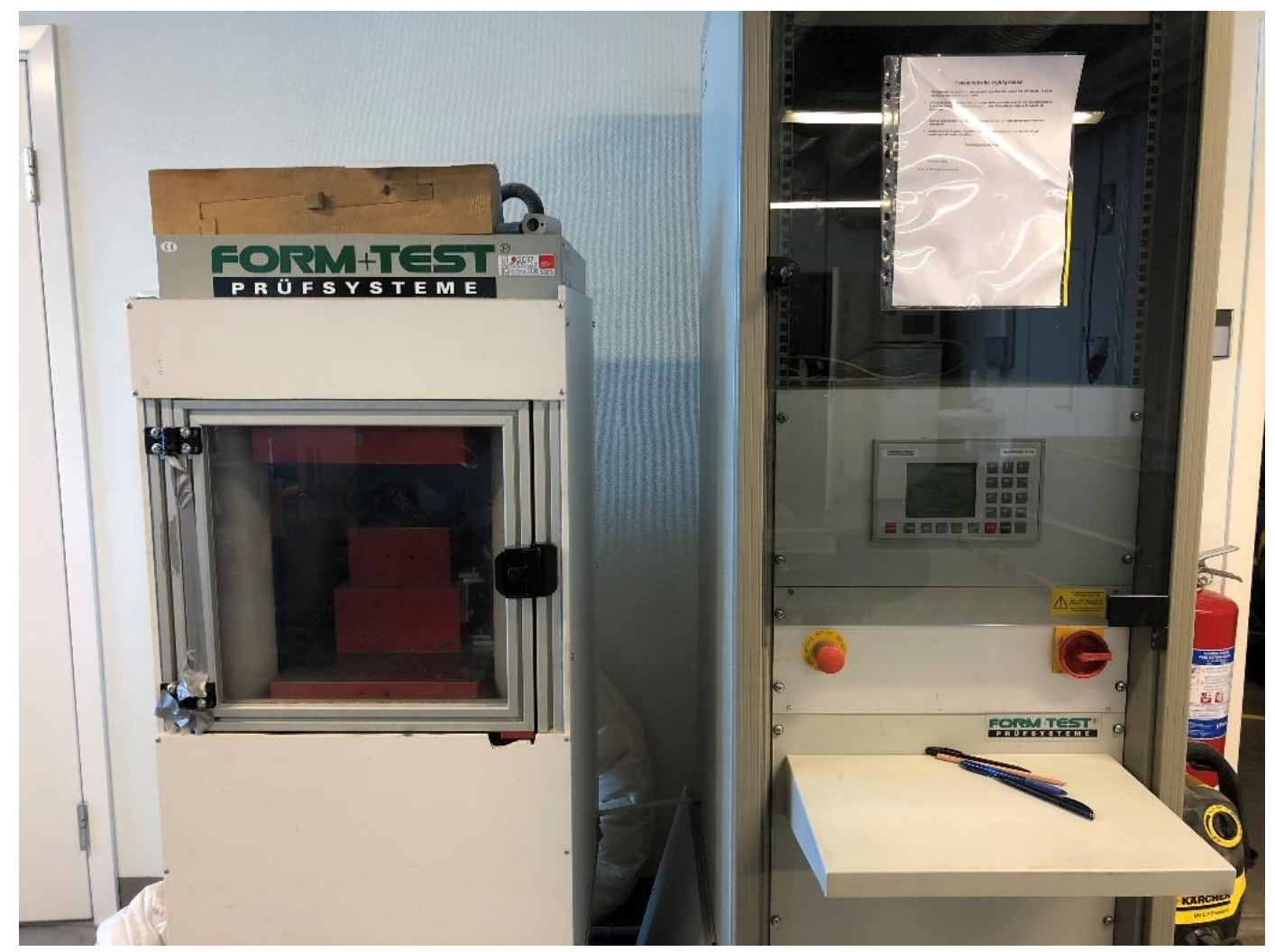

Figure III.14. Compressive strength test machine used in this study.

\section{III.3.3.2. Compressive strength at $40{ }^{\circ} \mathrm{C}$}

In order to determine the compressive strength at $40{ }^{\circ} \mathrm{C}$, the compressive strength machine was isolated thermally, and connected to a heating chamber by means of an isolated tube to keep the environmental temperature of the machine constant at $40{ }^{\circ} \mathrm{C}$ (Figure III.15). Before the compressive strength test, three cubes cured at $40{ }^{\circ} \mathrm{C}$ were kept in a heating chamber at $40{ }^{\circ} \mathrm{C}$ 
for $1 \mathrm{~h}$ (to remove free water from the surfaces while keeping the temperature of the cubes constant at $\left.40{ }^{\circ} \mathrm{C}\right)$. Immediately afterward, the cubes were weighed and tested. The reported values are the average of the three cubes.

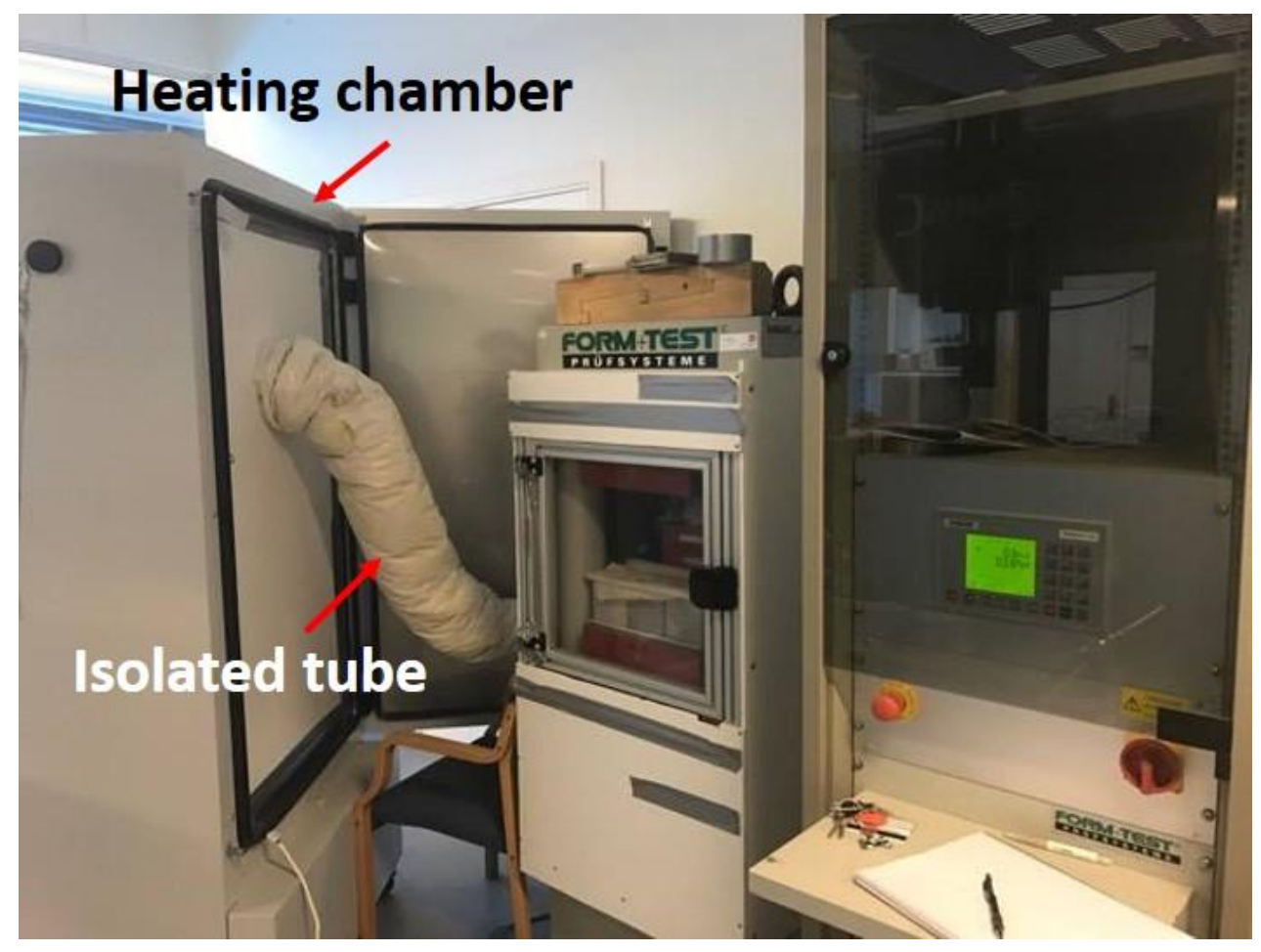

Figure III.15. Installation of compressive strength test machine at $40{ }^{\circ} \mathrm{C}$.

\section{III.3.3.3. Compressive strength after freeze-thaw cycles}

The compressive strength tests were performed at $20{ }^{\circ} \mathrm{C}$ on GPC and PCC specimens where $0 \%$ and $20 \%$ of the sand were replaced by PE-EVA-PCM or St-DVB-PCM after $0,7,14$, and 28 freeze-thaw cycles. For each compression test, after the freeze-thaw cycles, three cubes were left in air at ambient temperature for $1 \mathrm{~h}$ (to remove free water and ice from the surfaces), before they were weighed and tested. The reported values are the average of the three cubes. Figure III.16 shows a failed GPC cube after test. 


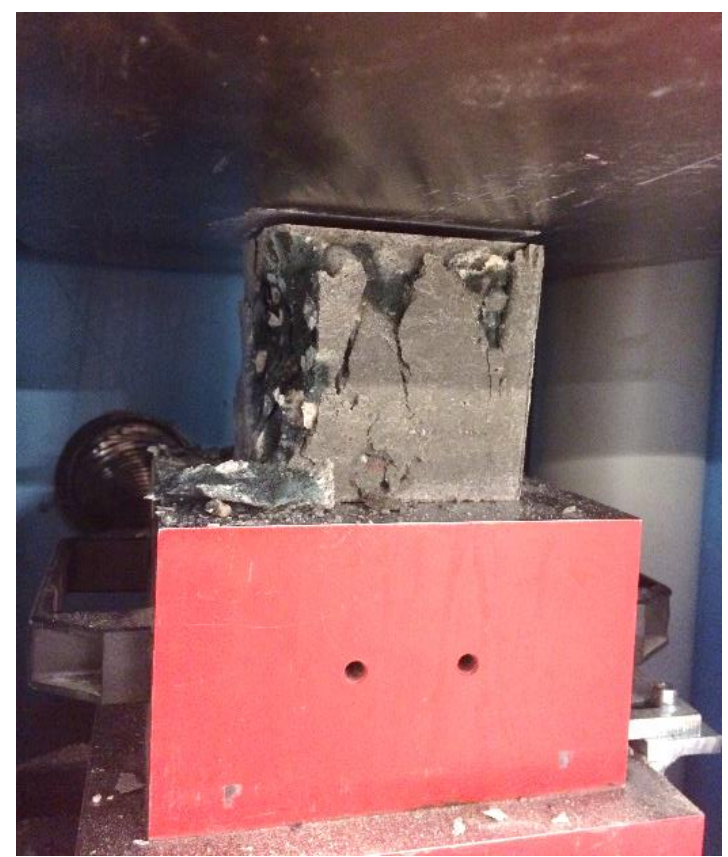

Figure III.16. A failed GPC sample after compressive strength test.

\section{III.3.3.4. Compressive strength after exposing to real weather conditions}

In addition to the standard freeze-thaw cycles, GPC and PCC containing 0\% and 20\% PE-EVAPCM or St-DVB-PCM, were stored outdoors with exposure to the natural weather variations for three months (November 2017 to January 2018, Fredrikstad, Norway) to examine the effect of exposure to real weather conditions. A weather station was installed next to the samples to record the weather fluctuations (Figure III.17) and the data was exported by EasyWeather software. After outdoor exposure, the compressive strength was measured. The reported values are the average of the three cubes. 


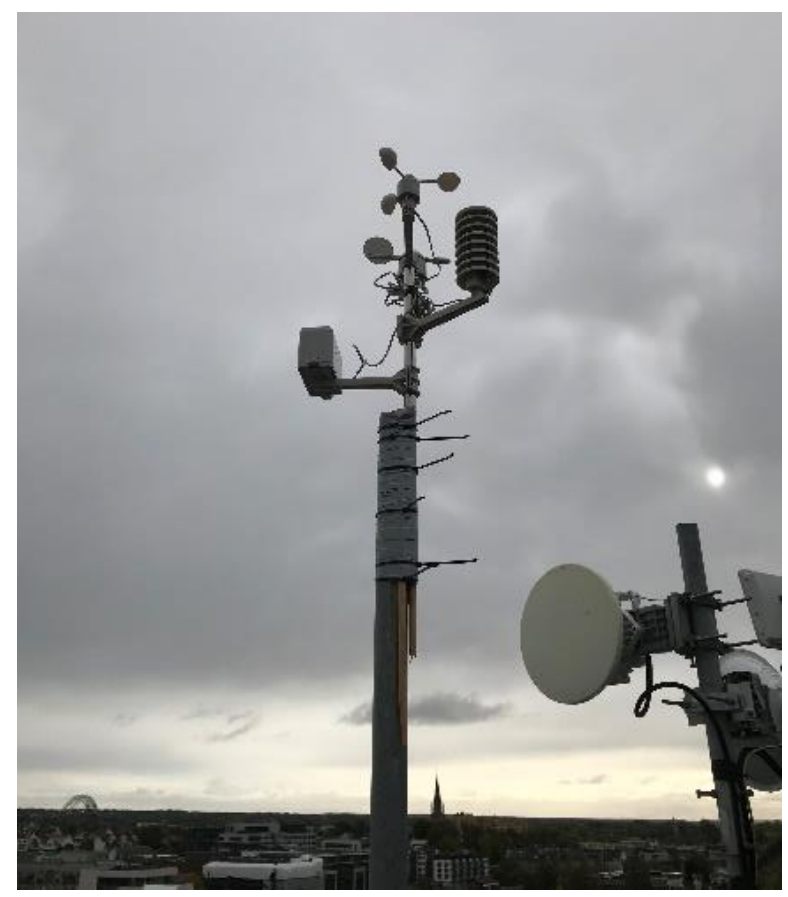

Figure III.17. A weather station installed on the roof of Østfold University College.

\section{III.3.4. X-ray micro-tomography analysis}

To study internal microstructure of GPC and PCC, X-ray tomography images were performed from cross-section of specimens in cylindrical form $(1 \mathrm{~cm}$ diameter and $1 \mathrm{~cm}$ height $)$ containing various percentages of PE-EVA-PCM and St-DVB-PCM after different curing conditions, using a Skyscan 1172 CT scanner (Bruker) with $85 \mathrm{kV}$ incident radiation, $400 \mathrm{~ms}$ exposure time per frame and $0.5^{\circ}$ rotation step (Figure III.18). The final sets of vertically stacked slices were reconstructed using the Feldkam algorithm [119] and have a voxel size of $10 \mu \mathrm{m}$. Sample preparation was done by means of a core drill at Østfold University College (Figure III.19). The data analysis was performed by Luca Valentini from the University of Padua, Italy. 


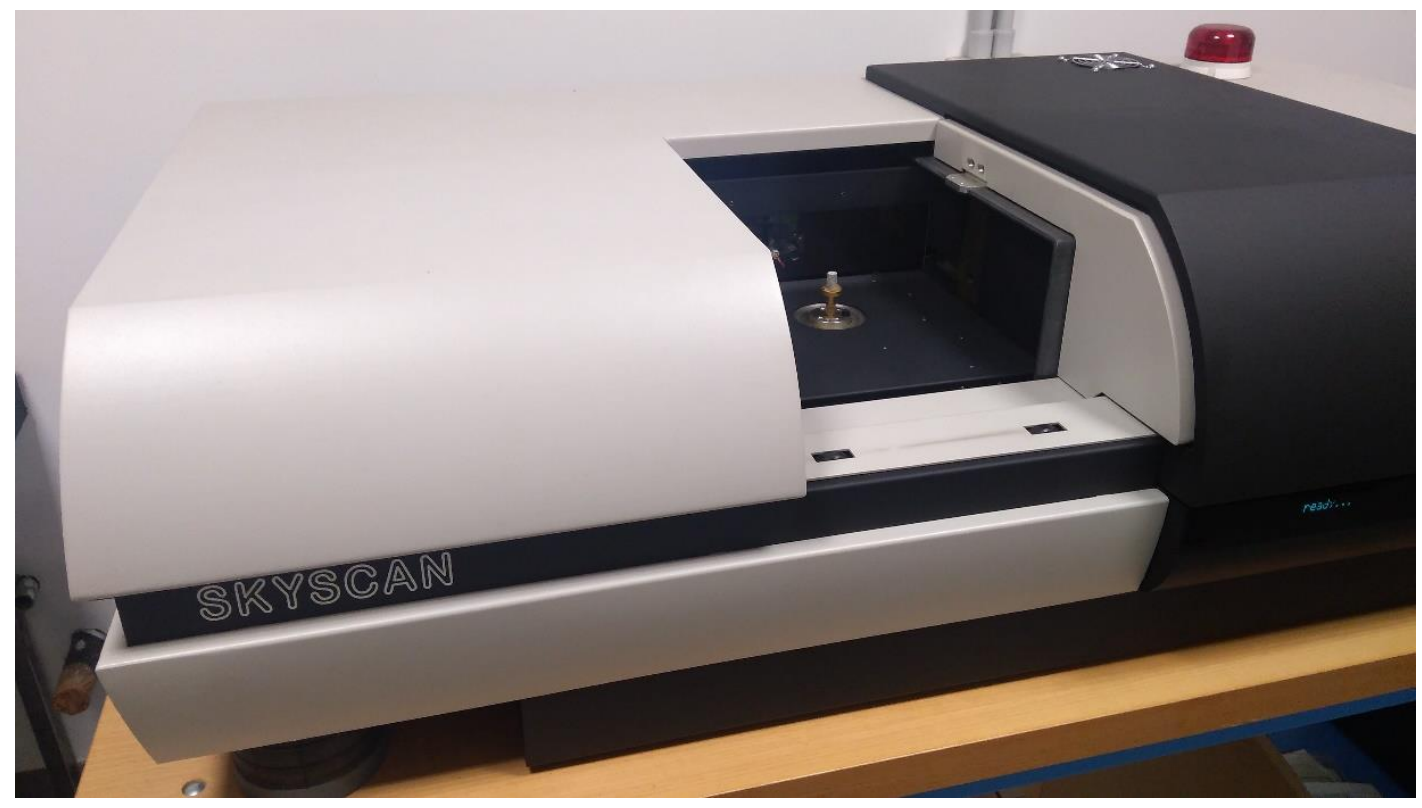

Figure III.18. Skyscan 1172 CT scanner.

Image thresholding based on a minimum cross entropy algorithm [120] was performed in order to convert the slices into binary images. Such images were then used to calculate the equivalent radii (e.g. the radius of a sphere having the same volume as the considered object) of the MPCM present in the samples and their standard deviations of the center-to-surface distance (SD), by using the ImageJ software [121]. The latter parameter is a measure of the deformation of an object (i.e. the extent to which its shape departs from that of a sphere, for which SD $=0$ ). Additionally, the micro-CT slices were loaded into ImageJ software (v 1.5i) to obtain additional information about shape descriptors of pores, such as perimeter, circularity and aspect ratio. This study was carried out by Marcos Lanzón at the Technical University of Cartagena. 


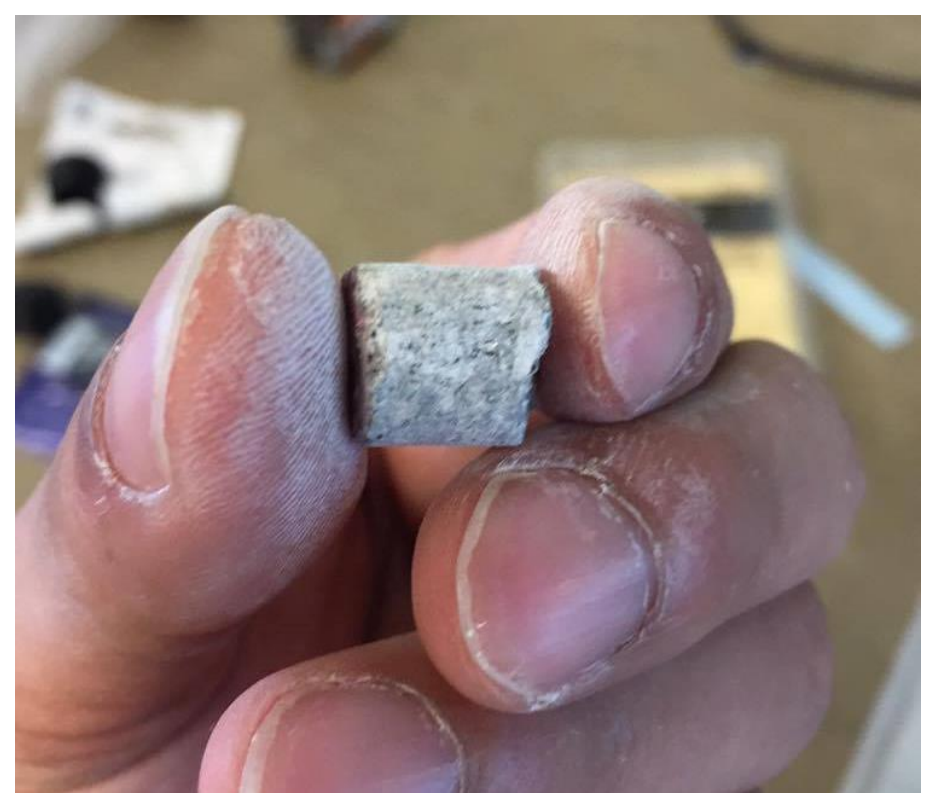

Figure III.19. Sample preparation for X-ray tomography imaging.

\section{III.3.5. Scanning electron microscopy (SEM) imaging}

SEM images were prepared from fractured surfaces of GPC and PCC specimens containing different percentages of PE-EVA-PCM and St-DVB-PCM after different curing conditions using Quanta FEG-250 Scanning Electron Microscope device at an accelerating voltage of 30 $\mathrm{kV}$. The methods of LFD (Large Field Detector) detector and vCD (Low voltage High Contrast) detector were applied for imaging. This section of analysis was carried out in MAPEI, Italy.

Additionally, some images were captured in BSE (back scattered electrons) mode to obtain adequate contrast between lightweight materials (MPCM) and the matrix of GPC and PCC at different curing conditions. The microstructure of the fractured surfaces of the samples was analyzed using Hitachi S3500N Scanning Electron Microscope (SEM) at an accelerating voltage of $15 \mathrm{Kv}$ (Figure III.20). These measurements were performed at the Technical University of Cartagena. 


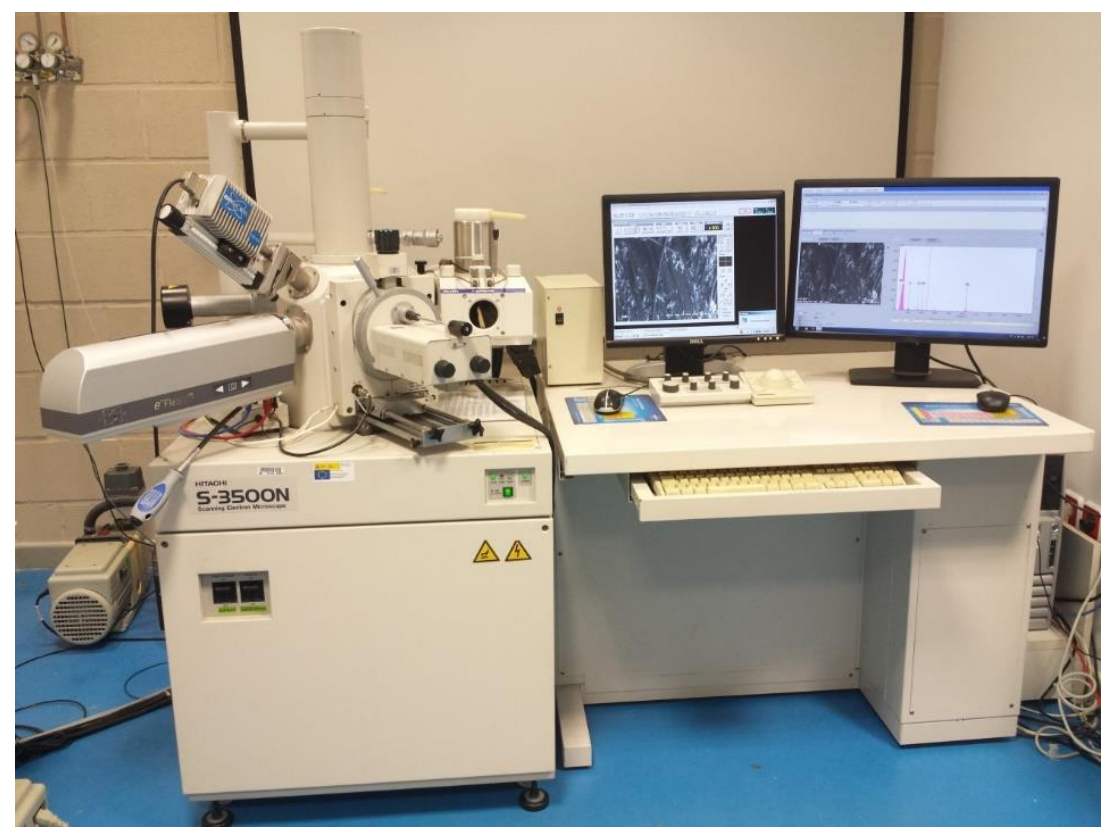

Figure III.20. Scanning Electron Microscope (SEM) located at the Technical University of Cartagena.

In this study, the fractured surfaces for SEM images were not polished or coated in order to prevent artifacts from the effect of coating on the surface.

\section{III.4. Experimental designs}

\section{III.4.1. Experimental design for Chapter $V$}

The utilized mix design for GPC and PCC was provided by the concrete laboratory at Østfold University college and MAPEI (Norway), respectively. For GPC, batch I of FA and GGBFS were used as the aluminosilicate materials. For the GPC mixtures, an alkaline solution (14 M) was prepared with a sodium silicate solution to sodium hydroxide solution weight ratio of 2.5.

The batch I of sand and gravel was used for both GPC and PCC. Dynamon SR-N was applied as the superplasticizing admixture for PCC. However, no chemical admixture was added to the GPC mixture. PE-EVA-PCM with a melting point of $28.4 \pm 0.9^{\circ} \mathrm{C}$ was used as the MPCM in 
this chapter. In order to have comparable data, the combined amount of sand and gravel for the samples without MPCM is approximately the same for GPC and PCC. However, in order to obtain samples with sufficiently high compressive strength while keeping a usable workability of the samples and avoid segregation of the gravel, the ratio between sand and gravel is different for GPC and PCC.

Sixteen concrete mixtures were used to study the effect of various parameters. The details of GPC and PCC mixtures design are given in Table III.2 and Table III.3. In both Tables, the mass of each component of a mixture is given in terms of $\mathrm{g}$ per 1 liter of concrete. All components were weighted utilizing a digital balance (BERGMAN) with an accuracy of $0.1 \mathrm{~g}$.

Table III.2. Mixture design of GPC, amounts represent $1 \mathrm{~L}$ of mixture. The MPCM percentages indicate the amount of sand replaced by MPCM.

\begin{tabular}{l|l|l|l|l|l|l|l|l}
\hline MPCM & MPCM & Alkaline & Water & FA & GGBFS & Sand & Aggregate & MPCM \\
$($ vol \% $)$ & $($ wt. \% $)$ & solution & $(\mathrm{g})$ & $(\mathrm{g})$ & $(\mathrm{g})$ & $(\mathrm{g})$ & $(\mathrm{g})$ & $(\mathrm{g})$ \\
\hline 0 & 0 & 161.6 & 56.4 & 242.6 & 161.4 & 893.1 & 868.6 & 0 \\
10 & 1.3 & 161.6 & 56.4 & 242.6 & 161.4 & 803.8 & 868.6 & 30 \\
20 & 2.6 & 161.6 & 56.4 & 242.6 & 161.4 & 714.5 & 868.6 & 60 \\
\hline
\end{tabular}


Table III.3. Mixture design of PCC, amounts represent $1 \mathrm{~L}$ of mixture. The MPCM percentages indicate the amount of sand replaced by MPCM.

\begin{tabular}{l|l|l|l|l|l|l|l}
\hline MPCM & MPCM & Cement & Water & Admixture & Sand & Aggregate & MPCM \\
$($ vol \% $)$ & $($ wt.\% $)$ & $(\mathrm{g})$ & $(\mathrm{g})$ & $(\mathrm{g})$ & $(\mathrm{g})$ & $(\mathrm{g})$ & $(\mathrm{g})$ \\
\hline 0 & 0 & 434 & 191.8 & 5.6 & 1057 & 705 & 0 \\
5 & 0.7 & 434 & 192 & 5.6 & 1004.2 & 705 & 18 \\
10 & 1.5 & 434 & 192.2 & 5.6 & 951.3 & 705 & 36 \\
\hline
\end{tabular}

\section{III.4.2. Experimental design for Chapter VI}

Class F fly ash and slag, sodium hydroxide and sodium silicate were chosen as binder and alkaline solution, respectively. For GPC, batch II of FA and GGBFS were used as the aluminosilicate sources The alkaline solution was prepared one day in advance by adding sodium hydroxide powder to water to prepare a solution at the desired molarities, before mixing with sodium silicate solution (35 wt. \%)

Batch II of sand and gravel was used for GPC. FLUBE OS 39 was applied as a superplasticizing admixture to improve the workability of GPC and decrease the amount of extra water. St-DVBPCM with a melting point of $24.2 \pm 0.9^{\circ} \mathrm{C}$ was utilized as the MPCM in this chapter. 


\section{III.4.3. Experimental design for Chapter VII}

For GPC preparation, the GPC mix design from Chapter VI is followed. For GPC, batch II of FA and GGBFS were used as the aluminosilicate materials. For all geopolymer mixtures, an alkaline solution with a sodium silicate solution to sodium hydroxide solution (14 M) ratio of 1.5 and total $\mathrm{SiO}_{2}$ to $\mathrm{Na}_{2} \mathrm{O}$ ratio of 0.7 was selected.

Batch II of sand and gravel was used for GPC. FLUBE OS 39 was applied as a superplasticizing admixture to improve the workability of GPC. In this chapter, the utilized MPCMs were PEEVA-PCM and St-DVB-PCM with melting points of $28.4 \pm 0.9{ }^{\circ} \mathrm{C}$ and $24.2 \pm 0.9{ }^{\circ} \mathrm{C}$, respectively.

The summary of mixture designs of geopolymer paste and concrete are given in Table III.4 and Table III.5, respectively. 
Table III.4. Mix design of geopolymer paste. For paste, the MPCM was added as an additional percentage of powder materials.

\begin{tabular}{|c|c|c|c|}
\hline \multirow{2}{*}{ Materials } & \multicolumn{3}{|c|}{ Paste (g) } \\
\hline & MPCM $0 \%$ & MPCM $10 \%$ & MPCM $20 \%$ \\
\hline Alkaline solution & 188.5 & 188.5 & 188.5 \\
\hline Fly ash & 280.2 & 280.2 & 280.2 \\
\hline GGBFS & 191 & 191 & 191 \\
\hline Sand & - & - & - \\
\hline Gravel & - & - & - \\
\hline Extra water & - & - & - \\
\hline Superplasticiser & - & - & - \\
\hline MPCMs & 0 & 17.5 & 35 \\
\hline
\end{tabular}


Table III.5. Mix design of geopolymer concrete. The concrete recipe gives $1 \mathrm{~L}$ of mixture. For concrete, the MPCM percentages indicate the amount of sand replaced by MPCM.

\begin{tabular}{|c|c|c|c|}
\hline \multirow{2}{*}{ Materials } & \multicolumn{3}{|c|}{ Concrete (g) } \\
\hline & MPCM $0 \%$ & MPCM $10 \%$ & MPCM $20 \%$ \\
\hline Alkaline solution & 189.8 & 189.8 & 189.8 \\
\hline Fly ash & 280.2 & 280.2 & 280.2 \\
\hline GGBFS & 191 & 191 & 191 \\
\hline Sand & 828.1 & 745.31 & 662.5 \\
\hline Gravel & 809.6 & 809.6 & 809.6 \\
\hline Extra water & 47 & 47 & 47 \\
\hline Superplasticiser & 4.8 & 4.8 & 4.8 \\
\hline MPCMs & 0 & 28 & 55.8 \\
\hline
\end{tabular}

\section{III.4.4. Experimental design for Chapter VIII and Chapter IX}

The mix design from Chapter VI is followed for GPC. The mix design of PCC is assigned by considering some parameters. To have comparable data for GPC and PCC, the total amount of liquid (alkaline solution + extra water) to the geopolymer binder and the water to cement ratio for the Portland cement were kept constant at 0.5. In addition, the combined amount of sand and gravel for the samples without MPCM was approximately the same for GPC and PCC. 
For GPC, batch II of FA and GGBFS was used as the aluminosilicate materials. For all geopolymer mixtures, an alkaline solution with a sodium silicate solution to sodium hydroxide solution $(14 \mathrm{M})$ ratio of 1.5 and total $\mathrm{SiO}_{2}$ to $\mathrm{Na}_{2} \mathrm{O}$ ratio of 0.7 was selected.

Batch II of sand and gravel was used for both GPC and PCC. FLUBE OS 39 and Dynamon SR$\mathrm{N}$ were applied as the superplasticizing admixtures to improve the workability of GPC and PCC, respectively. In this chapter the utilized MPCMs were PE-EVA-PCM and St-DVB-PCM with melting points of $28.4 \pm 0.9^{\circ} \mathrm{C}$ and $24.2 \pm 0.9^{\circ} \mathrm{C}$, respectively.

The summary of mixture designs of geopolymer and Portland cement compositions are given in Table III.6 and Table III.7, respectively. 


\section{Chapter III}

Table III.6. Mix design of geopolymer paste and concrete. The amounts of concrete represent

$1 \mathrm{~L}$ of mixture. For paste, the MPCM was added as an additional 20 vol. $\%$ of powder materials.

For concrete, the MPCM percentages indicate the amount of sand replaced by MPCM.

\begin{tabular}{|c|c|c|c|c|}
\hline \multirow{2}{*}{ Materials } & \multicolumn{2}{|c|}{ Paste (g) } & \multicolumn{2}{|c|}{ Concrete (g) } \\
\hline & MPCM $0 \%$ & MPCM $20 \%$ & MPCM $0 \%$ & MPCM $20 \%$ \\
\hline Alkaline solution & 188.5 & 188.5 & 189.8 & 189.8 \\
\hline Fly ash & 280.2 & 280.2 & 280.2 & 280.2 \\
\hline GGBFS & 191 & 191 & 191 & 191 \\
\hline Sand & - & - & 828.1 & 662.5 \\
\hline Gravel & - & - & 809.6 & 809.6 \\
\hline Extra water & - & - & 47 & 47 \\
\hline superplasticiser & - & - & 4.8 & 4.8 \\
\hline MPCMs & 0 & 35 & 0 & 55.8 \\
\hline
\end{tabular}


Table III.7. Mixture design of Portland paste and concrete. The amounts of concrete represent

$1 \mathrm{~L}$ of mixture. For paste, the MPCM was added as an additional 20 vol. $\%$ of powder materials.

For concrete, the MPCM percentages indicate the amount of sand replaced by MPCM.

\begin{tabular}{|c|c|c|c|c|}
\hline \multirow{2}{*}{ Materials } & \multicolumn{2}{|c|}{ Paste (g) } & \multicolumn{2}{|c|}{ Concrete (g) } \\
\hline & MPCM $0 \%$ & MPCM $20 \%$ & МPCM $0 \%$ & MPCM $20 \%$ \\
\hline Cement & 471.2 & 471.2 & 471.2 & 471.2 \\
\hline water & 212 & 212 & 235.6 & 235.6 \\
\hline Sand & - & - & 957 & 765.6 \\
\hline Gravel & - & - & 705 & 705 \\
\hline superplasticiser & - & - & 4.8 & 4.8 \\
\hline MPCMs & 0 & 28.3 & 0 & 64.3 \\
\hline
\end{tabular}


Chapter IV.

Characterization of raw materials 



\section{IV.1. Fly ash and ground granulated blast furnace}

\section{slag}

Table IV.1 shows the chemical compositions of FA and GGBFS. The properties of FA and GGBFS vary based on the composition and types of source. It can also differ in different batches, which is evident in the given XRF data (Table IV.1). For FA, the CaO content was very low (less than 10\%) in both batches of FA. Accordingly, the utilized fly ash is classified as FA class F.

Figure IV.1 and Figure IV.2 show microscopic images (SEM) of the supplied FA and GGBFS of batch II. The particle shape of the fly ash (Figure IV.1) was generally spherical, with a wide particle size distribution. The GGBFS (Figure IV.2) particles are angular in shape, which is a result of an intensive milling process. GGBFS also exhibits a wide particle size distribution.

The XRD analysis (Figure IV.3 and Figure IV.4) demonstrated that the percentages of crystalline phase of FA are 30 and 37 for batch I and batch II, respectively. For GGBFS (Figure IV.5 and Figure IV.6), batch I was completely amorphous whereas $2.7 \%$ crystalline phase was observed for batch II. 
Table IV.1. Chemical composition of fly ash (FA) and ground granulated blast furnace slag (GGBFS).

\begin{tabular}{|c|c|c|c|c|}
\hline \multirow{2}{*}{ Chemical } & \multicolumn{2}{|c|}{ FA (wt. \%) } & \multicolumn{2}{|c|}{ GGBFS (wt. \%) } \\
\hline & Batch I & Batch II & Batch I & Batch II \\
\hline $\mathrm{Al}_{2} \mathrm{O}_{3}$ & 25.71 & 23.15 & 10.65 & 10.30 \\
\hline $\mathrm{SiO}_{2}$ & 52.65 & 50.83 & 34.3 & 34.51 \\
\hline $\mathrm{CaO}$ & 6.24 & 6.87 & 43.97 & 42.84 \\
\hline $\mathrm{Fe}_{2} \mathrm{O}_{3}$ & 5.31 & 6.82 & 0.36 & 0.60 \\
\hline $\mathrm{MgO}$ & 1.40 & 1.70 & 5.03 & 7.41 \\
\hline $\mathrm{K}_{2} \mathrm{O}$ & 1.98 & 2.14 & 0.57 & 0.52 \\
\hline $\mathrm{TiO}_{2}$ & 1.2 & 1.01 & 1.19 & 0.67 \\
\hline $\mathrm{Na}_{2} \mathrm{O}$ & 1.1 & 1.29 & 0.28 & 0.4 \\
\hline $\mathrm{P}_{2} \mathrm{O}_{5}$ & 1.01 & 1.14 & - & 0.02 \\
\hline $\mathrm{SO}_{3}$ & 0.94 & 1.24 & 3.01 & 1.95 \\
\hline $\mathrm{SrO}$ & 0.19 & 0.19 & - & 0.05 \\
\hline $\mathrm{CO}_{2}$ & 1.74 & 3.07 & 0.13 & 0.30 \\
\hline
\end{tabular}




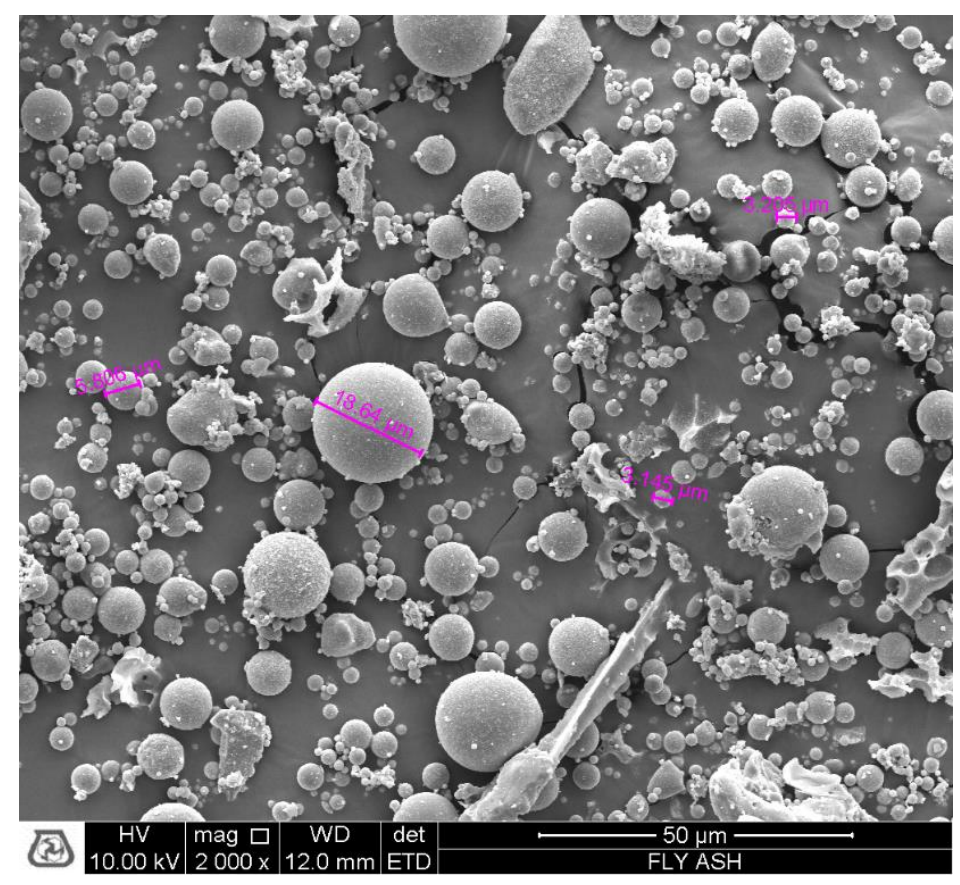

Figure IV.1. SEM image of fly ash of batch II

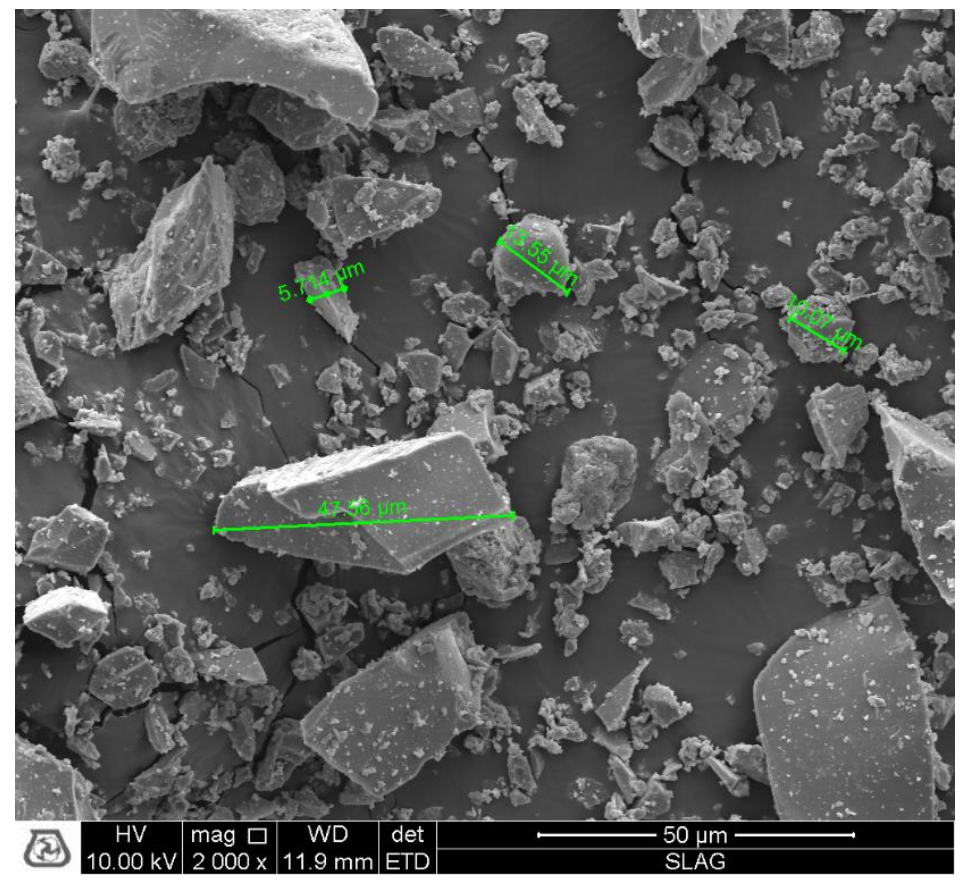

Figure IV.2. SEM image of ground granulated blast furnace slag of batch II. 


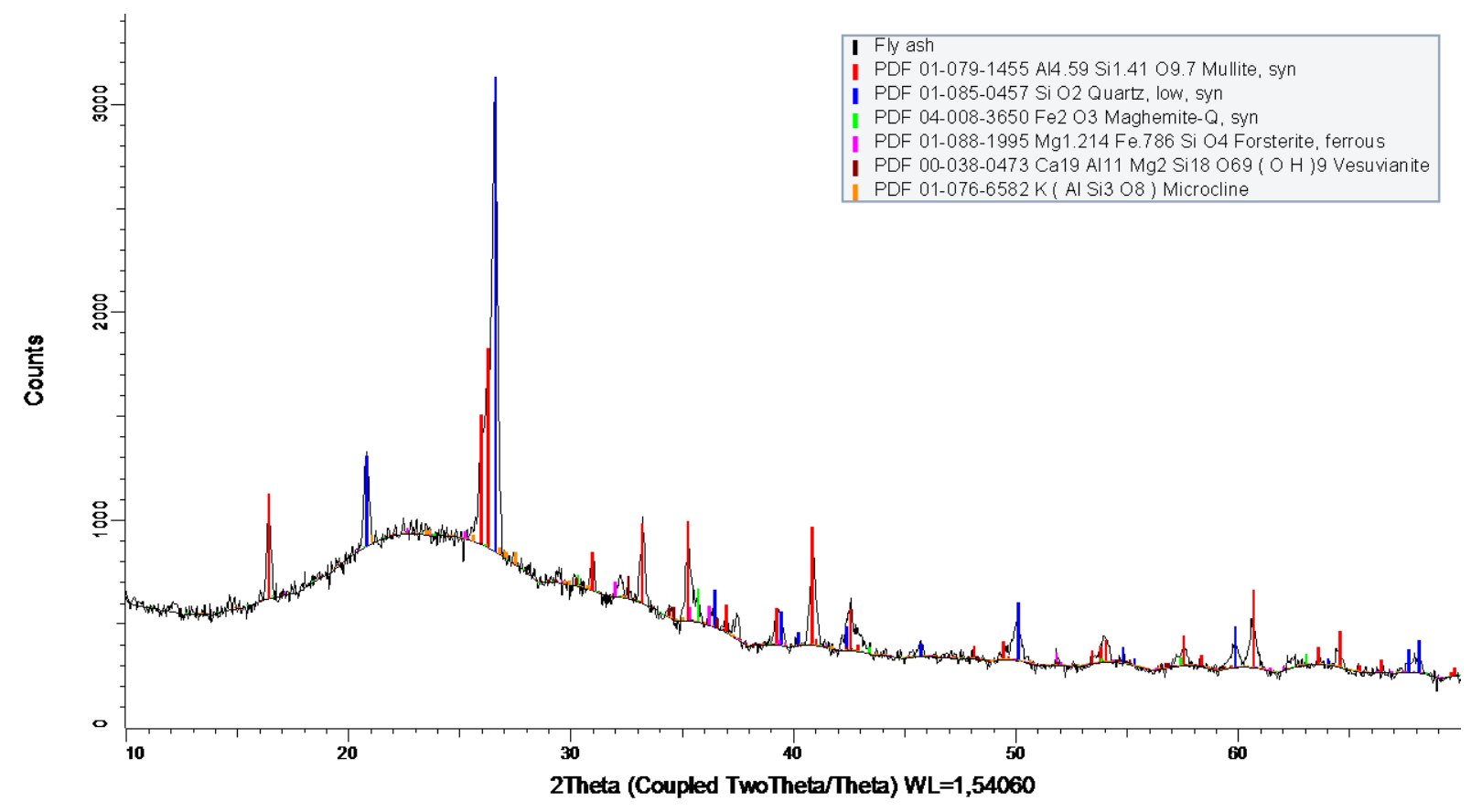

Figure IV.3. X- ray diffraction pattern of fly ash, batch I.

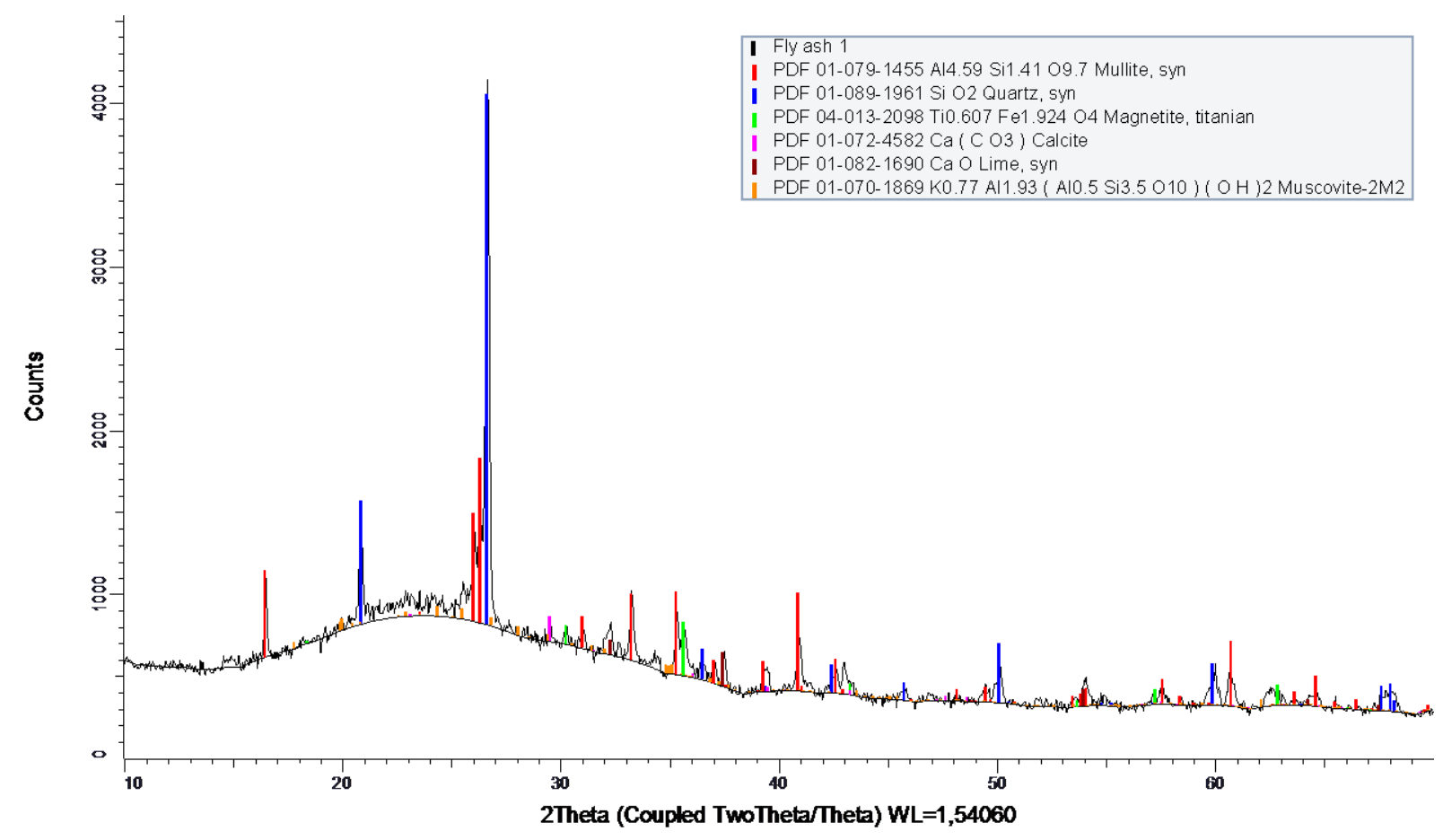

Figure IV.4. X- ray diffraction pattern of fly ash, batch II. 


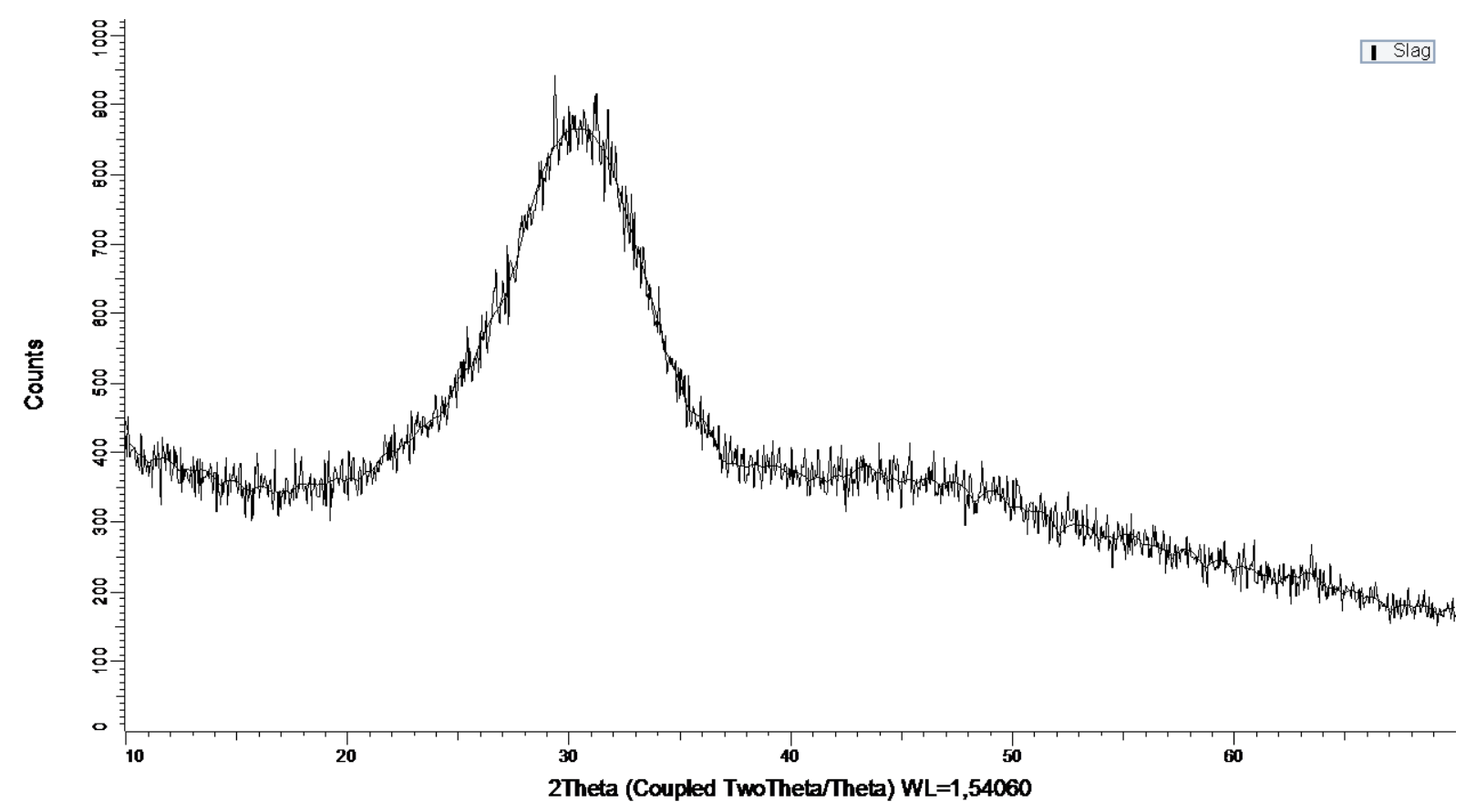

Figure IV.5. X- ray diffraction pattern of ground granulated blast furnace slag, batch I.

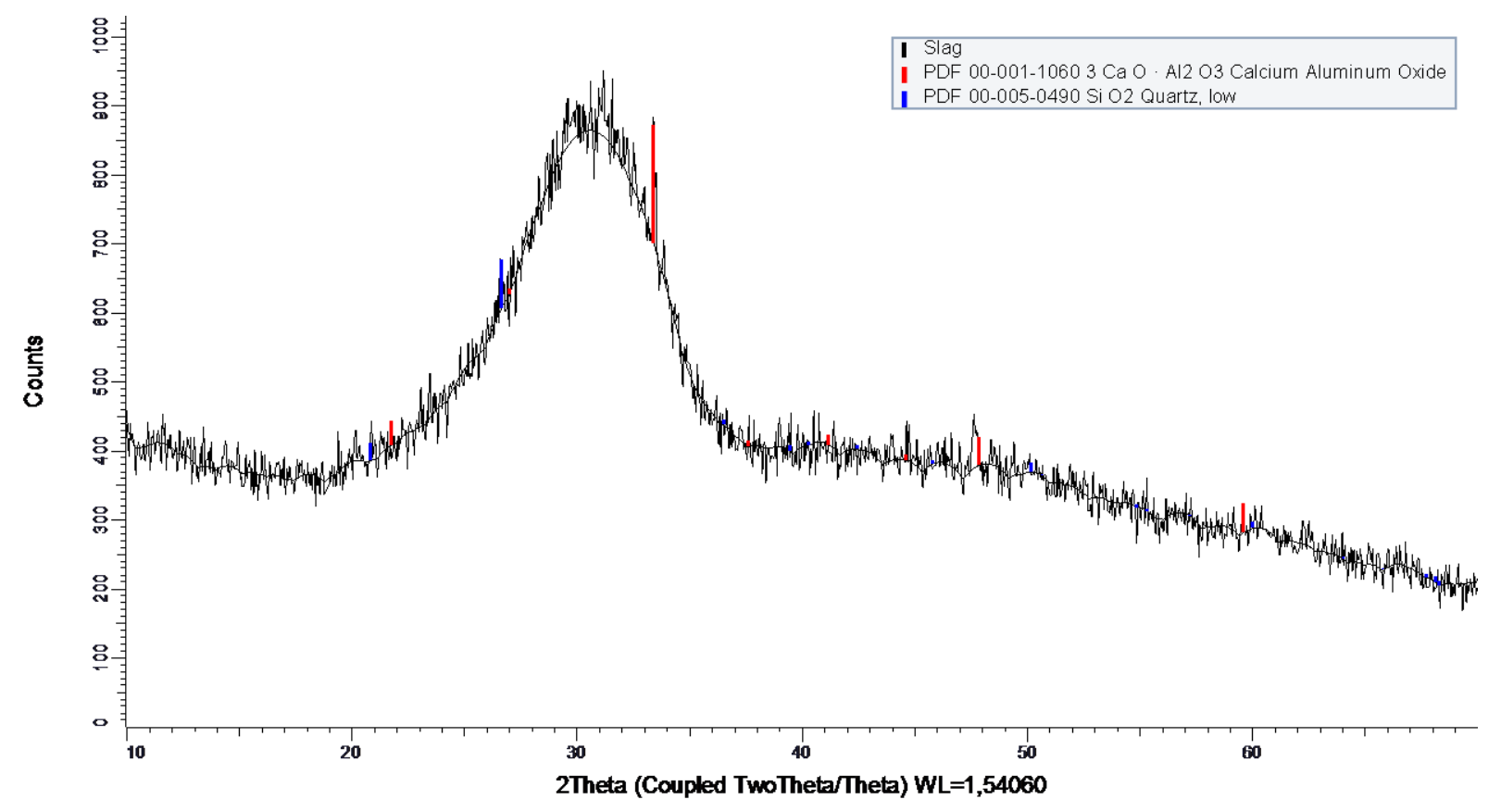

Figure IV.6. X- ray diffraction pattern of ground granulated blast furnace slag, batch II.

As can be seen in Figure IV.7, there is little batch to batch variation in the size distribution of GGBFS. However, Batch II of fly ash contains significantly larger particles than Batch I. For 
both batches, the FA particles are larger than the GGBFS. It should be noted that the nonspherical nature of the GGBFS particles (Figure IV.2) might affect the accuracy of the size determination (which is based on spherical particles).

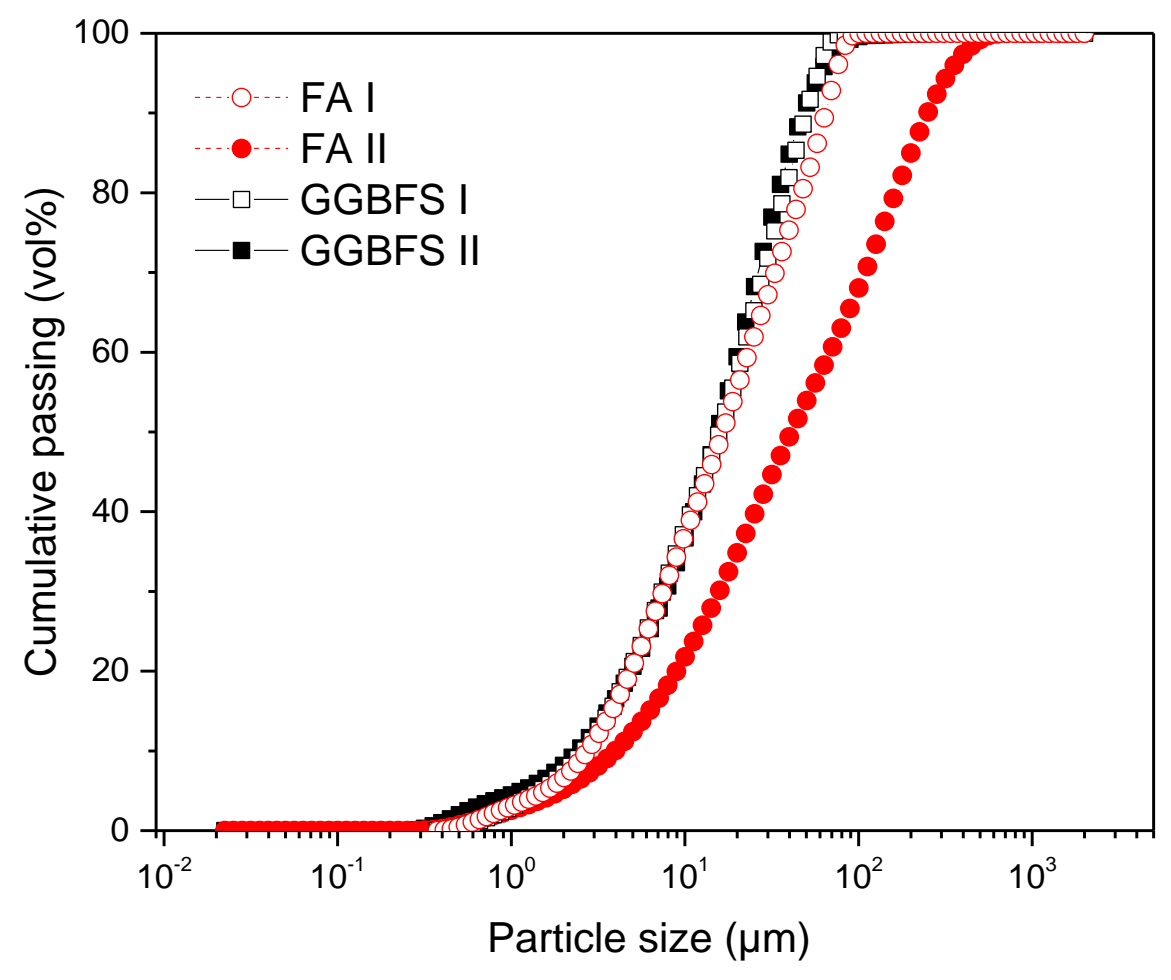

Figure IV.7. Particle size distribution for batch I and batch II of fly ash and slag.

\section{IV.2. Portland cement}

The results of the XRF and XRD of the Portland cement are presented in Table IV.2 and Figure IV.8. Based on XRD, $80 \%$ of Portland cement was in a crystalline phase. Figure IV.9 shows an electron microscope image (SEM) of the supplied Portland cement. The Portland cement particles are similar to GGBFS in shape, which is also a result of an intensive milling process. 
Table IV.2. Chemical composition of Portland cement.

\begin{tabular}{|c|c|}
\hline Chemical & Portland cement (wt. \%) \\
\hline $\mathrm{Al}_{2} \mathrm{O}_{3}$ & 6.68 \\
\hline $\mathrm{SiO}_{2}$ & 21.88 \\
\hline $\mathrm{CaO}$ & 53.87 \\
\hline $\mathrm{Fe}_{2} \mathrm{O}_{3}$ & 5.15 \\
\hline $\mathrm{MgO}$ & 1.49 \\
\hline $\mathrm{K}_{2} \mathrm{O}$ & 1.23 \\
\hline $\mathrm{TiO}_{2}$ & 0.43 \\
\hline $\mathrm{Na}_{2} \mathrm{O}$ & 0.59 \\
\hline $\mathrm{P}_{2} \mathrm{O}_{5}$ & 0.16 \\
\hline $\mathrm{SO}_{3}$ & 4,24 \\
\hline $\mathrm{SrO}$ & 0.1 \\
\hline $\mathrm{CO}_{2}$ & 2.57 \\
\hline
\end{tabular}




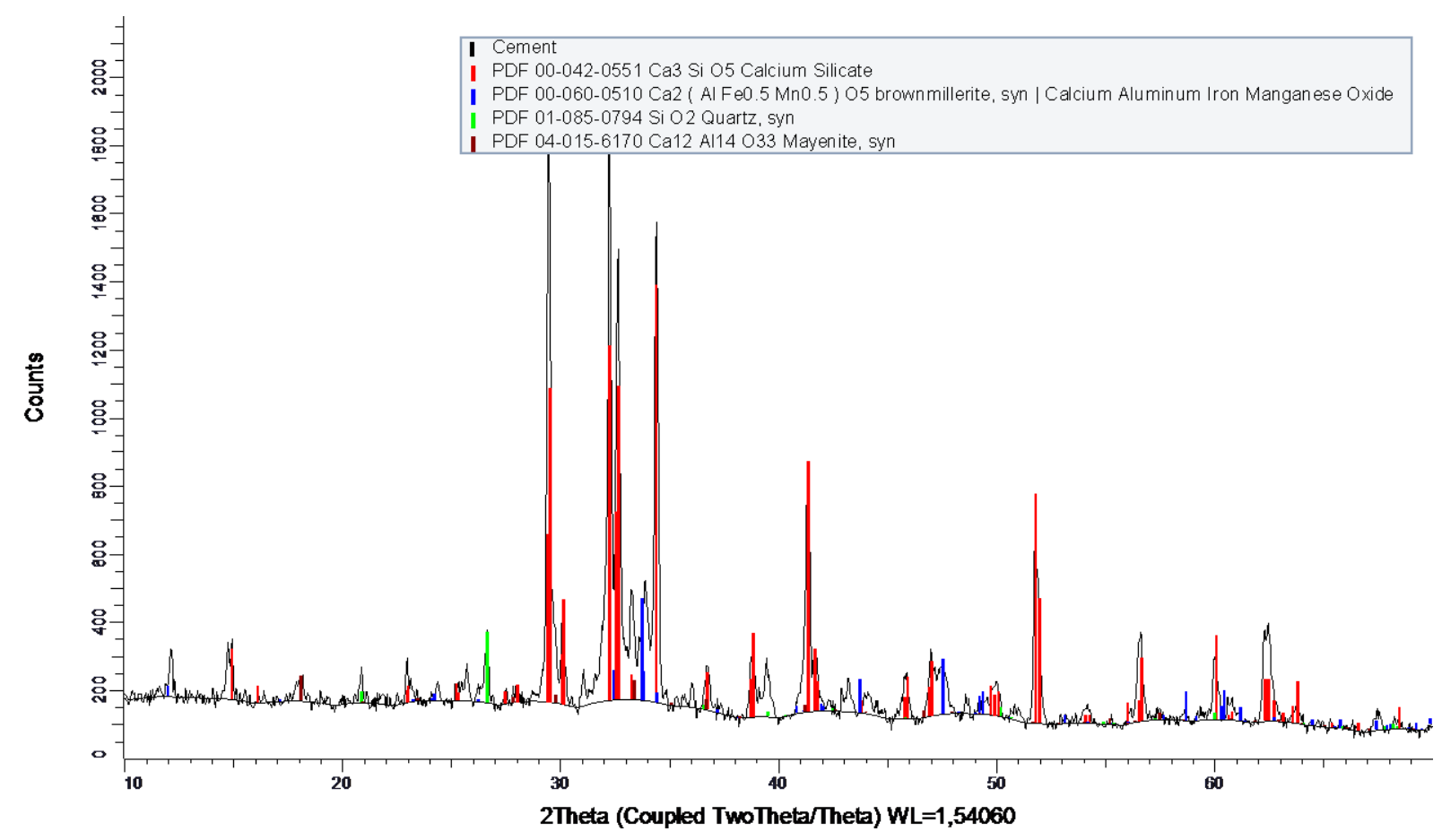

Figure IV.8. X- ray diffraction pattern of Portland cement.

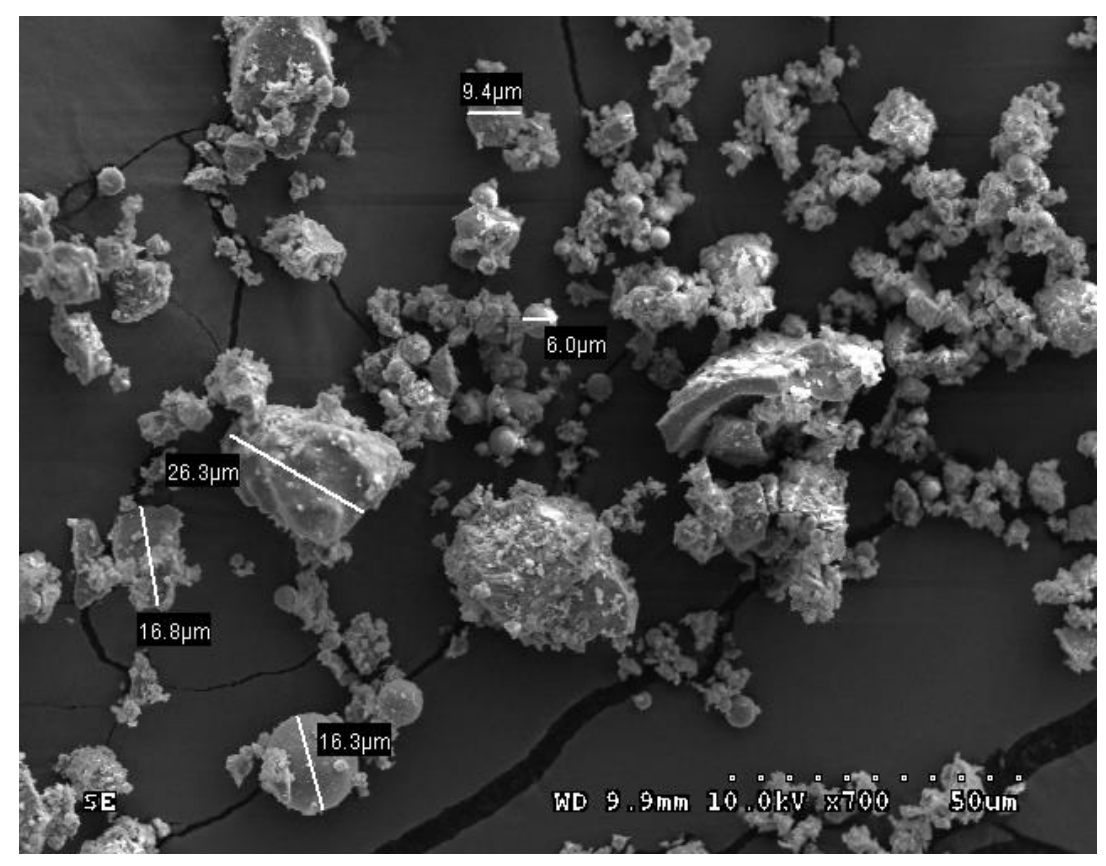

Figure IV.9. SEM image of Portland cement. 


\section{IV.3. Aggregates}

The particle size distribution (PSD) analysis of batch I and II of sand and gravel, is shown in Figure IV.10. The results illustrate that there is little batch-to-batch variation in the size distributions of the sand and gravel. As expected, the sand is much smaller than the gravel, but with a wider size distribution. The combination of sand and gravel was determined by judging the individual grading of aggregates and then combining them in different proportions.

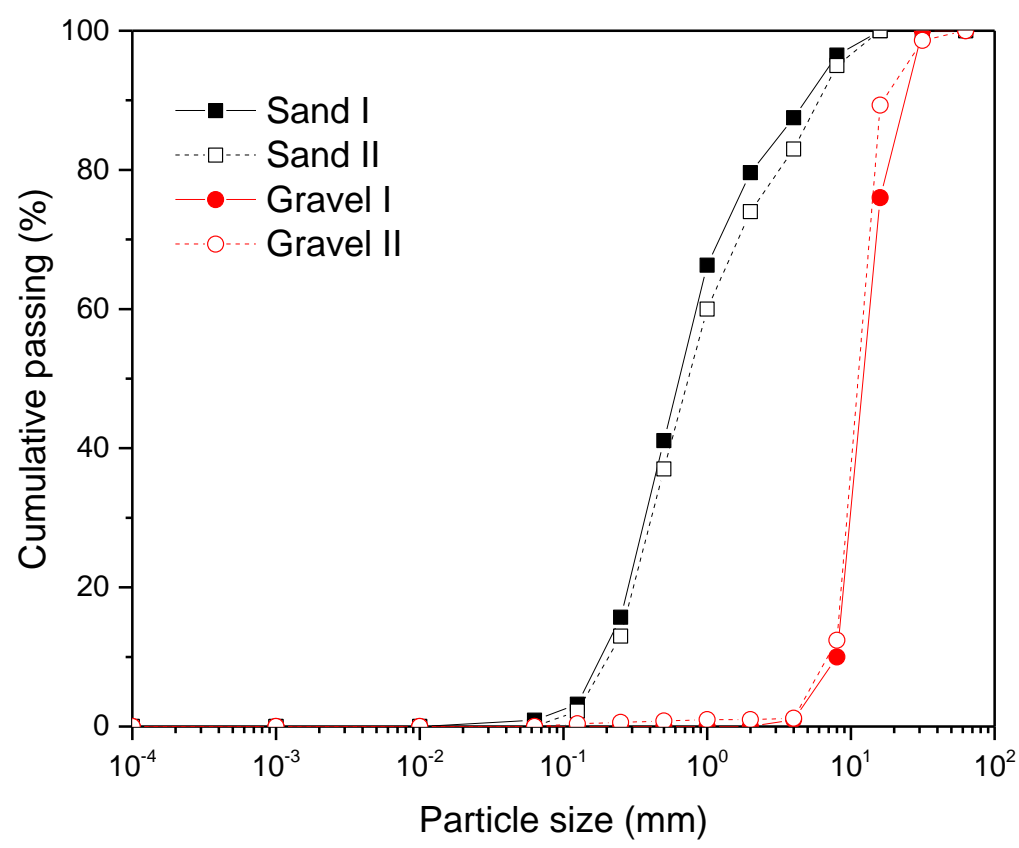

Figure IV.10. Particle size distribution for batch I and batch II of sand and gravel.

\section{IV.4. Micro-encapsulated phase change materials}

SEM images of PE-EVA-PCM and St-DVB-PCM are displayed in Figure IV.11 and Figure IV.12, respectively. The SEM is conducted at Technical University of Cartagena, Spain to illustrate the differences in shape and size. As can be seen from Figure IV.11, the individual 
particles of PE-EVA-PCM have an uneven shape and are agglomerated into clusters with an irregular structure, while St-DVB-PCM (Figure IV.12) is present as single, un-agglomerated spherical particles. In addition, St-DVB-PCM seems to have a narrower size distribution than PE-EVA-PCM.
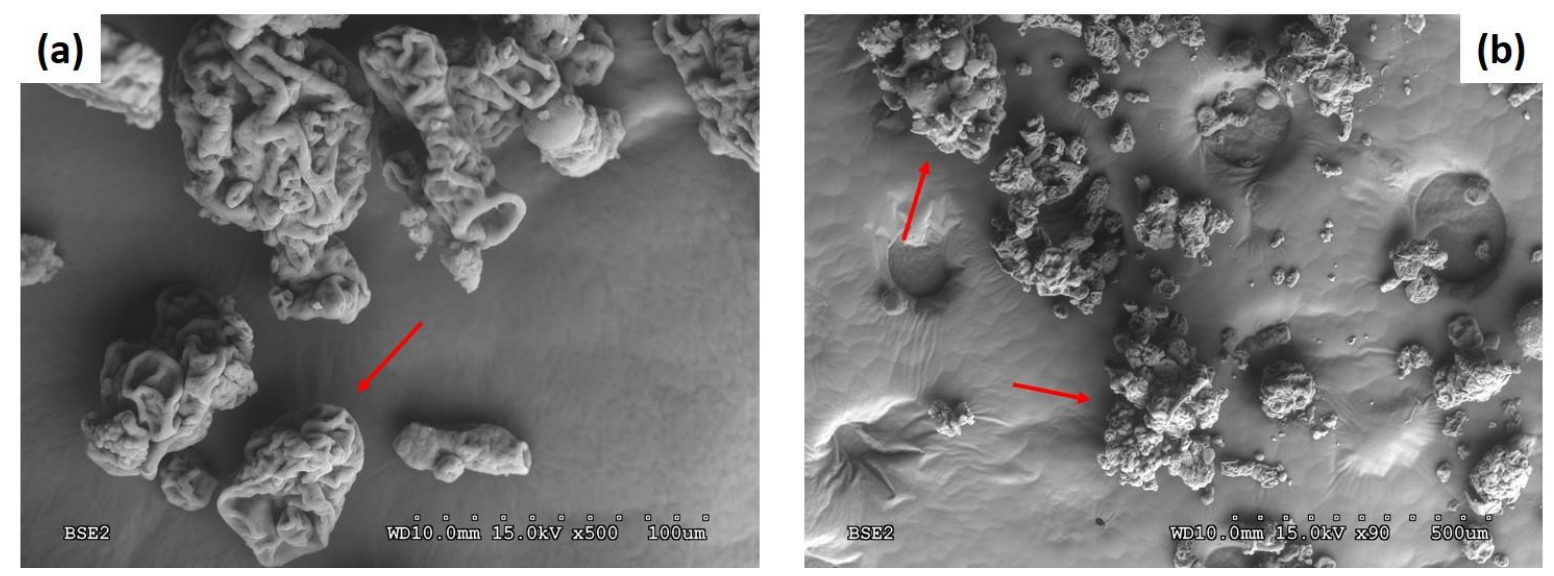

Figure IV.11. SEM images of (a) PE-EVA-PCM at a magnification of 500x (the arrow show the single PE-EVA-PC), (b) PE-EVA-PCM at a magnification of 90x (the arrows show the agglomerated structures of PE-EVA-PC).
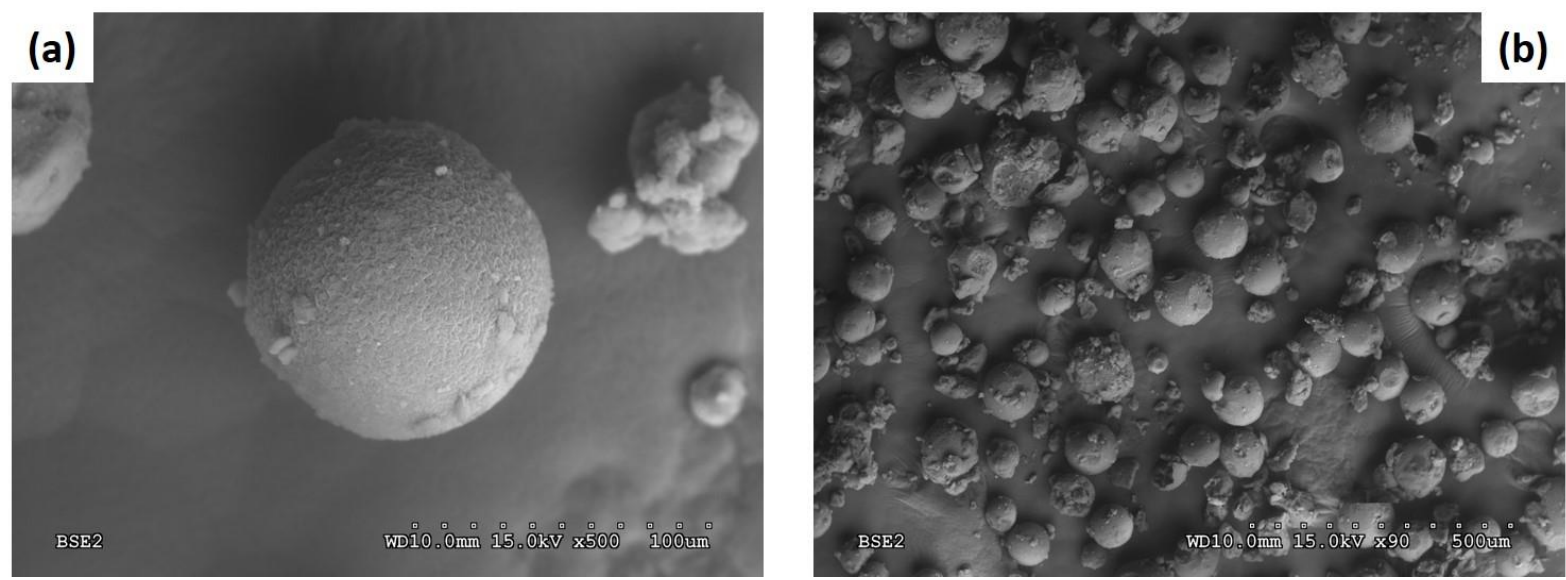

Figure IV.12. SEM images of (a) St-DVB-PCM in magnification of 500x, (b) St-DVB-PCM in magnification of $90 x$.

The particle size distributions of the MPCMs are displayed in Figure IV.13. Both types of microcapsules are smaller than the replaced sand (according to Figure IV.10). As can be seen 
in Figure IV.11, PE-EVA-PCM has a strong tendency to form large agglomerated structures $(\mathrm{D} 60=240 \mu \mathrm{m})[110,122]$, which is probably the main reason for the presence of larger particles in this sample. It should be noted that the uneven shapes of PE-EVA-PCM and its agglomerates might affect the apparent sizes displayed in Figure IV.13, as the calculations are based on spherical particles.

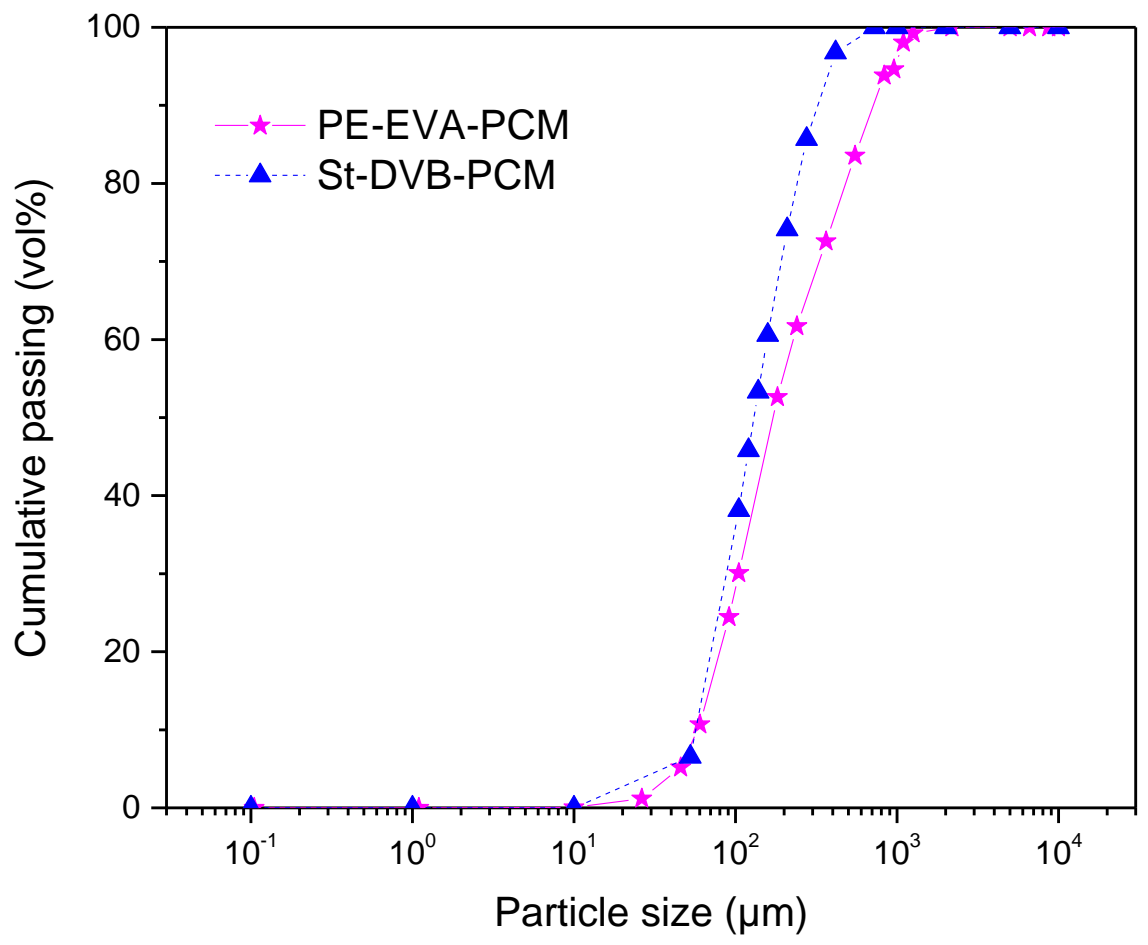

Figure IV.13. Particle size distributions of PE-EVA-PCM and St-DVB-PCM. 
Chapter V.

Effect of micro-encapsulated phase change materials on the mechanical properties and microscale changes of geopolymer concrete and Portland cement concrete at different curing conditions. 

Tables summarizing the results of this chapter are presented in Appendix A.3.

\section{V.1. Slump flow test}

A slump flow test was performed to determine the effect of MPCM addition on the workability of fresh GPC and PCC. The slump test was carried out immediately after finishing the mixing process of GPC and PCC with different amounts of MPCM at ambient temperature $\left(20^{\circ} \mathrm{C}\right)$. Figure V.1 shows the slump of mixtures versus the percentages of MPCM.

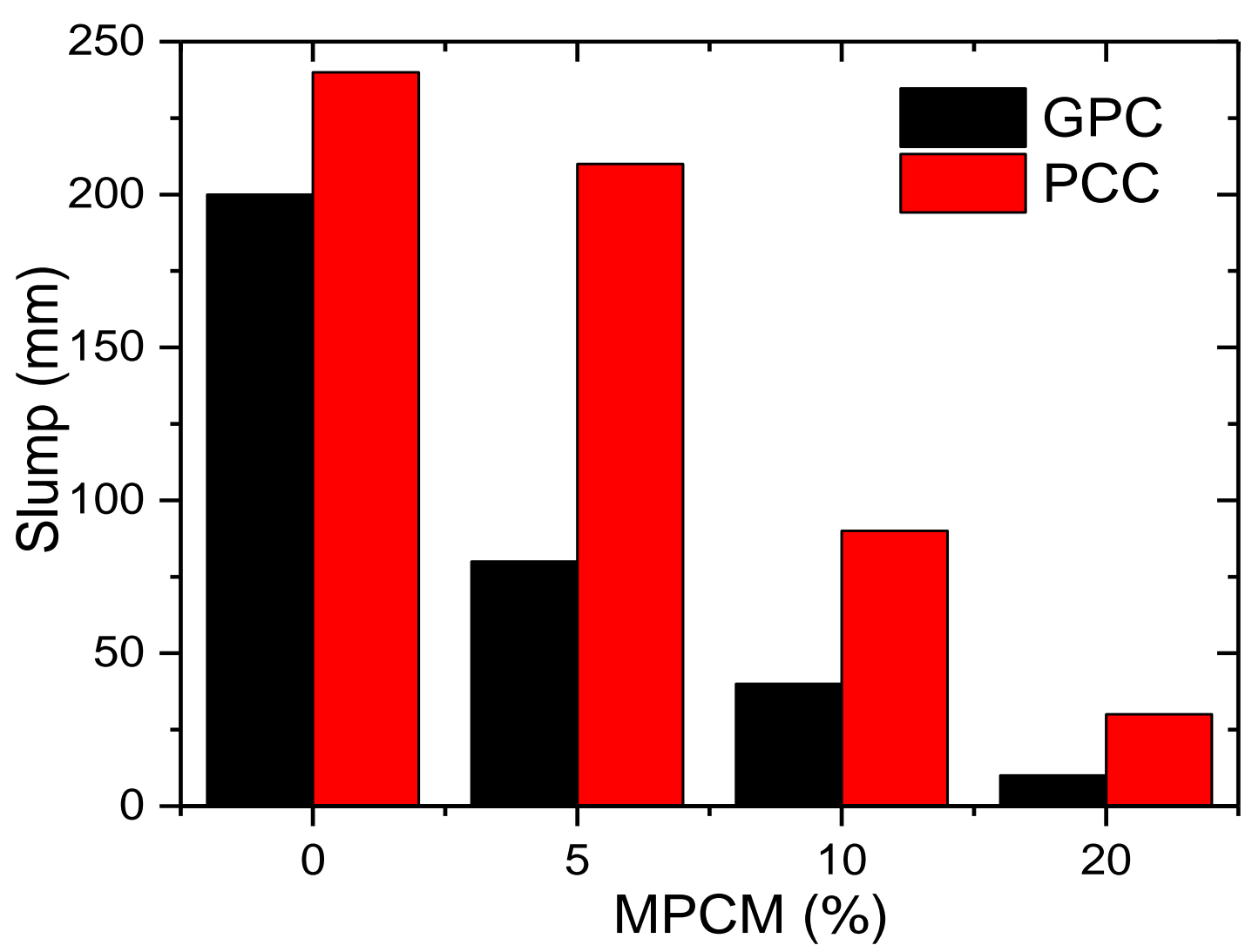

Figure V.1. Slump of GPC and PCC containing various amounts of MPCM.

In all cases, the fresh mixture of GPC tends to flow less and appears relatively more viscous than PCC. Generally, the alkaline solution of sodium hydroxide and sodium silicate produces a sticky mixture due to the high viscosity of sodium silicate. The contribution of the alkaline 
solution leads to a highly viscos and cohesive mixture compared to PCC (especially in the absence of substantial amount of superplasticizer) [15, 123]. Additionally, the presence of GGBFS in the GPC mixture decreases the slump and flow values significantly and the slump and flow values decrease when the slag content in the mixture is raised, especially at high concentrations of slag [15]. The reduction in the slump is due to the increased resistance of the angular shaped slag compared to the round fly ash particles [124], see Figure IV.1 and Figure IV.2. This increases the viscosity, stiffness and yield stress of GPC mixtures more than for PCC.

The slump of GPC varied between 10 and $200 \mathrm{~mm}$ depending on the concentration of MPCM (0 to 20\%), whereas corresponding PCC samples showed a slump in the range of 30-240 mm. Figure V.1 illustrates that increasing the percentage of MPCM from 0 to 20 reduces the workability of both GPC and PCC with 20 and 8 times, respectively. Accordingly, there is a markedly lower slump in the presence of MPCM compared to the sample without MPCM. The decrease of the slump flow with the addition of MPCM might be due to differences in the particle size of MPCM compared with the sand it replaces. This hypothesis is in agreement with previous findings $[104,105]$, where it was reported that a less rough surface, higher particle size, and adsorption and retention of water by the polymeric shell of the microcapsules decrease the flowability of fresh mortar and concrete mixtures. However, extra water or superplasticiser can be added to improve the workability; but this is likely to influence the mechanical properties of the hardened concrete. 


\section{V.2. Compressive strength}

\section{V.2.1. Effect of MPCM addition}

Figure V.2 show the variation of compressive strength of both GPC and PCC at an early age of 7 days and after curing for 28 days versus the percentage of MPCM in the mixture when cured at 20 and $40{ }^{\circ} \mathrm{C}$. Four different percentages of MPCM were applied (0\%, 5\%, 10\%, and 20\%). Generally, the compressive strength of both GPC and PCC decrease with increasing amounts of MPCM at all curing times and temperatures.

There are several hypothesizes for the reduction of the concrete compressive strength in the presence of MPCM. This decrease might be caused by the lower stiffness and strength of MPCM compared to sand, causing MPCM to be deformed or broken during the compression test $[102,125]$. PCM might also induce strength reducing voids and air bubbles in concrete [109]. Furthermore, it is also possible that gaps and cavities between the MPCM shell and the concrete matrix reduces the compressive strength [126]. These hypotheses will be further discussed in connection with the X-ray tomography and SEM analysis below. 

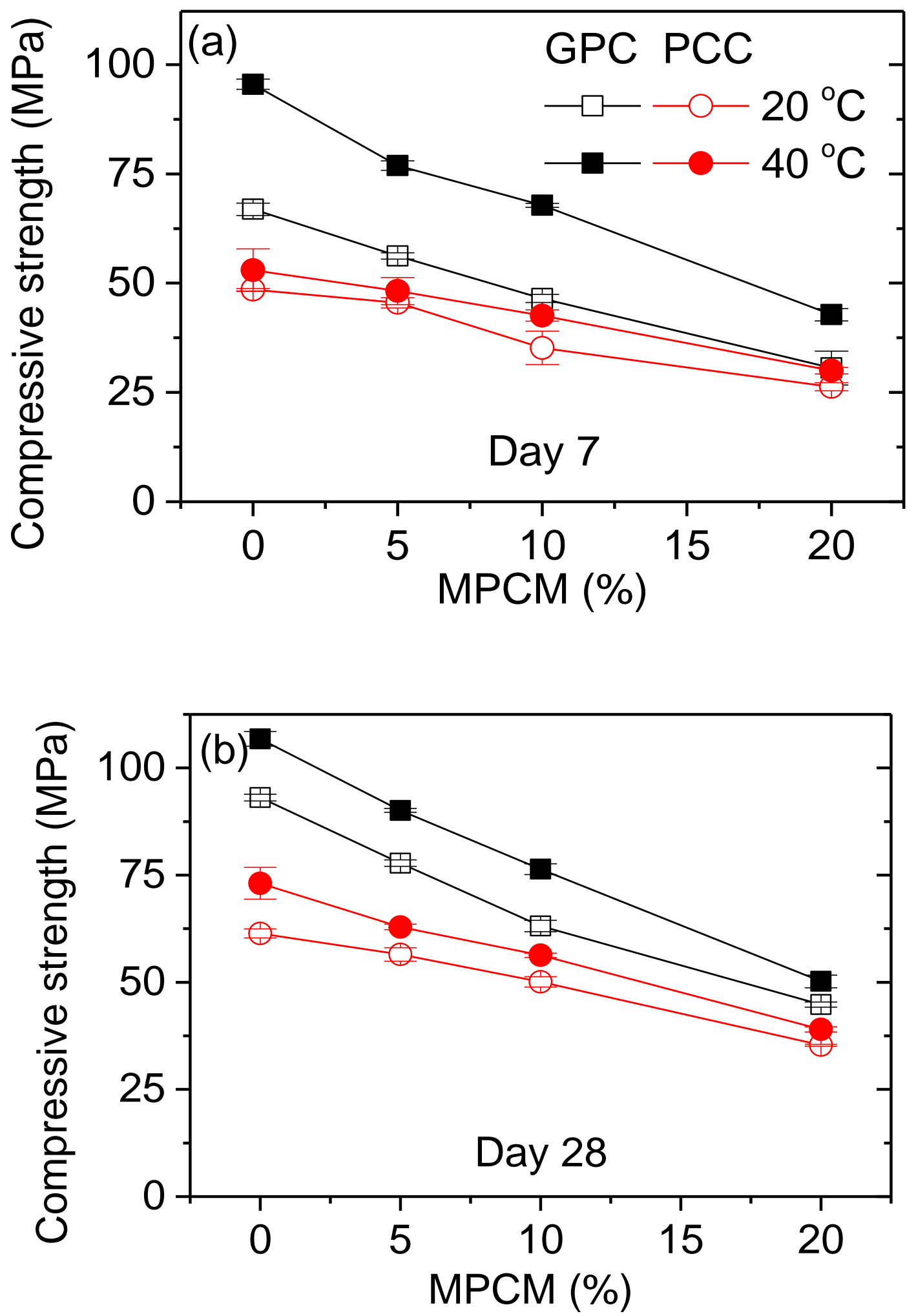

Figure V.2. Effect of MPCM addition on the compressive strength of GPC and PCC cured at $20^{\circ} \mathrm{C}$ and $40{ }^{\circ} \mathrm{C}$ after (a) curing for 7 days, (b) curing for 28 days. 


\section{V.2.2. Effect of curing temperature}

Figure V.3 shows the effect of curing temperature on the compressive strength of GPC and PCC when the mixtures contain 0 and $20 \%$ of MPCM. Curing at higher temperatures accelerates the reaction rates of GPC and PCC by geopolymerization and hydration, respectively. This causes a faster increase of the compressive strength, which is in agreement with previous findings $[36,50,51,127,128]$.

Additionally, longer curing times improve the geopolymerization and hydration processes resulting in higher compressive strength. The compressive strength approaches its final value at long curing times, and there the difference between the samples cured at 20 and $40{ }^{\circ} \mathrm{C}$ diminishes.

The percentage strength reduction of GPC and PCC versus curing time at $20^{\circ} \mathrm{C}$ and $40{ }^{\circ} \mathrm{C}$ shown in Figure V.4. After 28 days, the strength reduction is more pronounced for GPC than for PCC, especially at $20^{\circ} \mathrm{C}$. Low adhesion and weak bonds between the MPCM shell and the concrete matrix may contribute to the strength reduction $[126,129]$. This will be discussed in more detail below. 

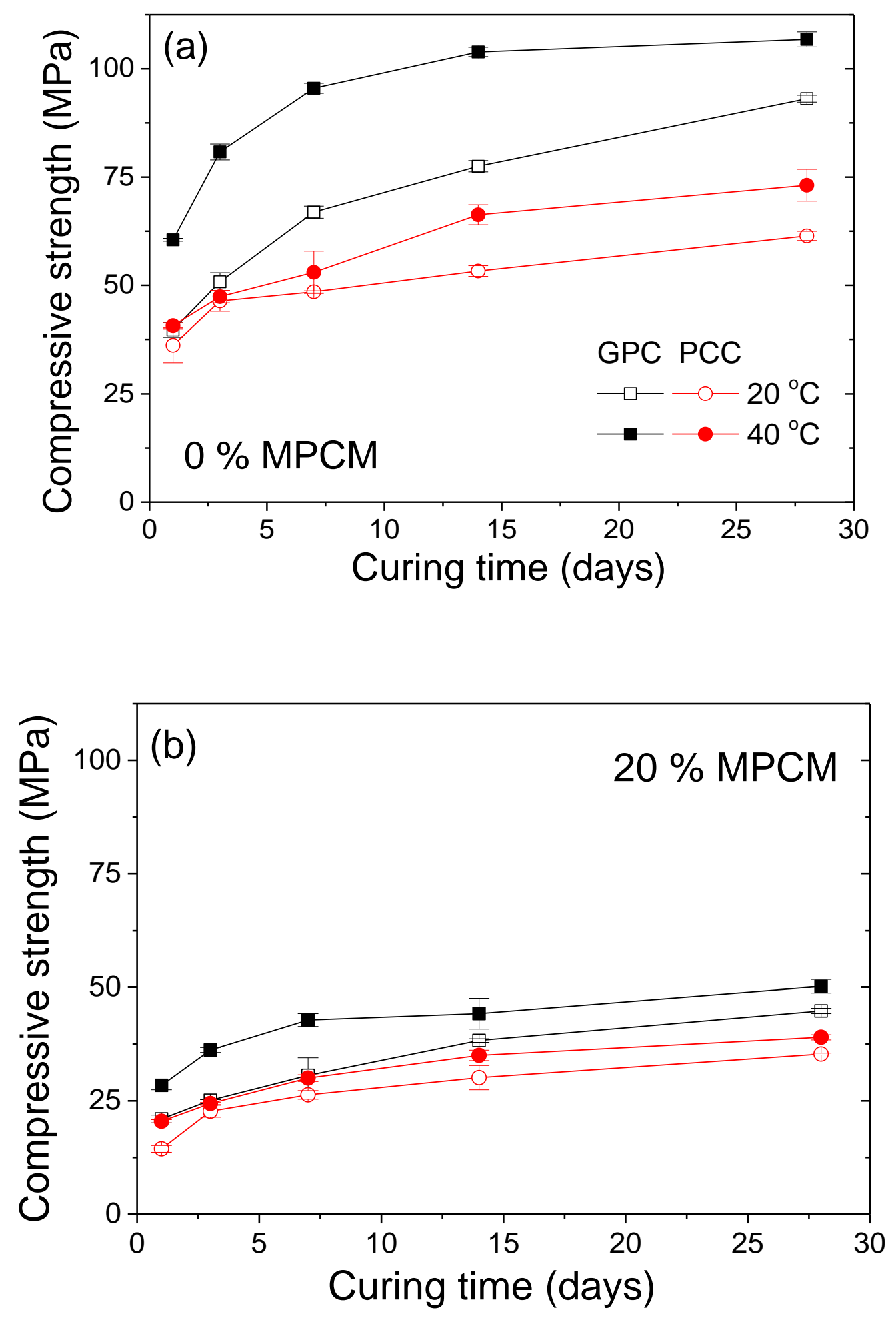

Figure V.3. Compressive strength of GPC and PCC cured at $20{ }^{\circ} \mathrm{C}$ and $40{ }^{\circ} \mathrm{C}$ (a) versus curing time in the absence of MPCM, and (b) versus curing time when 20 vol. $\%$ of the sand is replaced by MPCM. 

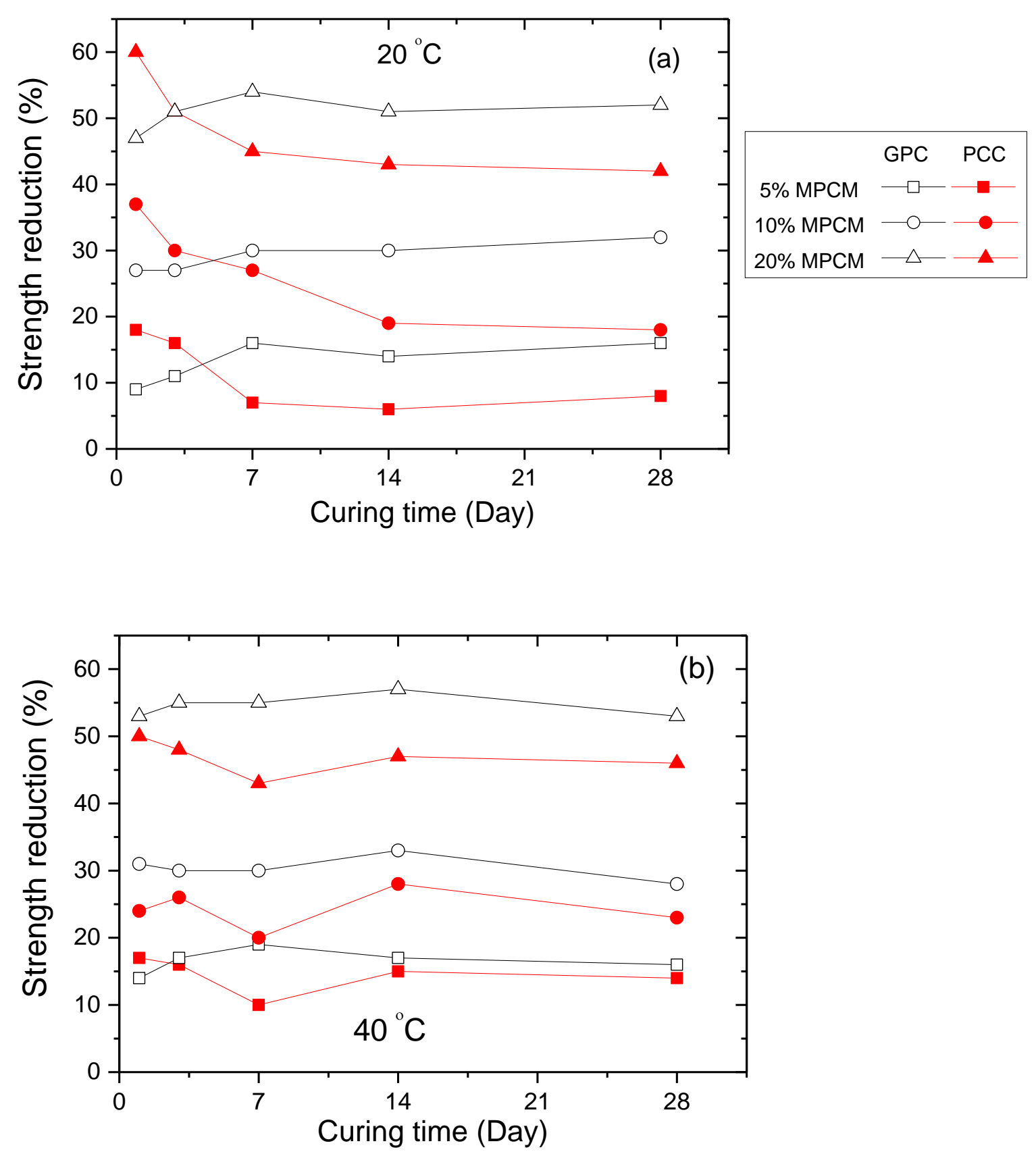

Figure V.4. The compressive strength reduction (percentage compared to samples without MPCM at the same curing time) for GPC and PCC versus curing time at (a) $20{ }^{\circ} \mathrm{C}$ and (b) 40 ${ }^{\circ} \mathrm{C}$.

For GPC cured at $20^{\circ} \mathrm{C}$, the percentage strength reduction increases at short curing times before it stabilizes at a nearly constant value after approximately 1 week. Interestingly, the strength reduction of PCC shows an opposite trend at short curing times. For PCC the strength reduction 
at $20{ }^{\circ} \mathrm{C}$ decreases with curing time, before stabilizing after about 1-2 weeks. The opposite trends at short curing times suggest that the addition of MPCM affects the curing process of GPC and PCC in different ways.

For both GPC and PCC, the effect of curing time on the percentage strength reduction is less obvious at $40{ }^{\circ} \mathrm{C}$ than at $20{ }^{\circ} \mathrm{C}$. This is due to the faster curing times at elevated temperatures, which is in agreement with Figure V.3.

\section{V.2.3. Effect of solid or liquid PCM}

Since the compressive strength stabilizes at the longest curing times (Figure V.3), the percentage strength reduction at 28 days provides a good estimate of whether the compressive strength of the GPC and PCC samples is affected by a solid or liquid state of the PCM.

Comparing 20 and $40{ }^{\circ} \mathrm{C}$, there are only small differences in the levels of strength reduction after 28 days for GPC (Figure V.5). Accordingly, whether the PCM is in solid or liquid state does not significantly affect the mechanical properties of GPC. However, the strength reduction of PCC after 28 days is more pronounced at $40{ }^{\circ} \mathrm{C}$ than at $20^{\circ} \mathrm{C}$ (Figure V.5). Thus, melting the PCM seems to affect PCC much more than GPC. Melting the PCM can make the microcapsules softer by having a liquid paraffin core or an increase in internal stress of the microcapsules at elevated temperatures (due to thermal expansion). GPC has a higher compressive strength than PCC, and the stronger matrix might be less affected by the introduction of soft particles or thermal expansion of MPCM. In addition, any PCM that is not properly encapsulated, either from broken capsules or from PCM that are not encapsulated during fabrication, will be in liquid state inside the concrete matrix. If the MPCM is poorly distributed within the concrete sample, microcapsule agglomerates containing unencapsulated PCM will become much weaker when the PCM is melted. A better distribution with less 
agglomerated microcapsules in the GPC matrix than in the PCC matrix, could explain why PCC is more affected by melting PCM. The distribution of microcapsules in the concrete samples will be discussed in connection with the X-ray micro-tomography below.

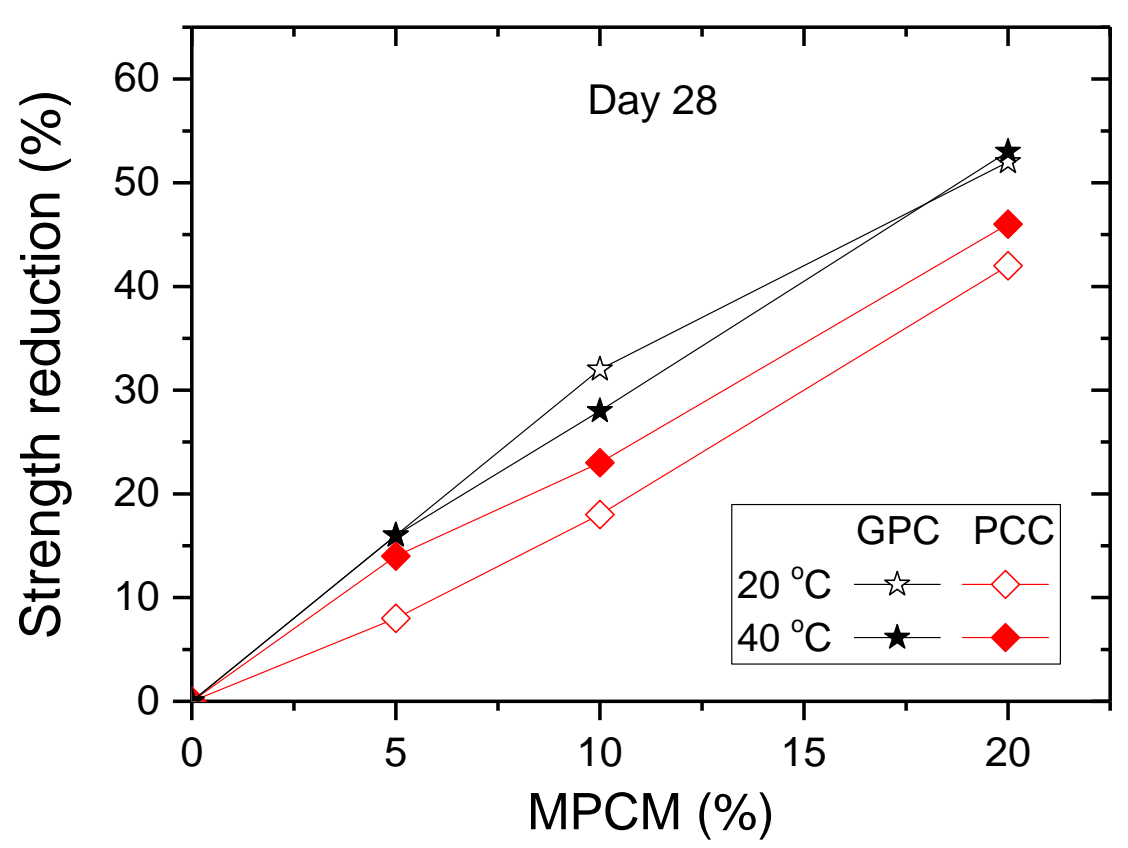

Figure V.5. The compressive strength reduction (percentage compared to samples without MPCM at the same curing time) for GPC and PCC as a function of MPCM concentration after 28 days.

\section{V.3. Microstructural studies}

In this section, microscopical structure chracterization of GPC and PCC containing 0\% and $20 \%$ of PE-EVA-PCM at $20{ }^{\circ} \mathrm{C}$ and $40{ }^{\circ} \mathrm{C}$ are performed by X-ray micro-tomography and scanning electron microscopy (SEM) imaging. 


\section{V.3.1. X-ray micro-tomography}

Typical 2D X-ray micro-tomography cross-sectional slices obtained from cylindrical samples of PCC and GPC, both without and with 20\% MPCM, are displayed in Figure V.6. More than $6002 \mathrm{D}$ slices were taken for each sample in order to obtain good statistical data.

Figure V.7 displays 3D renderings of the measured samples. The images in Figure V.7 were processed such that only air voids and MPCM are shown. The samples are in cylindrical shape with the approximately $1 \mathrm{~cm}$ field of view.

Given the low level of X-ray attenuation of the organic materials constituting the MPCM, it is not possible to discriminate them from air voids based on grey scale values. However, the discrimination is possible based on shape, which tends to be approximately spherical for air voids, due to interfacial tension effects. The MPCM may have a more irregular shape, as illustrated in Figure V.8.

An attempt of separating air voids and MPCM was done based on shape, and that parameter was used as a shape estimator. In spherical coordinates, each point on the surface of specimen can be described by a radial distance ( $r$ ) and two angles. For a sphere, the value of $r$ is constant and equal to the average value of $r$. Therefore, the standard deviation will be zero. A larger deformation of the specimens will cause the value of $r$ to depart from the average. This results in higher standard deviation values. From a quantitative point of view, the results of the image analysis provides a mean value of SD (standard deviation of the distance from the centre of mass to the surface) of 1.36 for PCC in the presence of $20 \%$ MPCM compared to a mean value of 0.83 for the plain sample. The mean value of SD increases from 0.56 to 1.24 when $20 \%$ MPCM is added to the GPC sample. These values testify to the less spherical nature of the incorporated MPCM compared to the air bubbles. 

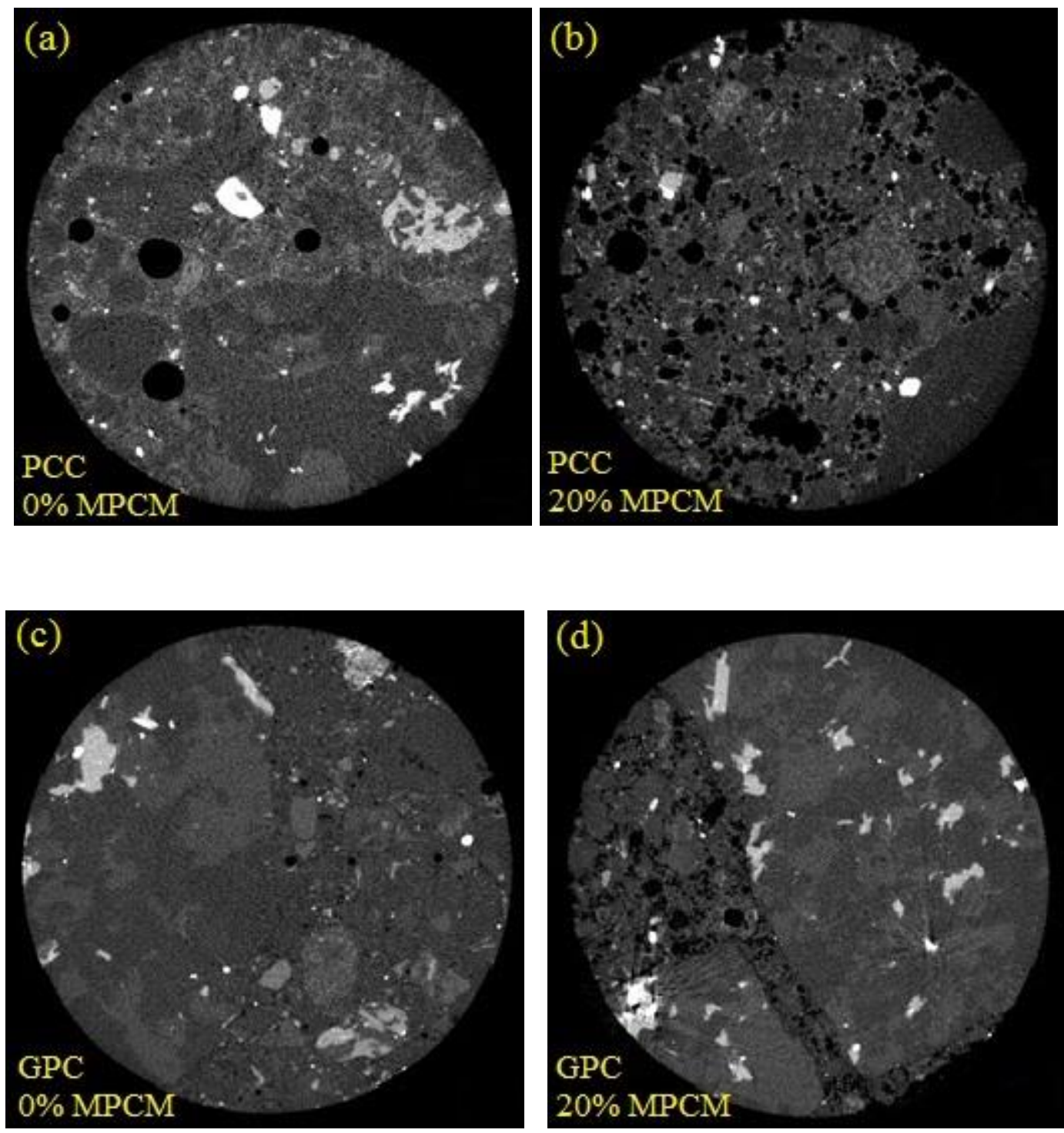

Figure V.6. X-ray-tomography images of samples (a) PCC without MPCM, (b) PCC with 20\% MPCM, (c) GPC without MPCM and (d) GPC with 20\% MPCM. In these images, dark colors correspond to low or no absorption of X-rays (e.g. air bubbles or microcapsules) and bright colors represent high absorption of X-rays (sand and gravel). The field of view is approximately $1 \mathrm{~cm}$.

A visual inspection of Figure V.7 suggests that a larger number of air voids, having smaller sizes, are present in GPC compared to PCC. This is confirmed by the results of the image analysis, which give a total volume of air voids of approximately $4 \%$ for PCC and $6 \%$ for GPC. The mean equivalent radius of the air voids drops from $50 \mu \mathrm{m}$ for PCC to $35 \mu \mathrm{m}$ for GPC. Such 
differences might be due to the higher viscosity of the alkaline solution or shorter setting time of fresh GPC mixture, which hinder the coalescence and release of air bubbles. The high viscosity is in agreement with the slump test illustrated in Figure V.1
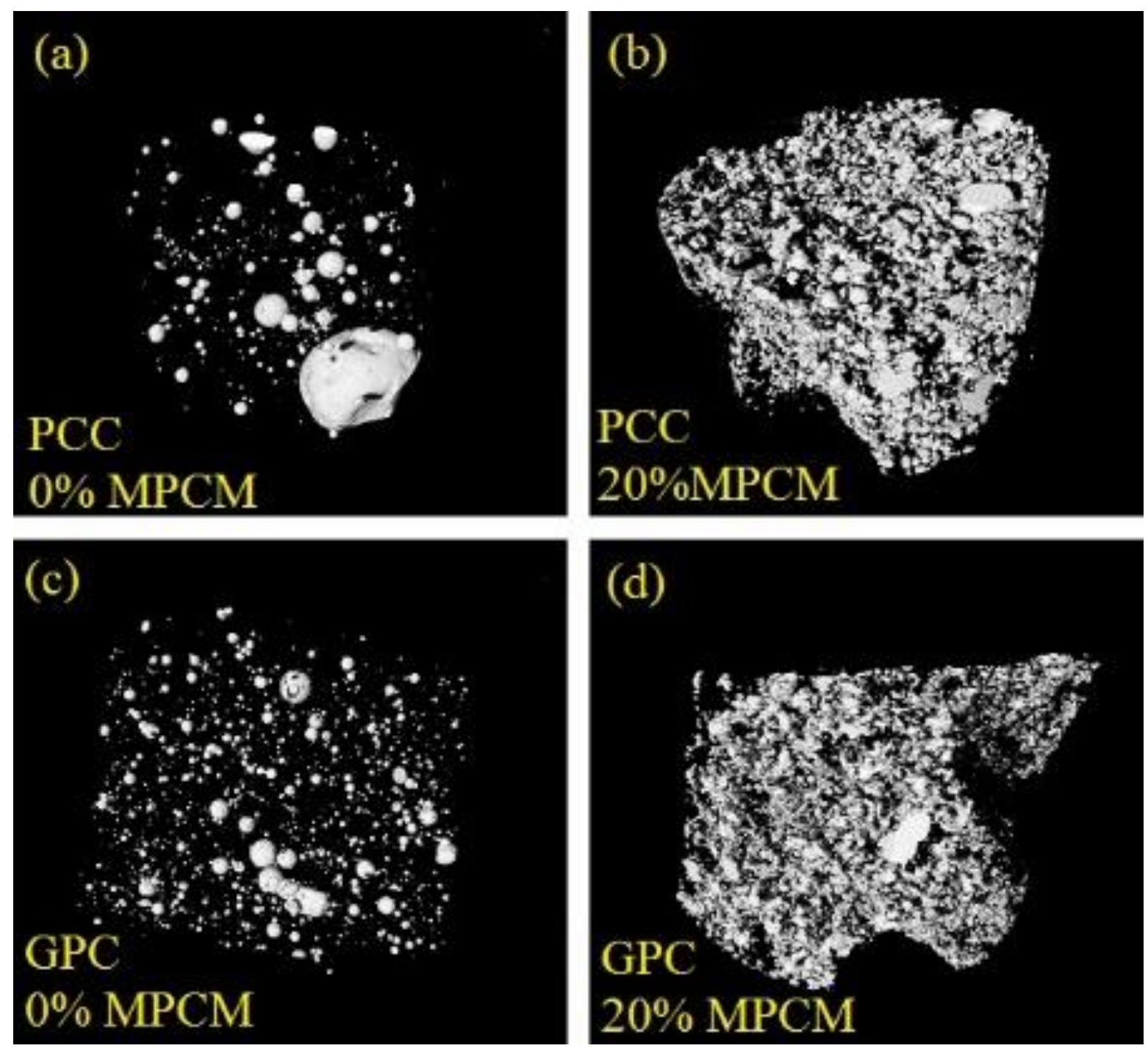

Figure V.7. 3D rendering of air bubbles and MPCM present in cylindrical samples $(1 \mathrm{~cm}$ diameter) of: (a) PCC without MPCM; (b) PCC with 20\% MPCM; (c) GPC without MPCM; (d) GPC with 20\% MPCM. 

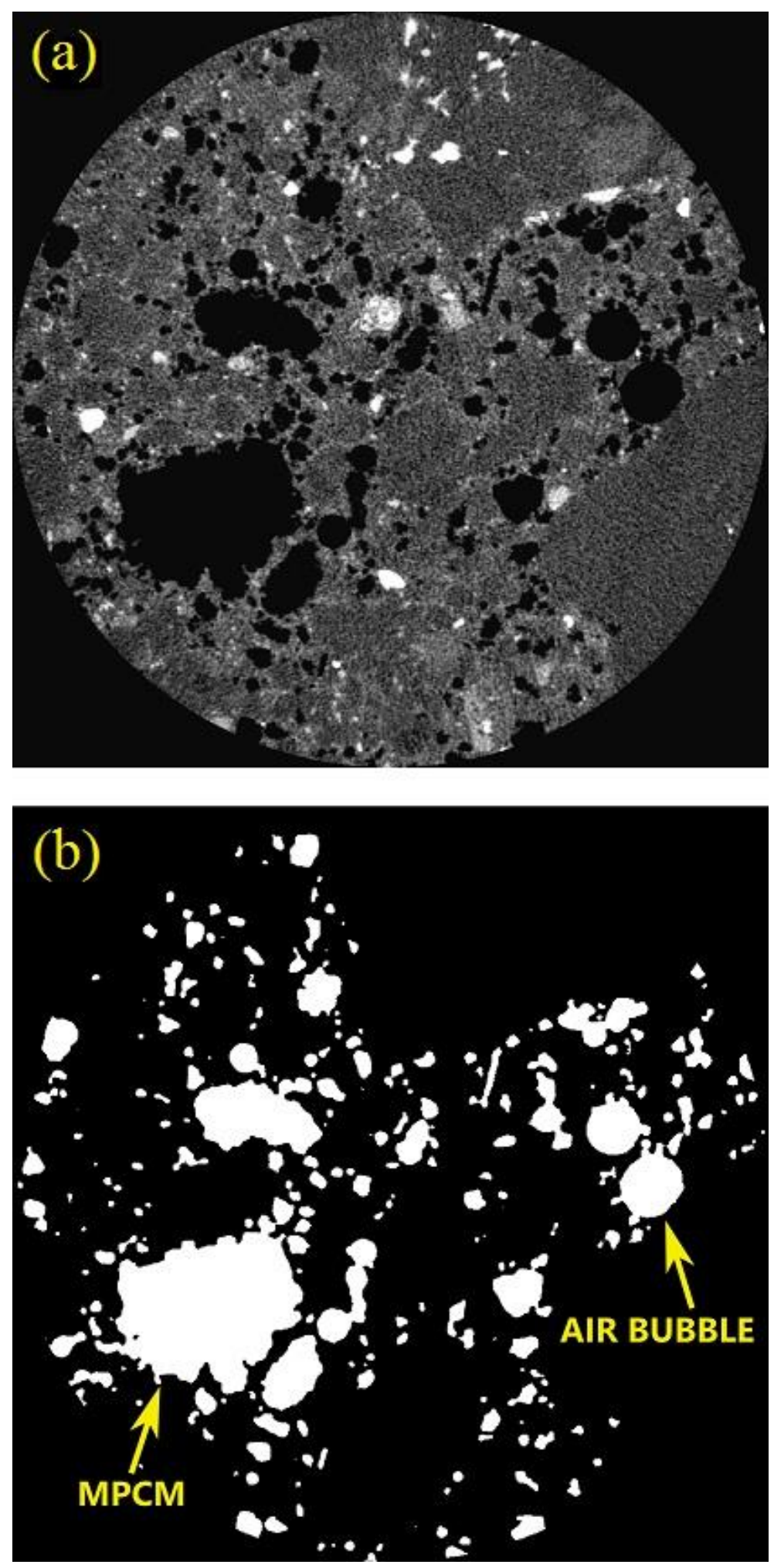

Figure V.8. (a) Grey scale 2D cross sectional slice relative to PCC with 20\% MPCM; (b) the same image after conversion to binary. The field of view is approximately $0.9 \mathrm{~cm}$. 
Considering that the unagglomerated single PE-EVA-PCM has a size of about $50 \mu \mathrm{m}$ (based on SEM images of PE-EVA-PCM, Figure IV.11), single microcapsules will be difficult to see in the X-ray tomography pictures. Accordingly, the large irregular shapes observed are due to agglomerated microcapsules. From Figure V.6, it can be seen that PCC has agglomerated MPCM distributed throughout the sample, while GPC has some areas with agglomerates and some more homogeneous parts where agglomerates are not observed. In addition, the agglomerates appear to be larger in the PCC sample. However, it should be noted that the field of view of study is approximately $1 \mathrm{~cm}$, and it may not be representative of the whole concrete sample. As discussed in section V.2 above, the presence of a high amount of large agglomerates might reduce the compressive strength of PCC when the PCM is melted. The presence of agglomerated structures suggests a poor affinity between the MPCM and the concrete matrix. It is possible that the high viscosity (low workability) of the pre-set GPC and the short setting times of GPC help prevent the formation of MPCM agglomerates.

\section{V.3.2. SEM analysis}

Figure V.9 shows the SEM images of the failure surface of the concrete after the compressive strength test for GPC and PCC without MPCM cured for 28 days at 20 and $40{ }^{\circ} \mathrm{C}$. The images in Figure V.9 are taken by LFD (Morphological detector) to illustrate how the GPC and PCC surfaces look at two different curing temperatures.

The rounded particles that can be seen in Figure V.9 at $20{ }^{\circ} \mathrm{C}$ are unreacted fly ash. At $40{ }^{\circ} \mathrm{C}$, almost all of the fly ash has reacted, which is expected to provide increased strength to the concrete cured at higher temperatures. This is in agreement with the compressive strengths shown in Figure V.3a. According to the SEM images in Figure V.9, the matrix of PCC and GPC is more uniform and compact when the curing temperature increases from $20^{\circ} \mathrm{C}$ to $40^{\circ} \mathrm{C}$. 
This explains at micro scale why the compressive strength of the GPC and PCC increase when the curing temperature increase (Figure V.3).
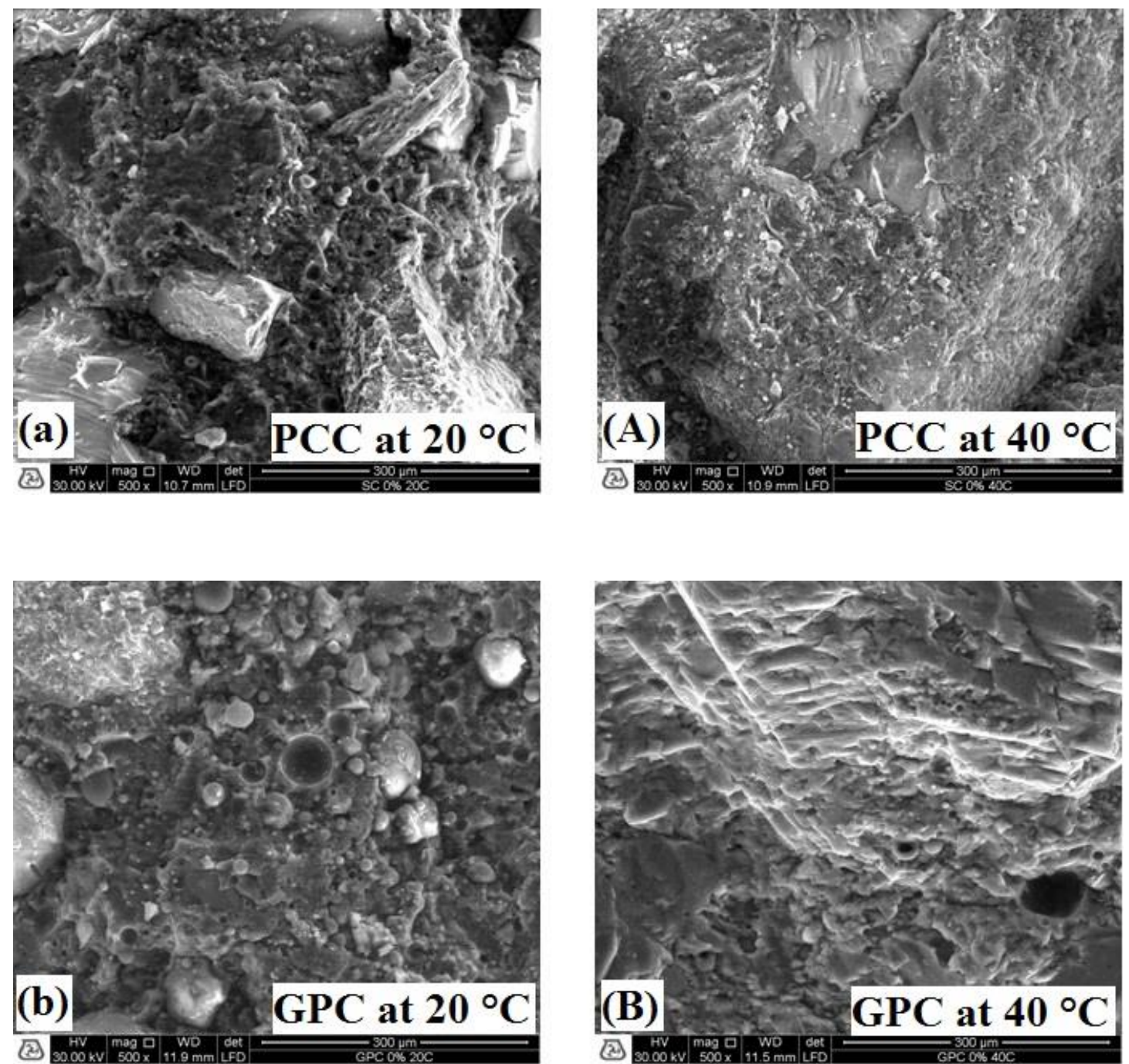

Figure V.9. SEM images of fracture surface of (a) PCC at $20{ }^{\circ} \mathrm{C}$, (A) PCC at $40{ }^{\circ} \mathrm{C}$, (b) GPC at $20^{\circ} \mathrm{C}$, and (B) GPC at $40{ }^{\circ} \mathrm{C}$. All samples are without MPCM addition.

The PCC and GPC with $20 \%$ MPCM after 28 days curing at 20 and $40{ }^{\circ} \mathrm{C}$ were chosen for further SEM analysis. Images in Figure V.10a, b, c and d are taken by vCD (Z compositional detector) to illustrate the organic (MPCM) and inorganic (concrete matrix) components. In these images, the organic MPCM will appear as darker areas in contrast to the brighter concrete matrix. Images of the same areas (Figure V.10A, B, C, D), taken with LFD (Morphological 
detector) show the topography of the sample (bright areas are extending higher up than dark areas). Accordingly, areas that are dark in vCD and light in LFD are microcapsules. Comparing vCD and LFD, it is obvious that there are gaps between the MPCM particles and the concrete matrix. Similar observations have been reported previously [122, 130].

The gaps between the microcapsules and the concrete indicate that the connection between the MPCM and the surrounding matrix is weak, and that MPCM may induce air voids in the samples. There are several mechanisms that might cause these gaps. The tendency of MPCM to agglomerate into larger structures reduces the ability of the MPCM to fill the cavities in the concrete structure [131-134]. However, this is counteracted by the cavity filling effect [135, 136]. The cavity between aggregates and sand can be filled up by small particles $(\leq 125 \mu \mathrm{m})$ [135] causing an increase of the packing density, thereby reducing the porosity of the concrete. The single microcapsules have a small size in the range of $1-100 \mu \mathrm{m}$, but due to agglomeration, the effective size too large to fill the cavities in the concrete structure. Accordingly, they may induce air voids. In addition, a poor compatibility between the microcapsule shell and the concrete matrix can cause voids to be formed between them. A poor compatibility indicates that the shell of the microcapsules does not bind nor associate with the concrete matrix. Previous studies showed that other kinds of microcapsules did not exhibit this problem [137]. This illustrates the importance of a good compatibility between the shell of the microcapsules and the concrete matrix. Accordingly, the shell used in the current MPCM is probably not optimal for inclusion in concrete structures.

The air voids are probably an important contributing factor to the compressive strength reduction in the presence of MPCM. The SEM results can thereby help explain the reduced compressive strength induced by the addition of MPCM to PCC and GPC (Figure V.5). 

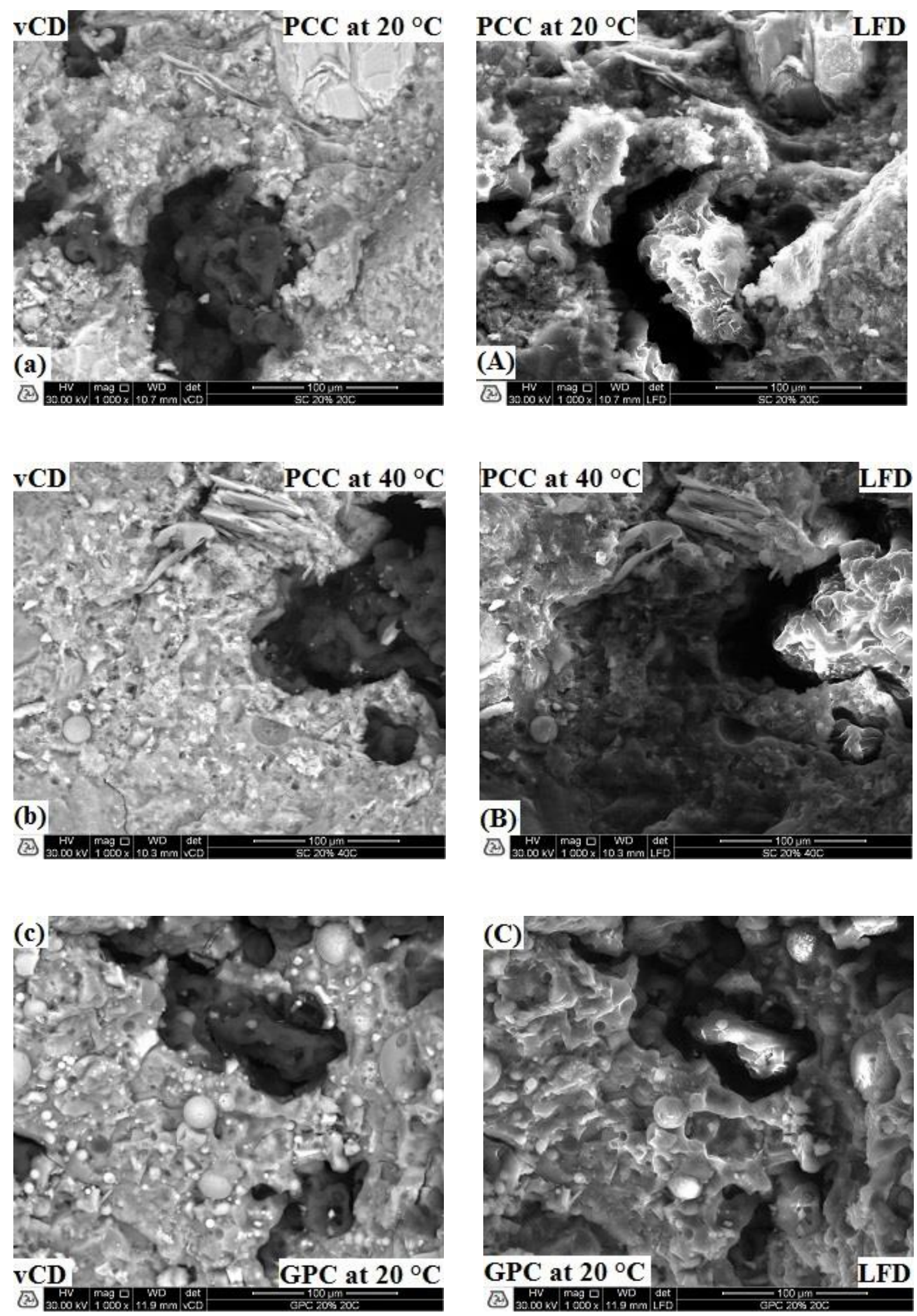

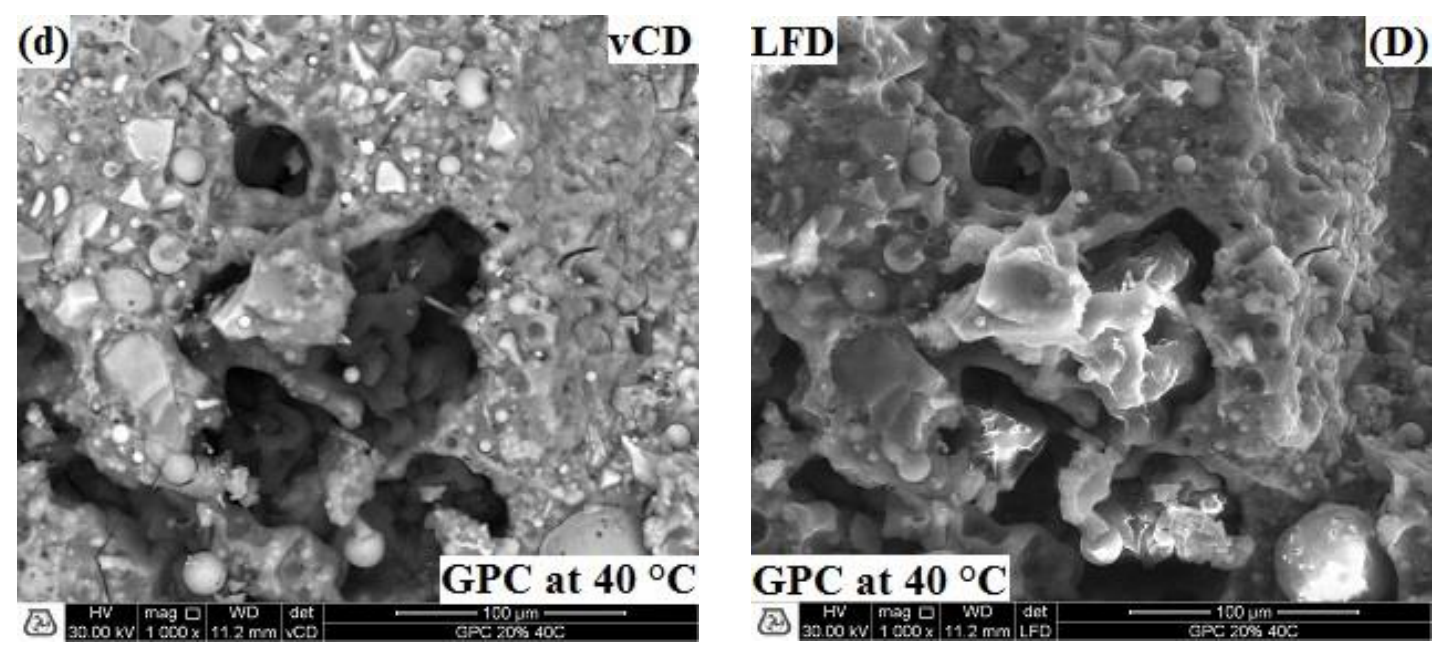

Figure V.10. SEM images of fracture surface of $20 \%$ MPCM incorporated in (a) PCC at $20{ }^{\circ} \mathrm{C}$, (b) PCC at $40{ }^{\circ} \mathrm{C}$, (c) GPC at $20^{\circ} \mathrm{C}$, and (d) GPC at $40{ }^{\circ} \mathrm{C}$ (by vCD detector), (A) PCC at 20 ${ }^{\circ} \mathrm{C}$, (B) PCC at $40{ }^{\circ} \mathrm{C}$, (C) GPC at $20{ }^{\circ} \mathrm{C}$, and (D) GPC at $40{ }^{\circ} \mathrm{C}$ (by LFD detector). MPCM will show up as dark areas in vCD and bright areas in LDF, while voids will be dark in both types of images. 
Chapter VI.

Mix design and compressive strength of fly ash/slag geopolymer concrete containing micro-encapsulated phase change materials. 



\section{VI.1. Contribution of constituents}

In order to formulate a good GPC mix-design, it is important to know how different factors will affect the properties of fly ash/slag based GPC. The description of all these factors is explained below.

\section{VI.1.1. Aluminasilicate}

Fly ash (FA) is considered to be one of the main sources of silica $\left(\mathrm{SiO}_{2}\right)$ and alumina $\left(\mathrm{Al}_{2} \mathrm{O}_{3}\right)$ in GPC. In accordance with ASTM C618, FA is classified based on its chemical composition, and the main difference between them is the calcium amount. FA class $\mathrm{C}$ has a higher content of calcium than FA class $\mathrm{F}$. A higher content of $\mathrm{CaO}$ in FA results in a higher compressive strength of GPC due to the formation of hydrated products such as calcium silicate hydrate (CSH) $[13,18]$. However, at these conditions the setting time of GPC decreases noticeably (less than $3 \mathrm{~min}$ ) [13]. Fly ash class F has therefore been selected as a good source material for GPC due to the lower reactivity rate, which leads to a slower setting time, convenient accessibility, and lower water demand [15]. In order to improve the mechanical properties of class F fly ash GPC, small amounts of other additives which are rich in $\mathrm{CaO}$ (e.g., blast furnace slag, silica fume, or natural pozzolan) can be added [15, 42, 138-140]. Ground granulated blast furnace slag (GGBFS) is one of the most common additives, due to the improved mechanical and microstructural properties $[123,141,142]$. However, adding GGBFS results in poor workability and mobility due to a higher stiffness [138]. The reduction of the slump is caused by the increased resistance of the angular shaped slag compared to the round fly ash particles [124]. This increases the viscosity and yield stress of the mixture. 


\section{VI.1.2. Alkaline solution}

The alkaline solution dissolves $\mathrm{Al}^{3+}$ and $\mathrm{Si}^{4+}$ ions from the aluminasilicate sources, which subsequently improves compressive strength by forming sodium alumino silicate hydrate (NASH), calcium alumino silicate (CASH), and/or CSH gels [46, 143]. The most common alkaline solutions are sodium hydroxide $(\mathrm{NaOH})$, potassium hydroxide $(\mathrm{KOH})$, sodium silicate $\left(\mathrm{Na}_{2} \mathrm{SiO}_{3}\right)$ and potassium silicate $\left(\mathrm{K}_{2} \mathrm{SiO}_{3}\right)$. The dissolution of fly ash and slag is dependent on the type and concentration of the alkaline solution [43, 44]. According to a leaching test, a sodium hydroxide alkaline solution dissolve a higher amount of $\mathrm{Al}^{3+}$ and $\mathrm{Si}^{4+}$ ions than a potassium hydroxide solution and geopolymerization seems to be accelerated by Na rather than $\mathrm{K}$ [45]. The concentration of the alkaline solution influences the workability and compressive strength of GPC, and an optimum value of $16 \mathrm{M} \mathrm{NaOH}$ has been reported for some systems [144]. Using a combination of sodium hydroxide and sodium silicate results in a higher compressive strength than when only sodium hydroxide is used [46]. When the ratio of sodium silicate to sodium hydroxide increases, the amount of soluble silica increases in the mixture, subsequently, the polymerization processes is accelerated to some extent and higher amount of calcium silicate hydrate $(\mathrm{CSH})$ in the presence of sodium silicate is formed [46, 47]. However, the high viscosity of sodium silicate in the alkaline solution reduces the slump of GPC in comparison with Portland cement concrete [110, 123, 144].

\section{VI.1.3. Micro-encapsulated phase change materials}

The workability of concrete decreases in the presence of MPCM. This might be due to differences in the particle size of MPCM compared with the sand it replaces, or a reduction of available water in the sample due to the water affinity of the MPCM shell [104, 105, 129]. It seems that the more polar functional groups on the polymer shell also helps to disperse the 
microcapsules into the concrete matrix better than a hydrophobic shell [145]. The addition of MPCM to mortar or concrete reduce the compressive strength [102, 109, 110, 122, 125]. However, the compressive strength is still sufficiently high for satisfying the mechanical European regulation (EN 206-1, compressive strength class C20/25) for concrete for structural applications (acceptable range of compressive strength is $25-40 \mathrm{MPa}$ ).

\section{VI.1.4. Extra water and chemical admixture}

Fresh GPC possesses a poor workability in comparison with fresh Portland cement concrete due to the higher viscosity of the alkaline solution. The workability and compressive strength of GPC are negatively influenced by the incorporation of MPCM. A better workability can be obtained by adding extra water to the mixture. However, this will reduce the compressive strength of GPC [144]. A better solution is therefore to utilize a chemical admixture. A naphthalene based superplasticizer is effective when fly ash class F is used in the mixture [146, 147]. For fly ash class C, a polycarboxylate-based superplasticizer is the best option due to the strong bonds between the positively charged calcium and the negatively charged polycarboxylate [146].

\section{VI.2. Mix design methodology}

After the description of the main parameters which affect the properties of MPCM-GPC, we propose a mix design taking into account all these factors. The proposed geopolymer concrete consists of sand, gravel, fly ash (FA), ground granulated blast furnace slag (GGBFS), $\mathrm{NaOH}(\mathrm{aq})$, and $\mathrm{Na}_{2} \mathrm{SiO}_{3}(\mathrm{aq})$. Unlike previous mix design procedures [148], the specific gravity and volume of each ingredient and air content are considered. Accordingly, the GPC contains these components: 
$\mathrm{GPC}=$ sand + gravel $+\mathrm{FA}+\mathrm{GGBFS}+\mathrm{NaOH}(\mathrm{aq})+\mathrm{Na}_{2} \mathrm{SiO}_{3}(\mathrm{aq})+$ entrapped air

The procedure and calculations are explained in more detail below based on 1 liter of GPC.

\section{VI.2.1. Preparation of alkaline solution}

For most applications, the cost of the GPC should be taken into account. The alkaline solution is the most expensive GPC components (not considering MPCMs). From the literature, $\mathrm{NaOH}$ and $\mathrm{Na}_{2} \mathrm{SiO}_{3}$ were found to be the most commonly used alkaline solution [148]. Therefore, in the present study, the combination of $\mathrm{NaOH}$ and $\mathrm{Na}_{2} \mathrm{SiO}_{3}$ is chosen as the alkaline solution.

The individual amount of $\mathrm{NaOH}$ and $\mathrm{Na}_{2} \mathrm{SiO}_{3}$ can be determined by:

$\mathrm{m}_{\mathrm{AS}}=\mathrm{m}_{\mathrm{NaOH}}+\mathrm{m}_{\mathrm{Na} 2 \mathrm{SiO} 3}$

where $\mathrm{m}_{\mathrm{AS}}$ is the mass of the alkaline solution, $\mathrm{m}_{\mathrm{NaOH}}$ is the mass of the $\mathrm{NaOH}$ solution, and $\mathrm{m}_{\mathrm{Na} 2 \mathrm{SiO} 3}$ is the mass of the $\mathrm{Na}_{2} \mathrm{SiO}_{3}$ solution.

The ratio $\left(\mathrm{R}_{\mathrm{AS}}\right)$ between the $\mathrm{Na}_{2} \mathrm{SiO}_{3}(\mathrm{aq})$ and $\mathrm{NaOH}(\mathrm{aq})$ is:

$\mathrm{R}_{\mathrm{AS}}=\mathrm{m}_{\mathrm{Na} 2 \mathrm{SiO} 3} / \mathrm{m}_{\mathrm{NaOH}}$

\section{VI.2.2. Liquids to geopolymer binder $(L / G B)$}

It has been proposed that the ratio of the total mass of water (free water and water in the alkaline solution) to the total mass of geopolymer solids (FA, GGBFS, $\mathrm{NaOH}$ pellets and sodium silicate solid) is similar to the water to cement ratio (w/c) in Portland cement concrete $[65,149]$. However in this work, the total mass of liquids $\left(m_{L}\right)$ includes the water and the entire alkaline solution, and the total amount geopolymer binder (GB) consists of FA and GGBFS [66]. Accordingly: 
$\mathrm{m}_{\mathrm{L}}=\mathrm{m}_{\mathrm{AS}}+\mathrm{m}_{\mathrm{water}}$

where $\mathrm{m}_{\text {water }}$ is the mass of free water added to the mixture

$\mathrm{m}_{\mathrm{GB}}=\mathrm{m}_{\mathrm{FA}}+\mathrm{m}_{\mathrm{GGBFS}}$

where $\mathrm{m}_{\mathrm{GB}}$ is the total mass of the geopolymer binder, $\mathrm{m}_{\mathrm{FA}}$ is the mass of $\mathrm{FA}$, and $\mathrm{m}_{\mathrm{GGBFS}}$ is the mass of GGBFS.

In order to reach an adequate compressive strength for structural applications an appropriate initial L/GB ratio should be chosen. However, in the proposed design, extra water can be added to improve the workability in further steps. After determination of extra water content during the mixing process, this amount will be added to the initial $\mathrm{L}$ of the mix design.

\section{VI.2.3. Determination of geopolymer binder $(G B)$}

For selecting the percentage of FA and GGBFS in the geopolymer binder (GB), both workability and compressive strength should be considered. With an initial L/GB ratio and L, we have for $1 \mathrm{~L}$ of sample:

$\mathrm{m}_{\mathrm{FA}}=\mathrm{R}_{\mathrm{FA}} \times \mathrm{m}_{\mathrm{GB}}$

where $\mathrm{R}_{\mathrm{FA}}$ is the ratio of FA in GB.

$\mathrm{m}_{\mathrm{GGBFS}}=\mathrm{R}_{\mathrm{GGBFS}} \times \mathrm{m}_{\mathrm{GB}}$

where $\mathrm{R}_{\mathrm{GGBFS}}$ is the ratio of GGBFS in $\mathrm{GB}$, and $\mathrm{R}_{\mathrm{FA}}+\mathrm{R}_{\mathrm{GGBFS}}=1$.

\section{VI.2.4. Determination of required sand and gravel}

The volume of FA, GGBFS, $\mathrm{NaOH}(\mathrm{aq})$, and $\mathrm{Na}_{2} \mathrm{SiO}_{3}(\mathrm{aq})$ are determined as: 
$\mathrm{V}_{\mathrm{FA}}=\mathrm{m}_{\mathrm{FA}} / \rho_{\mathrm{FA}}$

$\mathrm{V}_{\mathrm{GGBFS}}=\mathrm{m}_{\mathrm{GGBFS}} / \rho_{\mathrm{GGBFS}}$

$\mathrm{V}_{\mathrm{NaOH}(\mathrm{aq})}=\mathrm{m}_{\mathrm{NaOH}(\mathrm{aq})} / \rho_{\mathrm{NaOH}(\mathrm{aq})}$

$\mathrm{V}_{\mathrm{Na} 2 \mathrm{SiO} 3(\mathrm{aq})}=\mathrm{m}_{\mathrm{Na} 2 \mathrm{SiO} 3(\mathrm{aq})} / \rho_{\mathrm{Na} 2 \mathrm{SiO} 3(\mathrm{aq})}$

$\mathrm{V}_{\mathrm{GPC}}=\mathrm{V}_{\mathrm{Sand}+\mathrm{Gravel}}+\mathrm{V}_{\mathrm{FA}}+\mathrm{V}_{\mathrm{GGBFS}}+\mathrm{V}_{\mathrm{NaOH}(\mathrm{aq})}+\mathrm{V}_{\mathrm{Na} 2 \mathrm{SiO} \text { (aq) }}+\mathrm{V}_{\text {Entrapped air }}=1 \mathrm{~L}$

where $\rho_{\mathrm{FA}}, \rho_{\mathrm{GGBFS}}, \rho_{\mathrm{Water}}$, and $\rho_{\mathrm{Na} 2 \mathrm{SiO} 3}$ are the densities of FA, GGBFS, water, and $\mathrm{Na}_{2} \mathrm{SiO}_{3}$, respectively.

The percentage of entrapped air in GPC has previously been found to be approximately $2 \%$ of the total volume [150]. Sand and gravel should be added until the volume of the sample reaches the desired volume (1 L GPC).

According to the particle size distributions, the volume percentages of sand and gravel are each considered to be $50 \%$ of the total volume of the sand and gravel mixture.

$\mathrm{V}_{\text {Sand }}=\mathrm{V}_{\text {Gravel }}=0.5 \times \mathrm{V}_{\text {Sand }+ \text { Gravel }}$

$\mathrm{m}_{\text {sand }}=\mathrm{V}_{\text {Sand }} \times \rho$ Sand

$\mathrm{m}_{\text {gravel }}=\mathrm{V}_{\text {Gravel }} \times \rho_{\text {Gravel }}$

where $m_{\text {sand }}$ is the mass of sand, $m_{\text {gravel }}$ is the mass of gravel, and $\rho_{\text {Sand }}$ and $\rho_{\text {Gravel }}$ are the densities of sand and gravel, respectively. 


\section{VI.2.5. Calculation of water and superplasticizing admixture}

The total amount of water $\left(\mathrm{m}_{\mathrm{TW}}\right)$ is equal to the total water in alkaline solution $\left(\mathrm{m}_{\mathrm{ASwater}}\right)$ and extra water $\left(\mathrm{m}_{\text {water }}\right)$, which can be calculated as:

$\mathrm{m}_{\mathrm{TW}}=\mathrm{m}_{\mathrm{ASwater}}+\mathrm{m}_{\mathrm{water}}$

Therefore,

$m_{\mathrm{ASwater}}=\left(\mathrm{NaOH}_{(\mathrm{aq})} \times\left(1-\mathrm{m}_{\mathrm{NaOH}(\mathrm{s})}\right)\right)+\left(\mathrm{Na}_{2} \mathrm{SiO}_{3(\mathrm{aq})} \times\left(1-\mathrm{m}_{\mathrm{Na} 2 \mathrm{SiO}(\mathrm{s})}\right)\right)$.

The amounts of extra water and superplasticizer needed are obtained by experimental observation when mixing GPC without MPCMs. This step should be repeated several times to gain the optimal amounts of extra water and superplasticizer, while keeping the workability and strength at acceptable levels. According to Nematollahi et al. [151], a superplasticizer amount corresponding to $1 \%$ of the GB mass was chosen for the first step.

The amount of extra water can be varied depending on the properties of the raw materials.

\section{VI.2.6. Calculation of MPCM replacement}

There are two methods to add MPCMs to GPC which are called the MPCM replacement method and the MPCM additive method. Pania et al. [102] observed that the strength reduction of concrete was less when the MPCM replaced a certain percentage of sand (MPCM replacement method) than when the MPCM was added to the concrete mixture as an extra additive (MPCM additive method). Based on the MPCM replacement method, different MPCM percentages (in volume) are replacing the same percentages of sand:

$\mathrm{V}_{\text {sand }+\mathrm{MPCM}}=\mathrm{V}_{\text {Sand }}+\mathrm{V}_{\mathrm{MPCM}}$ 
Where $\mathrm{V}_{\text {sand+MPCM }}$ is the combined volume of sand and MPCM $\left(\mathrm{V}_{\text {sand+MPCM }}\right.$ is kept constant and corresponds to $\mathrm{V}_{\text {Sand }}$ for the sample without MPCM). $\mathrm{V}_{\text {MPCM }}$ is the volume of MPCM. The percentage of MPCM in the mixture (\%

$\%$ MPCM $=100 \times \mathrm{V}_{\mathrm{MPCM}} / \mathrm{V}_{\text {sand+MPCM }}$

The mass of MPCM (m $\left.\mathrm{m}_{\mathrm{MPCM}}\right)$ is:

$\mathrm{m}_{\mathrm{MPCM}}=\mathrm{V}_{\mathrm{MPCM}} \times \rho_{\mathrm{MPCM}}$

The mass of sand after replacement is:

$\mathrm{m}_{\text {Sand }}=\left(\mathrm{V}_{\text {sand }+\mathrm{MPCM}}-\mathrm{V}_{\mathrm{MPCM}}\right) \times \rho_{\text {Sand }}$

\section{VI.2.7. Validation of compressive strength with proposed mix design}

To evaluate whether the proposed GPC mix design (without MPCM addition) can satisfy the acceptable range of compressive strength, the 7 and 28-day compressive strength obtained from different mix designs are measured. The results obtained from the compression test is compared with the maximum compressive strength of Portland cement concrete after 28 days curing at ambient temperature in accordance with ACI standard [10]. For better comparison, the water to cement ratio of this Portland cement concrete is equal to the L/GB ratio in the current proposed mix design.

If it satisfies the strength requirement, final development of GPC can be carried out or else the mix should be re-designed by changing the parameters.

Utilizing the steps above, we have optimized the mix design of the GPC containing MPCM.

Figure VI.1 depicts the overall process of the mix design, in which the desirable workability 
and mechanical properties are reached by the selection and correct addition of the constituents of the final materials.

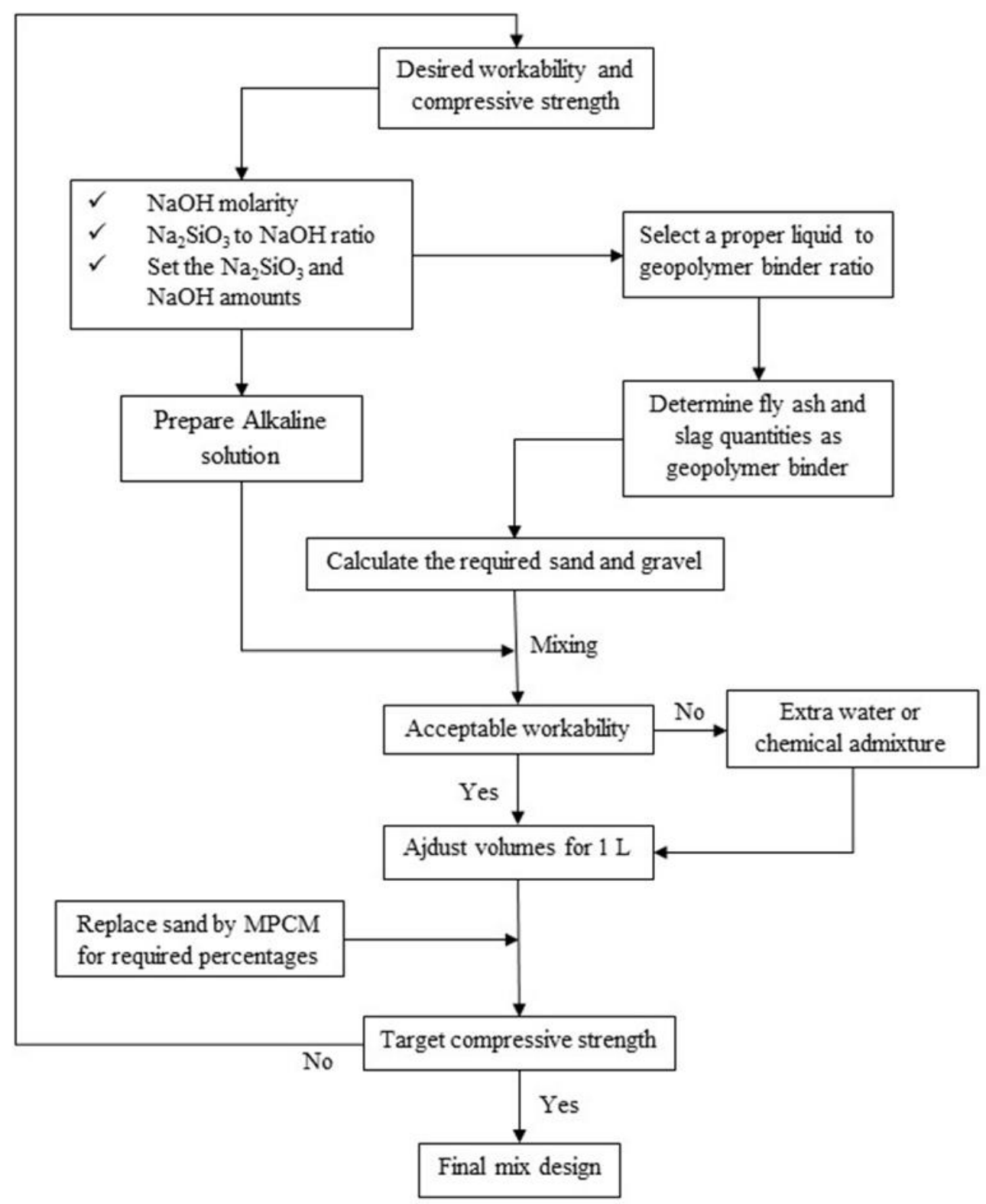

Figure VI.1. The overall mix design procedure. 


\section{VI.3. Verification of the mix design by using}

\section{experimental data}

In the first step of the validation, five different mix proportions for 1 L GPC without MPCM are designed. Different $\mathrm{NaOH}$ solutions with the molarity of 9,12 , and 14 were prepared. Mixture 1 and Mixture 2 have the same $\mathrm{NaOH}(\mathrm{aq})$ molarity of 9, but different extra water and superplasticizer content. The molarity of 12 is chosen for Mixture 3. For Mixture 4 and Mixture 5, the same $14 \mathrm{M}$ alkaline solution is selected, however the amount of extra water and superplasticizer are different.

From an economical point of view, a constant $\mathrm{Na}_{2} \mathrm{SiO}_{3}$ solution to $\mathrm{NaOH}$ solution ratio (R) of 1.5 was applied for all mixtures. The details of mix proportions for the GPC without MPCM are shown in Table VI.1.

Strength is generally considered as the principal selection criterium. Therefore, the compressive strength tests for 5 different mixtures were conducted on the mix designs proposed in Table VI.1. Figure VI.2 shows the compressive strength of the proposed GPC mixtures without MPCM after 7 and 28 days curing at $20{ }^{\circ} \mathrm{C}$. 
Table VI.1. Different mix proportions for 1 litre of GPC without MPCM.

\begin{tabular}{|c|c|c|c|c|c|}
\hline \multirow{3}{*}{ Ingredient } & \multicolumn{5}{|c|}{ Amounts (g) } \\
\hline & Mixture 1 & Mixture 2 & Mixture 3 & Mixture 4 & Mixture 5 \\
\hline & $9 \mathrm{M}, \mathrm{R}=1.5$ & $9 \mathrm{M}, \mathrm{R}=1.5$ & $12 \mathrm{M}, \mathrm{R}=1.5$ & $14 \mathrm{M}, \mathrm{R}=1.5$ & $14 \mathrm{M}, \mathrm{R}=1.5$ \\
\hline $\mathrm{NaOH}$ solution & 72.5 & 73.3 & 74 & 74.6 & 75.9 \\
\hline $\mathrm{Na}_{2} \mathrm{SiO}_{3}$ solution & 108.7 & 110 & 110 & 111.9 & 113.8 \\
\hline FA & 271.2 & 271.2 & 271.2 & 277.9 & 280.2 \\
\hline GGBFS & 182.4 & 182.4 & 182.4 & 188.1 & 190.9 \\
\hline Sand & 809.4 & 820.1 & 825.4 & 822.7 & 828.1 \\
\hline Gravel & 791.2 & 801.7 & 806.9 & 804.3 & 809.6 \\
\hline Extra water & 87 & 78 & 74 & 68 & 47 \\
\hline Superplasticizer & 6.7 & 4.6 & 6.6 & 6.9 & 4.8 \\
\hline
\end{tabular}




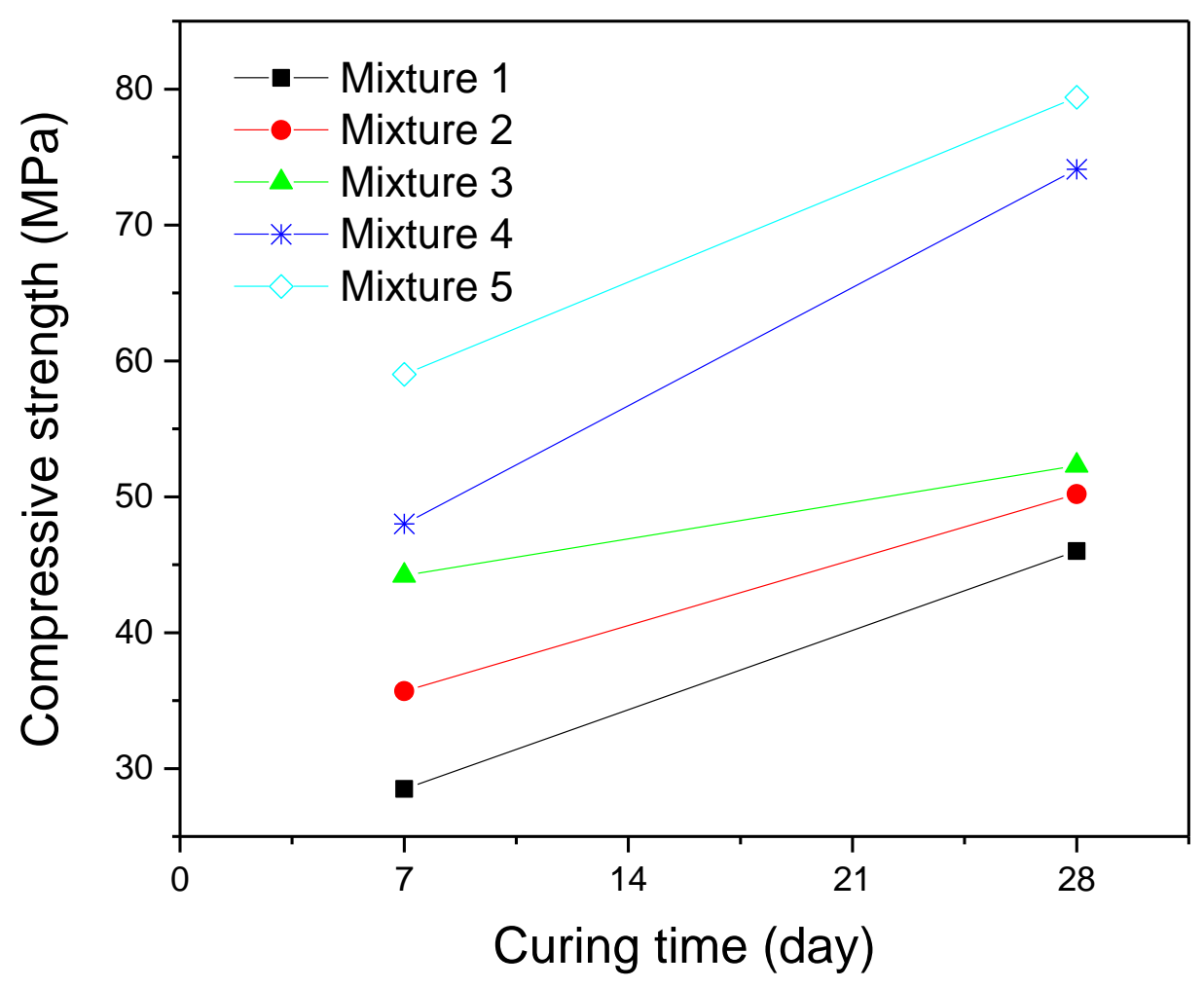

Figure VI.2. Compressive strength of GPC (cured at $20^{\circ} \mathrm{C}$ ) versus curing time for 5 different mix proportions.

According to Figure VI.2, different molarities, free water and chemical admixture can affect the compressive strength the mixture. When the molarity of $\mathrm{NaOH}(\mathrm{aq})$ increases (Mixture 2 (9M), Mixture 3 (12 M), Mixture $4(14 \mathrm{M}))$, compressive strength becomes higher. When the amount of extra water decreases from Mixture 1 to Mixture 2 (with the same $M=9$ and $R=1.5$ ) or Mixture 4 to Mixture 5 (with the same $\mathrm{M}=14$ and $\mathrm{R}=1.5$ ), a higher compressive strength is obtained. A decrease in superplasticizer dosage, from $1.5 \mathrm{wt} \%$ (Mixture 4) to $1 \%$ wt.\% (Mixture 5), improves the strength. As can be seen from Figure VI.2, the highest compressive strength was obtained for Mixture 5 after both 7 and 28 days curing. Additionally, the laboratory trials of workability tests showed that $14 \mathrm{M} \mathrm{NaOH}$ and a $\mathrm{R}$ of 1.5 , was optimal in terms of the 
flowability of the mixture. Therefore, the procedure to validate the proposed mix design is explained with the optimum data of Mixture 5.

\section{VI.3.1. Preparation of alkaline solution}

Based on previous studies [66], $200 \mathrm{~g} / \mathrm{l}$ of alkaline solution $\left(\mathrm{NaOH}(\mathrm{aq})+\mathrm{Na}_{2} \mathrm{SiO}_{3}(\mathrm{aq})\right.$ ) was selected to develop the strength effectively.

Based on the manufacturer data sheet, the $\mathrm{Na}_{2} \mathrm{SiO}_{3}$ solution contains 35 wt. $\% \mathrm{Na}_{2} \mathrm{SiO}_{3}$.

In order to determine the amount of $\mathrm{Na}_{2} \mathrm{SiO}_{3}$ solution and $\mathrm{NaOH}$ solution:

$\mathrm{R}=\mathrm{Na}_{2} \mathrm{SiO}_{3}(\mathrm{aq}) / \mathrm{NaOH}(\mathrm{aq})=1.5$

Alkaline solution $=\mathrm{Na}_{2} \mathrm{SiO}_{3}+\mathrm{NaOH}=200 \mathrm{~g} / \mathrm{L}$

Accordingly, $\mathrm{m}_{\mathrm{Na} 2 \mathrm{SiO} 3(\mathrm{aq})}=120 \mathrm{~g}$, and $\mathrm{m}_{\mathrm{NaOH}(\mathrm{aq})}=80 \mathrm{~g}$.

\section{VI.3.2. Liquids to geopolymer binder $(L / G B)$}

In order to reach an adequate compressive strength for structural applications an initial L/GB ratio of 0.4 was chosen. The reason of choosing 0.4 for the first step is that for Portland cement concrete, the water to cement $(\mathrm{w} / \mathrm{c})$ ratio of 0.4 ensures there is enough water for complete hydration [10]. Extra water can be determined during the mixing and added to the initial L.

\section{VI.3.3. Determination of geopolymer binder $(G B)$}

Considering both workability and compressive strength, as well as having similarity with the prepared mix design in Chapter V, a geopolymer binder (GB) consisting of $60 \%$ FA and $40 \%$ 
GGBFS was utilized. According to section VI.2.2, with an initial L/GB ratio of 0.4 , and $\mathrm{L}=$ $200 \mathrm{~g} / \mathrm{l}$, we have:

$\mathrm{m}_{\mathrm{GB}}=200 / 0.4=500 \mathrm{~g} / \mathrm{L}$

Accordingly, for $1 \mathrm{~L}$ of sample:

$\mathrm{m}_{\mathrm{FA}}=0.6 \times \mathrm{GB}=0.6 \times 500=300 \mathrm{~g}$

$\mathrm{m}_{\mathrm{GGBFS}}=0.4 \times \mathrm{GB}=0.4 \times 500=200 \mathrm{~g}$

\section{VI.3.4. Determination of required sand and gravel}

The volume of FA, GGBFS, $\mathrm{NaOH}(\mathrm{aq})$, and $\mathrm{Na}_{2} \mathrm{SiO}_{3}(\mathrm{aq})$ are determined as follow:

$\mathrm{V}_{\mathrm{FA}}=300 / 2260=0.13 \mathrm{~L}$

$\mathrm{V}_{\mathrm{GGBFS}}=200 / 2850=0.07 \mathrm{~L}$

$\mathrm{V}_{\mathrm{NaOH}(\mathrm{aq})}=0.0647 \mathrm{~L}$

$\mathrm{V}_{\mathrm{Na} 2 \mathrm{SiO} 3(\mathrm{aq})}=0.0622 \mathrm{~L}$

By considering the percentage of entrapped air in GPC, the total of $0.35 \mathrm{~L}$ for $1 \mathrm{~L}$ of GPC (700 $\mathrm{g} / \mathrm{L}$ ) is calculated. Thus, the total volume of sand and gravel in 1 L GPC is approximately 0.65 L. we have:

$\mathrm{V}_{\text {Sand }}=\mathrm{V}_{\text {Gravel }}=50 \% \mathrm{~V}_{\text {Sand }+ \text { Gravel }}=0.325 \mathrm{~L}$

Based on data sheets, the specific gravities of sand and gravel are 2680 and $2620 \mathrm{~g} / \mathrm{L}$, respectively. Accordingly, $\mathrm{m}_{\text {sand }} \approx 871.18 \mathrm{~g}$ and $\mathrm{m}_{\text {gravel }} \approx 851.68 \mathrm{~g}$. 


\section{VI.3.5. Calculation of water and superplasticizing admixture}

The first amount of water is calculated as:

$\mathrm{m}_{\mathrm{TW}}=\mathrm{m}_{\mathrm{ASwater}}=\mathrm{NaOH}_{(\mathrm{aq})}(1-0.36)+\mathrm{Na}_{2} \mathrm{SiO}_{3(\mathrm{aq})}(1-0.35)=(80 \times 0.64)+(120 \times 0.65)=$ $129.3 \mathrm{~g}$

Thus, the initial water content and the water to geopolymer solids are $129.3 \mathrm{~g}$ and 0.23 , respectively.

$50 \mathrm{~g}$ extra water was found to be optimal for Mixture 5 to provide a good workability. A superplasticizer amount of $5 \mathrm{~g} / \mathrm{L}$ was chosen for Mixture 5.

\section{VI.3.6. Adjustment of proposed mix design for 1 liter}

After adding extra water and superplasticizer to obtain an improved mixture, the total volume of the original $1 \mathrm{~L}$ mix increases to 1.05 liter. To obtain a $1 \mathrm{~L}$ mix design recipe again, the amount of each component is simply divided by 1.05 . After these adjustments, the mixture design for 1 Liter GPC containing 0\% MPCM is shown in Table VI.2. 
Table VI.2. Volume of ingredients per 1 liter of Geopolymer concrete.

\begin{tabular}{lcc}
\hline Ingredients & Volume $(\mathrm{mL})$ & Amount $(\mathrm{g})$ \\
\hline $\mathrm{NaOH}$ solution & 62 & 75.91 \\
$\mathrm{Na}_{2} \mathrm{SiO}_{3}$ solution & 59 & 113.87 \\
Fly ash & 124 & 280.24 \\
GGBFS & 67 & 828.12 \\
Sand & 309 & 809.58 \\
Gravel & 309 & 47 \\
Extra water & 1000 & \\
Total volume & 47 & 4.8 \\
superplasticiser & 4 & \\
\hline
\end{tabular}

\section{VI.3.7. Calculation of MPCMs replacement}

In this study, 0, 10 and 20\% of sand are replaced by MPCM with densities of $900 \mathrm{~g} / \mathrm{L}$.

For instance, for GPC10, 10\% of sand is replaced by the MPCM:

$\mathrm{V}_{\mathrm{MPCM}}=10 \% \mathrm{~V}_{\text {Sand }}=0.031 \mathrm{~L}$

For MPCM with density of $900 \mathrm{~g} / \mathrm{L}$, the mass of MPCMs can be calculated as: 
Mass of MPCM $\left(m_{M P C M}\right)=0.031 \times 900=27.9 \mathrm{~g}$

Mass of sand after $10 \%$ replacement $=828.12-82.81=745.31 \mathrm{~g}$

The summary of the amounts of sand replaced by MPCM is given in Table VI.3.

Table VI.3. Amount of sand replacement by MPCM.

\begin{tabular}{llcc}
\hline & MPCM (vol \%) & Sand $(\mathrm{g})$ & MPCM $(\mathrm{g})$ \\
\hline GPC0 & 0 & 828.12 & 0 \\
GPC10 & 10 & 745.31 & 27.9 \\
GPC20 & 20 & 662.49 & 55.8 \\
\hline
\end{tabular}

\section{VI.3.8. Mixing method}

The mixing method is explained in Chapter III.4.2.

\section{VI.3.9. Casting and curing method}

The GPC samples where 0,10 , and $20 \%$ of the sand was replaced with MPCM (St-DVB-PCM), were cast according to the procedure in Chapter III.4.2 at $20^{\circ} \mathrm{C}$.

\section{VI.3.10. Validation of Achieved Strength}

Figure VI.3 shows the compressive strength of the GPC mixture with incorporated 0, 10, and $20 \%$ of St-DVB-PCM after $1,7,14$, and 28 days curing at $20^{\circ} \mathrm{C}$. The maximum compressive strength of Portland cement concrete after 28 days curing at ambient temperature according to 
ACI standard [10] is also shown for comparison. The water to cement ratio of this Portland cement concrete is 0.5 which is equal to the $\mathrm{L} / \mathrm{GB}$ ratio in the current proposed mix design.

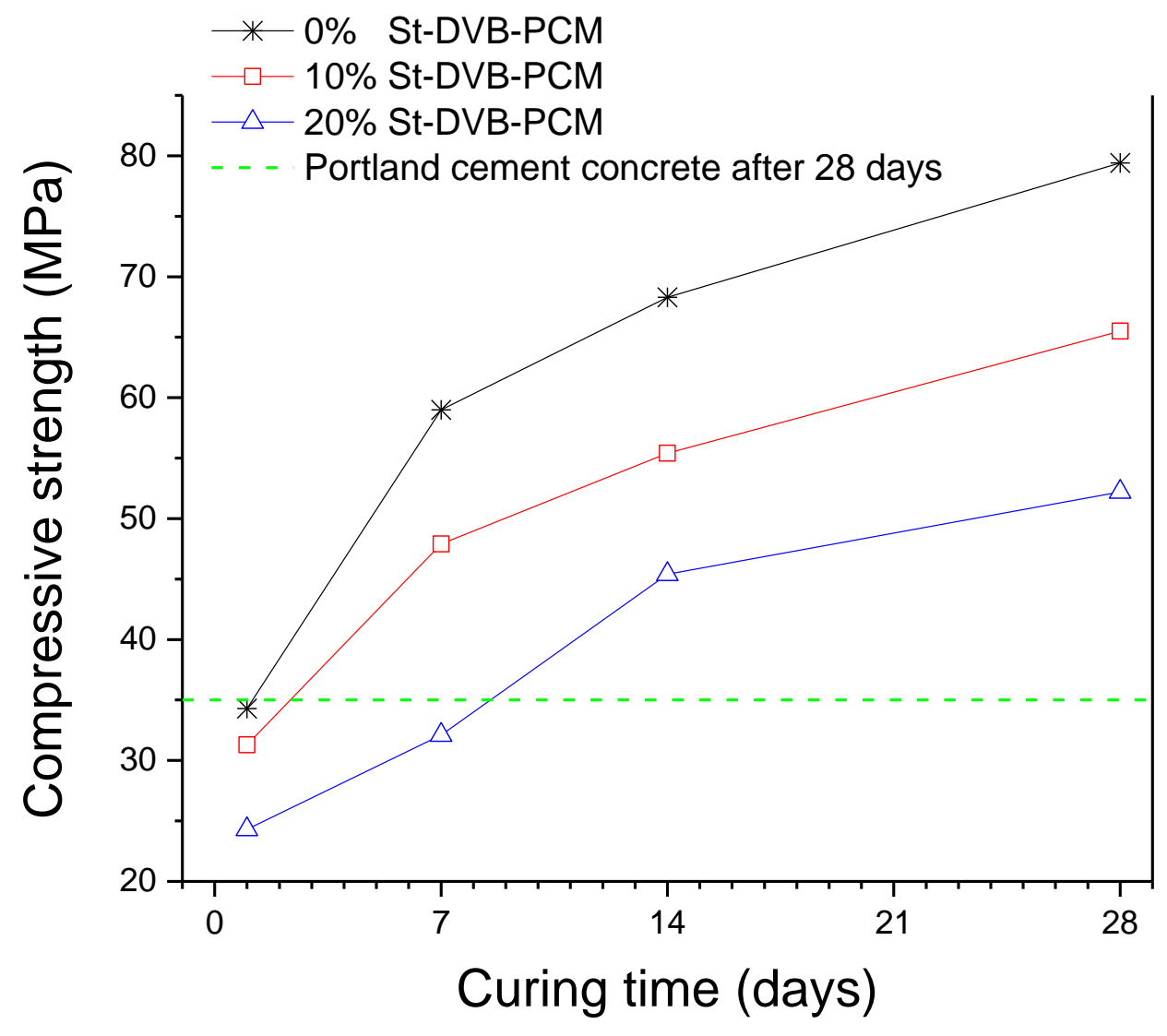

Figure VI.3. Compressive strength of GPC (cured at $20^{\circ} \mathrm{C}$ ) versus curing time when 0,10 , and $20 \%$ sand is replaced by St-DVB-PCM. The green dashed line illustrates the maximum compressive strength of PCC after 28 days curing at ambient temperature [10].

As expected, the compressive strength of the proposed GPC mixture increases with curing time. In order to evaluate whether the proposed GPC mix design with incorporated MPCMs is suitable for structural purposes, the maximum compressive strength of Portland cement concrete after 28 days [10] is shown for comparison. It can be seen that the first day strength of the proposed GPC without PCM is almost the same as for Portland cement concrete after 28 days (around $35 \mathrm{MPa}$ ). In spite of the negative effect of MPCM on the strength of GPC, the 
compressive strength of GPC with 20\% MPCMs after 28days curing is significantly higher than for Portland cement concrete.

Figure VI.3 also illustrates that the strength of GPC containing MPCM is lower than GPC without MPCM. There are several factors that can contribute to this effect, which will be explained comprehensively in Chapter VII. 
Chapter VII.

Physical and mechanical properties of proposed fly ash/slag geopolymer concrete containing different types of microencapsulated phase change materials. 

Tables summarizing the results of this chapter are presented in Appendix A.4.

\section{VII.1. Physical properties of MPCM shell}

\section{VII.1.1. Water affinity and adsorption}

According to the particle size distributions of sand, PE-EVA-PCM, and St-DVB-PCM (Figure IV.10 and Figure IV.13), it is evident that both types of microcapsules are smaller than the replaced sand.

The water adsorbed and retained by PE-EVA-PCM, St-DVB-PCM and sand after immersion in water is shown in Figure VII.1. The amount of water contained by the samples after immersion is related to how much water the particles retain in the geopolymer mixture.

It is clear from Figure VII.1 a that the MPCMs adsorb more water than sand per unit mass. This is probably due to the smaller sizes of the microcapsules (Figure IV.10 and Figure IV.13), which results in a larger total surface area. Although the sizes of the microcapsules are similar, PE-EVA-PCM adsorbs more water than St-DVB-PCM. This is in agreement with the more hydrophobic nature of the St-DVB shell, compared to PE-EVA which contains some polar groups. Since the MPCM replaces sand by volume in the geopolymer matrix, the water adsorption per volume unit of dry material is displayed in Figure VII.1b. The microcapsules also adsorb more water than sand when volumes are considered instead of weights. However, the difference between sand and St-DVB-PCM is less evident and the difference between the two types of microcapsules is much more obvious. Accordingly, the polarity of the microcapsule shell is more important for how much water the samples adsorb than the differences in sizes, although the latter also has a clear effect on the water adsorption. 

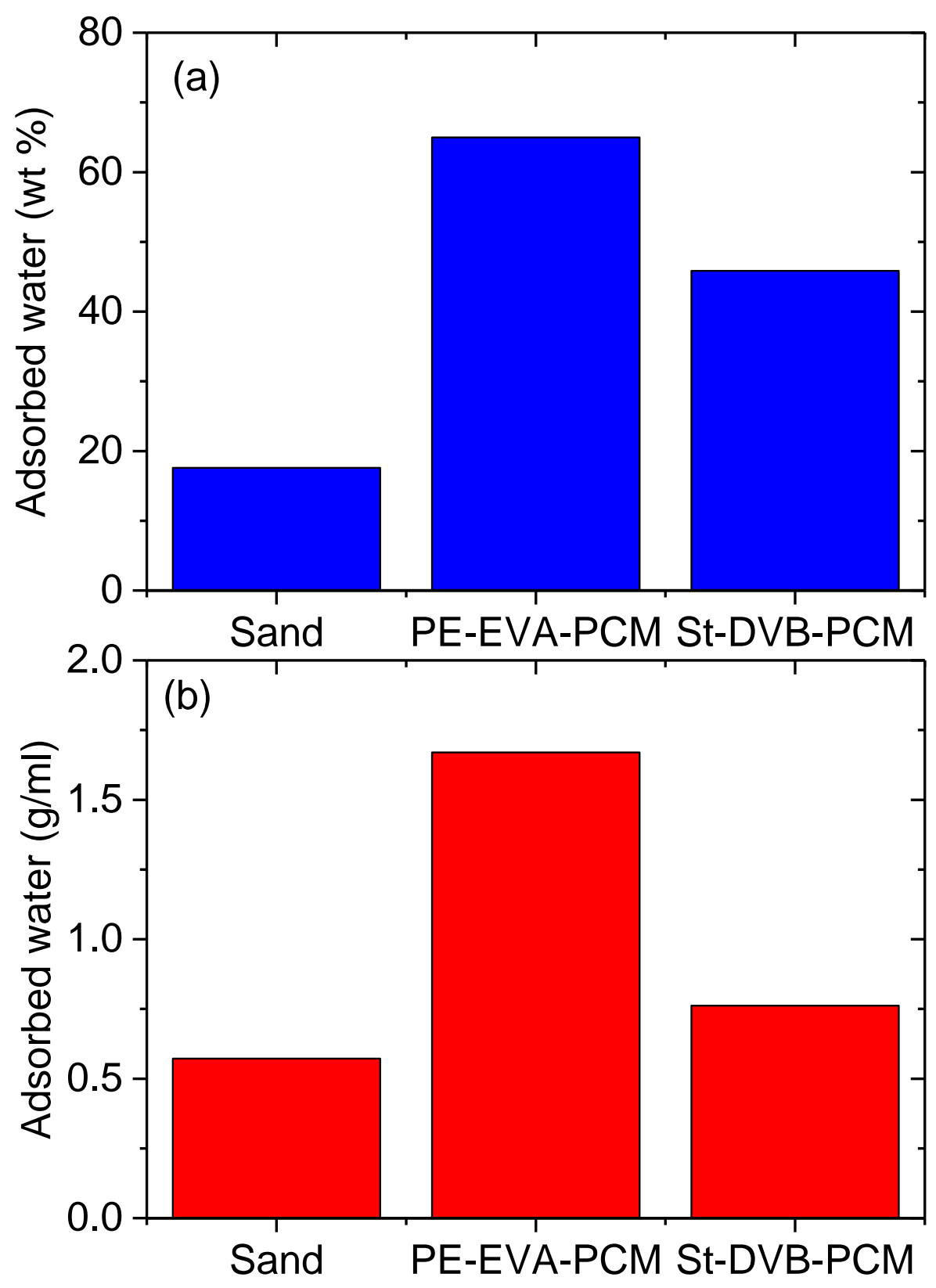

Figure VII.1. (a) Weight percentage of adsorbed water of sand, PE-EVA-PCM, and St-DVBPCM after immersion in water, and (b) adsorbed water per volume unit of sand, PE-EVA-PCM, and St-DVB-PCM. 


\section{VII.1.2. Resistance against alkaline solution and mixing process}

Figure VII.2a and $\mathrm{b}$ show EDX mapping and SEM images of St-DVB-PCM after immersion in the alkaline solution at two different magnifications. Due to the irregular shape of PE-EVAPCM, a damaged shell cannot be easily distinguished from an undamaged shell, thus this experiment is conducted on St-DVB-PCM.

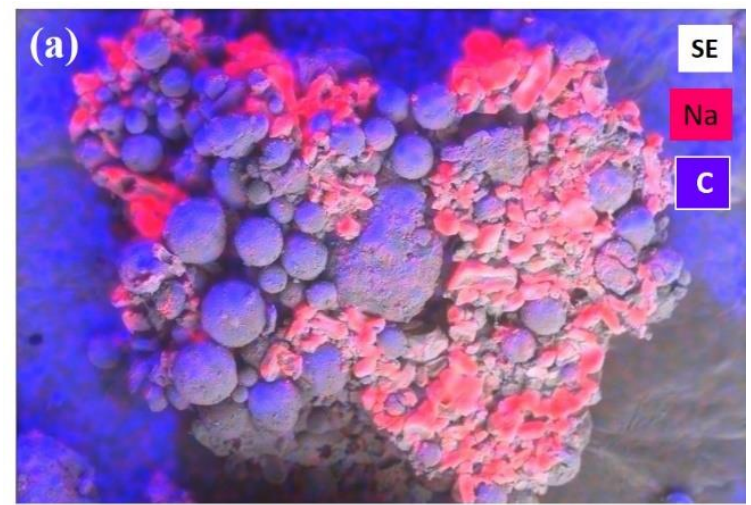

Alkaline solution/ St-DVB-PCM

MAG: $90 x$

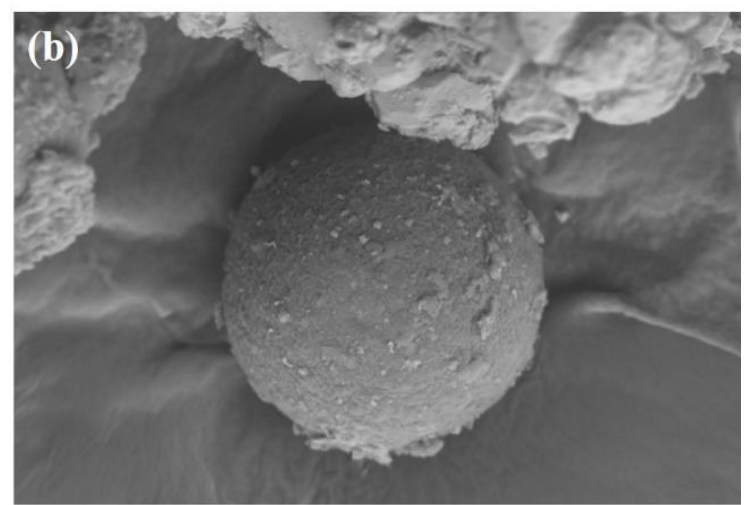

Alkaline solution/ St-DVB-PCM

MAG: 500x

Figure VII.2. (a) EDX a cluster of St-DVB-PCM immersed in alkaline solution (b) SEM image of a single particle of St-DVB-PCM after immersed in alkaline solution.

Figure VII.2a and $\mathrm{b}$ show how the microcapsules shell behaves after immersing in alkaline solution. It is clear from Figure VII.2 that although the alkaline solution covers all the microcapsules, the shell of the microcapsules is resistant against the highly basic nature of the alkaline solution. There is not observed any leakage or damaged microcapsules.

Figure VII.3 shows the SEM images of St-DVB-PCM after mixing with aggregates and water for 3 minutes to see how the mixing process can affect the shell of the microcapsules. This experiment is run on St-DVB-PCM because the irregular shape of PE-EVA-PCM shell makes it difficult to distinguish the damaged shell after the mixing process. 

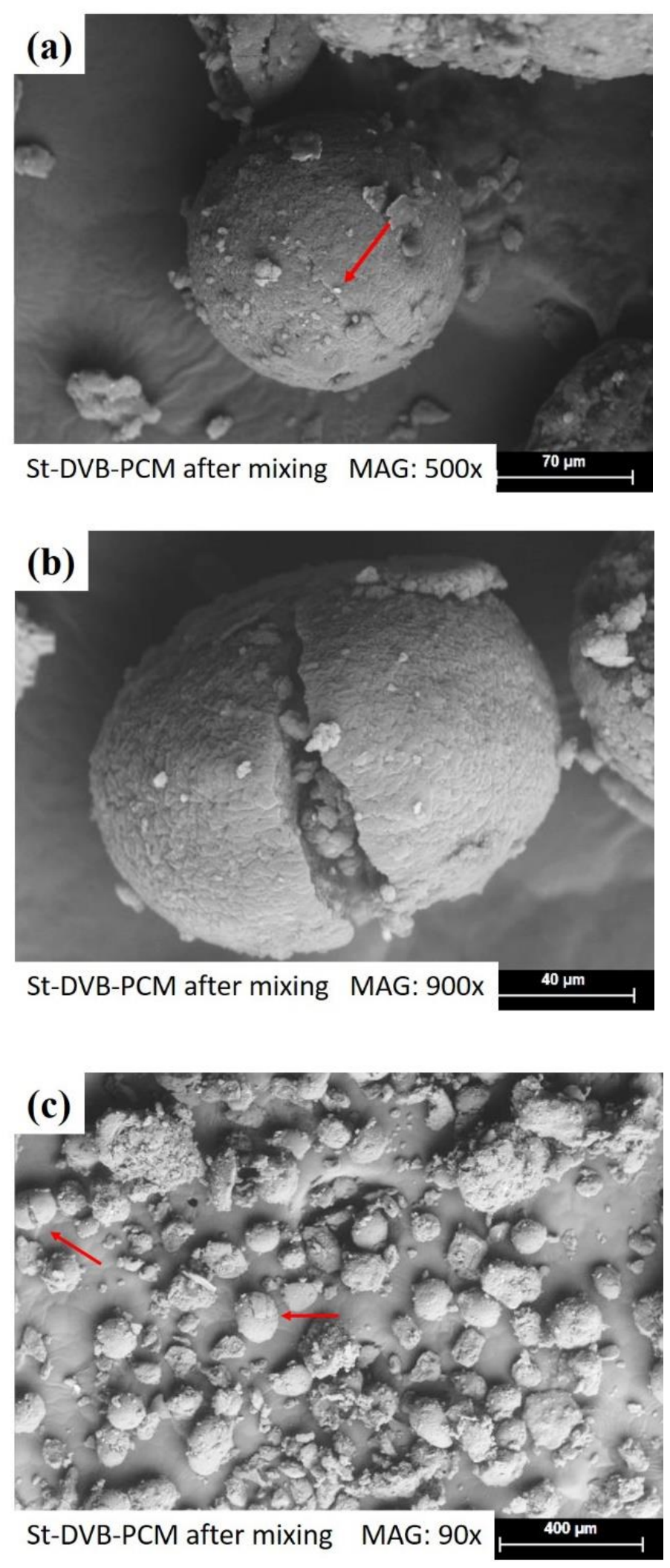

Figure VII.3. SEM images of the St-DVB-PCM after mixing (a) in magnification of 500x (the arrow shows a rupture of the shell), (b) in magnification of 900x, and (c) in magnification of 90x (the arrows show that a few microcapsules are broken). 
From Figure VII.3, it is evident that the mixing process can cause ruptures on the microcapsule shell. A possible rupture and a broken MPCM can be seen easily in Figure VII.3a and b, respectively. However, in Figure VII.3c, with a wider field of view, it can be seen that only a few microcapsules are broken and damaged during mixing process. As mentioned in previous chapters, lower stiffness and strength of MPCM compared to aggregates might cause deformation and fracture of MPCM during mixing, which might be a contributing factor to the reduced compressive strength of concrete.

\section{VII.2. Slump flow test}

In order to verify the quality of the mix design after the addition of MPCMs, the workability was carried out by a slump test. The results from the slump test are shown Figure VII.4. The slump of GPC decreased from 270 to $260 \mathrm{~mm}$ when the St-DVB-PCM was increased from 0 to 20\%, while PCC showed a slump in a wider range from 270 to $190 \mathrm{~mm}$ for the same percentages of PE-EVA-PCM.

As can be seen from Figure VII.4, there is a decrease in the workability (lower slump) of fresh GPC after adding both MPCMs. This can be explained by the higher amount of water adsorbed by the microcapsules compared to the MPCM replaces (Figure VII.1). This causes a reduction of the flowability of GPC, which is in agreement with our findings in Chapter V. Previous finding $[105,110,129]$ also claimed that the presence of MPCM leads to a slump reduction. Due to the higher water adsorption (Figure VII.1b), the addition of PE-EVA-PCM causes a much steeper decline of the slump (slope $=-4)$ than St-DVB-PCM $($ slope $=-0.5)$. 


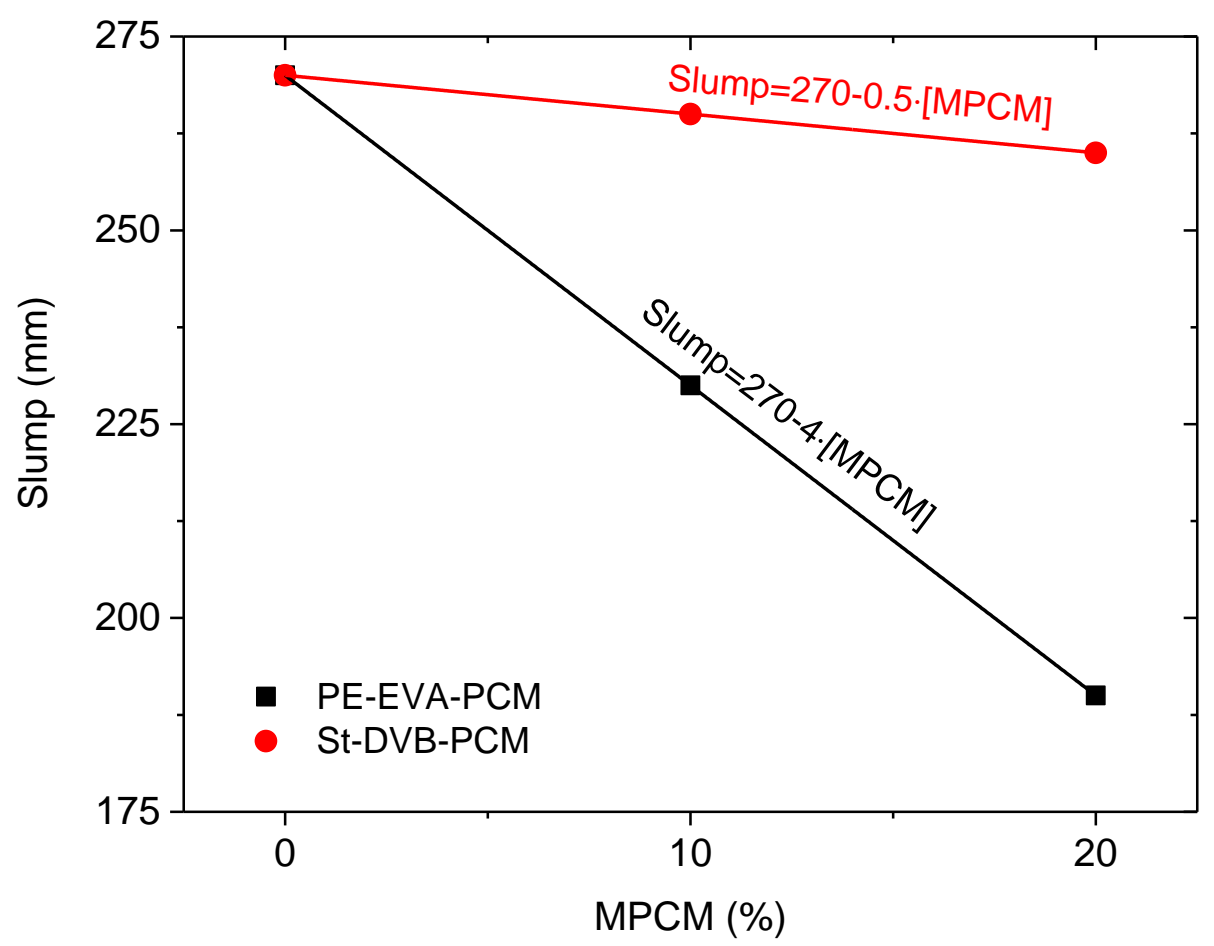

Figure VII.4. Slump of GPC containing various amounts of PE-EVA-PCM and St-DVB-PCM.

\section{VII.3. Setting time}

Figure VII.5a shows the effect of MPCM addition on the initial and final setting times of geopolymer paste. Increasing the MPCM concentration slightly delays the initial setting time, but causes a significantly faster final setting time in comparison to geopolymer paste without MPCM. As illustrated in Figure VII.6, reducing the amount of available water decreases both the initial and final setting times. This can explain why the final setting time becomes shorter when MPCM is added to the samples. However, a larger difference between the two types of MPCM should be expected, since PE-EVA-PCM adsorbs much more water than St-DVB-PCM (Figure VII.1b).

The geopolymer reaction rates can be slowed down when the viscosity of the samples increases $[43,152,153]$. This can help to explain the longer initial setting times in the presence of MPCM. Since PE-EVA-PCM has a much stronger effect on the slump than St-DVB-PCM (Figure 
VII.4), the effect of viscosity on the reaction rates is expected to be larger in the presence of PE-EVA-PCM. In addition, the latent heat of the microcapsules may slow down the setting times by absorbing reaction heat (preventing the samples from becoming warmer, which would speed up the reaction rate). This effect would probably be similar for the two types of MPCM, since their latent heat are practically the same (Table III.1).

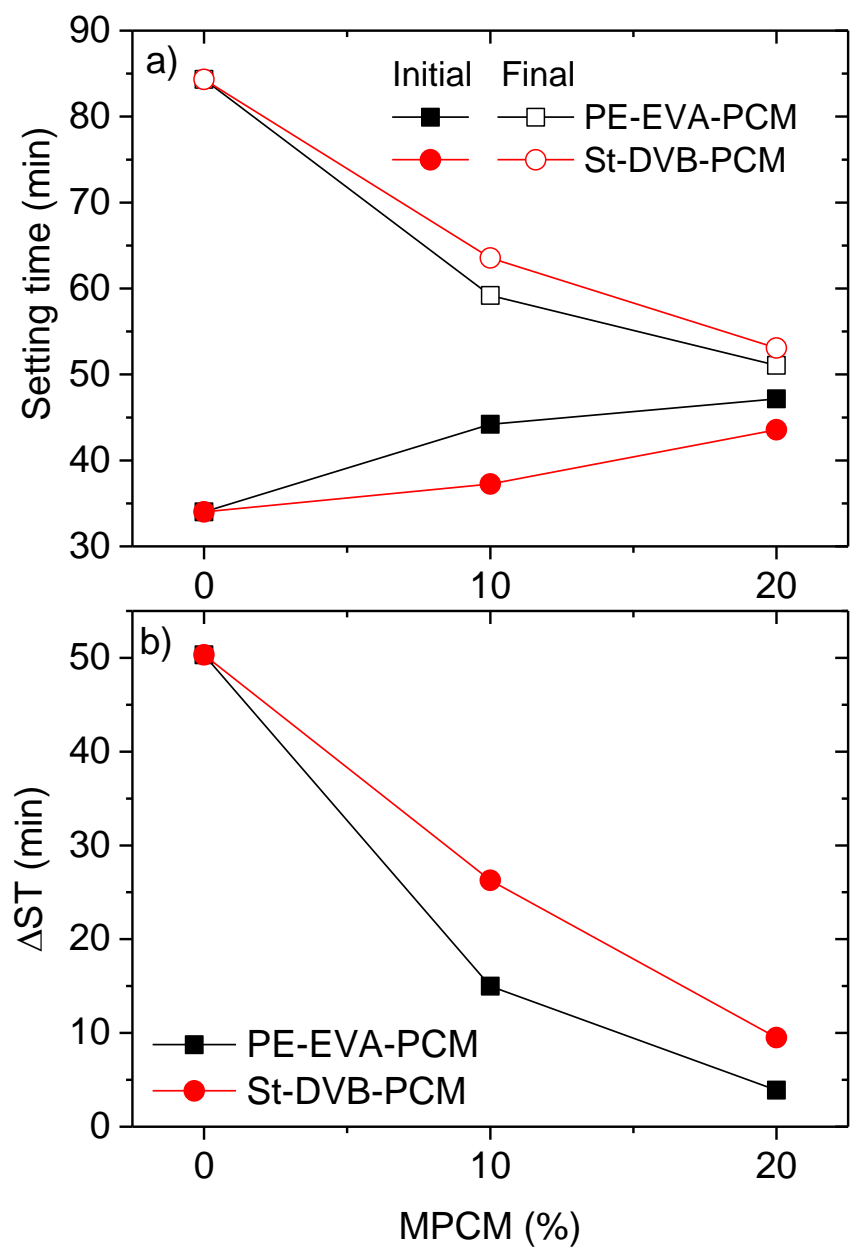

Figure VII.5. (a) The initial and final setting times of geopolymer paste containing various amounts of PE-EVA-PCM and St-DVB-PCM. (b) The difference between the initial and final setting times $(\Delta \mathrm{ST})$. 


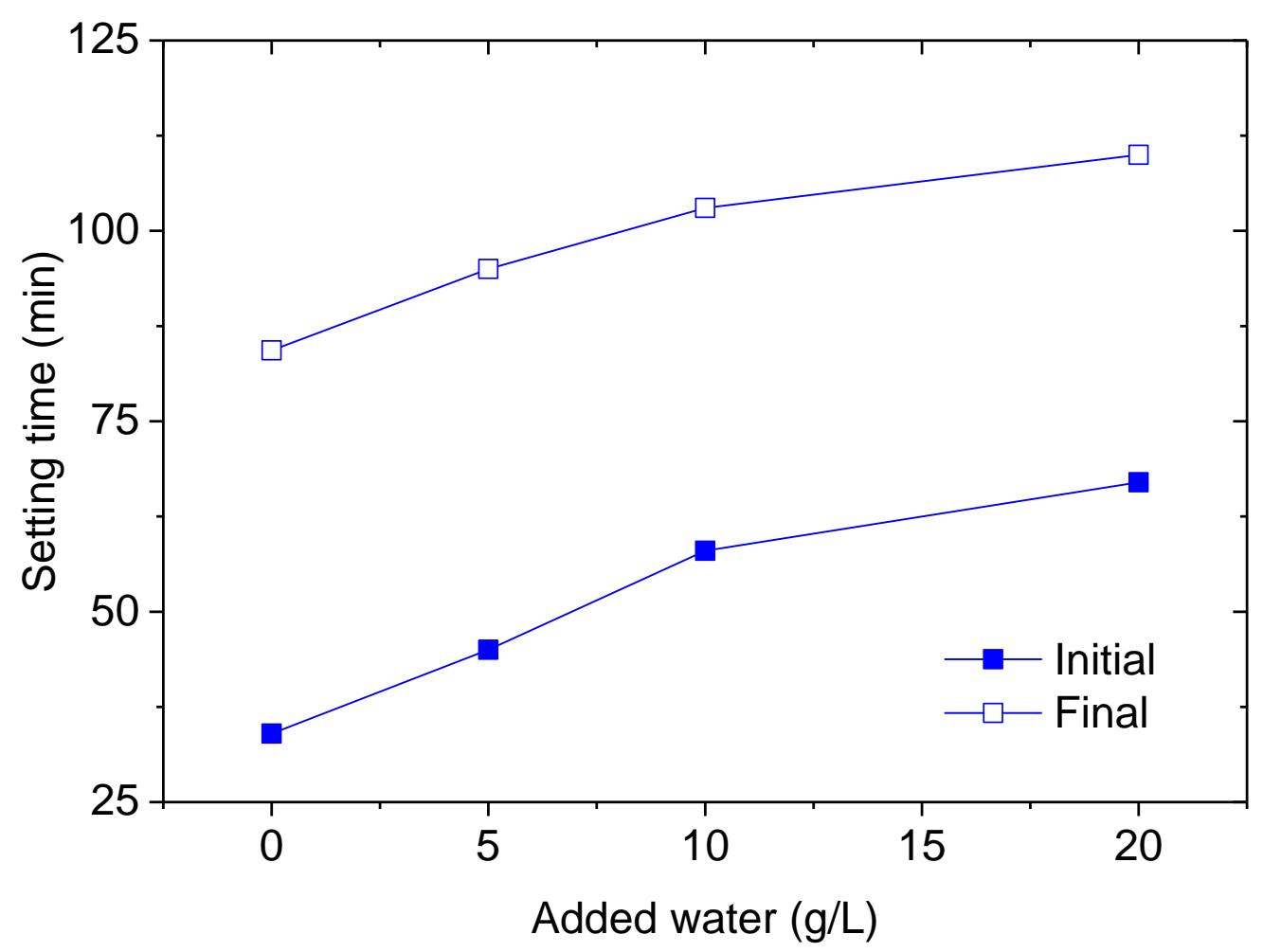

Figure VII.6. The effect of added water on the setting times.

Accordingly, when microcapsules are added to the geopolymer paste, the reduced amount of available water (Figure VII.1b) shortens the initial setting time while the increased viscosities (lower slump, Figure VII.4) and latent heat slow down the reaction rates. The initial setting times (Figure VII.5a) are a result of these competing mechanisms. The increase of the initial setting times illustrates that the viscosity and/or latent heat are the dominating effects at this stage. Since both the viscosity increase and the water adsorption are strongest for EP-EVAPCM, there is only a moderate difference in initial setting time between the two types of MPCM.

When the initial setting time is reached, the samples have started to solidify, and the effect of viscosity on further reactions is negligible for all samples. The release of reaction heat is strongest at short times, and the effect of the MPCM latent heat is probably small when the initial setting time is approached. Accordingly, at this stage the water content is the determining 
factor. Figure VII.5b shows the amount of time between the initial and final setting times $(\Delta \mathrm{ST})$. As expected, $\triangle \mathrm{ST}$ decreases with the concentration of MPCM due to the adsorption of water onto the surface of the microcapsules. This effect is strongest for PE-EVA-PCM, which has a higher water adsorption (Figure VII.1b).

The final setting times are a combination of the initial setting time and $\Delta \mathrm{ST}$. Since the water content influences the whole process while the viscosity and latent heat only affects the initial stage, the overall effect on the final setting time is dominated by the water content. Accordingly, the final setting time becomes shorter in the presence of MPCM. The dominating effect at each stage has a larger impact on PE-EVA-PCM than on St-DVB-PCM. As a result, the initial setting times are longer and the final setting times shorter for PE-EVA-PCM.

\section{VII.4. Compressive strength}

Figure VII.7 shows the compressive strength of the GPC mixture with incorporated PE-EVAPCM and St-DVB-PCM after 1, 7, 14, and 28 days curing at $20^{\circ} \mathrm{C}$. Three different percentages of both MPCMs were applied $(0 \%, 10 \%$, and $20 \%)$. The water to cement ratio of this Portland cement concrete is 0.5 which is equal to the L/GB ratio in the current proposed mix design.

As expected, the compressive strength of the proposed GPC mixture increases with curing time. In order to evaluate whether the proposed GPC mix design with incorporated MPCMs is suitable for structural purposes, the maximum compressive strength of Portland cement concrete after 28 days [10] is shown for comparison. 


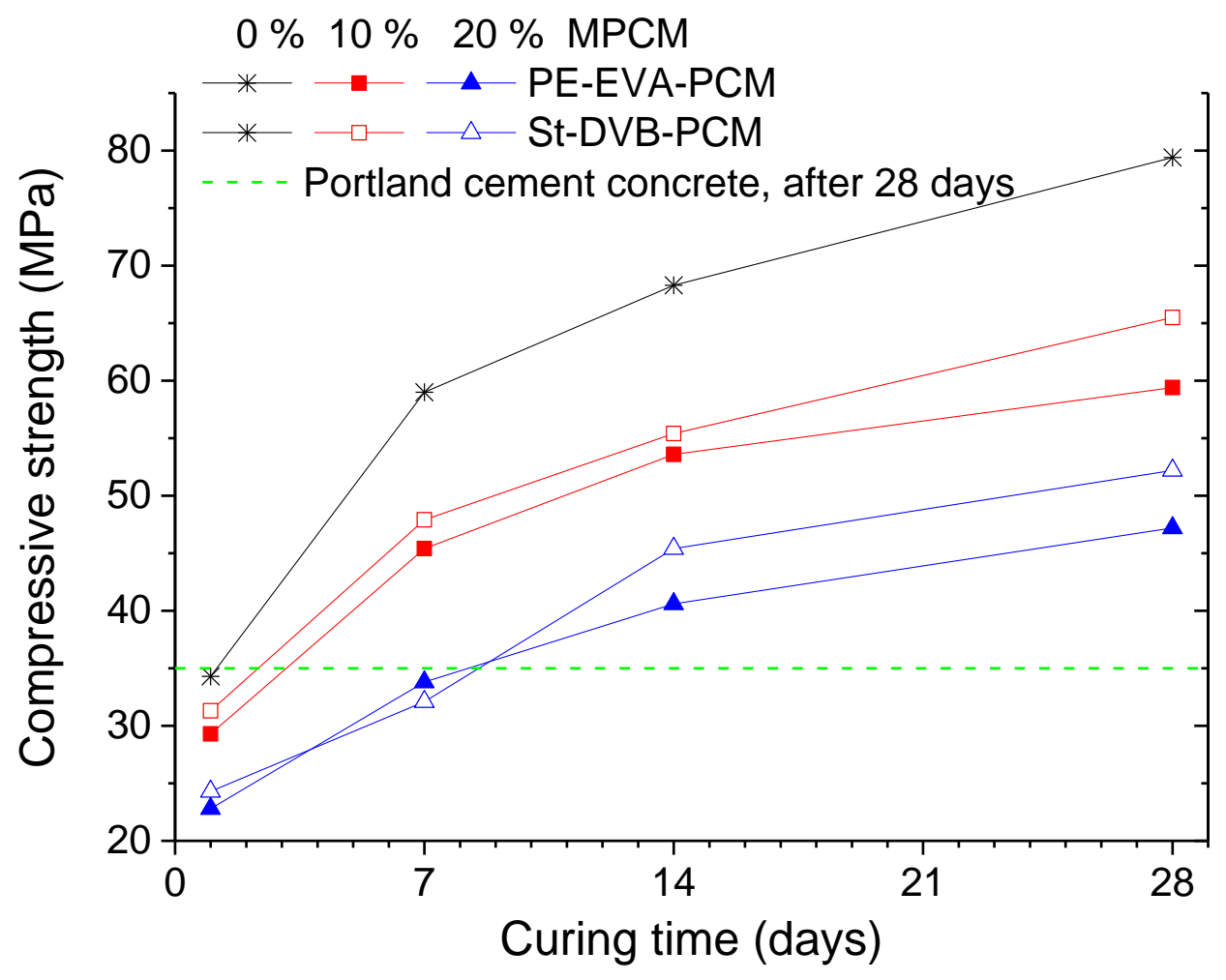

Figure VII.7. Compressive strength of GPC (cured at $20^{\circ} \mathrm{C}$ ) versus curing time when 0,10 , and $20 \%$ sand is replaced by PE-EVA-PCM or St-DVB-PCM. The green dashed line illustrates the maximum compressive strength of PCC after 28 days curing at ambient temperature [10].

The compressive strength of GPC decreases with increasing amounts of both MPCMs at all curing times (Figure VII.7). The first day strength of the proposed GPC without PCM is 34.3 $\mathrm{MPa}$, which is almost the same as for Portland cement concrete after 28 days (around $35 \mathrm{MPa}$ ). In spite of the negative effect of both PE-EVA-PCM and St-DVB-PCM on the strength of GPC, the compressive strength of GPC with 20\% MPCMs after 28 days curing is significantly higher than for Portland cement concrete. Utilizing a GGBFS in addition to fly ash contributes to this good mechanical strength [15].

Figure VII.7 also illustrates the effect of different types of MPCM on the mechanical properties of GPC. The strength of GPC containing MPCM is lower than GPC without MPCM, which is in agreement with previous findings $[103,110,125]$. This reduction of the mechanical 
properties is probably a combination of several effects. The sand is replaced by MPCM, which reduces the compressive strength due to a lower compactness and stiffness of the microcapsules compared to sand [8]. In addition, utilizing MPCM causes more air voids to be formed in the concrete matrix, which have a negative impact on the mechanical strength $[6,39]$. A poorer dispersion of small particles in the concrete can also have a negative effect on the compressive strength $[154,155]$, and air gaps between MPCM and the concrete matrix may reduce the compressive strength $[103,110]$.

The irregular shell of PE-EVA-PCM and its tendency to form agglomerates can contribute to the larger strength reduction of GPC containing with PE-EVA-PCM compared to St-DVBPCM. In addition, the lower workability of PE-EVA-PCM (Figure VII.4) might contribute to more air being trapped in these samples, thereby reducing the compressive strength. To further investigate how MPCM are affecting the microstructure of GPC, SEM analysis and X-ray micro-tomography have been conducted.

\section{VII.5. Microstructural analysis}

\section{VII.5.1. SEM imaging}

The failure surface of GPC samples with 20\% PE-EVA-PCM and St-DVB-PCM were selected for SEM analyses. Figure VII.8 shows an individual particle of PE-EVA-PCM and St-DVBPCM in the matrix as an example of MPCM diameters and the gap observed in the shellconcrete matrix transition zone. As can be seen from Figure VII.8, there are smaller gaps between St-DVB-PCM and the GPC matrix than for PE-EVA-PCM. This might contribute to the lower compressive strength of GPC containing PE-EVA-PCM (Figure VII.7). However, it 
should be noted that one microcapsule and its surrounded matrix may not be representative of the whole sample.
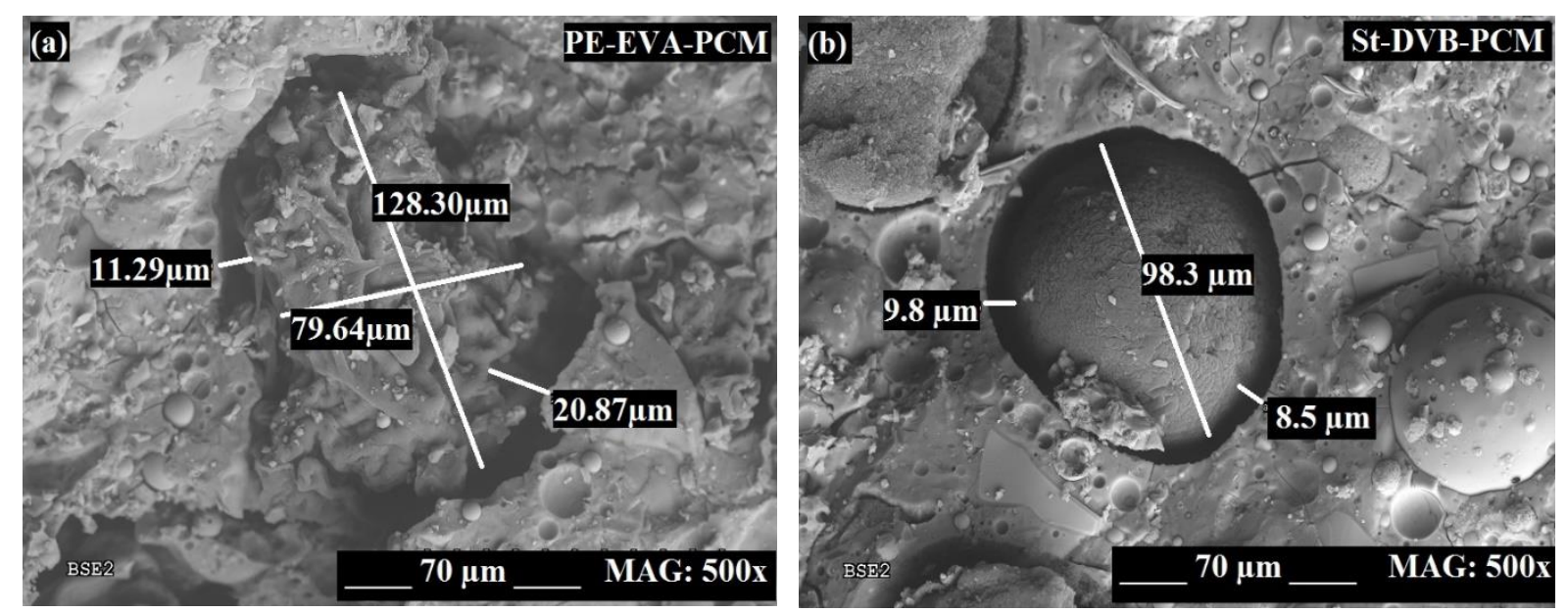

Figure VII.8. SEM images of the fracture surface of GPC with incorporated 20\% (a) PE-EVAPCM, (b) St-DVB-PCM.

Figure VII.9a and b show how the MPCMs are distributed in the concrete matrix. For St-DVBPCM, every particle is visible while for PE-EVA-PCM, large agglomerates are observed. Figure VII.9c and d show the single microcapsules after the compressive strength test (at the failure surface of the GPC). The shell of the microcapsules can be broken during the compressive strength measurements, which might be a contributing factor to the reduced compressive strength (Figure VII.7). This is illustrated in Figure VII.9d, where the St-DVBPCM capsule is clearly broken. Unfortunately, due to the irregular shell of PE-EVA-PCM, a broken shell cannot be easily distinguished from an undamaged shell. However, the line indicated by the arrow in Figure VII.9c might be a rupture on the PE-EVA-PCM shell. 

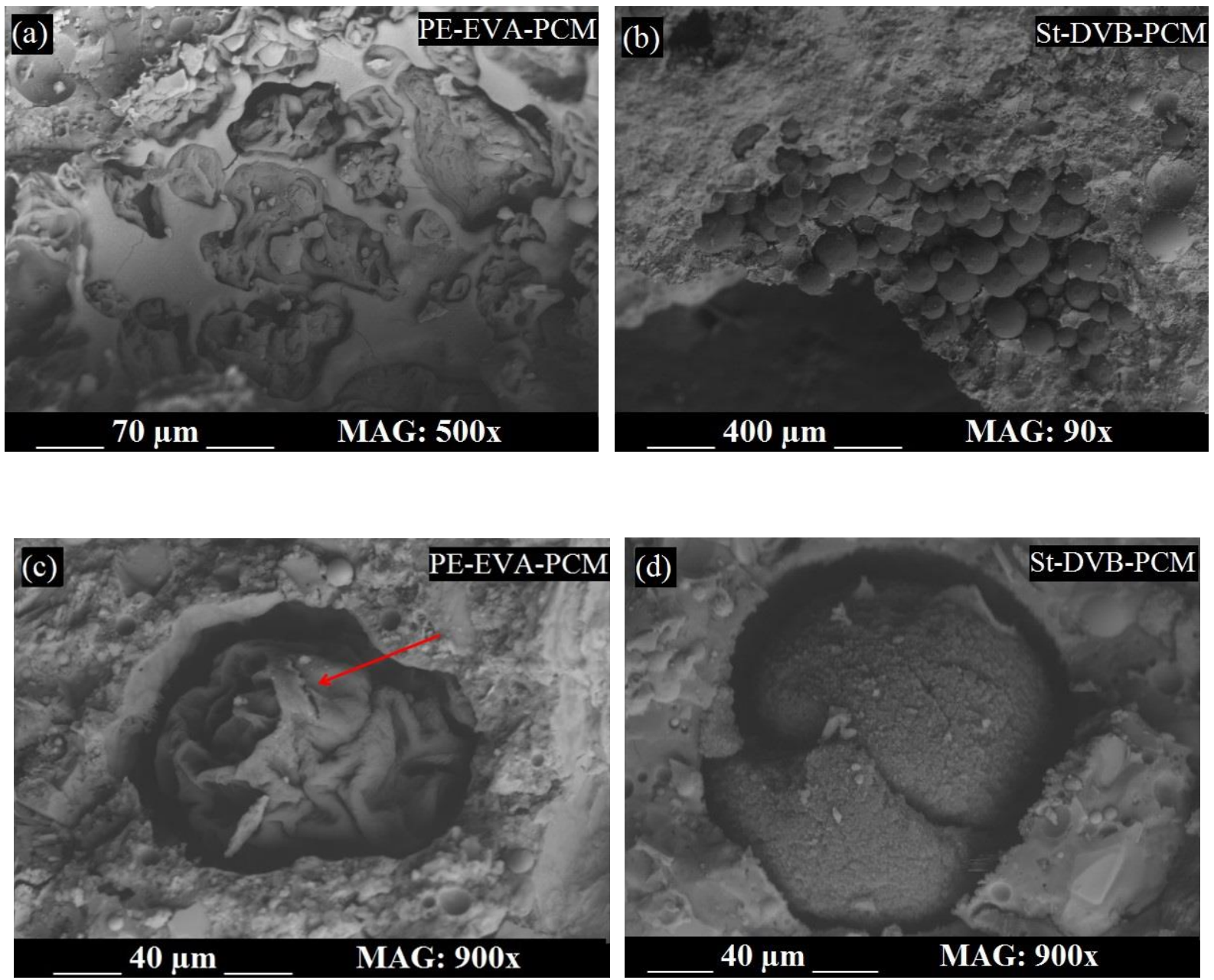

Figure VII.9. SEM images of the GPC matrix including agglomeration of (a) PE-EVA-PCM, (b) St-DVB-PCM, (c) shell of PE-EVA-PCM the arrow shows a possible rupture of the shell, and (d) damaged shell of St-DVB-PCM.

\section{VII.5.2. X-ray micro-tomography}

Typical 2D X-ray micro-tomography cross-sectional slices obtained from GPC, without and with 20\% PE-EVA-PCM and St-DVB-PCM, are shown in Figure VII.10. Due to the low X-ray attenuation of organic materials it is difficult to distinguish the microcapsules from air voids based on grey scale values. PE-EVA-PCM has an irregular shape which makes it possible to distinguish them from the spherical air voids. However, it is difficult to distinguish the nearly spherical St-DVB-PCM from the air voids. The large and relatively homogenous areas in Figure 
VII.10 are the gravel, which is surrounded by the GPC matrix where the MPCM and air voids are evident as black spots. Comparing the non-gravel parts of the concrete matrix, PE-EVAPCM seems to be riddled with more black areas than St-DVB-PCM, suggesting that PE-EVAPCM contains more air voids. This is probably a contributing factor to the lower compressive strength of PE-EVA-PCM (Figure VII.7). The higher amounts of air voids might be due to the poorer workability (Figure VII.4), which can cause air to be trapped within the concrete matrix.

3D volume rendering of GPC with PE-EVA-PCM and St-DVB-PCM are displayed in Figure VII.11. The irregular agglomerates of PE-EVA-PCM are also evident in Figure VII.11a. As discussed above, the presence of large agglomerates and a lower stiffness of the microcapsules might influence the properties of GPC.

Size distributions based on image analysis of the 3D X-ray-tomography are shown in Figure VII.12. As discussed above, it is difficult to distinguish the microcapsules and the air voids from each other, and accordingly the size distributions in Figure VII.12 are a combination of microcapsules and air. There are no significant differences between the two samples. The size distributions of the pure microcapsules are added to Figure VII.12b to show the absolute contribution of MPCM to the total porosity, which is computed by $\mu$-CT. Interestingly, the sizes measured inside the GPC matrix are much smaller than the pure microcapsules. This might be due to a disruption of agglomerates into smaller entities (caused by shear forces during the mixing process), or that the volume fractions are dominated by small air voids. 

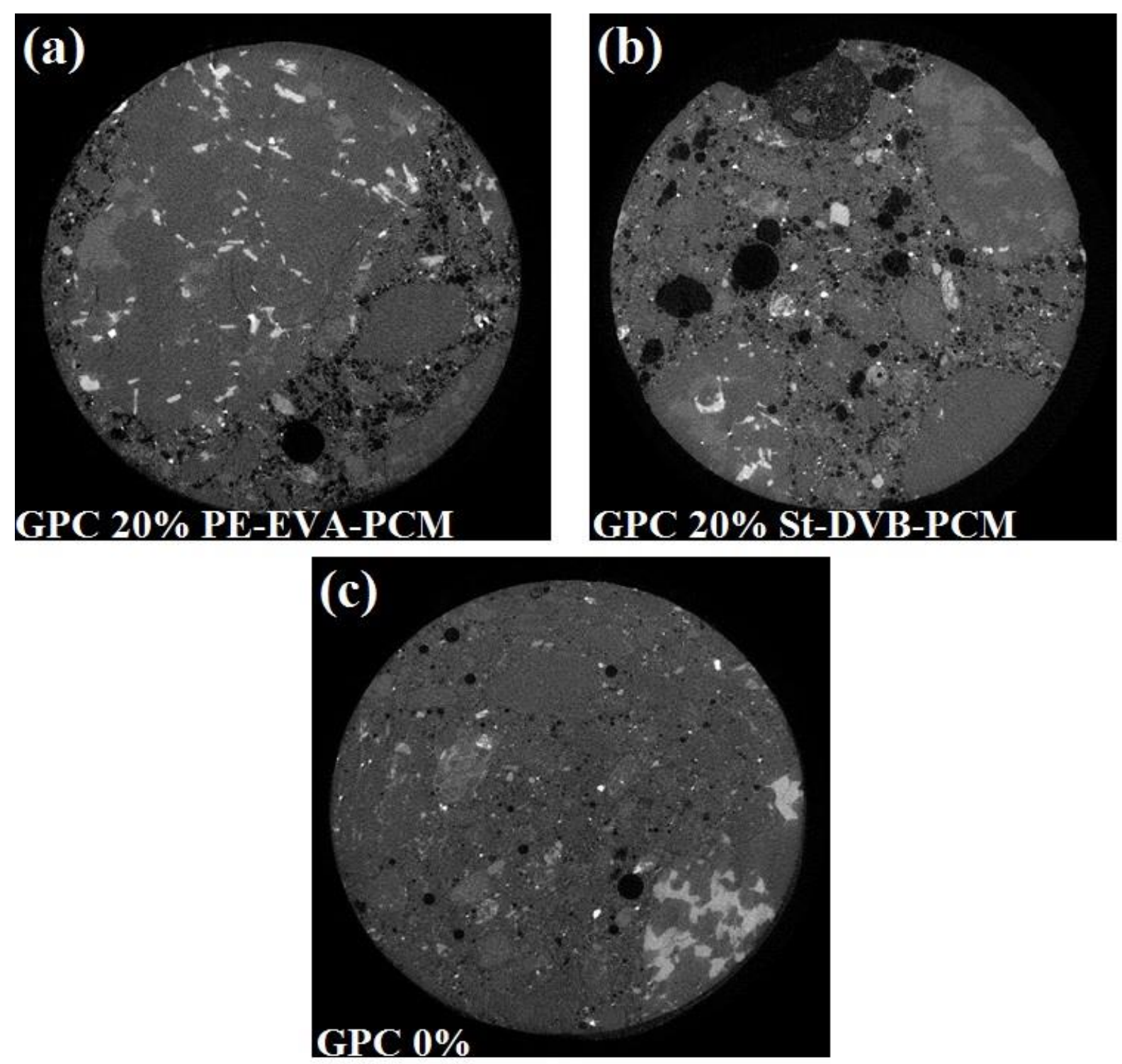

Figure VII.10. X-ray-tomography images of (a) GPC with 20\% PE-EVA-PCM, (b) GPC with 20\% St-DVB-PCM and (c) GPC without MPCM. Dark colors correspond to low or no absorption of X-rays (e.g. air bubbles or microcapsules) and bright colors represent high absorption of X-rays (sand and gravel). The field of view is approximately $1 \mathrm{~cm}$. 

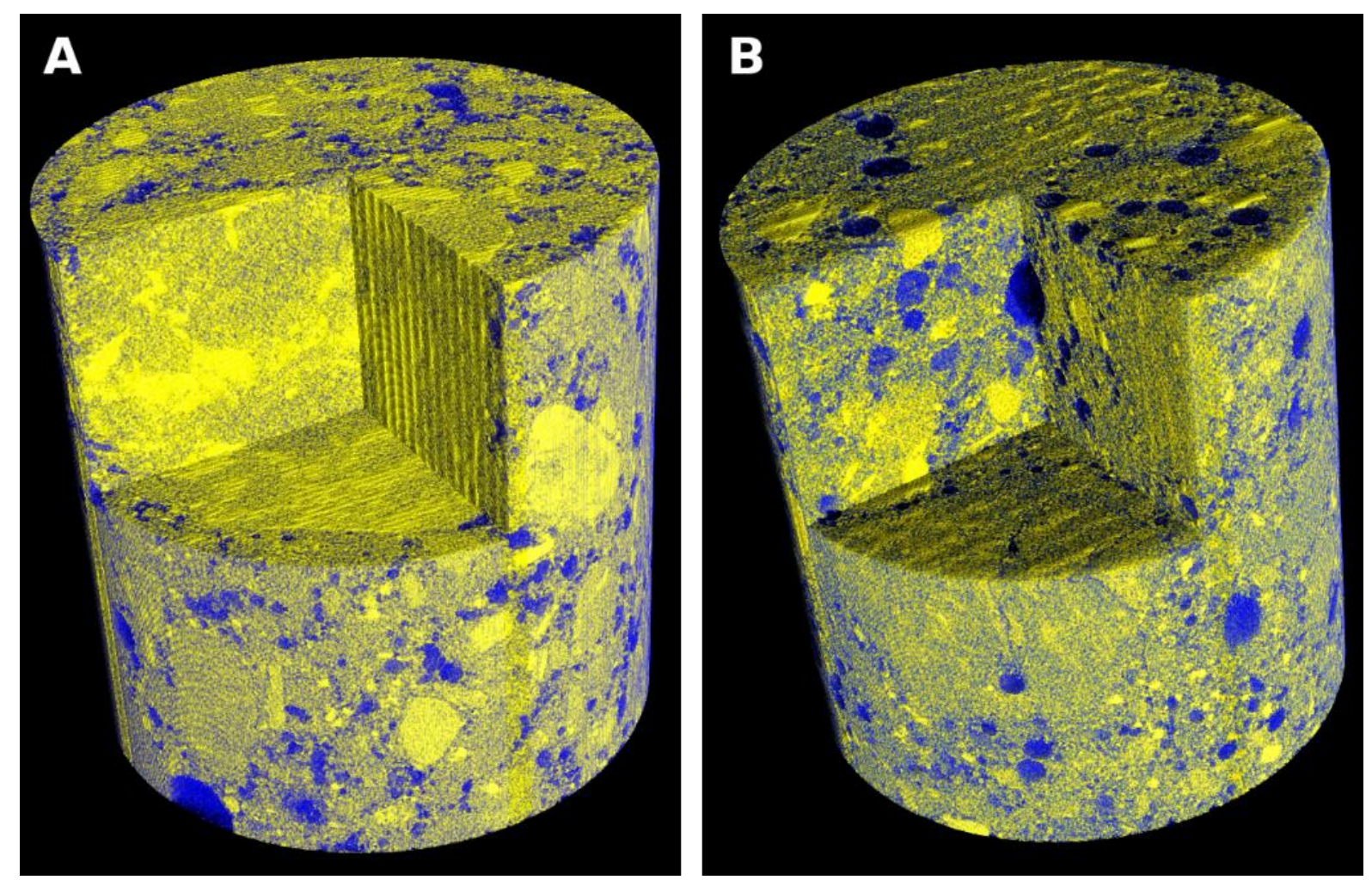

Figure VII.11. False-color 3D volume rendering of GPC cylindrical drill cores including A:

PE-EVA-PCM, B: St-DVB-PCM. The MPCMs and air voids are displayed in blue. 


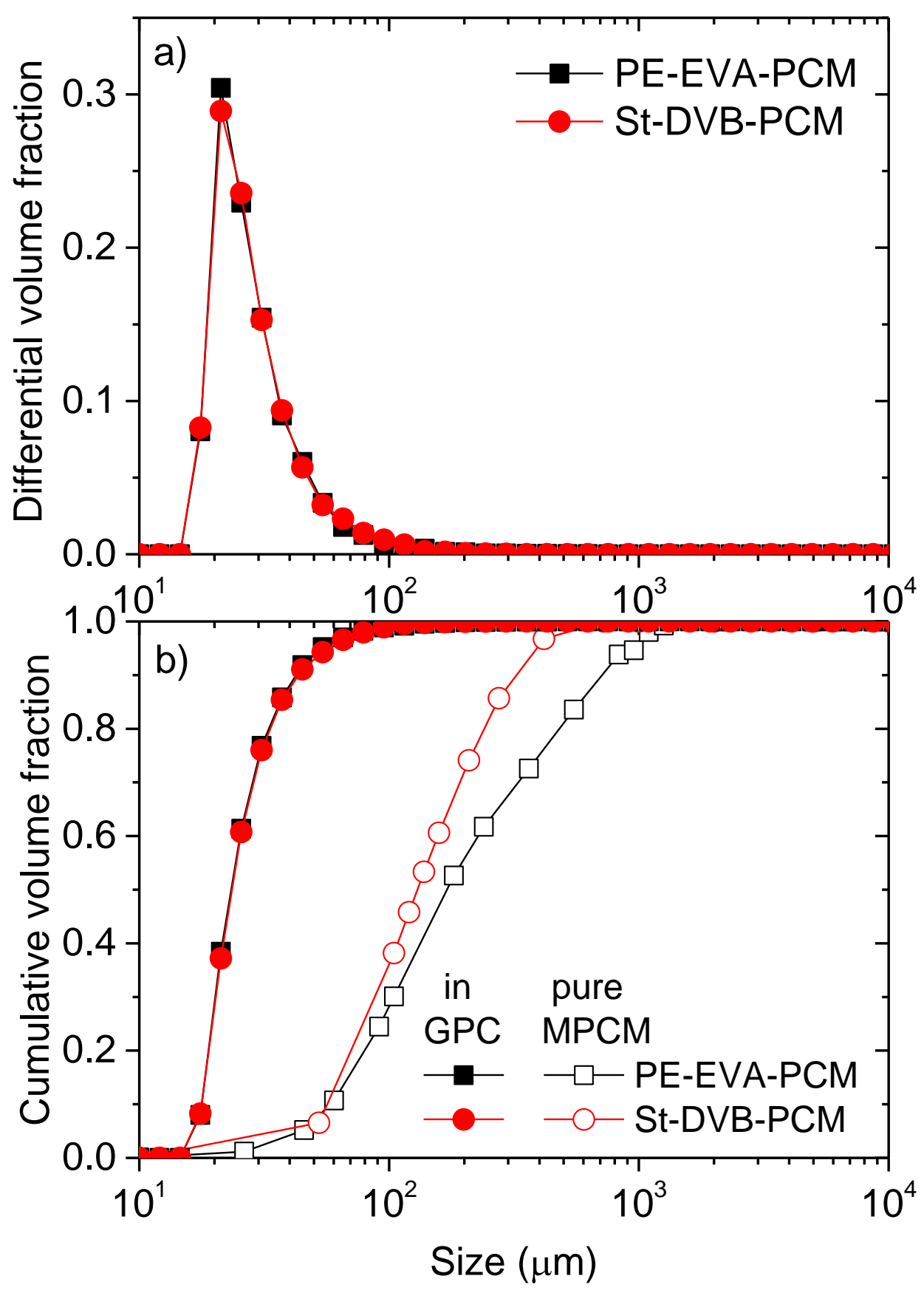

Figure VII.12. Differential (a) and cumulative (b) size distributions of MPCM and air voids inside the GPC samples, obtained from image analyses of the X-ray-tomography images. The cumulative size distributions of the pure microcapsules are shown for comparison. 


\section{Chapter VIII.}

Effect of freeze-thaw cycles on the physical and mechanical behaviors of geopolymer concrete and Portland cement concrete containing different types of micro-encapsulated phase change materials. 

Tables summarizing the results of this chapter are presented in Appendix A.5.

\section{VIII.1. Structural and microstructural study}

\section{VIII.1.1. Apparent structure}

To illustrate the effect of freeze-thaw cycle on the apparet structure of GPC and PCC containing PE-EVA-PCM and St-DVB-PCM, pictures of samples after 0 and 28 cycles are taken. Freezethaw cycles may erode the concrete. Figure VIII.1 illustrates that the MPCM is more visible on the surface of the samples after exposing to the freeze-thaw cycles. This might be due to the soft nature of the microcapsules and their poor connection to the concrete matrix, which can cause the MPCM to be easily eroded from the surface of concrete during severe conditions. In addition, MPCM can weaken the concrete structure, which might render it less resistant to freeze-thaw erosion. This might affect the concrete mass loss and the strength reduction after repeated freeze-thaw cycles.
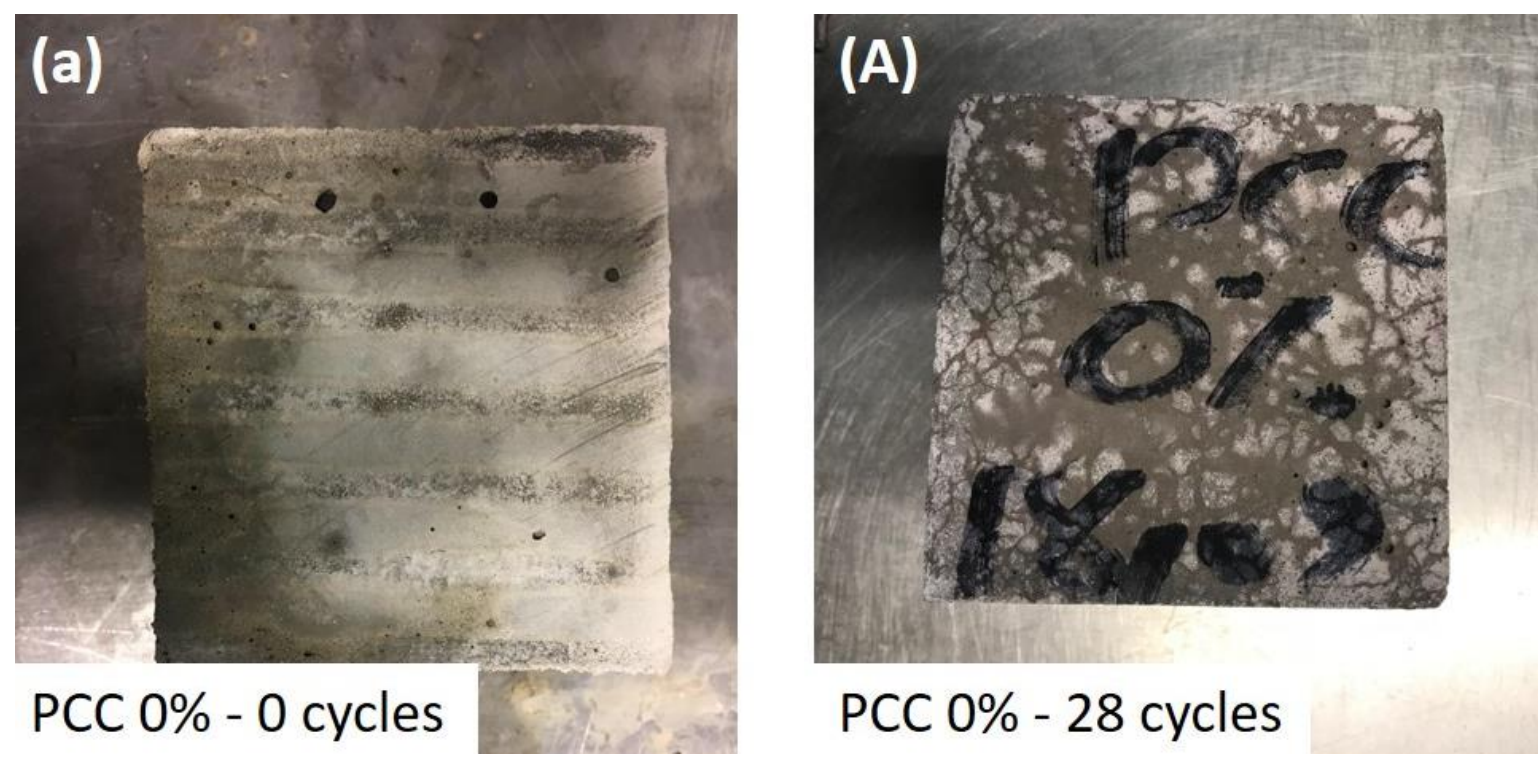


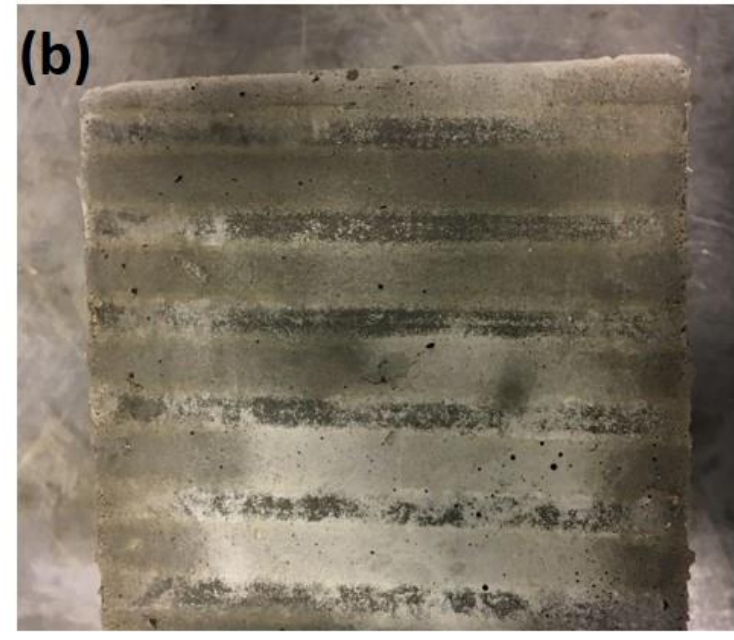

PCC $20 \%$ St-DVB-PCM - 0 cycles

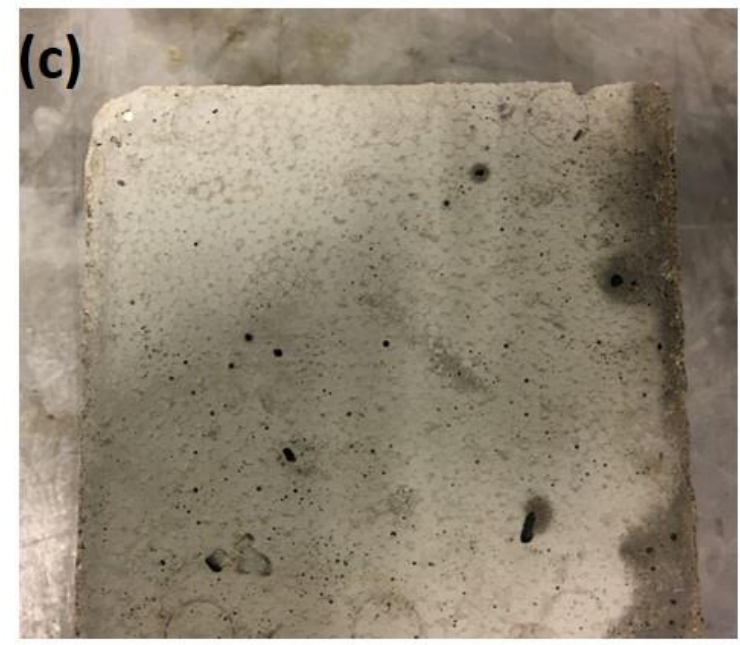

PCC $20 \%$ St-DVB-PCM - 0 cycles

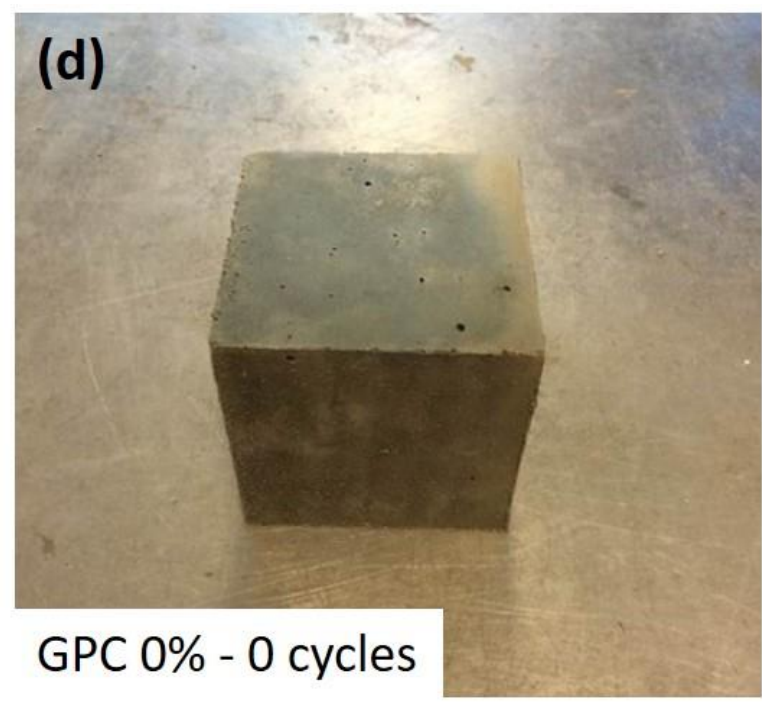

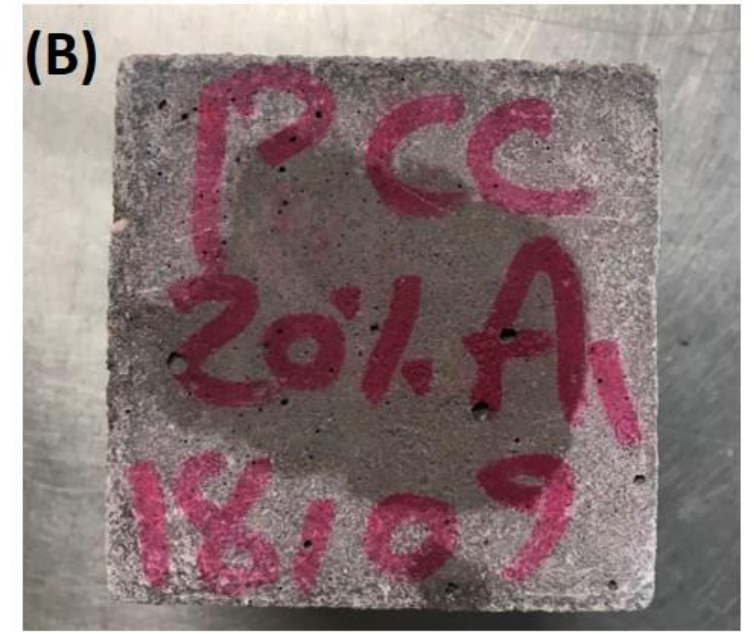

PCC $20 \%$ St-DVB-PCM - 28 cycles

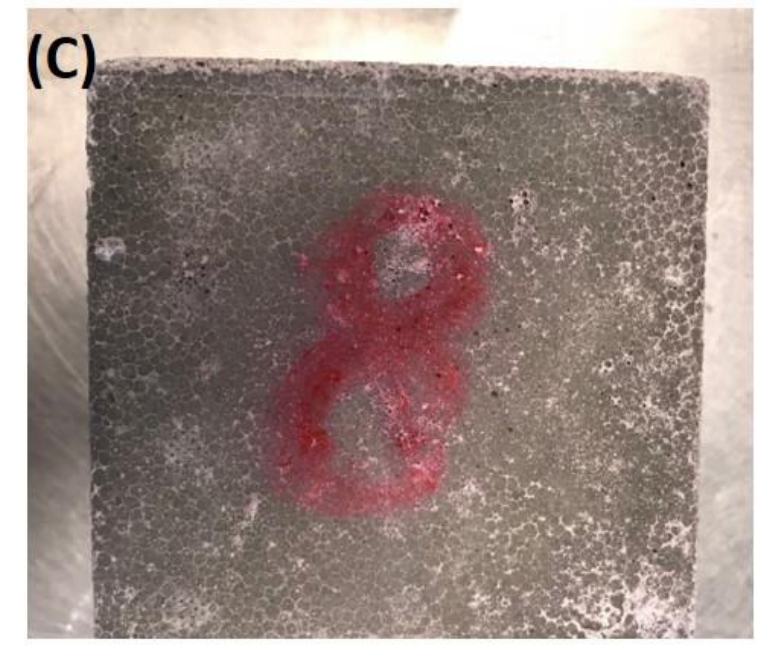

PCC $20 \%$ St-DVB-PCM - 28 cycles

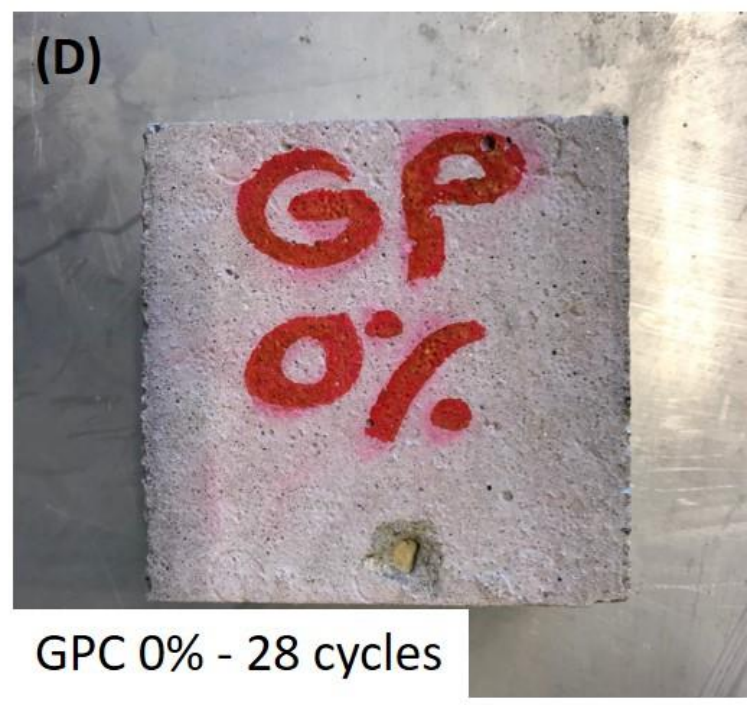




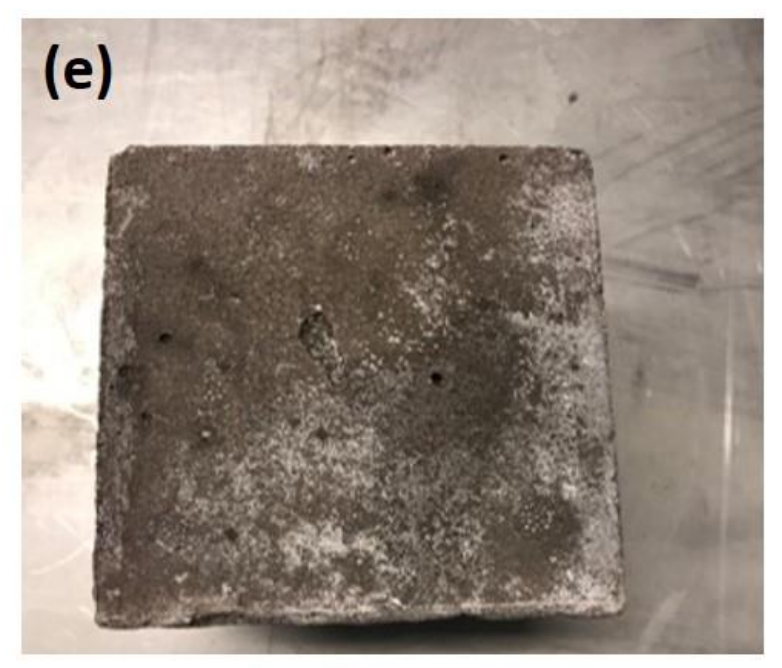

GPC 20\%PE-EVA-PCM - 0 cycles

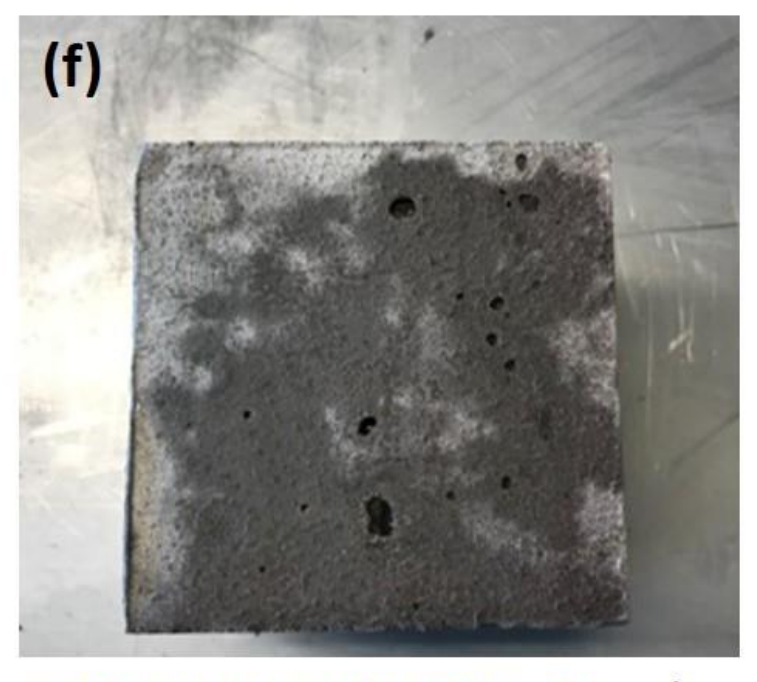

GPC 20\%St-DVB-PCM - 0 cycles

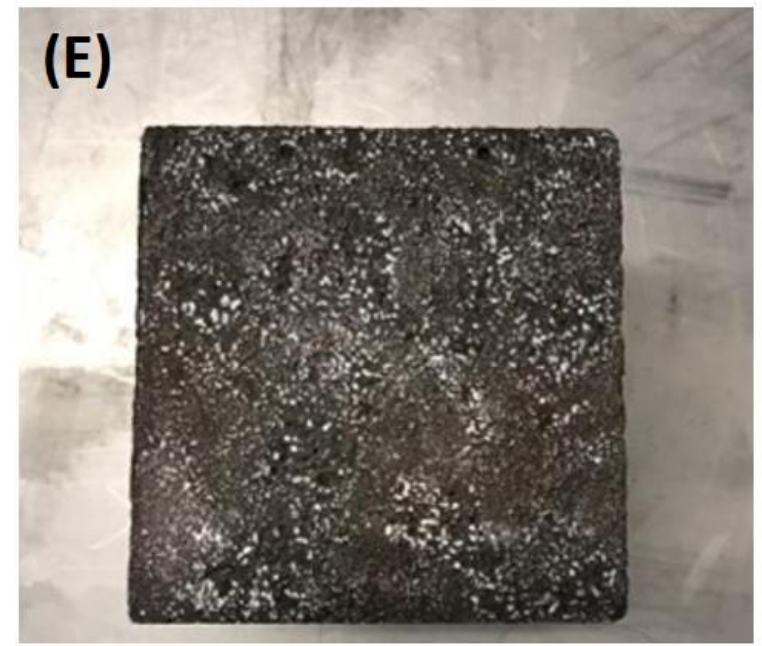

GPC 20\%PE-EVA-PCM - 28 cycles

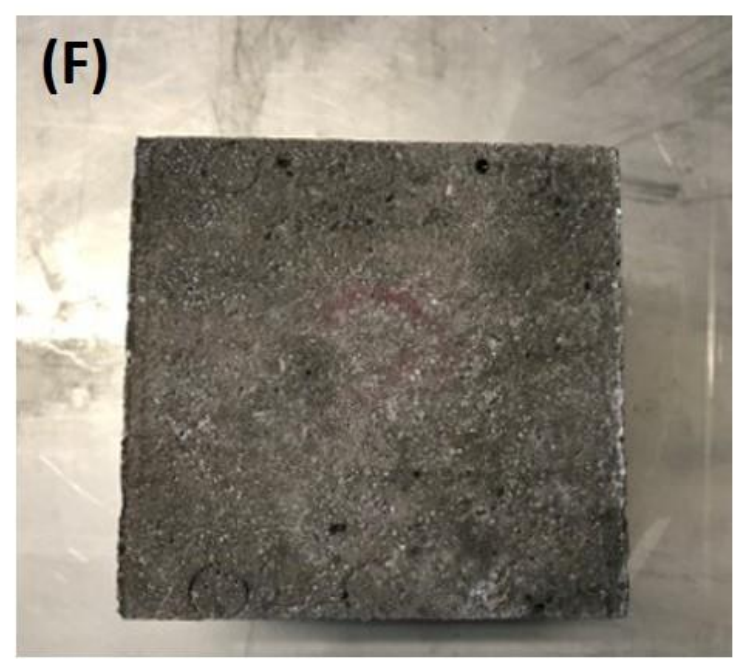

GPC 20\%St-DVB-PCM - 28 cycles

Figure VIII.1. Illustrative pictures of the structure of (a) PCC 0\%- 0 cycles, (A) PCC 0\%- 28 cycles, (b) PCC 20\% PE-EVA-PCM - 0 cycles, (B) PCC 20\% PE-EVA-PCM, (c) PCC 20\% StDVB-PCM - 0 cycles, and (C) PCC 20\% St-DVB-PCM - 28 cycles, (D) GPC 0\% - 0 cycles, (d) GPC 0\% - 28 cycles, (E) GPC 20\% PE-EVA-PCM - 0 cycles, (e) GPC 20\% PE-EVA-PCM, (F) GPC 20\% St-DVB-PCM - 0 cycles, and (f) GPC 20\% St-DVB-PCM after 28 freeze-thaw cycles. 
For PCC without MPCM, visible cracks appeared on the concrete surface after 28 freeze-thaw cycles. However, for PCC containing MPCM, the surface of samples seems more uniform and undamaged. This suggests that the MPCM can prevent and reduce concrete deterioration in comparison with specimens without MPCM.

\section{VIII.1.2. SEM imaging}

Microscopical structure chracterization of GPC and PCC containing PE-EVA-PCM and StDVB-PCM after 0 and 28 freeze-thaw cycles were performed by SEM and X-ray tomography imaging. Figure VIII.2 exhibits SEM images of the samples before and after 28 freeze-thaw cycles. In Figure VIII.3 the samples containing microcapsules subjected to 28 freeze-thaw cycles are displayed at a higher maginfication. For both GPC and PCC there are visible gaps between the microcapsules and the concrete matrix (Figure VIII.2B, b, C, c, E, e, F, f), illustrating that the bonds between the concrete and MPCM are poor. This might affect the concrete mass loss and the strength reduction after repeated freeze-thaw cycles. The shellconcrete matrix transition zone depends on the microcapsule shell [110]. Accordingly, GPC and PCC containing different types of MPCMs can exhibit different durability and strength. From Figure VIII.2a it is evident that ettringite crystals are formed in PCC as one of the hydration products during the freeze-thaw cycles. Figure VIII.3a and $2 \mathrm{c}$ shows that in the presence of microcapsules, ettringite crystalls form in the gap between the microcapsules and the concrete matirx. The formation of ettringite crystals is expected to reduce the compressive strength of PCC by expansion and an increase of solid volume [156, 157].

Figure VIII.2d shows the SEM images of GPC, where microcracks are formed after the freeze thaw cycles. In addition, it is evident that microcrackes are present after the freeze thaw cycles in all the samples containing PCM (see Figure VIII.2b, c, e, f). This might contribute to the concrete deterioration. 


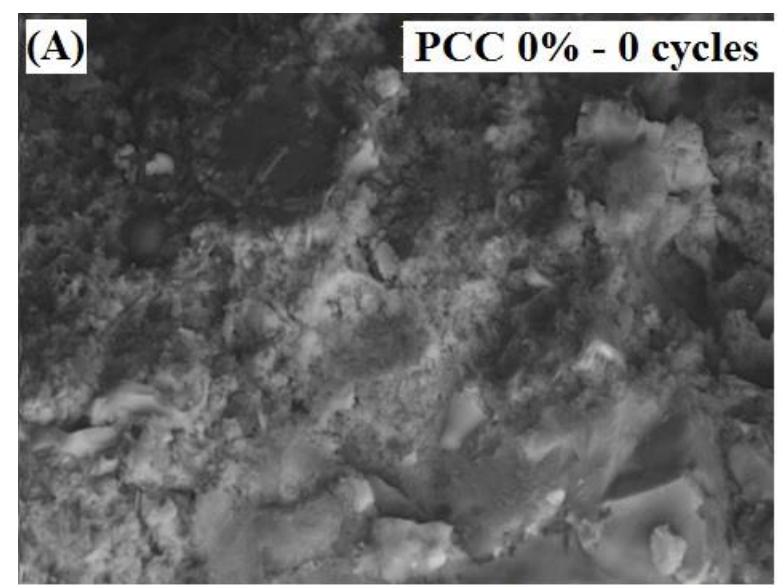

$20 \mu \mathrm{m}$

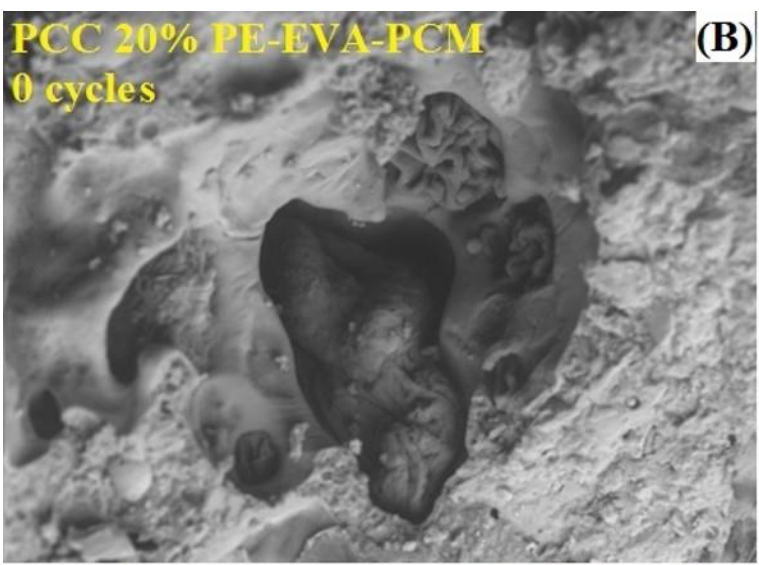

$70 \mu \mathrm{m}$

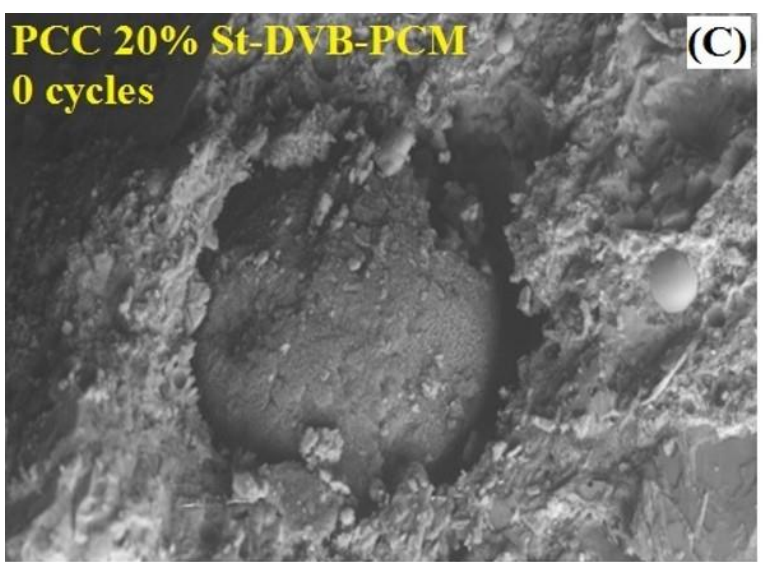

$70 \mu \mathrm{m}$
MAG: 500x

MAG: 500x

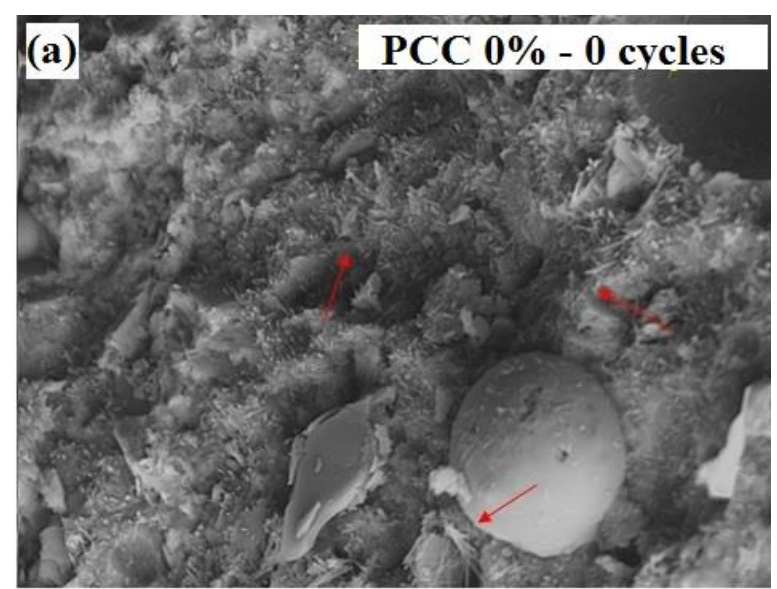

$20 \mu \mathrm{m}$

MAG: 2000x

(b)

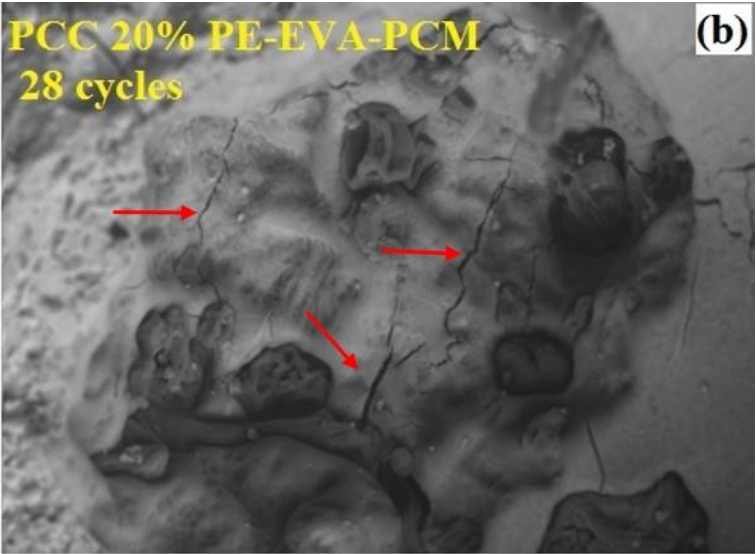

$70 \mu \mathrm{m}$

MAG: 500x

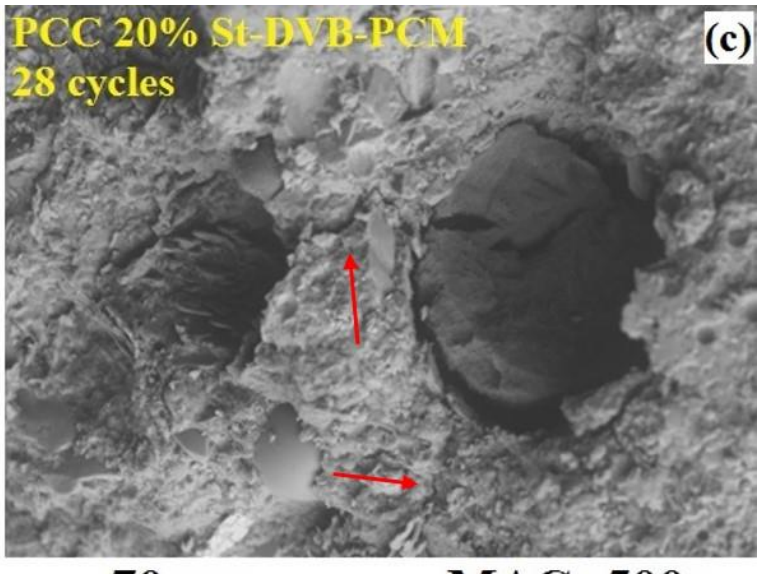

$70 \mu \mathrm{m}$

MAG: 500x 


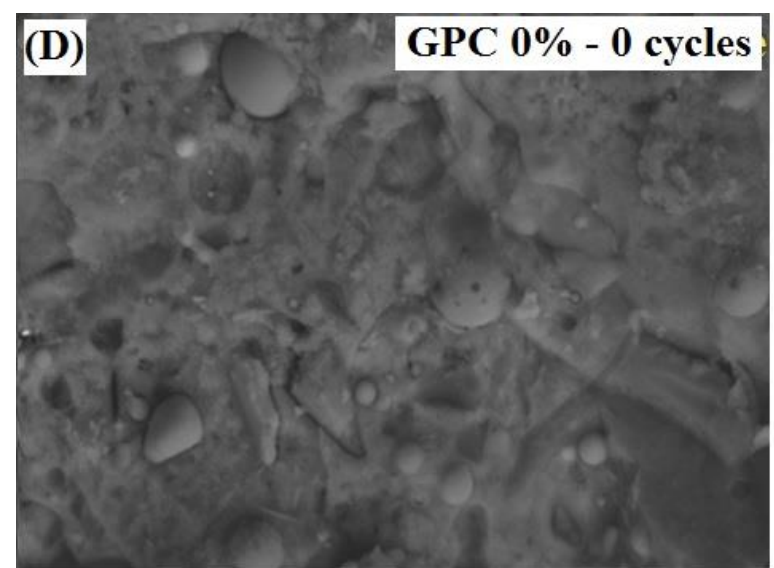

$20 \mu \mathrm{m}$

GPC 20\% PE-EVA-PCM

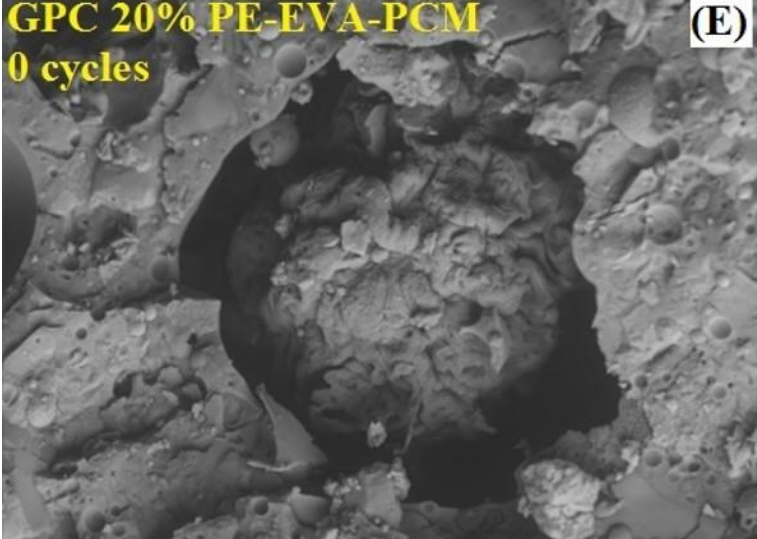

$70 \mu \mathrm{m}$

MAG: 500x

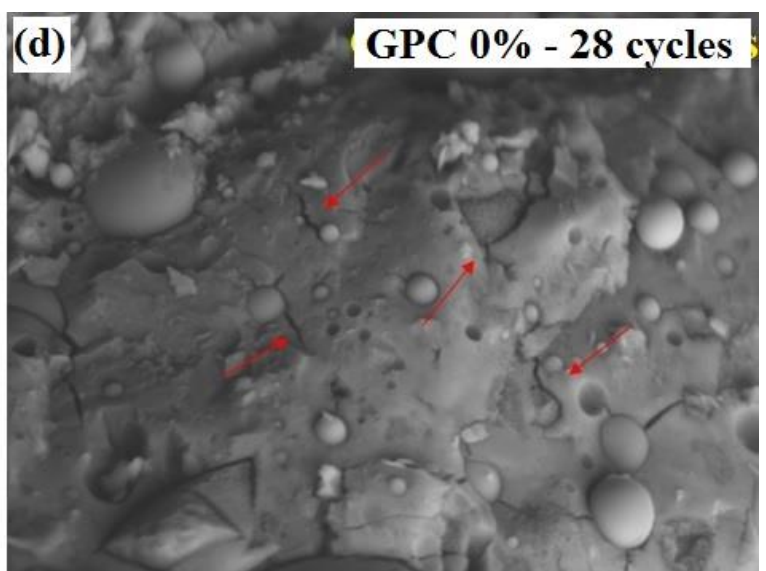

$20 \mu \mathrm{m}$

MAG: 2000x

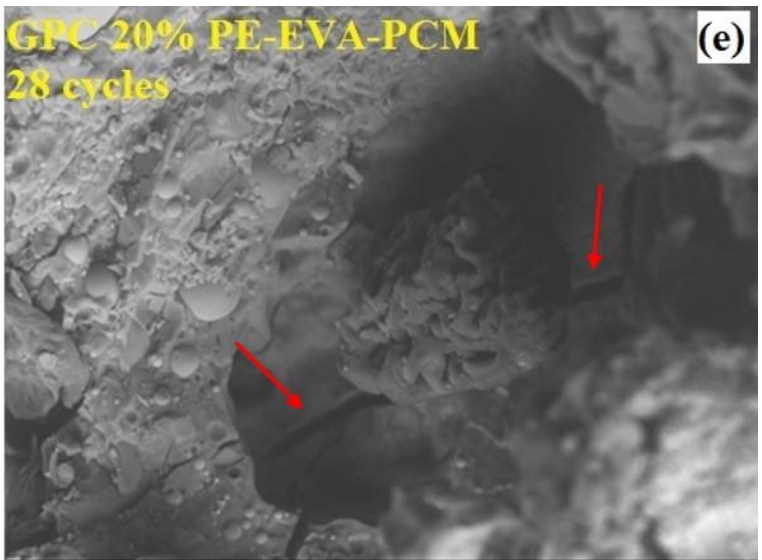

$70 \mu \mathrm{m}$

MAG: 500x 


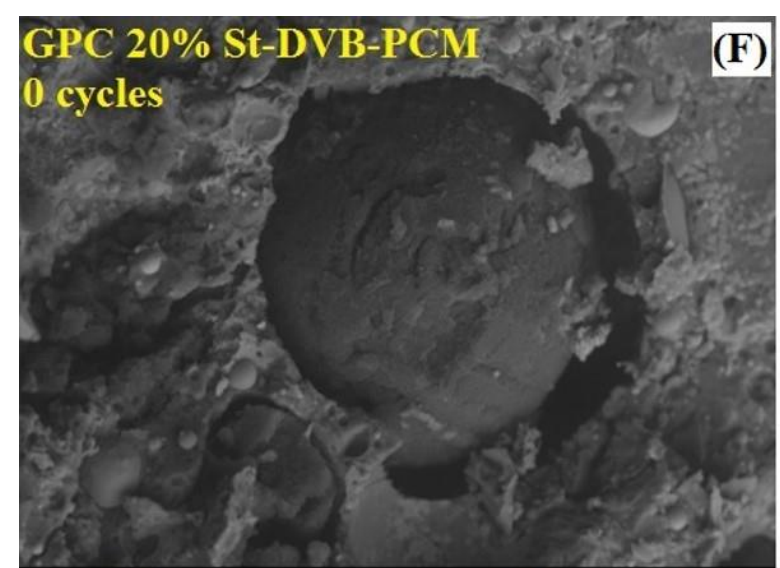

$70 \mu \mathrm{m}$
MAG: 500x

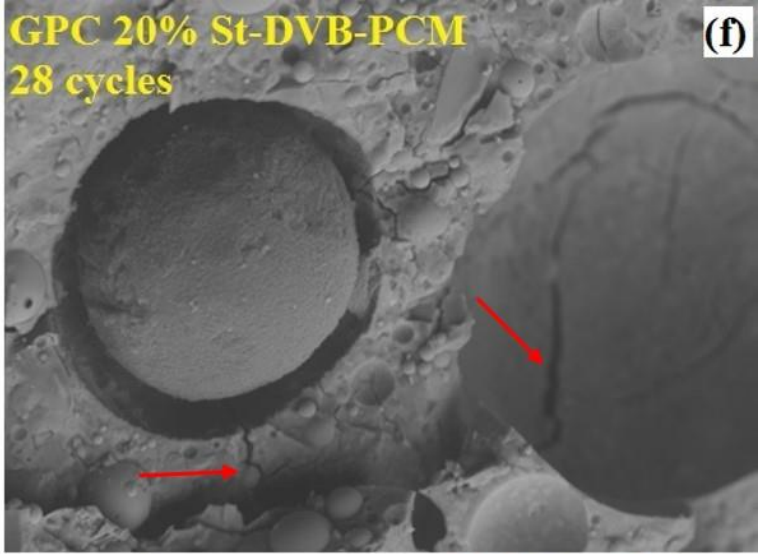

$70 \mu \mathrm{m}$
MAG: 500x

Figure VIII.2. SEM images of the fracture surface of (A) PCC $0 \%-0$ cycles, (a) PCC $0 \%-28$ cycles (the arrows show ettringite crystals), (B) PCC 20\% PE-EVA-PCM - 0 cycles, (b) PCC 20\% PE-EVA-PCM - 28 cycles (the arrows show microcracks in the matrix), (C) PCC 20\% StDVB-PCM - 0 cycles (c) PCC 20\% St-DVB-PCM - 28 cycles (the arrows show microcracks in the matrix), (D) GPC 0\% - 0 cycles, (d) GPC $0 \%-28$ cycles (the arrows show microcracks in the matrix), (E) GPC 20\% PE-EVA-PCM - 0 cycles, (e) GPC 20\% PE-EVA-PCM (the arrows show microcracks in the matrix), (F) GPC $20 \%$ St-DVB-PCM - 0 cycles, and(f) GPC $20 \%$ StDVB-PCM after 28 freeze-thaw cycles (the arrows show microcracks in the matrix). 


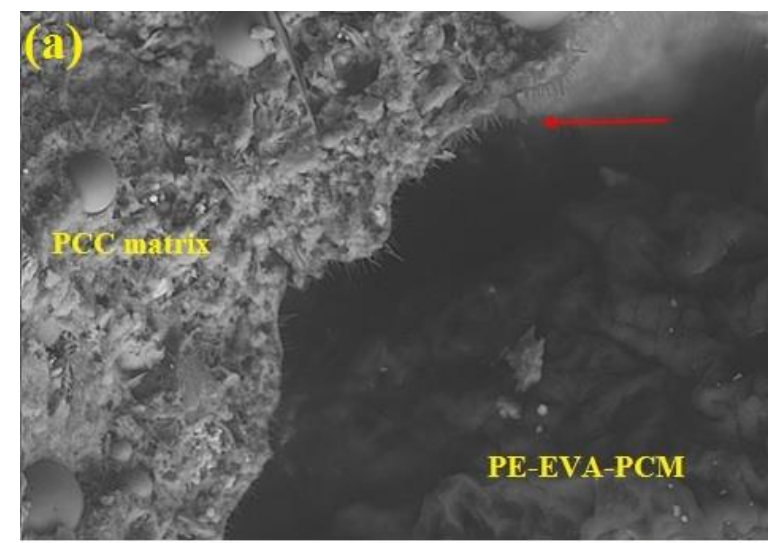

PCC 20\% PE-EVA-PCM $30 \mu \mathrm{m}$

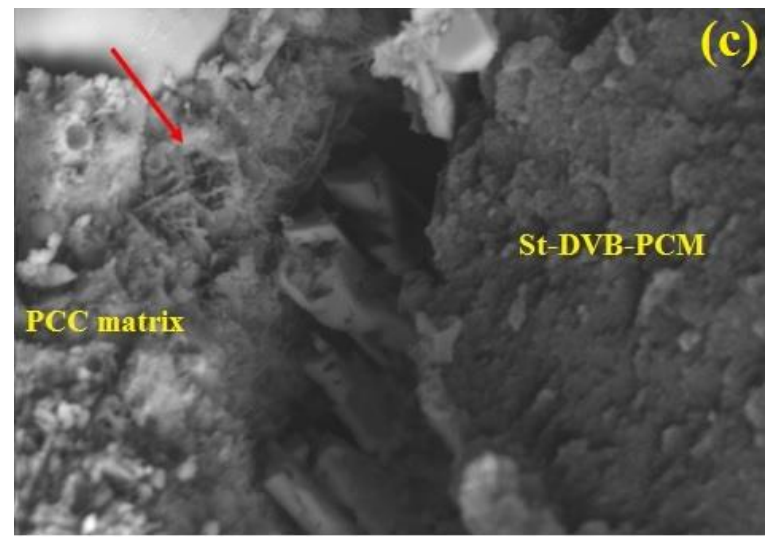

PCC 20\% St-DVB-PCM $20 \mu \mathrm{m}$
28 cycles

MAG: 2000x
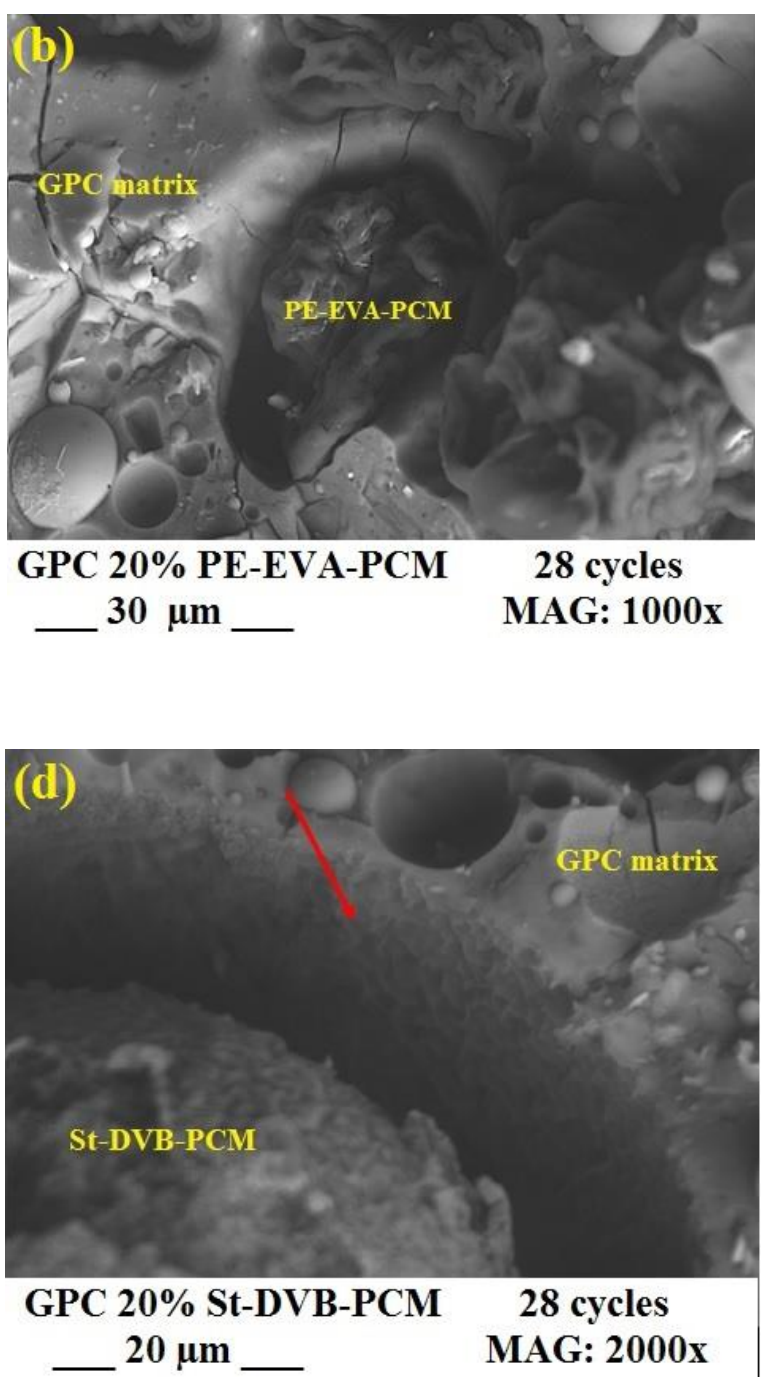

Figure VIII.3. SEM images of (a) the PCC matrix and PE-EVA-PCM, the arrow shows ettingite and crystalized structures located in the gap between matrix and MPCM. (b) the GPC matrix and PE-EVA-PCM, the weak interfacial transition zone is visible (c) the PCC matrix and StDVB-PCM, the arrow shows crystalized products located in the gap between matrix and MPCM. (d) the GPC matrix and St-DVB-PCM, the arrow shows the trace of microcapsule shell on the gap between MPCM and the concrete matrix.

\section{VIII.1.3. X-ray micro-tomography}

Typical 2D X-ray micro-tomography cross-sectional slices obtained from PCC and GPC without MPCMs are shown in Figure VIII.4. In these images, bright colors are associated with 
components with high X-ray attenuation such as sand and gravel, whereas components with low or no X-ray attenuation (air voids and MPCM) are displayed in dark colors. The field of view is approximately $1 \mathrm{~cm}$. Figure VIII.4A, a, D and d show the microstructural changes of PCC and GPC without MPCMs before and after exposure to freeze-thaw cycles, respectively. After the freeze-thaw cycles, microcracks are evident in the PCC matrix (Figure VIII.4a) and at the interfacial transition zone between geopolymer paste and the gravel (Figure VIII.4d, e, f). This indicates that the generated microcracks provoked by freeze-thaw cycles are contributing to the damage and deterioration of PCC and GPC. Interestingly, microcracks are not observed between the PCC paste and the aggregates in the presence of the MPCM after the freeze-thaw cycles (Figure VIII.4b, c). This illustrates that stronger bonds are formed between the PCC paste and the aggregates than for GPC where microcracks are evident (Figure VIII.4d, e, f).
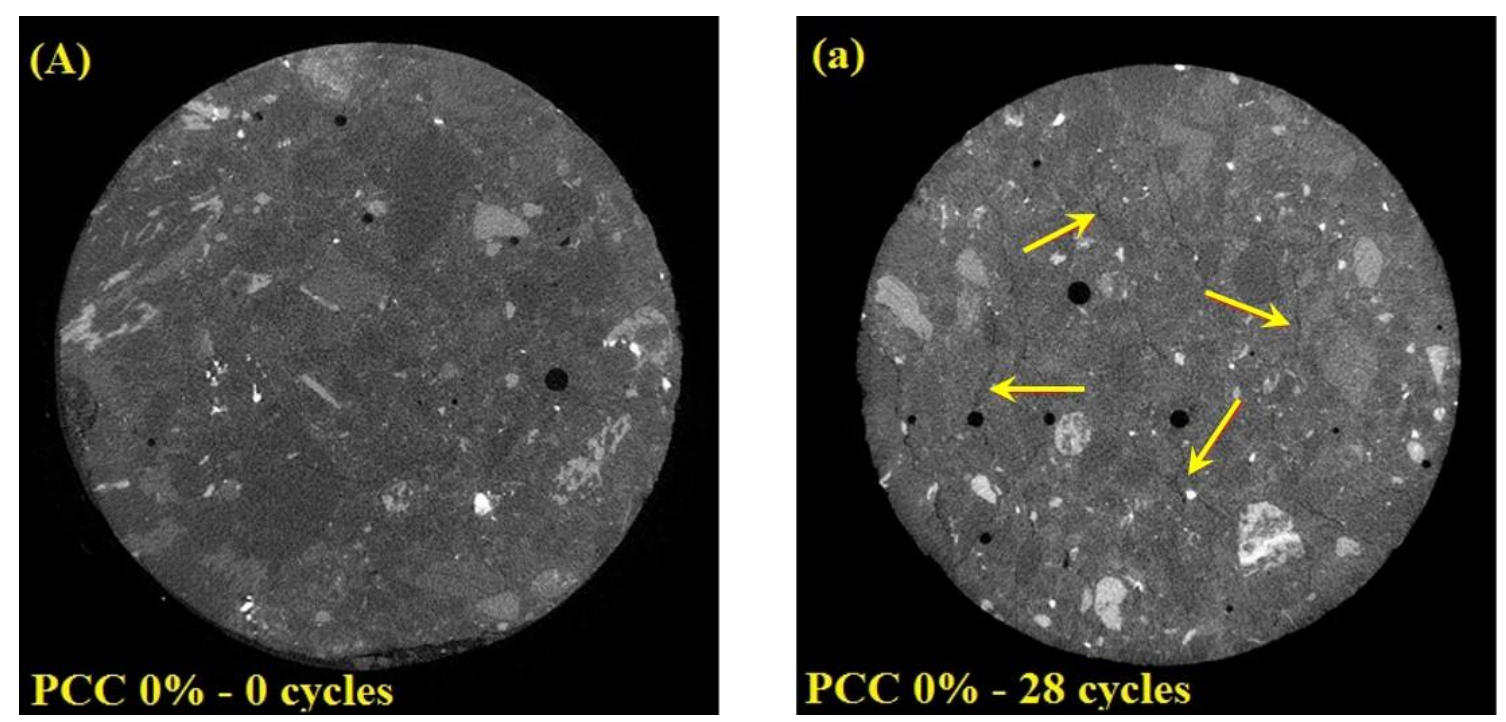

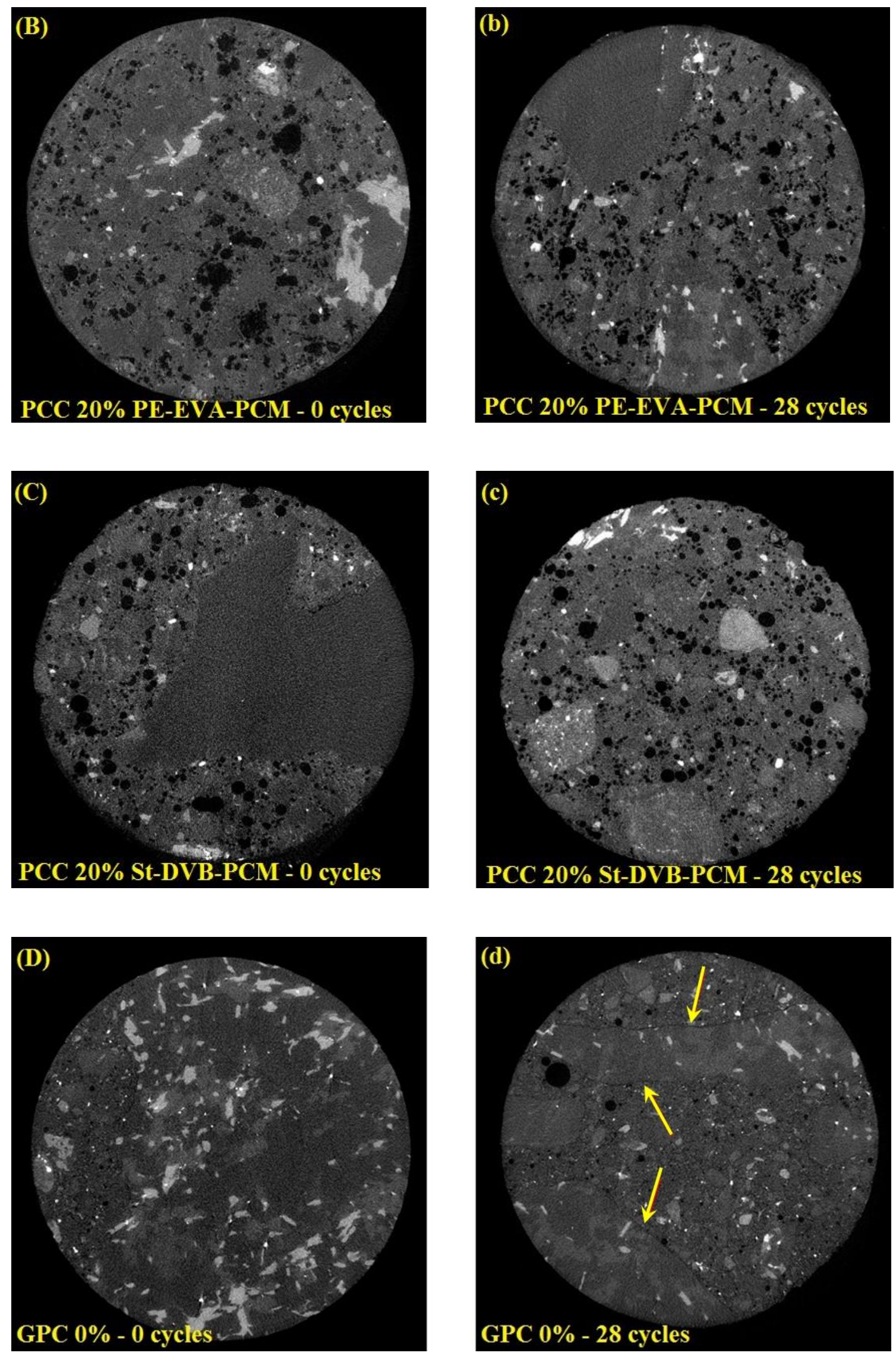

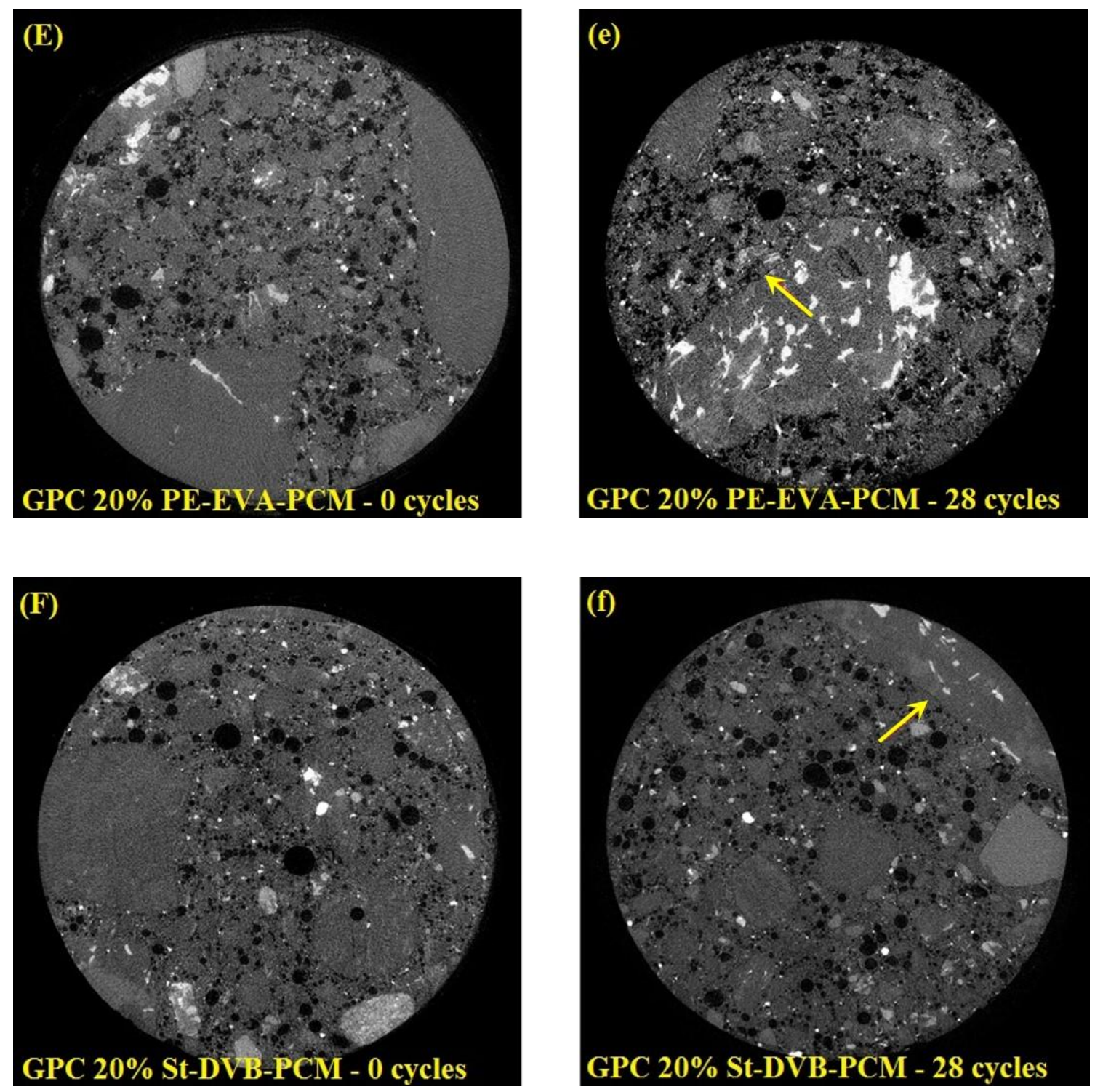

Figure VIII.4. 2D X-ray-tomography images of samples (A) PCC 0\% - 0 cycles, (a) PCC 0\% 28 cycles, (B) PCC 20\% PE-EVA-PCM - 0 cycles, (b) PCC 20\% PE-EVA-PCM - 28 cycles, (C) PCC 20\% St-DVB-PCM - 0 cycles (c) PCC 20\% St-DVB-PCM - 28 cycles, (D) GPC 0\% - 0 cycles, (d) GPC 0\% - 28 cycles, (E) GPC 20\% PE-EVA-PCM - 0 cycles, (e) GPC 20\% PEEVA-PCM, (F) GPC 20\% St-DVB-PCM - 0 cycles, and (f) GPC 20\% St-DVB-PCM after 28 freeze-thaw cycles. The arrows show the gap in interfacial transition zone and microcracks in the concrete matrix. 
Additionally, the micro-CT images revealed the microstructure of GPC 0\% samples is slightly different from that of PC 0\% (Figure VIII.5). To corroborate this, the micro-CT slices were loaded into ImageJ software (v 1.5i) to obtain additional information about shape descriptors of pores, such as perimeter, circularity and aspect ratio. The images were transformed into binary images (segmented) and nine pores, three per slice, were analyzed as shown in Figure VIII.5. The perimeter is calculated by the software as the length in pixels of the outside boundary of the pore. Circularity, computed as $4 \pi$ area / perimeter $^{2}$, indicates how circular an object is. As the value approaches to 1.0, pores are nearly circular, while elongated pores return values close to zero. Finally, the aspect ratio of the pore measures the ratio of the major axis and the minor axis of the best-fit ellipse.

Overall, pores in GPC are clearly smaller in size and fewer pores are observed in the micro-CT images. Pores in PCC samples provided larger perimeters suggesting that they are more tortuous and irregular in shape. Moreover, circularity and aspect ratio indicate the pores are indeed more circular for GPC samples. 

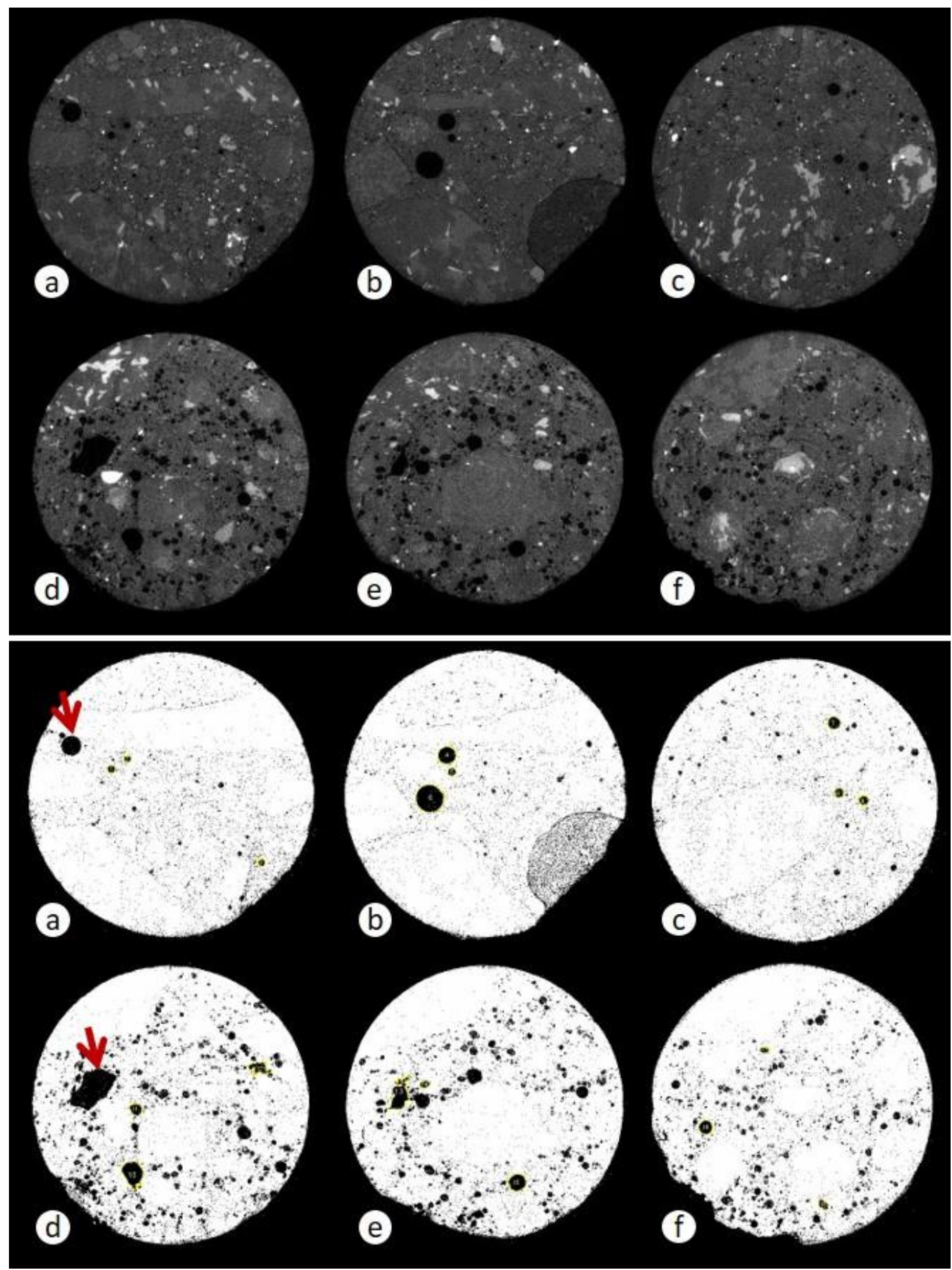

Figure VIII.5. Montage for GPC 0\% (a-c) and PC 0\% samples (d-f). The morphology of the pores is clearly different in the grayscale images (top). The binary images (bottom) show the selection of pores for perimeter, circularity and aspect ratio analysis (three per slice). To test the reliability of the study, an additional analysis was performed for clearly rounded and elongated pores found in both samples (red arrow). 
MPCMs are made of low-density elements and therefore, they are not clearly distinguished from air pores by segmentation [158]. However, the total amount of pores was easily calculated in samples not containing phase change materials (PCC 0\% and GPC 0\%). To do this, microCT slices were transformed into grayscale 8-bit images and converted into binary images. Then the area of pores was calculated in percentage over the entire area of the images. The area of pores was $7.10 \%$ and $2.56 \%$ for PCC $0 \%$ and GPC $0 \%$ samples, respectively. The porosity data are consistent with the mechanical performance of the samples since the higher fraction of pores, the lower mechanical resistance. Table VIII.1 and Table VIII.2 present the results obtained from microstructural analysis of GPC and PCC pores, respectively. To test the reliability of the analysis, the process was separately conducted on visibly rounded and elliptical pores (red arrows in Figure VIII.6). The aspect ratio was 1 (circularity 0.7 ) and 1.8 (circularity 0.2 ) for GPC 0\% and PCC 0\% pores, respectively. 
Table VIII.1. Microstructural analysis of GPC pores.

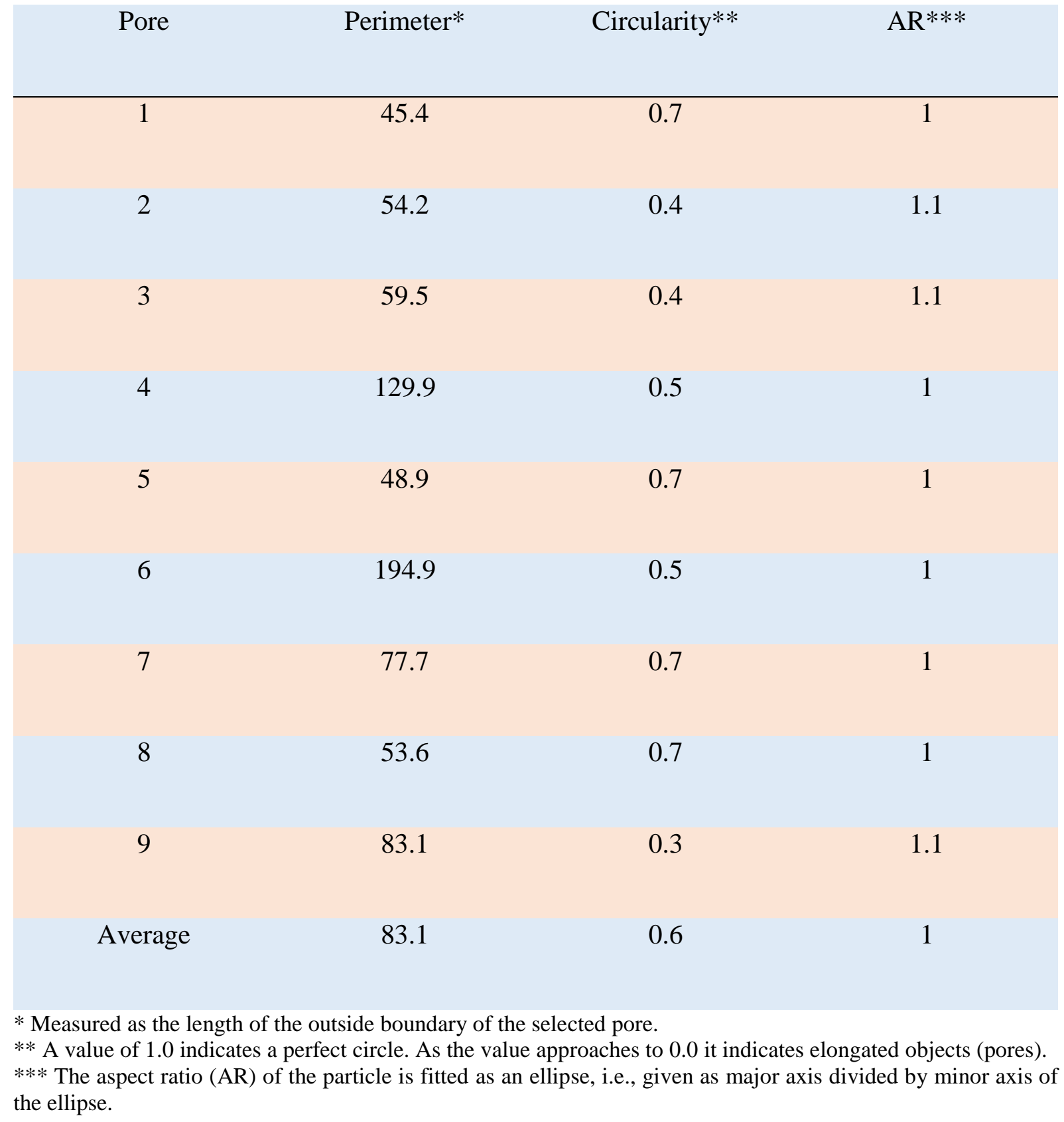


Table VIII.2. Microstructural analysis of PCC pores.

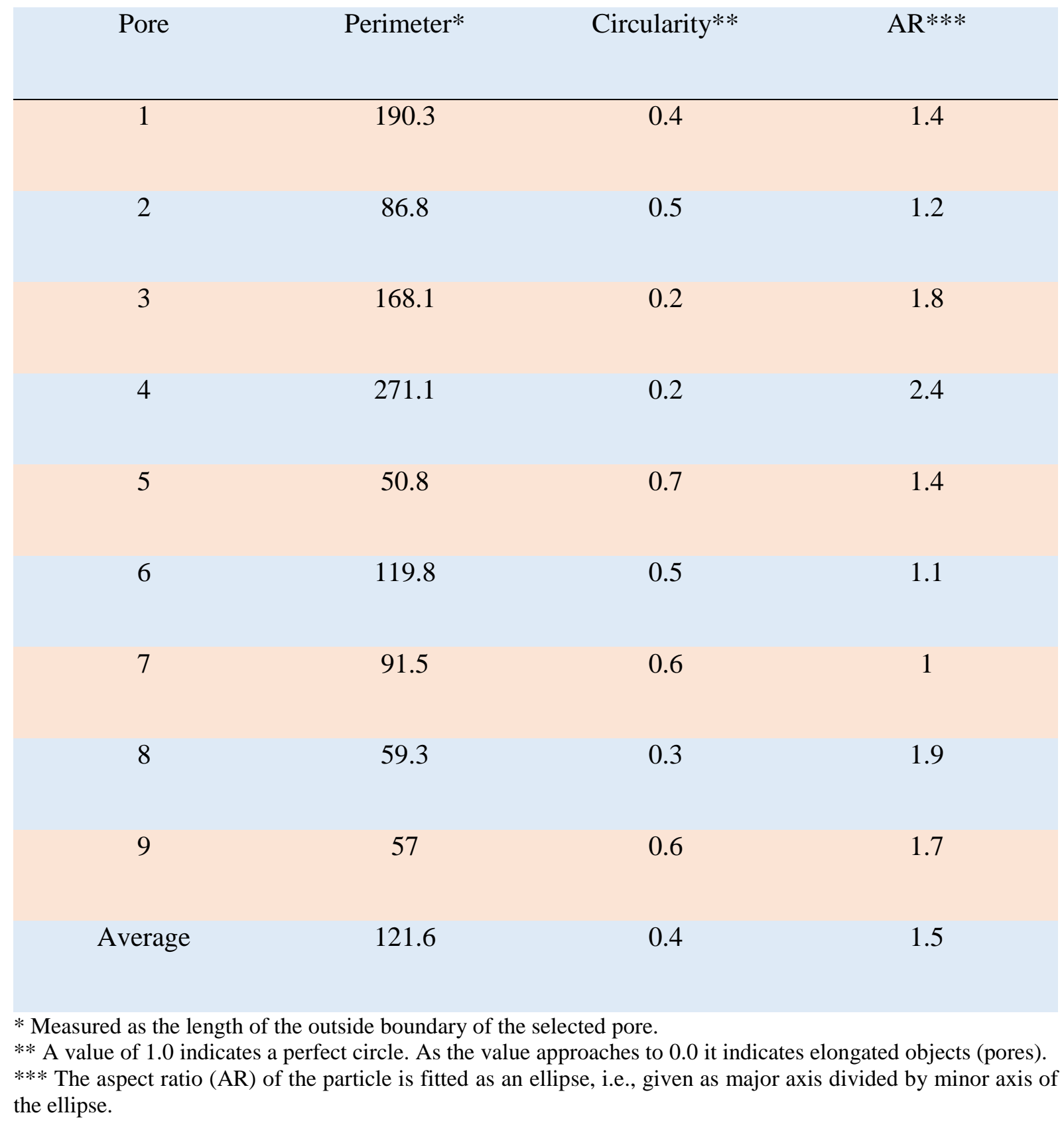



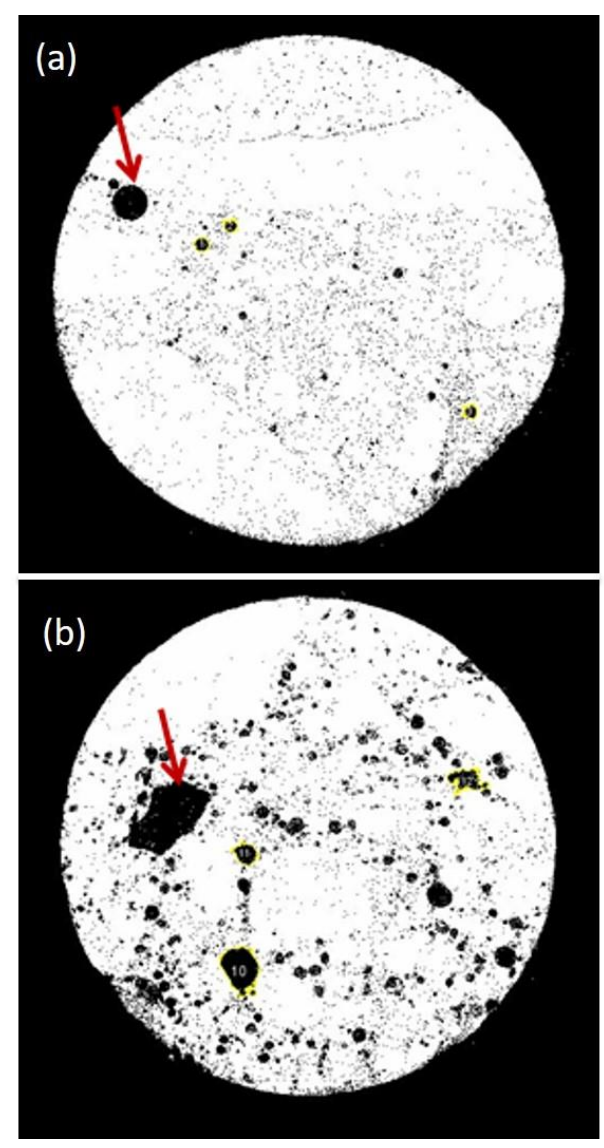

Figure VIII.6. The binary images of 2D cross sectional slice relative to (a) GPC with $0 \%$ MPCM, (b) PCC with 0\% MPCM to verify the analyze.

3D volumes obtained by rendering of the stacked cross-sectional slices from the X-raytomography images are displayed in Figure VIII.7. As can be seen from the images, the inclusion of MPCM's led to a substantial increase of porosity, thus reducing the mechanical performance of the materials. 

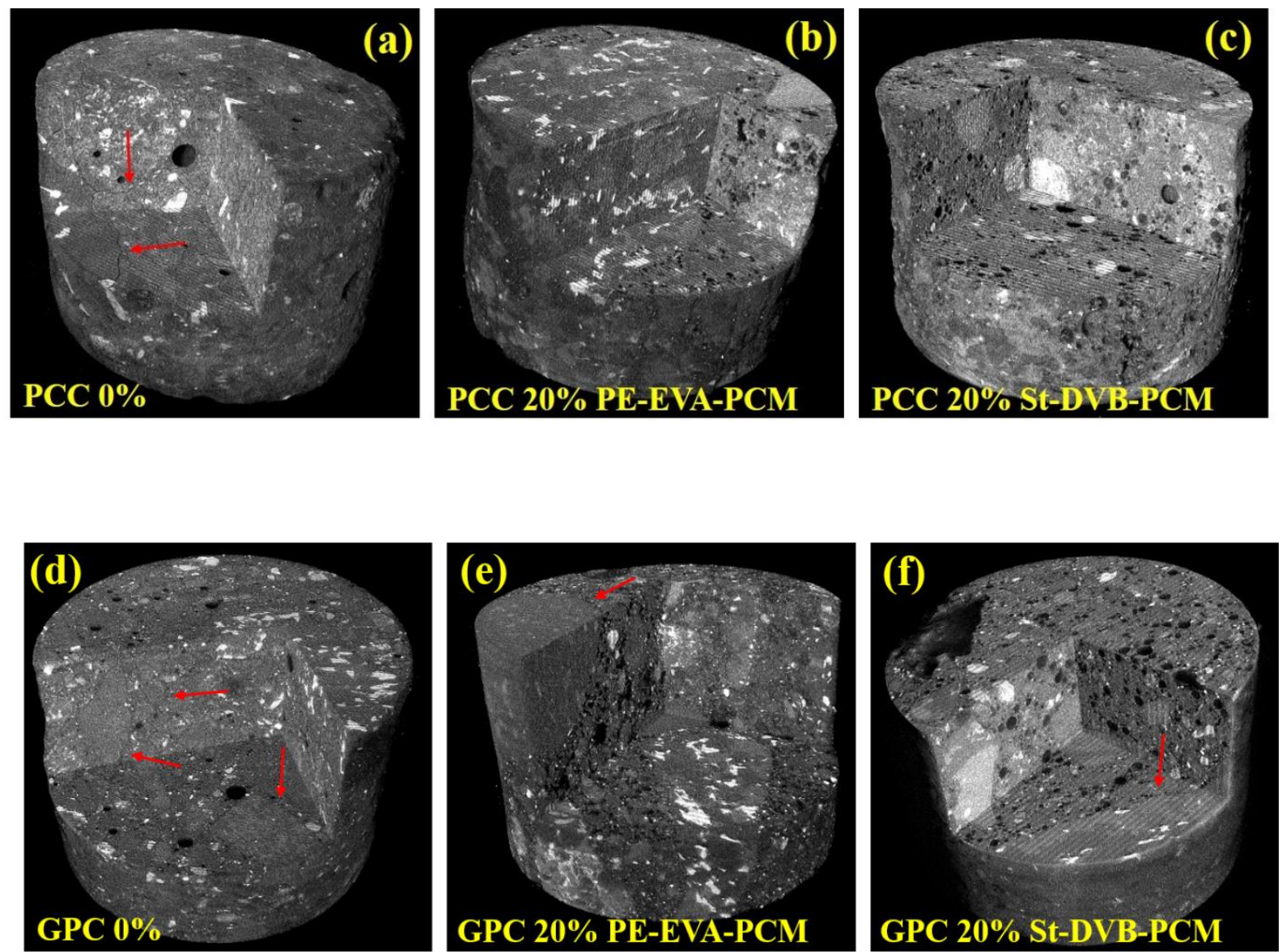

Figure VIII.7. X-ray-tomography 3D rendering of (a) PCC 0\%, (b) PCC 20\% PE-EVA-PCM, (c) PCC 20\% St-DVB-PCM, (d) GPC 0\%, (e) GPC 20\% PE-EVA-PCM, (f) GPC 20\% St-DVBPCM after 28 freeze-thaw cycles. The arrows show the gap in interfacial transition zone and microcracks in the concrete matrix.

\section{VIII.2. Freeze-thaw test}

\section{VIII.2.1. Mass loss}

Freeze-thaw cycles can erode the concrete. It is therefore interesting to examine the mass loss for GPC and PCC with and without MPCM. Figure VIII.8 illustrates that when the percentage of MPCM increases, the mass loss after 28 cycles becomes higher for both GPC and PCC. This 
might be due to the soft nature of the microcapsules and their poor connection to the concrete matrix (as is evident from the gaps between the concrete and MPCM in Figure VIII.2). This can cause the MPCM to be easily eroded from the surface. In addition, MPCM can weaken the concrete structure, which might render it less resistant to freeze-thaw erosion.

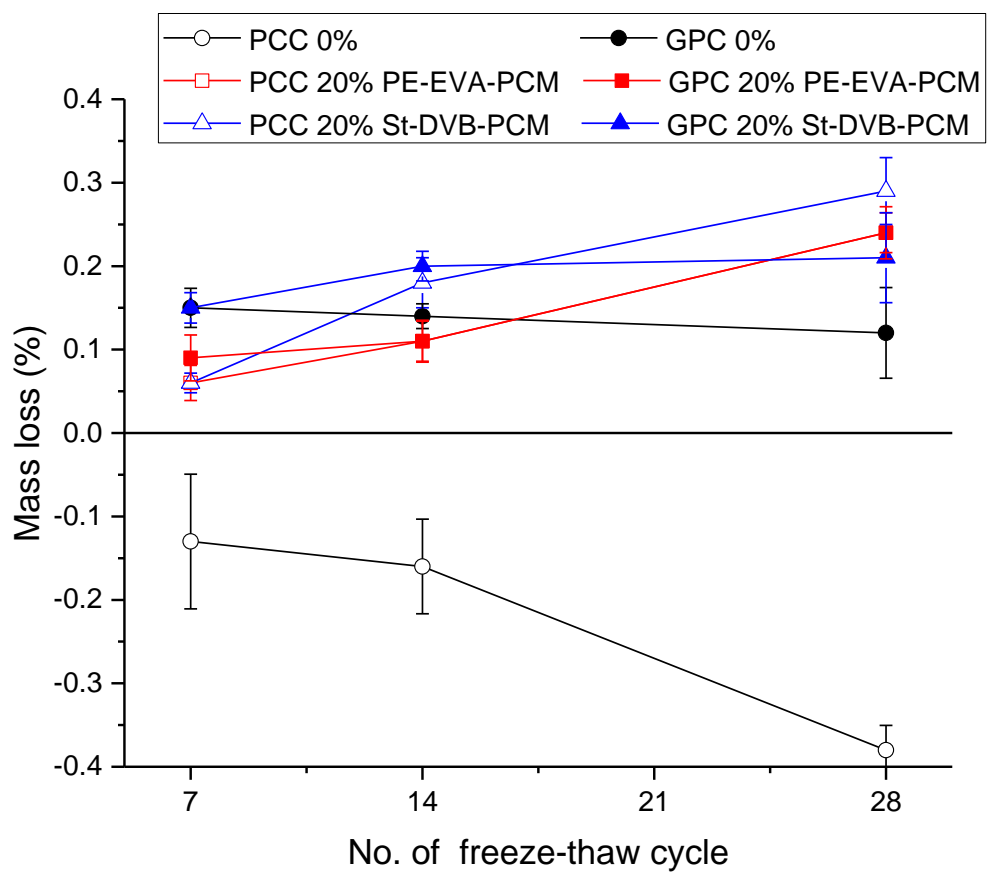

Figure VIII.8. Variation of mass loss with the number of free-thaw cycles.

For PCC without MPCM, the mass loss is negative (i.e., the samples gain weight). This is probably due to water being adsorbed within pores and microcracks $[159,160]$ and ettringite formation [157]. Since the PCC without MPCM gains weight during the freeze thaw cycles, the mass loss is not an accurate measure of the concrete degradation [53].

To evaluate the effect of real weather conditions, GPC and PCC with and without microcapsules were left outdoors from the $16^{\text {th }}$ of October 2017 until the $16^{\text {th }}$ of January 2018 in Fredrikstad, Norway. As can be seen in Figure VIII.9, the samples were submerged in snow for parts of the period. 

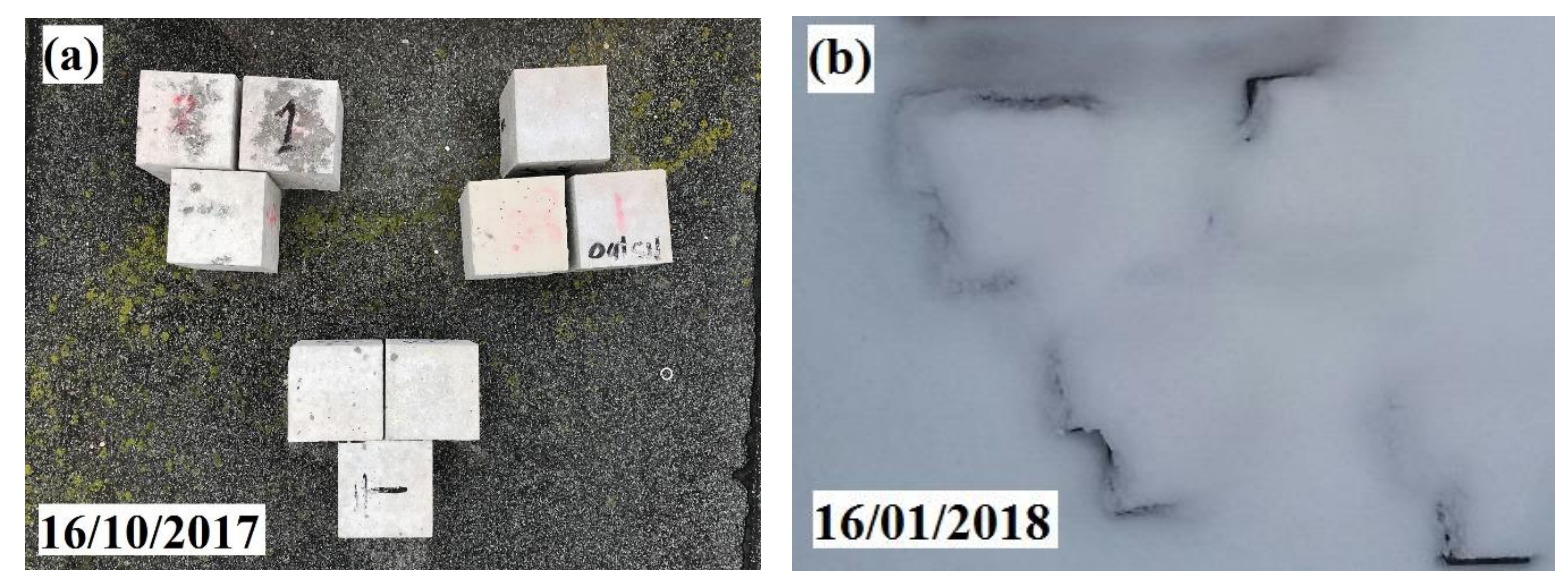

Figure VIII.9. Illustrative pictures of the outdoor conditions at (a) October 2017 and (b) January.

The mass loss of GPC are less than for the samples exposed to freeze-thaw cycles (Figure VIII.10a). This is probably due to less severe outdoor conditions compared to the freeze-thaw test. As can be seen from Figure VIII.10b, the temperature fluctuations during this time period were moderate compared to the freeze thaw cyclses. Interestingly, the PCC samples gain weight (negative weight loss). This might be due to adsorption of water in microcracks $[159,160]$. 

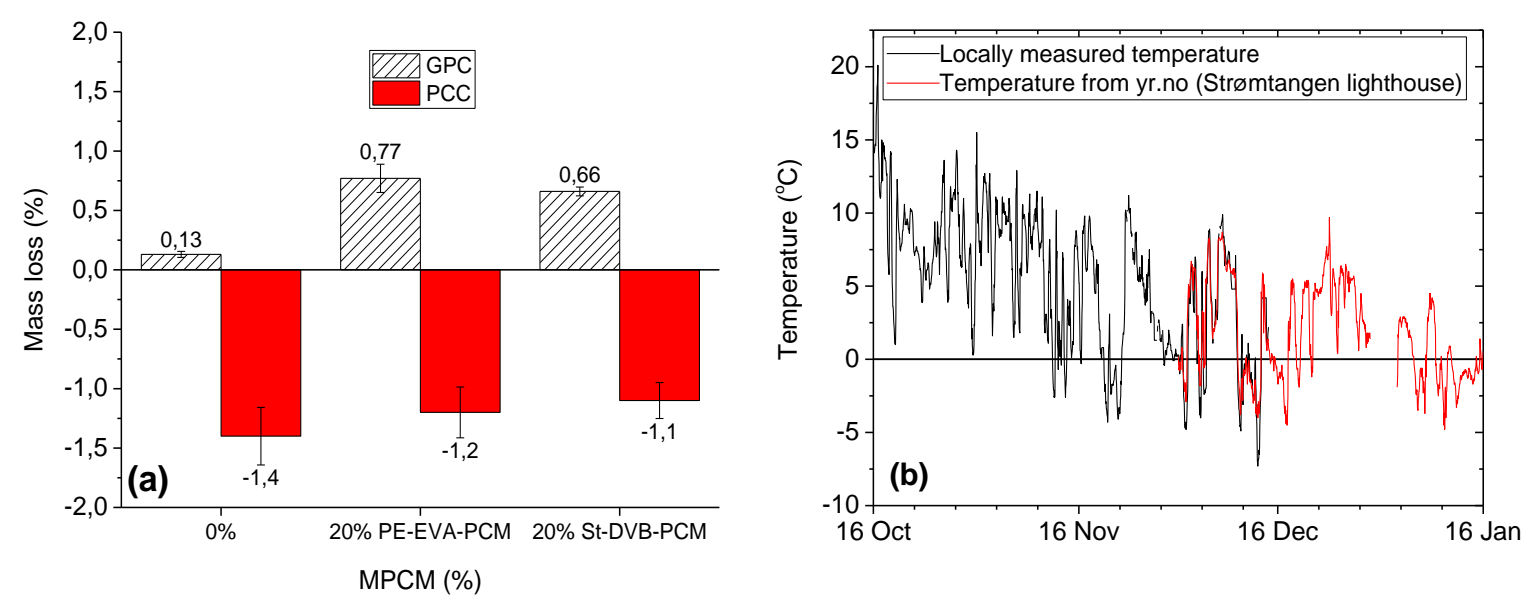

Figure VIII.10. (a) Mass loss for PCC and GPC with and without MPCM after three months at outdoor conditions, (b) temperature fluctuations during these three months. The weather station located next to the samples broke down during the measurements, which is why the temperature during the last month is represented by data from yr.no at Strømtangen lighthouse about $9 \mathrm{~km}$ SW of the measuring site. The 2 week overlap between the two measuring sites show that they are in reasonably good agreement with each other.

\section{VIII.2.2. Compressive strength}

Figure VIII.11 shows the compressive strength and the compressive strength reduction of GPC and PCC with incorporated PE-EVA-PCM and St-DVB-PCM after 0, 7, 14, and 28 freeze-thaw cycles. 


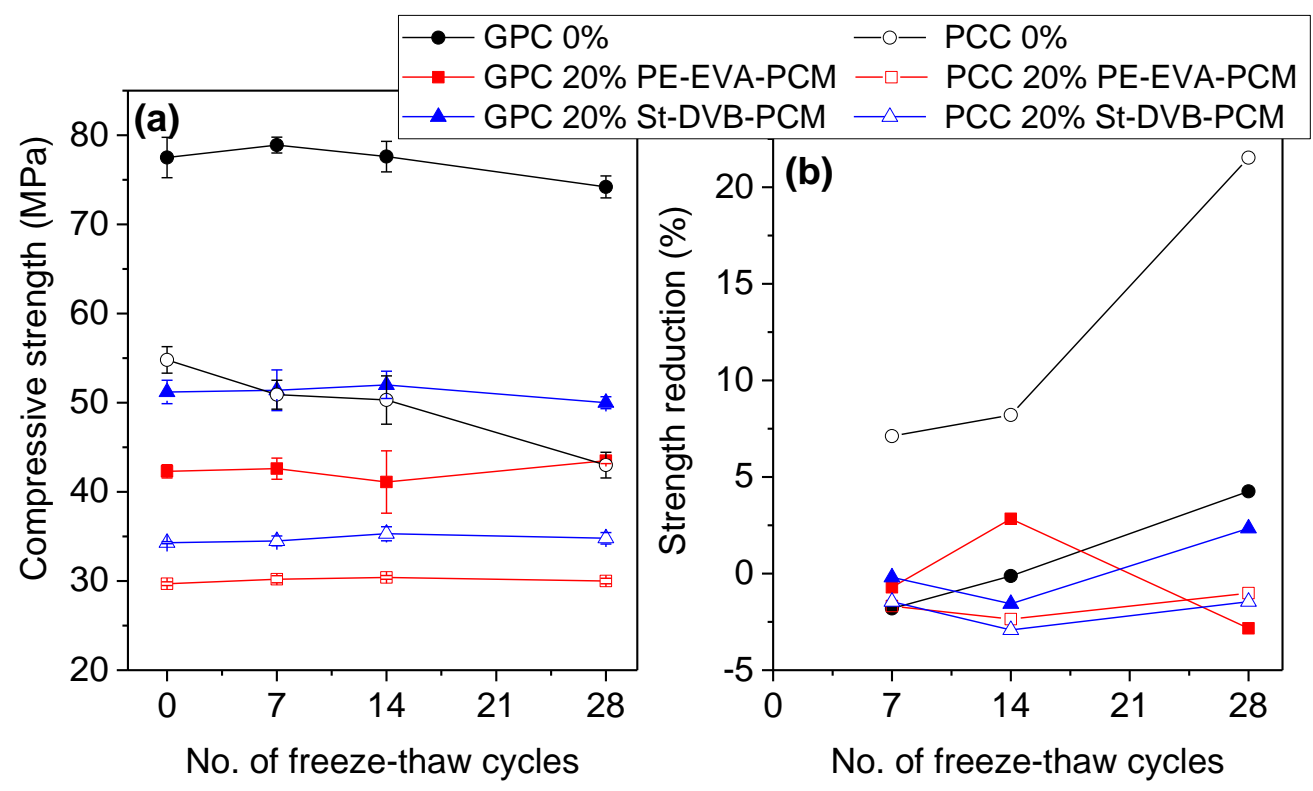

Figure VIII.11. (a) Compressive strength of GPC and PCC versus the number of freeze-thaw cycles when 0 and $20 \%$ sand is replaced by PE-EVA-PCM or St-DVB-PCM, (b) the compressive strength reduction (percentage compared to samples without MPCM at the same curing time) for GPC and PCC versus the number of freeze-thaw cycles.

As observed previously, GPC exhibits better compressive strength than PCC and incorporation of MPCM cause a decrease of the compressive strength [110]. The freeze-thaw induced changes in compressive strength of GPC is less than $5 \%$ at all conditions, showing that the strength of GPC from this recipe is stable against freeze thaw cycles both with and without added microcapsules. However, PCC without MPCM exhibit a pronounced strength reduction as a result of the freeze thaw cycles. There are several theories regrading concrete deterioration under freeze-thaw cycles. The most important effect is expansion of water in the permeable concrete when it freezes. Freezing water generates a hydraulic pressure in the concrete capillaries and within the interfacial transition zones between the cement and the aggregates/MPCM. When the volume expansion of water overcomes the tensile stress of concrete, microcracks are created and cause concrete degradation (Figure VIII.2) [161-163]. This is expected to reduce the compressive strength [52, 162-164]. In addition, ettringite can be 
seen in the PCC matrix after the freeze-thaw cycles (Figure VIII.2) [164]. The ettringite needle structure generate microcracks, which deterioate the concrete [157]. Despite this, the compressive strength of the samples containing MPCM are not significantly affected by the freeze-thaw cycles. MPCM addition increases the concrete porosity inducing air voids in the concrete matrix $[165,166]$. In addition, the gaps between MPCM and the concrete matrix (Figure VIII.2 and Figure VIII.3) provide air within the concrete structure [110, 167]. These air voids can improve the frost resistance of concrete by acting as expansion reservoirs for the freezing water and thereby reduce frost induced stress [168].

As for the freeze thaw cycles, there is little effect on the compressive strength of GPC after three months exposure to outdoor conditions (Figure VIII.12a). Interestingly, for PCC the compressive strength after three months exposure to outdoor conditions is actually higher than before exposure to the environment. Since the outdoor conditions are less severe than the freeze-thaw cycles (Figure VIII.10b), the degradation of the concrete strength is probably moderate. The increased compressive strength suggest that the strength continues to grow even after 28 days [51, 169, 170]. 

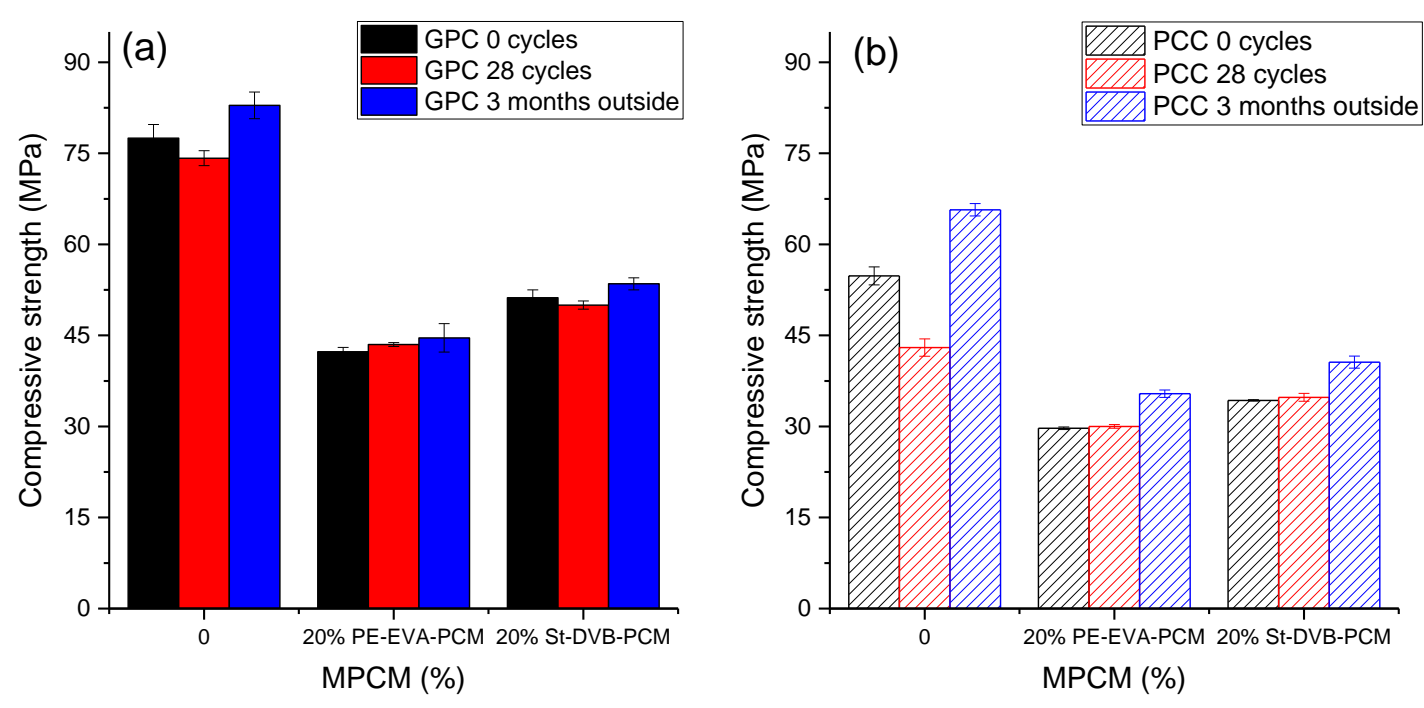

Figure VIII.12. The effect of MPCM on the compressive strength of 28 freeze-thaw cycles and of exposure to outdoor conditions three months (a) for GPC and (b) for PCC.

\section{VIII.2.3. Setting times}

Figure VIII.13 shows the effect of temperature and MPCM on the initial and final setting times of Portland cement and geopolymer pastes. It is clear from Figure VIII.13 that the geopolymer reaction is much faster than the hydration of Portland cement (note the differences in the scaling of the y-axis). As expected, decreasing temperature slows down the hydration of Portland cement paste [171], resulting in longer setting times. Interestingly, the setting times for geopolymer pastes are much faster at low temperatures. 

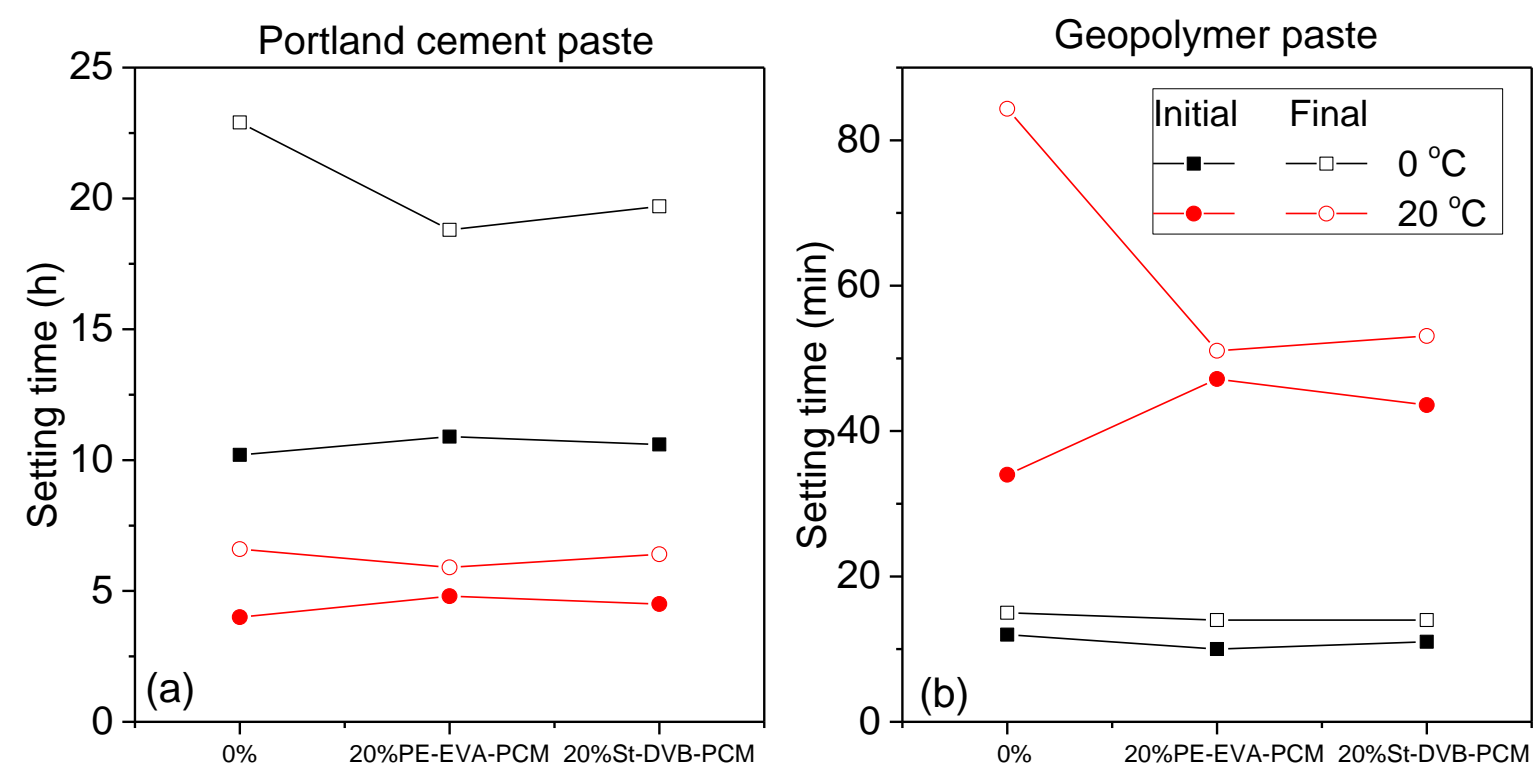

Figure VIII.13. The initial and final setting times of (a) Portland cement paste and (b) geopolymer paste containing 20 vol.\% of PE-EVA-PCM and St-DVB-PCM at $0{ }^{\circ} \mathrm{C}$ and $20{ }^{\circ} \mathrm{C}$.

When MPCM is added to cement paste, water is adsorbed on the surface of the microcapsules, thereby reducing the amount of available water in the paste $[145,172]$. The initial setting time becomes longer when MPCM is added to the samples because the higher viscosity can slow down the start of the cement reaction [173]. PE-EVA-PCM exhibits a more pronounced effect on the initial setting time since it adsorbs much more water and has lower slump (higher viscosity) than St-DVB-PCM [172]. When the initial setting time is reached, the solidification of the samples becomes faster due to the water shortage [172]. Accordingly, the final setting time becomes shorter in the presence of MPCM.

For geopolymer paste at ambient temperature, a similar behavior has been observed previously [172]. However, at $0{ }^{\circ} \mathrm{C}$, the setting times are very fast without a significant effect of MPCM addition. The fast setting times at $0{ }^{\circ} \mathrm{C}$ are probably due to the reduced solubility of the alkaline solution at low temperatures, which causes a phase separation within the sample. The incipient 
formation of solid particles from the alkaline solution seems to significantly speed up the solidification process causing very short setting times. 
Chapter IX.

Effect of different types of micro-encapsulated phase change materials in liquid state on the mechanical properties of geopolymer concrete 

Tables summarizing the results of this chapter are presented in Appendix A.6.

\section{IX.1. Setting times}

Figure IX.1. shows the effect of temperature and MPCM on the initial and final setting times of geopolymer paste. It is clear from Figure IX.1 that the geopolymer reaction is much faster when the temperature increases from $20{ }^{\circ} \mathrm{C}$ to $40{ }^{\circ} \mathrm{C}$. The behavior of geopolymer paste at ambient temperature has been investigated in Chapter VI. However, at $40{ }^{\circ} \mathrm{C}$ the setting times are very fast without any significant effect of MPCM addition. As expected, the geopolymerization reaction is accelerated at higher temperatures. When the temperature increases, the solubility of aluminosilicate is higher which causes larger amounts of silica and alumina to participate in the geopolymerization, speeding up the setting times of the geopolymer paste [174]. MPCM in liquid state $\left(40{ }^{\circ} \mathrm{C}\right)$ has no noticeable effect on the setting times in comparison with solid state $\left(20^{\circ} \mathrm{C}\right)$ which discussed in VII.3. 


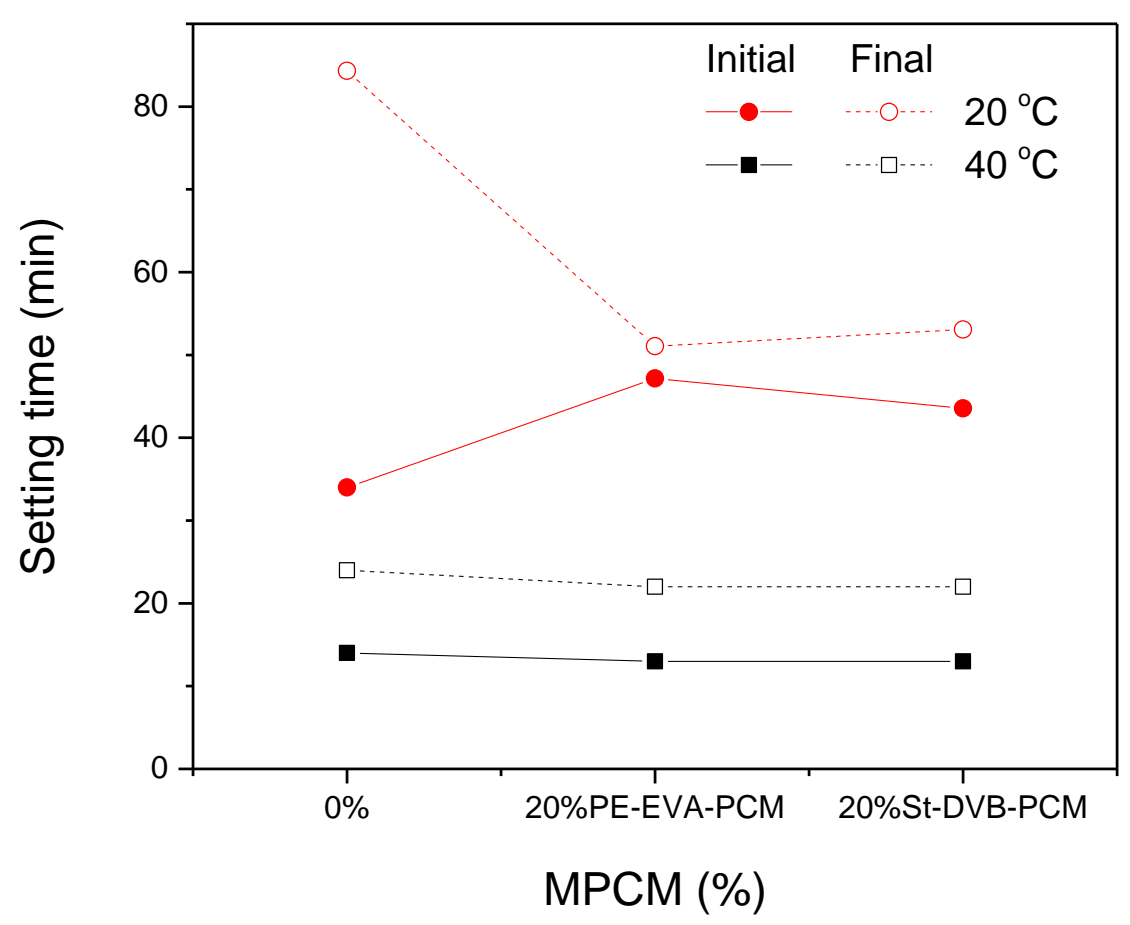

Figure IX.1. The initial and final setting times of geopolymer paste containing 20 vol.\% of PEEVA-PCM and St-DVB-PCM at $20^{\circ} \mathrm{C}$ and $40^{\circ} \mathrm{C}$.

\section{IX.2. Compressive strength}

In order to investigate the effect of two different MPCMs in liquid state on the mechanical properties of the proposed GPC, the compressive strength with incorporated PE-EVA-PCM and St-DVB-PCM was tested after $1,7,14$, and 28 days curing at $40{ }^{\circ} \mathrm{C}$ (Figure IX.2).

\section{IX.2.1. Effect of curing time and temperature}

As seen in Figure IX.2, the compressive strength of both GPC and PCC increase with curing time and temperature. For GPC, the elevated temperature accelerates the formation of a hard structure, especially in the early-stage of the geopolymerization reaction. Analogously, the hydration reaction increases the strength of PCC. Despite the negative effect of both PE-EVA- 
PCM and St-DVB-PCM on the strength of concrete, the compressive strength of GPC with $20 \%$ MPCMs after 28 days curing is significantly higher than for Portland cement concrete (Figure IX.2). At early curing times, the increase of the strength with the temperature is more pronounced since the geopolymerization and hydration are faster at higher temperatures [127].

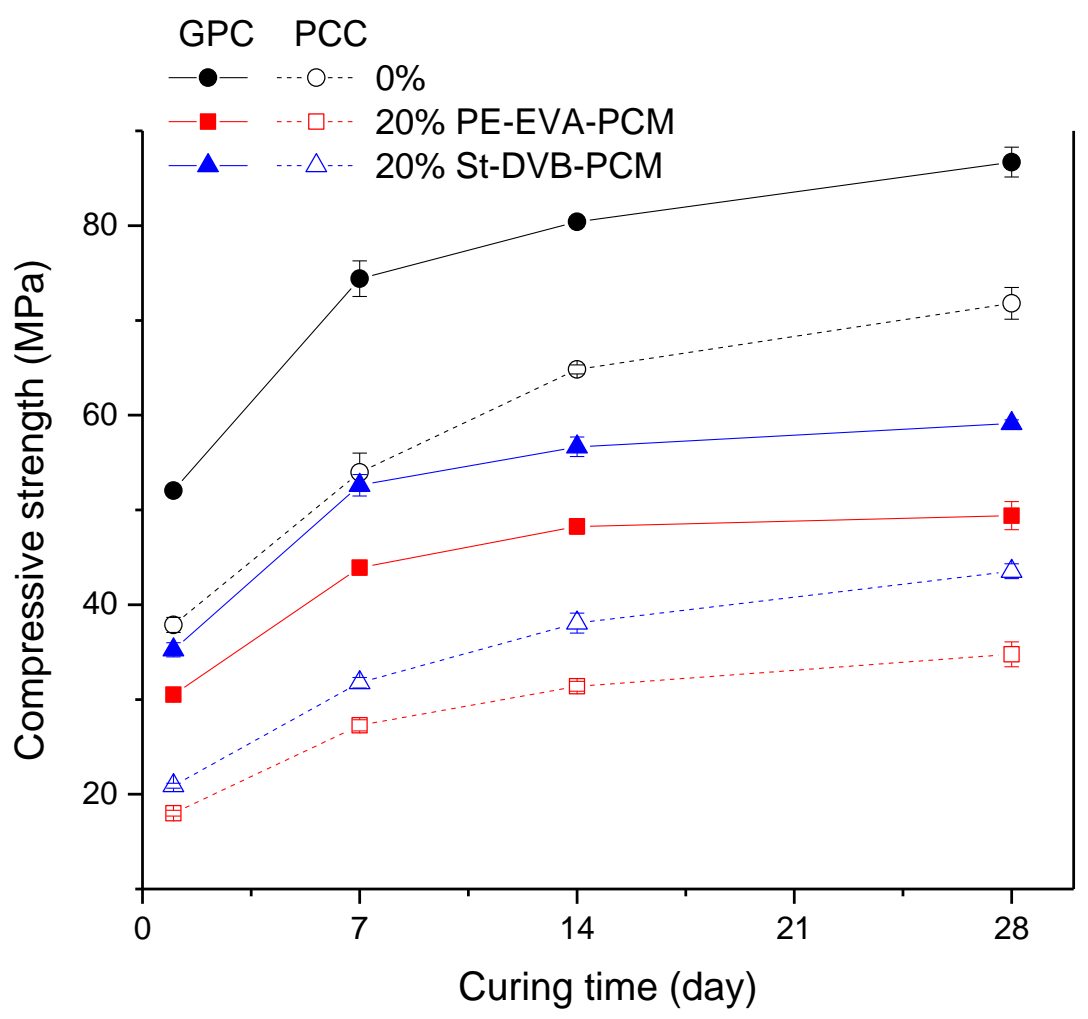

Figure IX.2. Compressive strength of GPC and PCC versus curing time at $40{ }^{\circ} \mathrm{C}$.

The percentage strength reduction of GPC versus curing time at $20^{\circ} \mathrm{C}$ and $40{ }^{\circ} \mathrm{C}$ shown in Figure IX.3. For GPC cured at $20{ }^{\circ} \mathrm{C}$, the percentage strength reduction increases noticeably at short curing times before it stabilizes at a nearly constant value after approximately 1 week. However, for GPC cured at $40{ }^{\circ} \mathrm{C}$, the strength reduction is almost constant at all curing ages. This is due to the faster curing times at elevated temperatures, which is in agreement with Figure IX.2. At long times the strength reduction is approximately the same for the samples cured at 20 and $40{ }^{\circ} \mathrm{C}$. 


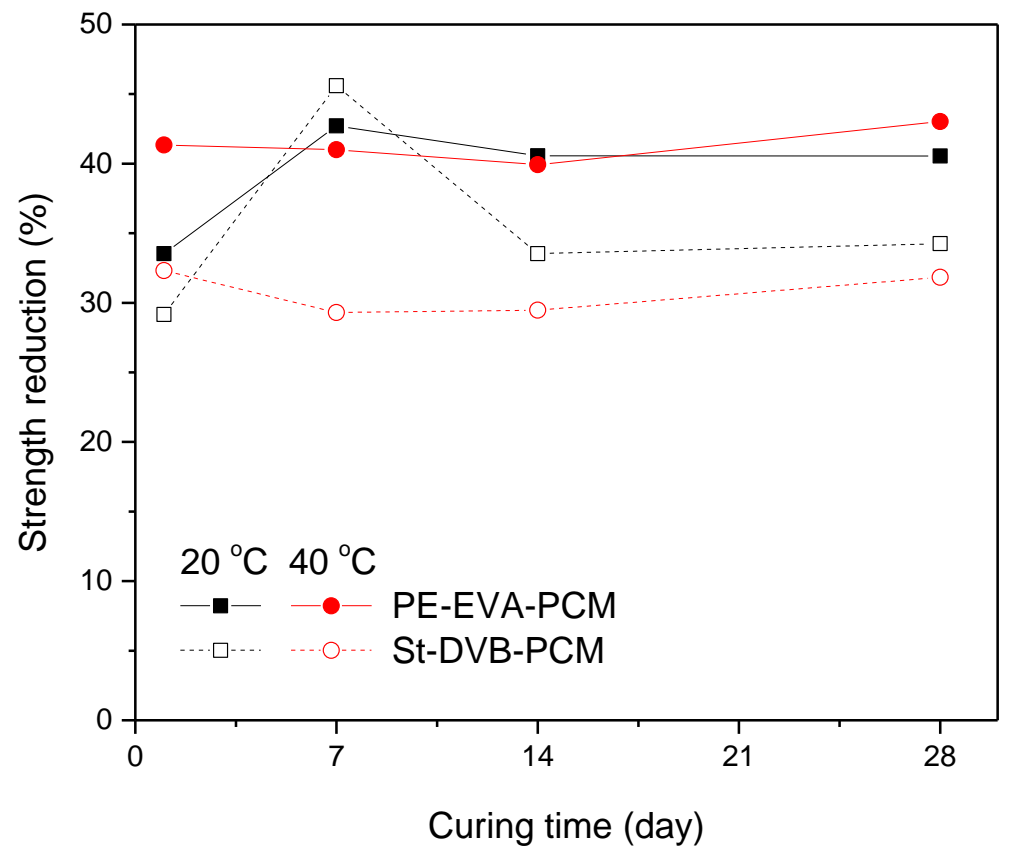

Figure IX.3. The compressive strength reduction (percentage compared to samples without MPCM at the same curing time) for GPC containing 20\% PE-EVA-PCM and St-DVB-PCM versus curing time at $20^{\circ} \mathrm{C}$ and $40{ }^{\circ} \mathrm{C}$.

\section{IX.2.2. Effect of MPCM type and state}

As can be seen from Figure IX.2, samples containing St-DVB-PCM have higher compressive strength than PE-EVA-PCM. To illustrate the effect of different types of MPCM in liquid state on the mechanical properties of GPC and PCC, the 28-day compressive strength at $20{ }^{\circ} \mathrm{C}$ and $40{ }^{\circ} \mathrm{C}$ is provided in Figure IX.4a and b, respectively. At $20^{\circ} \mathrm{C}$ after 28 days Figure IX.4a), the strength of PCC containing PE-EVA-PCM and St-DVB-PCM are almost the same. However, the strength of GPC containing PE-EVA-PCM is lower than for St-DVB-PCM. In addition, there is a much higher difference between the strength of PCC containing PE-EVA-PCM and St-DVB-PCM after 28 days at $40{ }^{\circ} \mathrm{C}$ than at $20{ }^{\circ} \mathrm{C}$ (Figure IX.5b). However, for GPC the strength of the samples containing PE-EVA-PCM and St-DVB-PCM is very similar for $40{ }^{\circ} \mathrm{C}$ 
and $20^{\circ} \mathrm{C}$ (Figure IX.5). Thus, the MPCMs in liquid state affect PCC much more than GPC. A more uniform and compact structure of GPC may contribute to the resistance against thermal expansion or soft particles.
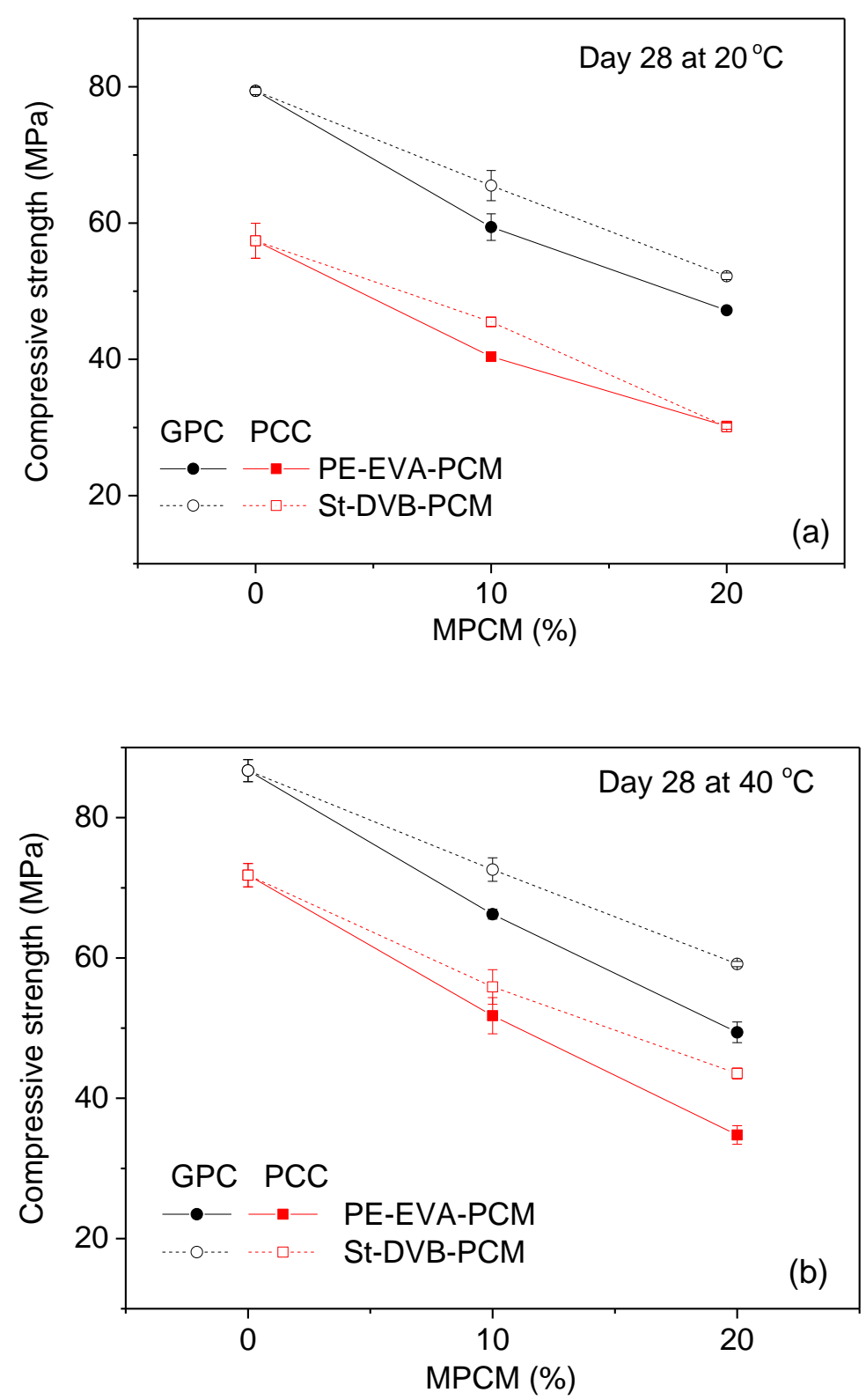

Figure IX.4. Compressive strength of GPC and PCC versus percentage of sand replaced by MPCM after curing for 28 days (a) cured at $20^{\circ} \mathrm{C}$, (b) cured at $40{ }^{\circ} \mathrm{C}$. 

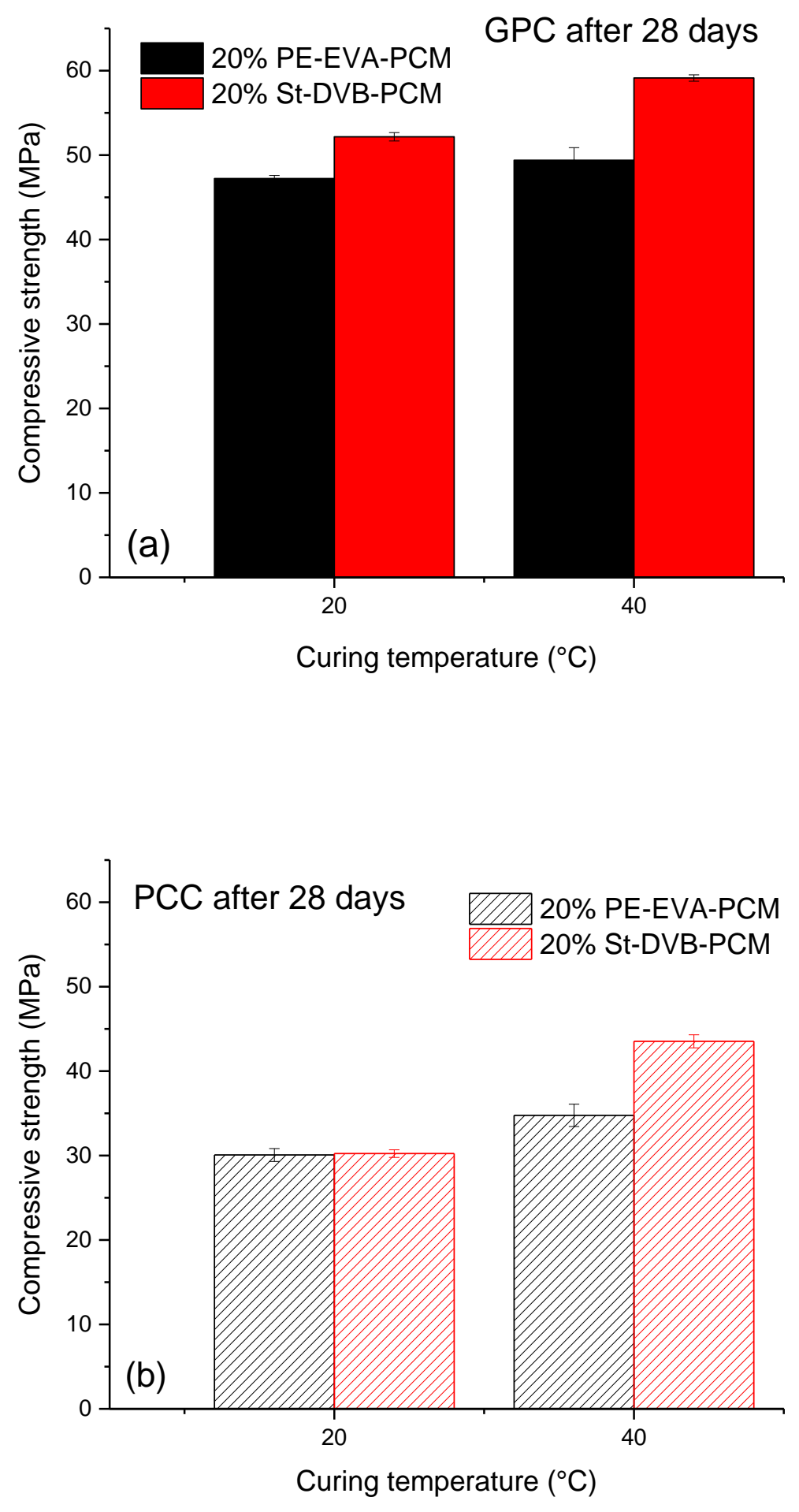

Figure IX.5. Compressive strength after 28 days versus curing temperatures (a) for GPC, (b) for PCC. 
Figure IX.3 illustrates that the strength reduction is more pronounced for samples containing PE-EVA-PCM than for St-DVB-PCM, especially at early ages at $20^{\circ} \mathrm{C}$. The lower mechanical properties of concrete containing PE-EVA-PCM compared to St-DVB-PCM is probably a combination of several effects. The irregular shell of PE-EVA-PCM and its tendency to form agglomerates can contribute to the larger strength reduction of concrete containing with PEEVA-PCM compared to St-DVB-PCM. In addition, the lower workability of PE-EVA-PCM (see VII.2) might contribute to more air being trapped in these samples, thereby reducing the compressive strength in comparison with St-DVB-PCM. It should also be noted that PE-EVAPCM contains significant amounts of non-encapsulated PCM, [175] which might reduce the strength of the concrete.

\section{IX.3. Microstructural analysis}

\section{IX.3.1. SEM imaging}

The failure surface of GPC and PCC samples with 20\% PE-EVA-PCM and St-DVB-PCM at $40{ }^{\circ} \mathrm{C}$ were selected for SEM analyses. Figure IX.6 presents an individual particle of PE-EVAPCM and St-DVB-PCM in the GPC and PCC matrixes as an example of how the MPCM shells binds with the surrounding matrix. As can be seen from Figure IX.6, there are more uniform and undamaged edges in the shell-concrete matrix transition zone of GPC than PCC. This illustrates a better compatibility between the MPCMs shell with GPC than for PCC. This might contribute to the better performance of GPC than PCC in the presence of MPCMs when the samples are exposed to temperature fluctuations from $20^{\circ} \mathrm{C}$ to $40{ }^{\circ} \mathrm{C}$ or vice versa (Figure IX.4a and b). However, it should be noted that one microcapsule and its surrounded matrix may not be representative of the whole sample. The reasons that how PE-EVA-PCM and St-DVB-PCM might contribute to the reduced compressive strength was discussed previously (see VII.5.1). 


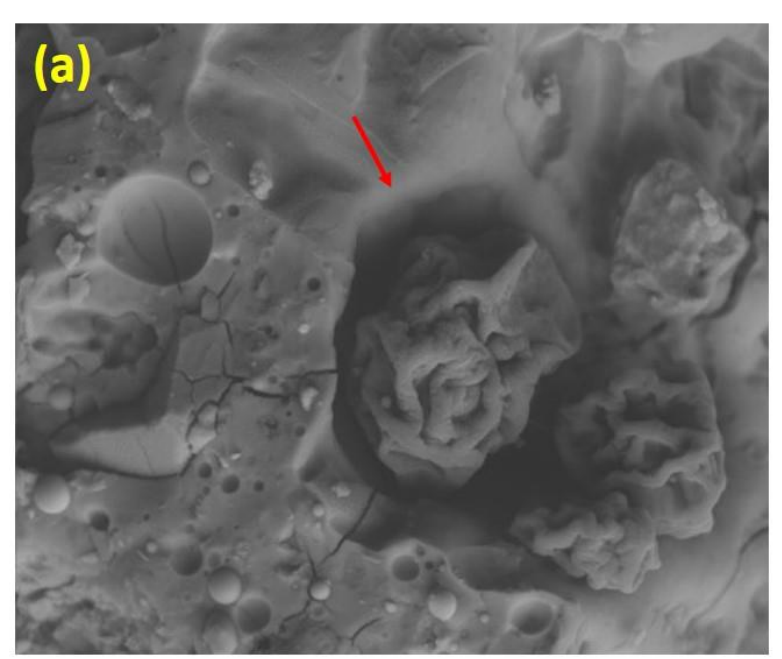

GPC 20\% PE-EVA-PCM MAG:900x

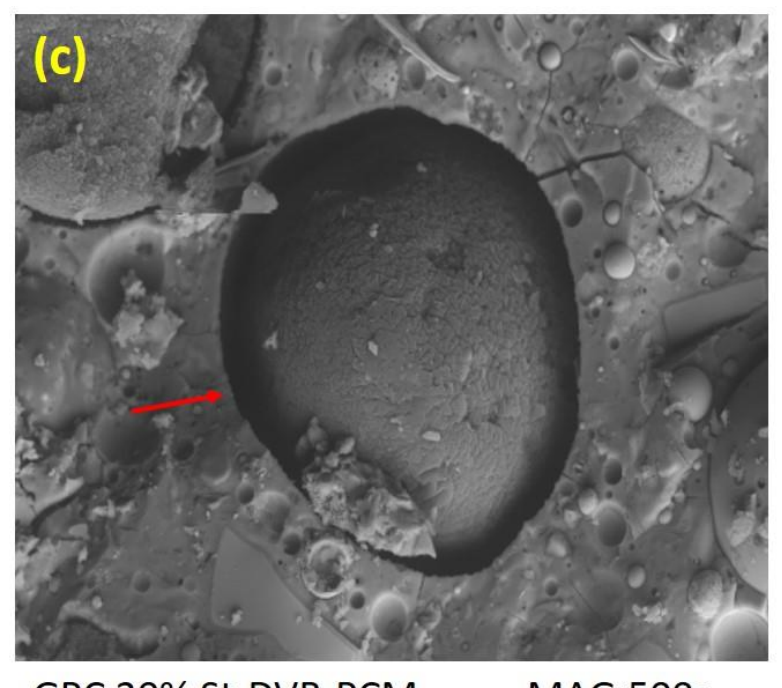

GPC 20\% St-DVB-PCM
MAG:500x

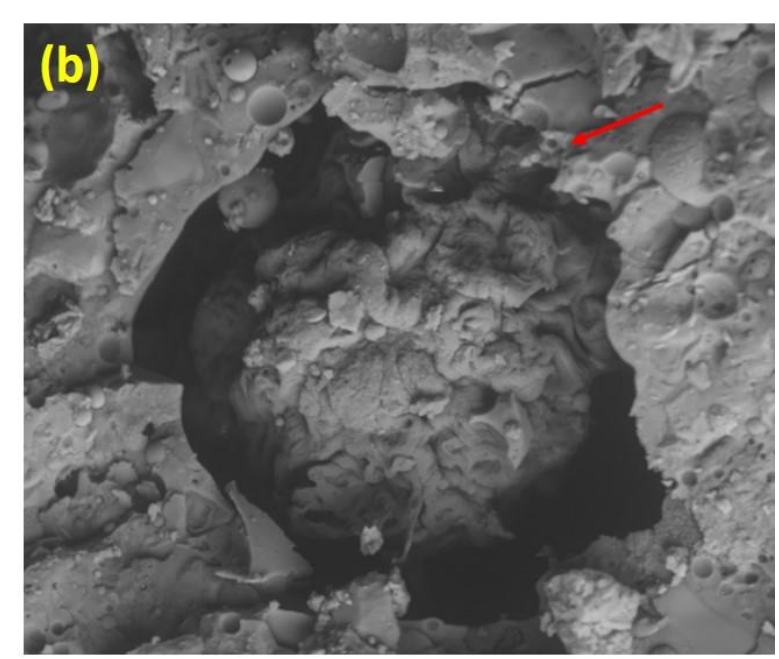

PCC 20\% PE-EVA-PCM MAG:900x

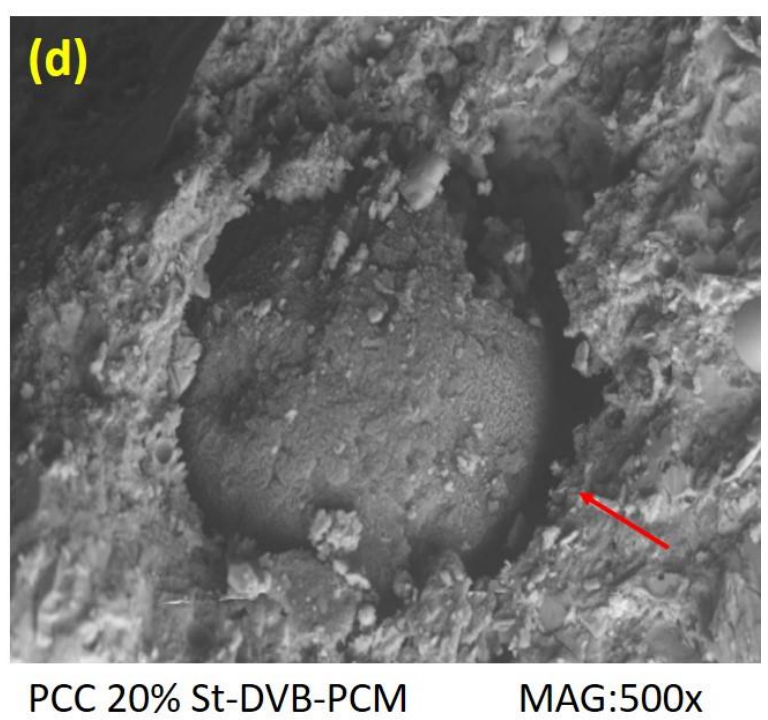

Figure IX.6. SEM images of the fracture surface of (a) GPC with incorporated 20\% PE-EVAPCM, (b) PCC with incorporated 20\% PE-EVA-PCM, (c) GPC with incorporated 20\% StDVB-PCM, and (d) PCC with incorporated 20\% St-DVB-PCM. The arrows show the edge of shell-concrete matrix transition zone. 


\section{IX.3.2. X-ray micro-tomography}

Typical 2D X-ray micro-tomography cross-sectional slices obtained from GPC and PCC without MPCMs cured at $20{ }^{\circ} \mathrm{C}$ and $40{ }^{\circ} \mathrm{C}$ are displayed in Figure IX.7. More than 600 2D slices were taken for each sample in order to obtain good statistical data.

As can be seen from Figure IX.7a and b, a larger number of air voids are visible in the GPC samples cured at $40{ }^{\circ} \mathrm{C}$ than $20{ }^{\circ} \mathrm{C}$. Increasing the curing temperature is known to increase the extent of dissolution of $\mathrm{Si}$ and $\mathrm{Al}$ from the amorphous phases and accelerates the formation of a hard structure, especially in the early-stage of geopolymerization reaction. Accordingly, at elevated temperatures the exothermic geopolymerization reaction causes the water to be lost faster than at lower temperatures[176]. This leads to formation of micro-cavities, and therefore an increase in the porosity of GPC matrix. For PCC higher temperatures enhance the hydration rates, which produces denser hydration products such as $\mathrm{C}-\mathrm{S}-\mathrm{H}$. This results in a more heterogeneous hydration distribution, and enhanced porosity. At lower temperatures, the hydrates are more homogeneously distributed which results not only in smaller pores, but also more uniform distribution of the hydrates [177]. 

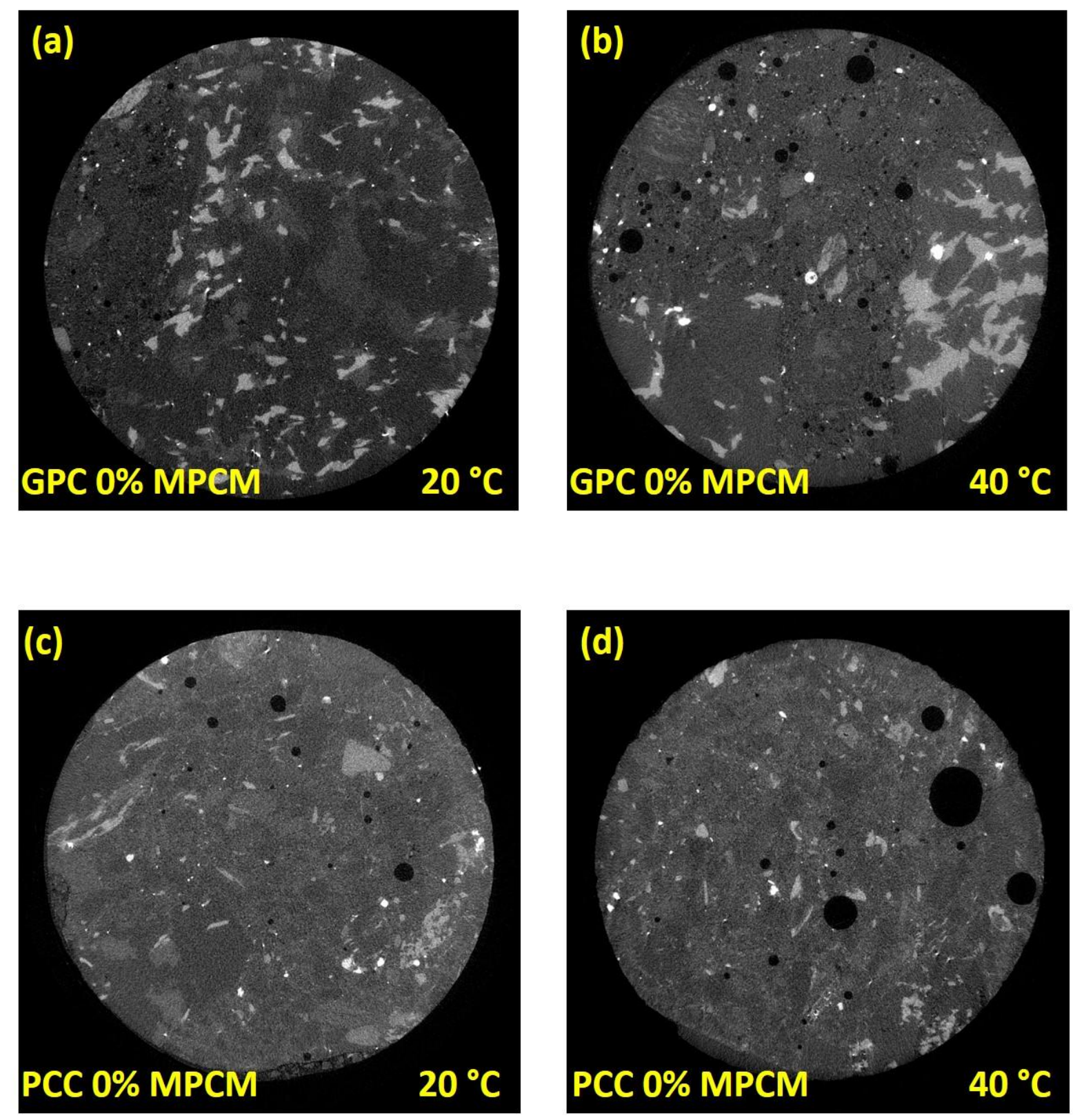

Figure IX.7. X-ray-tomography images of samples (a) GPC without MPCM at $20{ }^{\circ} \mathrm{C}$, (b) GPC without MPCM at $40{ }^{\circ} \mathrm{C}$, (c) PCC without MPCM at $20{ }^{\circ} \mathrm{C}$, and (d) PCC without MPCM at 40 ${ }^{\circ} \mathrm{C}$. In these images, dark colors correspond to low or no absorption of X-rays (e.g. air bubbles or microcapsules) and bright colors represent high absorption of X-rays (sand and gravel). The field of view is approximately $1 \mathrm{~cm}$. 
Figure IX.8 shows how the MPCMs are distributed in the GPC and PCC matrix. As discussed in previous chapters, it is difficult to distinguish the microcapsules and the air voids from each other. The large irregular shapes is due to agglomerated microcapsules. From Figure IX.8, it can be seen that both agglomerated PE-EVA-PCM and St-DVB-PCM are distributed throughout the PCC sample. The GPC has some areas with agglomerated MPCMs and some more homogeneous parts without any MPCMs distribution. The high viscosity (low workability) of the fresh GPC and the short setting times of GPC especially at $40{ }^{\circ} \mathrm{C}$ can contribute to the prevention of a homogeneous distribution of MPCM throughout the matrix. However, it should be noted that the field of view of study is approximately $1 \mathrm{~cm}$, and it may not be representative of the whole concrete sample. 

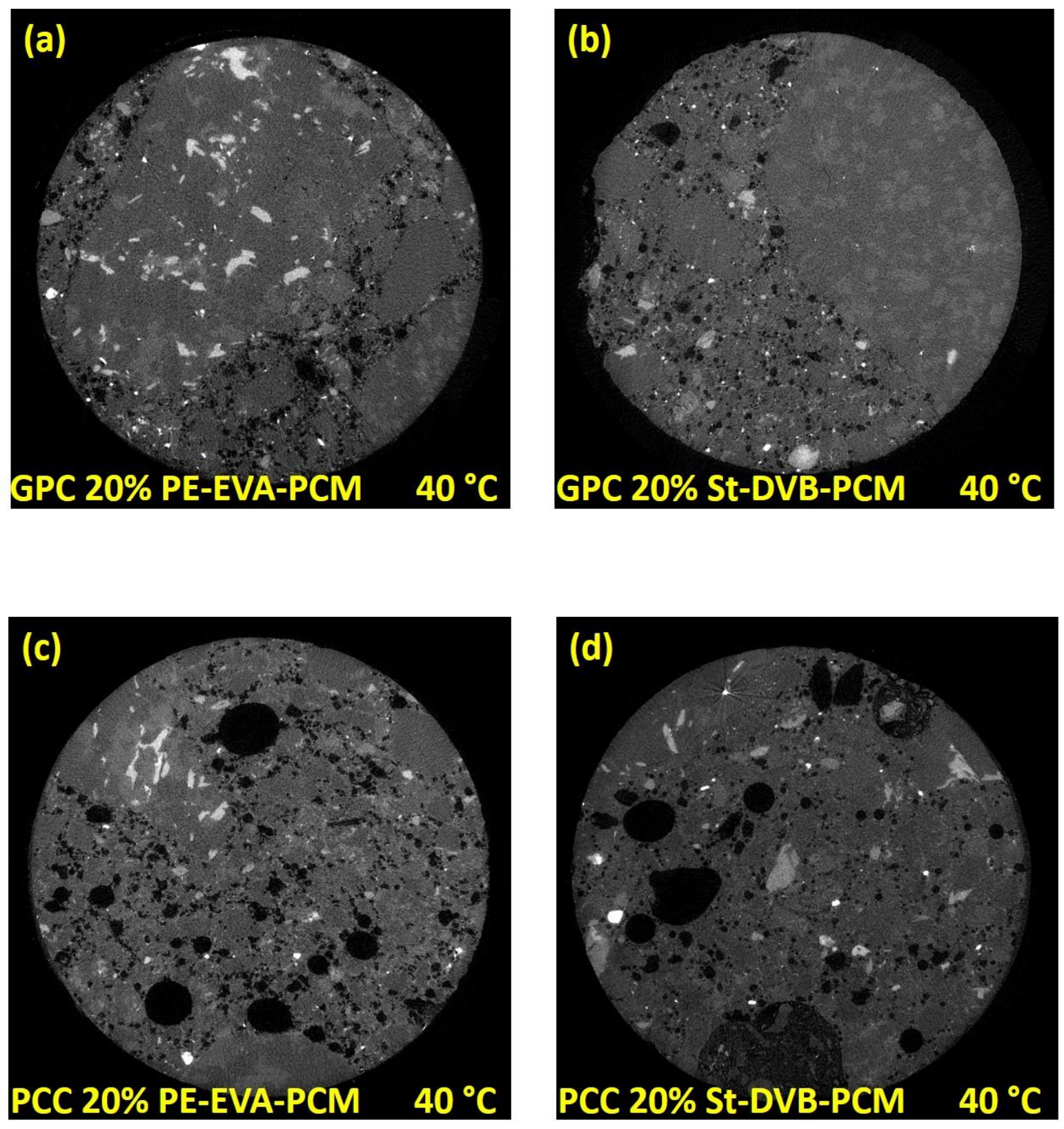

Figure IX.8. X-ray-tomography images of (a) GPC with 20\% PE-EVA-PCM, (b) GPC with 20\% St-DVB-PCM, (c) PCC with 20\% PE-EVA-PCM, and (d) PCC with 20\% St-DVB-PCM at $40{ }^{\circ} \mathrm{C}$. Dark colors correspond to low or no absorption of X-rays (e.g. air bubbles or microcapsules) and bright colors represent high absorption of X-rays (sand and gravel). The field of view is approximately $1 \mathrm{~cm}$. 
Chapter X.

Conclusions, publications, conferences and future work 



\section{X.1. Conclusions}

The effect of micro-encapsulated phase change materials (MPCM) on the structural and mechanical properties of geopolymer concrete (GPC) has been studied. Different conditions such as whether the samples are below or above the melting point of the phase change material (PCM), and the effect of freeze-thaw cycles have been scrutinized. In order to have comparable data for GPC, the same experiments were carried out on Portland cement concrete (PCC).

The investigation of the development of GPC mixture design with improved physical and mechanical properties for construction applications reviled that:

- Increasing the percentage of MPCM from 0 to $20 \%$ reduced the workability of both GPC and PCC. However all the final mixtures exhibited a good enough workability for placing or casting. The slump of GPC was lower than for PCC due to the high viscosity of the GPC alkaline solution.

- The addition of MPCM induced a compressive strength reduction for both PCC and GPC. For PCC, this reduction was affected by the state (solid or liquid) of the PCM. Whether the PCM is in solid or liquid state does not significantly affect the mechanical properties of GPC. This suggests that GPC is a more suitable option for concrete with incorporated MPCM.

- Despite the negative effect of the MPCMs on the compressive strength of GPC and PCC, the compressive strength is still sufficiently high for structural applications.

- A reliable mix design procedure for class F fly ash/slag GPC was developed to achieve high compressive strength after the addition of MPCM. The mix design and the effect of two different types of MPCM were verified by water absorption of the raw materials, setting time, slump test and compressive strength determination. 
- The percentage of absorbed and retained water of the MPCMs is higher than for sand. More water is adsorbed onto PE-EVA-PCM than for St-DVB-PCM due to the polar groups of the PE-EVA-PCM shell. The shell of the microcapsules is resistant against the highly basic nature of the alkaline solution. A few microcapsules are broken and damaged during the mixing process. The higher water adsorption PE-EVA-PCM caused a lower slump of GPC containing PE-EVA-PCM than for St-DVB-PCM.

- The initial setting time of geopolymer paste increased with the addition of MPCM, while the final setting time became shorter. There are several competing factors affecting the setting time. The adsorbed water reduces the setting time while the setting time is raised by a slower reaction rate caused by the increased viscosity of the samples and possibly, by the latent heat of the MPCM, which can prevent a temperature rise from the reaction heat.

- The proposed mix design could successfully overcome the strength reduction after adding MPCM. After 28 days, the compressive strength of GPC including 20\% MPCM (replacing sand) was higher than for Portland cement concrete without MPCM. The compressive strength is lower in the presence of PE-EVA-PCM. The agglomerated and non-spherical structure of PE-EVA-PCM and a higher amount of air voids might contribute to the reduced workability and lower compressive strength.

- Microstructural studies reveal smaller gaps between St-DVB-PCM and the GPC matrix than for PE-EVA-PCM. MPCM agglomeration and MPCM capsules that are broken during the compressive strength test are probably contributing to the strength reduction after adding MPCM to GPC.

- As expected, decreasing the temperature slowed down the reaction rate for Portland cement, causing longer setting times. Interestingly, the setting times for geopolymer 
pastes are much faster at low temperatures. This might be caused by a phase separation of the alkaline solution at low temperatures.

- The mass loss after 28 freeze-thaw cycles was less than $1 \%$ for all samples. However, the compressive strength of GPC and PCC decrease after exposure to 28 freeze-thaw cycles. Interestingly, the samples containing MPCM exhibit better resistance against frost conditions. Air voids and gaps between the MPCM and the concrete matrix provide free expansion space for water when it freezes, thereby reducing the frost induced stress.

- Microstructural studies illustrated that ettringite crystals are formed in the PCC after exposure to freeze-thaw cycles. In addition, microcracks appeared in the matrix, which will contribute to the deterioration of the concrete. For GPC microcracks also appeared in the interface between the paste and aggregates due to the expansion of capillary water during freeze-thaw cycles.

- The setting times of geopolymer paste is accelerated at higher temperatures due to higher solubility of aluminosilicate, consequently, faster geopolymerization. The compressive strength of both GPC and PCC including MPCMs increase with curing time and temperature. The MPCMs in liquid state affect PCC much more than GPC. A more uniform and compact structure of GPC may contribute to the resistance against thermal expansion or soft particles.

- There are more uniform and undamaged edges in the shell-concrete matrix transition zone of GPC than PCC that might contribute to the better performance of GPC than PCC in the presence of MPCMs when the samples are exposed to temperature fluctuations. Porosity is enhanced at higher temperatures in both GPC and PCC. High viscosity (low workability) of the fresh GPC and the short setting times of GPC especially at $40{ }^{\circ} \mathrm{C}$ can contribute to the prevention of a homogeneous distribution of MPCM throughout the matrix. 


\section{X.2. Publications}

1. Shima Pilehvar, Anna M. Szczotok, Juan Francisco Rodríguez, Luca Valentini, Marcos Lanzón, Ramón Pamies, Anna-Lena Kjøniksen, "Effect of different micro-encapsulated phase change materials in liquid state on the physical and mechanical properties of geopolyer concrete and Portland cement concrete", draft prepared.

2. Shima Pilehvar, Anna M. Szczotok, Manuel Carmona, Ramón Pamies, Anna-Lena Kjøniksen, "Rheological behavior of geopolymer mortar and Portland cement mortar containing different micro-encapsulated phase change materials", draft prepared.

3. Shima Pilehvar, Anna M. Szczotok, Juan Francisco Rodríguez, Luca Valentini, Marcos Lanzón, Ramón Pamies, Anna-Lena Kjøniksen "Effect of freeze-thaw cycles on the mechanical behavior of geopolymer concrete and Portland cement concrete containing micro-encapsulated phase change materials." Submitted to Cement and Concrete Research.

4. Vinh Duy Cao, Shima Pilehvar, Carlos Salas-Bringas, Anna M. Szczotok, Tri Quang Bui, Manuel Carmona, Juan F. Rodriguez, and Anna-Lena Kjøniksen "Thermal analysis of geopolymer concrete walls containing microencapsulated phase change materials for building applications" Submitted to Solar Energy.

5. Vinh Duy Cao, Shima Pilehvar, Carlos Salas Bringas, Anna M-Szczotok, Nu Bich Duyen Do, Hoa Thank Le, Manuel Carmona, Juan F. Rodriguez, Anna-Lena Kjøniksen "Influence of microcapsules size and shell polarity on the time-dependent viscosity of geopolymer paste" Industrial \& Engineering Chemistry Research, in press.

6. Shima Pilehvar, Vinh Duy Cao, Anna M. Szczotok, Manuel Carmona, Luca Valentini, Marcos Lanzón, Ramón Pamies, Anna-Lena Kjøniksen, "Physical and mechanical properties of fly ash and slag geopolymer concrete containing different types of micro-encapsulated phase change materials", Construction and Building Materials, (2018), 173, 28-39.

7. Vinh Duy Cao, Shima Pilehvar, Carlos Salas-Bringas, Anna M. Szczotok, Tri Quang Bui, Manuel Carmona, Juan F. Rodriguez, Anna-Lena Kjøniksen, “Thermal performance and 
numerical simulation of geopolymer concrete containing different types of thermoregulating materials for passive building applications”, Energy and Buildings, (2018), 173, 678-688.

8. Vinh Duy Cao, Shima Pilehvar, Carlos Salas-Bringas, Anna M. Szczotok, Tri Quang Bui, Manuel Carmona, Juan F. Rodriguez, Anna-Lena Kjøniksen, “Influence of microcapsule size and shell polarity on thermal and mechanical properties of thermoregulating geopolymer concrete for passive building applications”, Energy Conversion and Management, (2018), 164, 198-209.

9. Shima Pilehvar, Vinh Duy Cao, Anna M. Szczotok, Luca Valentini, Davide Salvioni, Matteo Magistri, Ramón Pamies, Anna-Lena Kjøniksen, "Mechanical properties and microscale changes of geopolymer concrete and Portland cement concrete containing micro-encapsulated phase change materials", Cement and Concrete Research (2017), 100, 341-349.

10. Vinh Duy Cao, Shima Pilehvar, Carlos Salas-Bringas, Anna M. Szczotok, Juan F.Rodriguez, Manuel Carmona, Nodar Al-Manasir, Anna-Lena Kjøniksen, "Microencapsulated phase change materials for enhancing the thermal performance of Portland cement concrete and geopolymer concrete for passive building applications”, Energy Conversion and Management, (2017), 133, $56-66$. 


\section{X.3. Conferences}

1. Shima Pilehvar, Anna M. Szczotok, Ramón Pamies, Anna-Lena Kjøniksen, “ The Effect of Micro-encapsulated Phase Change Materials in Liquid State on the Properties of Geopolymer and Portland Cement Concrete", $3^{\text {rd }} \quad$ International Conference on "Innovative Materials, Structures and Technologies" Riga, Latvia (2017), Poster.

2. V.D. Cao, S. Pilehvar, C. Salas-Bringas, A.M. Szczotok, A.-L. Kjøniksen, Smart Geopolymer Concrete Containing Microencapsulated Phase Change Materials for Passive Building Applications, $3^{\text {rd }}$ International Conference on "Innovative Materials, Structures and Technologies” IMST 2017. Riga, Latvia (2017). Poster.

3. Shima Pilehvar, "Investigating the mechanical properties of geopolymer concrete with incorporated micro-encapsulated phase change materials", The $9^{\text {th }}$ Geopolymer Camp, SaintQuentin, France (2017), Oral presentation.

4. Shima Pilehvar, "The Effect of Micro-encapsulated Phase Change Materials in Liquid State on Properties of Geopolymer and Portland Cement Concrete", International Conference on Energy, Environment and Economics, Heriot-Watt University, Edinburgh, The UK (2016), Oral presentation.

5. Shima Pilehvar, "The mechanical behavior of geopolymer and Portland cement concretes with different contents of micro-encapsulated PCM", Advanced Building Skins, Bern, Switzerland (2016), Oral presentation.

6. Shima Pilehvar, "Investigating the mechanical properties of geopolymer concrete with microencapsulated phase change materials", The $8^{\text {th }}$ Geopolymer Camp, Saint-Quentin, France (2016), Oral presentation. 


\section{X.4. Future work}

The following recommendations are interesting for future research:

- Utilizing other waste materials in the production of GPC to eliminate the amount of waste dumped in landfills.

- Extending the study to optimize geopolymer composite recipe for producing other building materials such as brick, pavement stone, and tunnel elements incorporated with MPCM.

- Improving the mixture design of GPC incorporated with MPCM by investigating different steps or different procedures to optimize GPC with MPCM.

- Completing the study of the mechanical properties of GPC such as freeze or fire resistance by considering a large variety of melting points of MPCMs.

- Performing an economical evaluation and life cycle assessment of the production of GPC with incorporation of MPCM. 


\section{References}

1. Flower, D.J.M. and Sanjayan, J.G., Green house gas emissions due to concrete manufacture. The International Journal of Life Cycle Assessment, 2007. 12(5): p. 282, DOI: $10.1065 /$ lca2007.05.327.

2. (USGS), U.S.G.S. Mineral commodity summaries. 2018; Available from: https://minerals.usgs.gov/minerals/pubs/commodity/cement/mcs-2018-cemen.pdf.

3. Müller, N. and Harnisch, J., A blueprint for a climate friendly cement industry. Gland: WWF lafarge conservation partnership, 2008.

4. Benhelal, E., Zahedi, G., Shamsaei, E., and Bahadori, A., Global strategies and potentials to curb CO2 emissions in cement industry. Journal of Cleaner Production, 2013. 51: p. 142-161, DOI: 10.1016/j.jclepro.2012.10.049.

5. Centre, C.D.I.A. Recent Greenhouse Gas Concentrations. 2016.

6. Andrew, R.M., Global CO2 emissions from cement production. Earth Syst. Sci. Data, 2018. 10(1): p. 195-217, DOI: 10.5194/essd-10-195-2018.

7. Administration, U.S.E.I. International Energy Outlook 2017 21.11.2017 ]; Available from: https://www.eia.gov/.

8. Administration, U.S.E.I. Annual energy outlook 2018. 2018; Available from: https://www.eia.gov/.

9. WBCSD, I., Cement Technology Roadmap 2009: carbon emissions reductions up to 2050. World Business Council for Sustainable Development and International Energy 
Agency.< http://wbcsdcement. org/pdf/technology/WBCSD-IEA_Cement\% 20Roadmap. pdf, 2009.

10. Kosmatka, S.H., Kerkhoff, B., Panarese, W.C., MacLeod, N.F., and McGrath, R.J., Design and Control of Concrete Mixtures, Seventh Canadian Edition. Cement Association of Canada, 2002: p. 151.

11. Mehta, P.K., Greening of the concrete industry for sustainable development. Concrete international, 2002. 24(7): p. 23-28.

12. Siddique, R., Waste Materials and By-Products in Concrete. 2007: Springer Berlin Heidelberg.

13. Diaz, E.I., Allouche, E.N., and Eklund, S., Factors affecting the suitability of fly ash as source material for geopolymers. Fuel, 2010. 89(5): p. 992-996, DOI: 10.1016/j.fuel.2009.09.012.

14. Nazari, A., Bagheri, A., and Riahi, S., Properties of geopolymer with seeded fly ash and rice husk bark ash. Materials Science and Engineering: A, 2011. 528(24): p. 7395-7401, DOI: 10.1016/j.msea.2011.06.027.

15. Nath, P. and Sarker, P.K., Effect of GGBFS on setting, workability and early strength properties of fly ash geopolymer concrete cured in ambient condition. Construction and Building Materials, 2014. 66: p. 163-171.

16. Oh, J.E., Monteiro, P.J.M., Jun, S.S., Choi, S., and Clark, S.M., The evolution of strength and crystalline phases for alkali-activated ground blast furnace slag and fly ash-based geopolymers. Cement and Concrete Research, 2010. 40(2): p. 189-196, DOI: 10.1016/j.cemconres.2009.10.010. 
17. Pelisser, F., Guerrino, E.L., Menger, M., Michel, M.D., and Labrincha, J.A., Micromechanical characterization of metakaolin-based geopolymers. Construction and Building Materials, 2013. 49: p. 547-553, DOI: 10.1016/j.conbuildmat.2013.08.081.

18. Yip, C.K., Lukey, G.C., Provis, J.L., and van Deventer, J.S.J., Effect of calcium silicate sources on geopolymerisation. Cement and Concrete Research, 2008. 38(4): p. 554-564, DOI: 10.1016/j.cemconres.2007.11.001.

19. He, J., Jie, Y., Zhang, J., Yu, Y., and Zhang, G., Synthesis and characterization of red mud and rice husk ash-based geopolymer composites. Cement and Concrete Composites, 2013. 37: p. 108-118, DOI: 10.1016/j.cemconcomp.2012.11.010.

20. Dimas, D.D., Giannopoulou, I.P., and Panias, D., Utilization of alumina red mud for synthesis of inorganic polymeric materials. Mineral processing \& Extractive metallurgy review, 2009. 30(3): p. 211-239.

21. Zhou, F., Barr, B., and Lydon, F., Fracture properties of high strength concrete with varying silica fume content and aggregates. Cement and concrete research, 1995. 25(3): p. 543-552.

22. Bhanja, S. and Sengupta, B., Optimum silica fume content and its mode of action on concrete. ACI Materials Journal, 2003. 100(5): p. 407-412.

23. Querol, X., Moreno, N., Umaña, J.C., Alastuey, A., Hernández, E., López-Soler, A., and Plana, F., Synthesis of zeolites from coal fly ash: an overview. International Journal of Coal Geology, 2002. 50(1): p. 413-423, DOI: 10.1016/S0166-5162(02)00124-6.

24. Ahmaruzzaman, M., A review on the utilization of fly ash. Progress in Energy and Combustion Science, 2010. 36(3): p. 327-363, DOI: 10.1016/j.pecs.2009.11.003. 
25. Yunsheng, Z., Wei, S., Qianli, C., and Lin, C., Synthesis and heavy metal immobilization behaviors of slag based geopolymer. Journal of Hazardous Materials, 2007. 143(1): p. 206-213, DOI: 10.1016/j.jhazmat.2006.09.033.

26. Ulubeyli, G.C. and Artir, R., Sustainability for Blast Furnace Slag: Use of Some Construction Wastes. Procedia - Social and Behavioral Sciences, 2015. 195: p. 21912198, DOI: 10.1016/j.sbspro.2015.06.297.

27. Davidovits, J., Geopolymer Chemistry and Applications. 2011, Saint-Quentin, France: Institute Géopolymère. 612.

28. Li, C., Sun, H., and Li, L., A review: The comparison between alkali-activated slag $(\mathrm{Si}+\mathrm{Ca})$ and metakaolin $(\mathrm{Si}+\mathrm{Al})$ cements. Cement and Concrete Research, 2010. 40(9): p. 1341-1349, DOI: 10.1016/j.cemconres.2010.03.020.

29. Sabir, B.B., Wild, S., and Bai, J., Metakaolin and calcined clays as pozzolans for concrete: a review. Cement and Concrete Composites, 2001. 23(6): p. 441-454, DOI: 10.1016/S0958-9465(00)00092-5.

30. Liu, R.-X. and Poon, C.-S., Utilization of red mud derived from bauxite in selfcompacting concrete. Journal of Cleaner Production, 2016. 112: p. 384-391, DOI: 10.1016/j.jclepro.2015.09.049.

31. Tang, L., Study of the Possibilities of Using Red Mud as An Additive in Concrete and Grout Mortar, Svensk Kärnbränslehantering AB Swedish Nuclear Fuel and Waste Management Co. Report-14-04, 2014.

32. Ashok, P. and Sureshkumar, M., Experimental studies on concrete utilising red mud as a partial replacement of cement with hydrated lime. J. Mech. Civil Eng, 2014: p. 1-10. 
33. Roy, D.M., Alkali-activated cements Opportunities and challenges. Cement and Concrete Research, 1999. 29(2): p. 249-254, DOI: 10.1016/S0008-8846(98)00093-3.

34. Glukhovsky, V., Soil silicates. Their properties, technology and manufacturing and fields of application. Doct. Tech. Sc. Degree Thesis, Civil Engineering Institute, Kiev, Ukraine, 1965.

35. $\mathrm{Xu}, \mathrm{H}$. and Van Deventer, J.S.J., The geopolymerisation of alumino-silicate minerals. International Journal of Mineral Processing, 2000. 59(3): p. 247-266, DOI: 10.1016/S0301-7516(99)00074-5.

36. Khale, D. and Chaudhary, R., Mechanism of geopolymerization and factors influencing its development: a review. Journal of Materials Science, 2007. 42(3): p. 729-746, DOI: 10.1007/s10853-006-0401-4.

37. Van Jaarsveld, J.G.S., Van Deventer, J.S.J., and Lorenzen, L., Factors affecting the immobilization of metals in geopolymerized flyash. Metallurgical and Materials Transactions B, 1998. 29(1): p. 283-291, DOI: 10.1007/s11663-998-0032-z.

38. Komnitsas, K. and Zaharaki, D., Geopolymerisation: A review and prospects for the minerals industry. Minerals Engineering, 2007. 20(14): p. 1261-1277, DOI: 10.1016/j.mineng.2007.07.011.

39. Van Jaarsveld, J.G.S., Van Deventer, J.S.J., and Lorenzen, L., The potential use of geopolymeric materials to immobilise toxic metals: Part I. Theory and applications. Minerals Engineering, 1997. 10(7): p. 659-669, DOI: 10.1016/S0892-6875(97)000460.

40. Rangan, B.V., Fly ash-based geopolymer concrete. 2008. 
41. Davidovits, J., Geopolymers: inorganic polymeric new materials. Journal of Thermal Analysis and calorimetry, 1991. 37(8): p. 1633-1656.

42. Thokchom, S., Dutta, D., and Ghosh, S., Effect of incorporating silica fume in fly ash geopolymers. World Academy of Science, Engineering and Technology, 2011. 60: p. 243-247.

43. Rattanasak, U. and Chindaprasirt, P., Influence of NaOH solution on the synthesis of fly ash geopolymer. Minerals Engineering, 2009. 22(12): p. 1073-1078, DOI: 10.1016/j.mineng.2009.03.022.

44. Panias, D., Giannopoulou, I.P., and Perraki, T., Effect of synthesis parameters on the mechanical properties of fly ash-based geopolymers. Colloids and Surfaces A: Physicochemical and Engineering Aspects, 2007. 301(1-3): p. 246-254, DOI: 10.1016/j.colsurfa.2006.12.064.

45. van Jaarsveld, J.G.S. and van Deventer, J.S.J., Effect of the Alkali Metal Activator on the Properties of Fly Ash-Based Geopolymers. Industrial \& Engineering Chemistry Research, 1999. 38(10): p. 3932-3941, DOI: 10.1021/ie980804b.

46. Phoo-ngernkham, T., Maegawa, A., Mishima, N., Hatanaka, S., and Chindaprasirt, P., Effects of sodium hydroxide and sodium silicate solutions on compressive and shear bond strengths of FA-GBFS geopolymer. Construction and Building Materials, 2015. 91: p. 1-8, DOI: 10.1016/j.conbuildmat.2015.05.001.

47. Criado, M., Palomo, A., and Fernández-Jiménez, A., Alkali activation of fly ashes. Part 1: Effect of curing conditions on the carbonation of the reaction products. Fuel, 2005. 84(16): p. 2048-2054, DOI: 10.1016/j.fuel.2005.03.030. 
48. Hardjito, D., Cheak, C.C., and Ing, C.H.L., Strength and setting times of low calcium fly ash-based geopolymer mortar. Modern applied science, 2008. 2(4): p. p3.

49. Li, Z., Ding, Z., and Zhang, Y. Development of sustainable cementitious materials. in Proceedings of international workshop on sustainable development and concrete technology, Beijing, China. 2004.

50. Ryu, G.S., Lee, Y.B., Koh, K.T., and Chung, Y.S., The mechanical properties of fly ash-based geopolymer concrete with alkaline activators. Construction and Building Materials, 2013. 47: p. 409-418, DOI: 10.1016/j.conbuildmat.2013.05.069.

51. Allahverdi, A., Pilehvar, S., and Mahinroosta, M., Influence of curing conditions on the mechanical and physical properties of chemically-activated phosphorous slag cement. Powder Technology, 2016. 288: p. 132-139, DOI: 10.1016/j.powtec.2015.10.053.

52. Sun, P. and Wu, H.-C., Chemical and freeze-thaw resistance of fly ash-based inorganic mortars. Fuel, 2013. 111: p. 740-745, DOI: 10.1016/j.fuel.2013.04.070.

53. Fu, Y., Cai, L., and Yonggen, W., Freeze-thaw cycle test and damage mechanics models of alkali-activated slag concrete. Construction and Building Materials, 2011. 25(7): p. 3144-3148, DOI: 10.1016/j.conbuildmat.2010.12.006.

54. Bakharev, T., Resistance of geopolymer materials to acid attack. Cement and Concrete Research, 2005. 35(4): p. 658-670, DOI: 10.1016/j.cemconres.2004.06.005.

55. Bakharev, T., Durability of geopolymer materials in sodium and magnesium sulfate solutions. Cement and Concrete Research, 2005. 35(6): p. 1233-1246, DOI: 10.1016/j.cemconres.2004.09.002. 
56. Cheng, T.W. and Chiu, J.P., Fire-resistant geopolymer produced by granulated blast furnace slag. Minerals Engineering, 2003. 16(3): p. 205-210, DOI: 10.1016/S08926875(03)00008-6.

57. Kong, D.L.Y. and Sanjayan, J.G., Effect of elevated temperatures on geopolymer paste, mortar and concrete. Cement and Concrete Research, 2010. 40(2): p. 334-339, DOI: 10.1016/j.cemconres.2009.10.017.

58. Ana M. Fernandez-Jimenez, A.P. and Cecilio, L.-H., Engineering Properties of AlkaliActivated Fly Ash Concrete. ACI Materials Journal, 2006. 103(2): p. 106-112, DOI: $10.14359 / 15261$.

59. Davidovits, J., High-alkali cements for 21st century concretes. Special Publication, 1994. 144: p. 383-398.

60. Singh, B., Ishwarya, G., Gupta, M., and Bhattacharyya, S., Geopolymer concrete: a review of some recent developments. Construction and building materials, 2015. 85: p. 78-90.

61. Hardjito, D., Wallah, S.E., Sumajouw, D.M., and Rangan, B., Factors influencing the compressive strength of fly ash-based geopolymer concrete. civil engineering dimension, 2004. 6(2): p. pp. 88-93.

62. Part, W.K., Ramli, M., and Cheah, C.B., An overview on the influence of various factors on the properties of geopolymer concrete derived from industrial by-products. Construction and Building Materials, 2015. 77: p. 370-395, DOI: 10.1016/j.conbuildmat.2014.12.065. 
63. Soutsos, M., Boyle, A.P., Vinai, R., Hadjierakleous, A., and Barnett, S.J., Factors influencing the compressive strength of fly ash based geopolymers. Construction and Building Materials, 2016. 110: p. 355-368, DOI: 10.1016/j.conbuildmat.2015.11.045.

64. Hardjito, D., Wallah, S.E., Sumajouw, D.M., and Rangan, B.V., On the development of fly ash-based geopolymer concrete. ACI Materials Journal-American Concrete Institute, 2004. 101(6): p. 467-472.

65. Talha Junaid, M., Kayali, O., Khennane, A., and Black, J., A mix design procedure for low calcium alkali activated fly ash-based concretes. Construction and Building Materials, 2015. 79: p. 301-310, DOI: 10.1016/j.conbuildmat.2015.01.048.

66. Pavithra, P., Reddy, M.S., Dinakar, P., Rao, B.H., Satpathy, B., and Mohanty, A., A mix design procedure for geopolymer concrete with fly ash. Journal of Cleaner Production, 2016. 133: p. 117-125.

67. Zhang, H., Baeyens, J., Cáceres, G., Degrève, J., and Lv, Y., Thermal energy storage: Recent developments and practical aspects. Progress in Energy and Combustion Science, 2016. 53(Supplement C): p. 1-40, DOI: 10.1016/j.pecs.2015.10.003.

68. Akeiber, H., Nejat, P., Majid, M.Z.A., Wahid, M.A., Jomehzadeh, F., Zeynali Famileh, I., Calautit, J.K., Hughes, B.R., and Zaki, S.A., A review on phase change material (PCM) for sustainable passive cooling in building envelopes. Renewable and Sustainable Energy Reviews, 2016. 60: p. 1470-1497, DOI: 10.1016/j.rser.2016.03.036.

69. Kalnæs, S.E. and Jelle, B.P., Phase change materials and products for building applications: A state-of-the-art review and future research opportunities. Energy and Buildings, 2015. 94: p. 150-176, DOI: 10.1016/j.enbuild.2015.02.023. 
70. Khudhair, A.M. and Farid, M.M., A review on energy conservation in building applications with thermal storage by latent heat using phase change materials. Energy Conversion and Management, 2004. 45(2): p. 263-275, DOI: 10.1016/S01968904(03)00131-6.

71. You, M., Wang, X., Zhang, X., Zhang, L., and Wang, J., Microencapsulated nOctadecane with styrene-divinybenzene co-polymer shells. Journal of Polymer Research, 2011. 18(1): p. 49-58, DOI: 10.1007/s10965-010-9390-8.

72. Qiu, X., Li, W., Song, G., Chu, X., and Tang, G., Microencapsulated n-octadecane with different methylmethacrylate-based copolymer shells as phase change materials for thermal energy storage. Energy, 2012. 46(1): p. 188-199, DOI: 10.1016/j.energy.2012.08.037.

73. Chaiyasat, P., Islam, M.Z., and Chaiyasat, A., Preparation of poly(divinylbenzene) microencapsulated octadecane by microsuspension polymerization: oil droplets generated by phase inversion emulsification. RSC Advances, 2013. 3(26): p. 1020210207, DOI: 10.1039/C3RA40802G.

74. Qiu, X., Song, G., Chu, X., Li, X., and Tang, G., Preparation, thermal properties and thermal reliabilities of microencapsulated n-octadecane with acrylic-based polymer shells for thermal energy storage. Thermochimica Acta, 2013. 551(Supplement C): p. 136-144, DOI: 10.1016/j.tca.2012.10.027.

75. Yafei, A., Yong, J., Jing, S., and Deqing, W., Microencapsulation of n-hexadecane as phase change material by suspension polymerization. e-Polymers, 2007. 7(1), DOI: 10.1515/epoly.2007.7.1.1124 M4 - Citavi. 
76. Lashgari, S., Arabi, H., Mahdavian, A.R., and Ambrogi, V., Thermal and morphological studies on novel PCM microcapsules containing $n$-hexadecane as the core in a flexible shell. Applied Energy, 2017. 190: p. 612-622.

77. Sánchez, L., Sánchez, P., Lucas, A., Carmona, M., and Rodríguez, J.F., Microencapsulation of PCMs with a polystyrene shell. Colloid and Polymer Science, 2007. 285(12): p. 1377-1385, DOI: 10.1007/s00396-007-1696-7.

78. Sánchez, L., Lacasa, E., Carmona, M., Rodríguez, J.F., and Sánchez, P., Applying an Experimental Design to Improve the Characteristics of Microcapsules Containing Phase Change Materials for Fabric Uses. Industrial \& Engineering Chemistry Research, 2008. 47(23): p. 9783-9790, DOI: 10.1021/ie801107e.

79. Sánchez, L., Sánchez, P., Carmona, M., Lucas, A., and Rodríguez, J.F., Influence of operation conditions on the microencapsulation of PCMs by means of suspension-like polymerization. Colloid and Polymer Science, 2008. 286(8-9): p. 1019-1027, DOI: 10.1007/s00396-008-1864-4.

80. Kumar, M., Nano and microparticles as controlled drug delivery devices. J. Pharm. Pharm. Sci, 2000. 3(2): p. 234-258.

81. Zhao, Q. and Li, B., pH-controlled drug loading and release from biodegradable microcapsules. Nanomedicine: Nanotechnology, Biology and Medicine, 2008. 4(4): p. 302-310.

82. Desai, S., Perkins, J., Harrison, B.S., and Sankar, J., Understanding release kinetics of biopolymer drug delivery microcapsules for biomedical applications. Materials Science and Engineering: B, 2010. 168(1-3): p. 127-131. 
83. F. Gibbs, S.K., Inteaz Alli, Catherine N. Mulligan, Bernard, Encapsulation in the food industry: a review. International journal of food sciences and nutrition, 1999. 50(3): p. 213-224.

84. Gharsallaoui, A., Roudaut, G., Chambin, O., Voilley, A., and Saurel, R., Applications of spray-drying in microencapsulation offood ingredients: An overview. Food Research International, 2007. 40(9): p. 1107-1121, DOI: 10.1016/j.foodres.2007.07.004.

85. Estevinho, B.N., Rocha, F., Santos, L., and Alves, A., Microencapsulation with chitosan by spray drying for industry applications $-A$ review. Trends in Food Science \& Technology, 2013. 31(2): p. 138-155, DOI: 10.1016/j.tifs.2013.04.001.

86. Nejman, A., Cieślak, M., Gajdzicki, B., Goetzendorf-Grabowska, B., and Karaszewska, A., Methods of PCM microcapsules application and the thermal properties of modified knitted fabric. Thermochimica Acta, 2014. 589: p. 158-163, DOI: 10.1016/j.tca.2014.05.037.

87. Sánchez, P., Sánchez-Fernandez, M.V., Romero, A., Rodríguez, J.F., and SánchezSilva, L., Development of thermo-regulating textiles using paraffin wax microcapsules. Thermochimica Acta, 2010. 498(1): p. 16-21, DOI: 10.1016/j.tca.2009.09.005.

88. Reddy, K.R., Sin, B.C., Yoo, C.H., Sohn, D., and Lee, Y., Coating of multiwalled carbon nanotubes with polymer nanospheres through microemulsion polymerization. Journal of Colloid and Interface Science, 2009. 340(2): p. 160-165, DOI: 10.1016/j.jcis.2009.08.044.

89. Reddy, K.R., Lee, K.-P., and Gopalan, A.I., Self-assembly directed synthesis of poly (ortho-toluidine)-metal (gold and palladium) composite nanospheres. Journal of nanoscience and nanotechnology, 2007. 7(9): p. 3117-3125. 
90. Hassan, M., Reddy, K.R., Haque, E., Minett, A.I., and Gomes, V.G., High-yield aqueous phase exfoliation of graphene for facile nanocomposite synthesis via emulsion polymerization. Journal of Colloid and Interface Science, 2013. 410: p. 43-51, DOI: 10.1016/j.jcis.2013.08.006.

91. Yu, F., Fang, Y., Wang, J., Xu, Y., and Shi, J., Fabrication of compact poly(methyl methacrylate-co-butyl methacrylate-co-acrylic acid) microcapsules for electrophoretic displays by using emulsion droplets as templates. Colloid and Polymer Science, 2016. 294(8): p. 1359-1367, DOI: 10.1007/s00396-016-3901-z.

92. Konuklu, Y., Ostry, M., Paksoy, H.O., and Charvat, P., Review on using microencapsulated phase change materials (PCM) in building applications. Energy and Buildings, 2015. 106: p. 134-155, DOI: 10.1016/j.enbuild.2015.07.019.

93. Hawlader, M.N.A., Uddin, M.S., and Khin, M.M., Microencapsulated PCM thermalenergy storage system. Applied Energy, 2003. 74(1-2): p. 195-202, DOI: 10.1016/S0306-2619(02)00146-0.

94. Hawes, D., Banu, D., and Feldman, D., Latent heat storage in concrete. II. Solar energy materials, 1990. 21(1): p. 61-80.

95. Pons, O., Aguado, A., Fernández, A.I., Cabeza, L.F., and Chimenos, J.M., Review of the use of phase change materials (PCMs) in buildings with reinforced concrete structures. Materiales de Construcción, 2014. 64(315): p. 031.

96. Zhou, D., Zhao, C.Y., and Tian, Y., Review on thermal energy storage with phase change materials (PCMs) in building applications. Applied Energy, 2012. 92(Supplement C): p. 593-605, DOI: 10.1016/j.apenergy.2011.08.025. 
97. Barreneche, C., Navarro, H., Serrano, S., Cabeza, L.F., and Fernández, A.I., New Database on Phase Change Materials for Thermal Energy Storage in Buildings to Help PCM Selection. Energy Procedia, 2014. 57(Supplement C): p. 2408-2415, DOI: 10.1016/j.egypro.2014.10.249.

98. Giro-Paloma, J., Martínez, M., Cabeza, L.F., and Fernández, A.I., Types, methods, techniques, and applications for microencapsulated phase change materials (MPCM): A review. Renewable and Sustainable Energy Reviews, 2016. 53(Supplement C): p. 1059-1075, DOI: 10.1016/j.rser.2015.09.040.

99. Zhu, N., Ma, Z., and Wang, S., Dynamic characteristics and energy performance of buildings using phase change materials: A review. Energy Conversion and Management, 2009. 50(12): p. 3169-3181, DOI: 10.1016/j.enconman.2009.08.019.

100. de Gracia, A. and Cabeza, L.F., Phase change materials and thermal energy storage for buildings. Energy and Buildings, 2015. 103 (Supplement C): p. 414-419, DOI: 10.1016/j.enbuild.2015.06.007.

101. Ling, T.-C. and Poon, C.-S., Use of phase change materials for thermal energy storage in concrete: An overview. Construction and Building Materials, 2013. 46: p. 55-62, DOI: 10.1016/j.conbuildmat.2013.04.031.

102. Pania, M. and Yunping, X., Effect of Phase-Change Materials on Properties of Concrete. Materials Journal. 109(1), DOI: 10.14359/51683572.

103. Hunger, M., Entrop, A., Mandilaras, I., Brouwers, H., and Founti, M., The behavior of self-compacting concrete containing micro-encapsulated phase change materials. Cement and Concrete Composites, 2009. 31(10): p. 731-743. 
104. Cunha, S., Aguiar, J.B., Ferreira, V.M., and Tadeu, A., Influence of the Type of Phase Change Materials Microcapsules on the Properties of Lime-Gypsum Thermal Mortars. Advanced Engineering Materials, 2014. 16(4): p. 433-441.

105. Park, S.-K., Kim, J.-H.J., Nam, J.-W., Phan, H.D., and Kim, J.-K., Development of antifungal mortar and concrete using Zeolite and Zeocarbon microcapsules. Cement and Concrete Composites, 2009. 31(7): p. 447-453, DOI: 10.1016/j.cemconcomp.2009.04.012.

106. Eddhahak-Ouni, A., Drissi, S., Colin, J., Neji, J., and Care, S., Experimental and multiscale analysis of the thermal properties of Portland cement concretes embedded with microencapsulated Phase Change Materials (PCMs). Applied Thermal Engineering, 2014. 64(1-2): p. 32-39, DOI: 10.1016/j.applthermaleng.2013.11.050.

107. Cabeza, L.F., Castellón, C., Nogués, M., Medrano, M., Leppers, R., and Zubillaga, O., Use of microencapsulated PCM in concrete walls for energy savings. Energy and Buildings, 2007. 39(2): p. 113-119, DOI: 10.1016/j.enbuild.2006.03.030.

108. Figueiredo, A., Lapa, J., Vicente, R., and Cardoso, C., Mechanical and thermal characterization of concrete with incorporation of microencapsulated PCM for applications in thermally activated slabs. Construction and Building Materials, 2016. 112: p. 639-647, DOI: 10.1016/j.conbuildmat.2016.02.225.

109. Lecompte, T., Le Bideau, P., Glouannec, P., Nortershauser, D., and Le Masson, S., Mechanical and thermo-physical behaviour of concretes and mortars containing phase change material. Energy and buildings, 2015.94: p. 52-60.

110. Pilehvar, S., Cao, V.D., Szczotok, A.M., Valentini, L., Salvioni, D., Magistri, M., Pamies, R., and Kjøniksen, A.-L., Mechanical properties and microscale changes of 
geopolymer concrete and Portland cement concrete containing micro-encapsulated phase change materials. Cement and Concrete Research, 2017. 100: p. 341-349, DOI: 10.1016/j.cemconres.2017.07.012.

111. Hawes, D., Banu, D., and Feldman, D., The stability of phase change materials in concrete. Solar energy materials and solar cells, 1992. 27(2): p. 103-118.

112. Bentz, D.P. and Turpin, R., Potential applications of phase change materials in concrete technology. Cement and Concrete Composites, 2007. 29(7): p. 527-532, DOI: 10.1016/j.cemconcomp.2007.04.007.

113. Hawes and W, D., Latent heat storage in concrete, in Centre for Building Studies 1991: Concordia University

114. Borreguero, A.M., Valverde, J.L., Rodríguez, J.F., Barber, A.H., Cubillo, J.J., and Carmona, M., Synthesis and characterization of microcapsules containing Rubitherm®RT27 obtained by spray drying. Chemical Engineering Journal, 2011. 166(1): p. 384-390, DOI: 10.1016/j.cej.2010.10.055.

115. Szczotok, A.M., Carmona, M., Kjøniksen, A.-L., and Rodriguez, J.F., Equilibrium adsorption of polyvinylpyrrolidone and its role on thermoregulating microcapsules synthesis process. Colloid and Polymer Science, 2017. 295(5): p. 783-792, DOI: 10.1007/s00396-017-4061-5.

116. Peippo, K., Kauranen, P., and Lund, P.D., A multicomponent PCM wall optimized for passive solar heating. Energy and Buildings, 1991. 17(4): p. 259-270, DOI: 10.1016/0378-7788(91)90009-R. 
117. Medved, S. and Arkar, C., Correlation between the local climate and the free-cooling potential of latent heat storage. Energy and Buildings, 2008. 40(4): p. 429-437, DOI: 10.1016/j.enbuild.2007.03.011.

118. EN, B., 12350-2, Testing fresh concrete: slump test. London: British Standards Institution, 2000.

119. Feldkamp, L., Davis, L., and Kress, J., Practical cone-beam algorithm. JOSA A, 1984. 1(6): p. 612-619.

120. Li, C. and Tam, P.K.-S., An iterative algorithm for minimum cross entropy thresholding. Pattern Recognition Letters, 1998. 19(8): p. 771-776.

121. Schneider, C.A., Rasband, W.S., and Eliceiri, K.W., NIH Image to ImageJ: 25 years of image analysis. Nat methods, 2012. 9(7): p. 671-675.

122. Cao, V.D., Pilehvar, S., Salas-Bringas, C., Szczotok, A.M., Rodriguez, J.F., Carmona, M., Al-Manasir, N., and Kjøniksen, A.-L., Microencapsulated phase change materials for enhancing the thermal performance of Portland cement concrete and geopolymer concrete for passive building applications. Energy Conversion and Management, 2017. 133: p. 56-66, DOI: 10.1016/j.enconman.2016.11.061.

123. Deb, P.S., Nath, P., and Sarker, P.K., The effects of ground granulated blast-furnace slag blending with fly ash and activator content on the workability and strength properties of geopolymer concrete cured at ambient temperature. Materials \& Design, 2014. 62: p. 32-39, DOI: 10.1016/j.matdes.2014.05.001. 
124. Provis, J.L., Duxson, P., and van Deventer, J.S.J., The role of particle technology in developing sustainable construction materials. Advanced Powder Technology, 2010. 21(1): p. 2-7, DOI: 10.1016/j.apt.2009.10.006.

125. Shadnia, R., Zhang, L., and Li, P., Experimental study of geopolymer mortar with incorporated PCM. Construction and Building Materials, 2015. 84: p. 95-102, DOI: 10.1016/j.conbuildmat.2015.03.066.

126. Cui, H., Liao, W., Mi, X., Lo, T.Y., and Chen, D., Study on functional and mechanical properties of cement mortar with graphite-modified microencapsulated phase-change materials. Energy and Buildings, 2015. 105: p. 273-284, DOI: 10.1016/j.enbuild.2015.07.043.

127. Rovnaník, P., Effect of curing temperature on the development of hard structure of metakaolin-based geopolymer. Construction and Building Materials, 2010. 24(7): p. 1176-1183.

128. Bingöl, A.F. and Tohumcu, İ., Effects of different curing regimes on the compressive strength properties of self compacting concrete incorporating fly ash and silica fume. Materials \& Design, 2013. 51: p. 12-18, DOI: 10.1016/j.matdes.2013.03.106.

129. Cunha, S., Aguiar, J., and Pacheco-Torgal, F., Effect of temperature on mortars with incorporation of phase change materials. Construction and Building Materials, 2015. 98: p. 89-101, DOI: 10.1016/j.conbuildmat.2015.08.077.

130. Hunger, M., Entrop, A.G., Mandilaras, I., Brouwers, H.J.H., and Founti, M., The behavior of self-compacting concrete containing micro-encapsulated Phase Change Materials. Cement and Concrete Composites, 2009. 31(10): p. 731-743, DOI: 10.1016/j.cemconcomp.2009.08.002. 
131. M. Hunger, A.G.E., I. Mandilaras, H.J.H. Brouwers, M. Founti, The behavior of selfcompacting concrete containing micro-encapsulated Phase Change Materials. Cement \& Concrete Composites, 2009. 31: p. 731-743.

132. Pejman Keikhaei Dehdezi , M.R.H., Andrew R. Dawson \& Sean P. Casey, Thermal, mechanical and microstructural analysis of concrete containing microencapsulated phase change materials. International Journal of Pavement Engineering, 2012: p. 449462.

133. Borreguero, A.M., Serrano, A., Garrido, I., Rodríguez, J.F., and Carmona, M., Polymeric-SiO2-PCMs for improving the thermal properties of gypsum applied in energy efficient buildings. Energy Conversion and Management, 2014. 87: p. 138-144.

134. Moosberg-Bustnes, H., Lagerblad, B., and Forssberg, E., The function of fillers in concrete Materials and Structures, 2004. 37: p. 74-81.

135. Norvell, C., Sailor, D.J., and Dusicka, P., The effect of microencapsulated phase-change material on the compressive strength of structural concrete. Journal of Green Building, 2013. 8(3): p. 116-124.

136. Nikbin, I., Beygi, M., Kazemi, M., Amiri, J.V., Rabbanifar, S., Rahmani, E., and Rahimi, S., A comprehensive investigation into the effect of water to cement ratio and powder content on mechanical properties of self-compacting concrete. Construction and Building Materials, 2014. 57: p. 69-80.

137. Aguayo, M., Das, S., Maroli, A., Kabay, N., Mertens, J.C.E., Rajan, S.D., Sant, G., Chawla, N., and Neithalath, N., The influence of microencapsulated phase change material (PCM) characteristics on the microstructure and strength of cementitious 
composites: Experiments and finite element simulations. Cement and Concrete Composites, 2016. 73: p. 29-41, DOI: 10.1016/j.cemconcomp.2016.06.018.

138. Kumar, S., Kumar, R., and Mehrotra, S.P., Influence of granulated blast furnace slag on the reaction, structure and properties of fly ash based geopolymer. Journal of Materials Science, 2010. 45(3): p. 607-615, DOI: 10.1007/s10853-009-3934-5.

139. Kusbiantoro, A., Nuruddin, M.F., Shafiq, N., and Qazi, S.A., The effect of microwave incinerated rice husk ash on the compressive and bond strength of fly ash based geopolymer concrete. Construction and Building Materials, 2012. 36: p. 695-703.

140. Rashad, A.M., A comprehensive overview about the influence of different admixtures and additives on the properties of alkali-activated fly ash. Materials \& Design, 2014. 53: p. 1005-1025, DOI: 10.1016/j.matdes.2013.07.074.

141. Xu, H., Gong, W., Syltebo, L., Izzo, K., Lutze, W., and Pegg, I.L., Effect of blast furnace slag grades on fly ash based geopolymer waste forms. Fuel, 2014. 133: p. 332-340, DOI: 10.1016/j.fuel.2014.05.018.

142. Islam, A., Alengaram, U.J., Jumaat, M.Z., and Bashar, I.I., The development of compressive strength of ground granulated blast furnace slag-palm oil fuel ash-fly ash based geopolymer mortar. Materials \& Design, 2014. 56: p. 833-841.

143. Görhan, G. and Kürklü, G., The influence of the NaOH solution on the properties of the fly ash-based geopolymer mortar cured at different temperatures. Composites Part B: Engineering, 2014. 58: p. 371-377, DOI: 10.1016/j.compositesb.2013.10.082.

144. Aliabdo, A.A., Abd Elmoaty, A.E.M., and Salem, H.A., Effect of water addition, plasticizer and alkaline solution constitution on fly ash based geopolymer concrete 
performance. Construction and Building Materials, 2016. 121: p. 694-703, DOI: 10.1016/j.conbuildmat.2016.06.062.

145. Cao, V.D., Pilehvar, S., Salas-Bringas, C., Szczotok, A.M., Valentini, L., Carmona, M., Rodriguez, J.F., and Kjøniksen, A.-L., Influence of microcapsule size and shell polarity on thermal and mechanical properties of thermoregulating geopolymer concrete for passive building applications. Energy Conversion and Management, 2018. 164: p. 198209, DOI: 10.1016/j.enconman.2018.02.076.

146. Xie, J. and Kayali, O., Effect of superplasticiser on workability enhancement of Class F and Class C fly ash-based geopolymers. Construction and Building Materials, 2016. 122: p. 36-42.

147. Jang, J., Lee, N., and Lee, H., Fresh and hardened properties of alkali-activated fly ash/slag pastes with superplasticizers. Construction and Building Materials, 2014. 50: p. $169-176$.

148. Lloyd, N. and Rangan, V. Geopolymer concrete with fly ash. in Proceedings of the Second International Conference on Sustainable Construction Materials and Technologies. 2010. UWM Center for By-Products Utilization.

149. Ferdous, W., Manalo, A., Khennane, A., and Kayali, O., Geopolymer concrete-filled pultruded composite beams - Concrete mix design and application. Cement and Concrete Composites, 2015. 58: p. 1-13, DOI: 10.1016/j.cemconcomp.2014.12.012.

150. Anuradha, R., Sreevidya, V., Venkatasubramani, R., and Rangan, B.V., Modified guidelines for geopolymer concrete mix design using Indian standard. Asian Journal of civil engineering (Building and Housing), 2012. 13(3): p. 353-64. 
151. Nematollahi, B. and Sanjayan, J., Effect of different superplasticizers and activator combinations on workability and strength of fly ash based geopolymer. Materials \& Design, 2014. 57: p. 667-672, DOI: 10.1016/j.matdes.2014.01.064.

152. Sashi, P. and Bhuyan, A.K., Viscosity Dependence of Some Protein and Enzyme Reaction Rates: Seventy-Five Years after Kramers. Biochemistry, 2015. 54(29): p. 4453-4461, DOI: 10.1021/acs.biochem.5b00315.

153. Kumar, A. and Pawar, S.S., High viscosity of ionic liquids causes rate retardation of Diels-Alder reactions. Science China-Chemistry, 2012. 55(8): p. 1633-1637, DOI: 10.1007/s11426-012-4684-9.

154. Vahedi, F., Shahverdi, H.R., Shokrieh, M.M., and Esmkhani, M., Effects of carbon nanotube content on the mechanical and electrical properties of epoxy-based composites. New Carbon Materials, 2014. 29: p. 419-425.

155. Elkady, H., I.Serag, M., and Elfeky, M.S., Effect of Nano Silica De-agglomeration, and Methods of Adding Super-plasticizer on the Compressive Strength, and Workability of Nano Silica Concrete. Civil and Environmental Research, 2013. 3: p. 21-34.

156. González, M.A. and Irassar, E.F., ETTRINGITE FORMATION IN LOW C3A PORTLAND CEMENT EXPOSED TO SODIUM SULFATE SOLUTION. Cement and Concrete Research, 1997. 27(7): p. 1061-1072, DOI: 10.1016/S0008-8846(97)00093-8.

157. Odler, I. and Colán-Subauste, J., Investigations on cement expansion associated with ettringite formation. Cement and Concrete Research, 1999. 29(5): p. 731-735, DOI: 10.1016/S0008-8846(99)00048-4. 
158. Lanzón, M., Cnudde, V., De Kock, T., and Dewanckele, J., Microstructural examination and potential application of rendering mortars made of tire rubber and expanded polystyrene wastes. Construction and Building Materials, 2015. 94: p. 817825, DOI: 10.1016/j.conbuildmat.2015.07.086.

159. Setzer, M.J., Micro-Ice-Lens Formation in Porous Solid. Journal of Colloid and Interface Science, 2001. 243(1): p. 193-201, DOI: 10.1006/jcis.2001.7828.

160. Wang, Z., Zeng, Q., Wang, L., Li, K., Xu, S., and Yao, Y., Characterizing frost damages of concrete with flatbed scanner. Construction and Building Materials, 2016. 102: p. 872-883, DOI: 10.1016/j.conbuildmat.2015.11.029.

161. Basheer, L., Kropp, J., and Cleland, D.J., Assessment of the durability of concrete from its permeation properties: a review. Construction and Building Materials, 2001. 15(2): p. 93-103, DOI: 10.1016/S0950-0618(00)00058-1.

162. Allahverdi, A., Abadi, M.M.B.R., Anwar Hossain, K.M., and Lachemi, M., Resistance of chemically-activated high phosphorous slag content cement against freeze-thaw cycles. Cold Regions Science and Technology, 2014. 103(Supplement C): p. 107-114, DOI: 10.1016/j.coldregions.2014.03.012.

163. Vancura, M., MacDonald, K., and Khazanovich, L., Microscopic analysis of paste and aggregate distresses in pervious concrete in a wet, hard freeze climate. Cement and Concrete Composites, 2011. 33(10): p. 1080-1085, DOI: 10.1016/j.cemconcomp.2011.05.011.

164. NIU., D., JIANG., L., and FEI., Q., Deterioration Mechanism of Sulfate Attack onnConcrete under Freeze-thaw Cycles Journal of Wuhan University of Technology. Materials Science Edition, 2013. 28(6): p. 4. 
165. Dehdezi, P.K., Hall, M.R., Dawson, A.R., and Casey, S.P., Thermal, mechanical and microstructural analysis of concrete containing microencapsulated phase change materials. International Journal of Pavement Engineering, 2013. 14(5): p. 449-462, DOI: $10.1080 / 10298436.2012 .716837$.

166. Jayalath, A., San Nicolas, R., Sofi, M., Shanks, R., Ngo, T., Aye, L., and Mendis, P., Properties of cementitious mortar and concrete containing micro-encapsulated phase change materials. Construction and Building Materials, 2016. 120(Supplement C): p. 408-417, DOI: 10.1016/j.conbuildmat.2016.05.116.

167. Moosberg-Bustnes, H., Lagerblad, B., and Forssberg, E., The function of fillers in concrete. Materials and Structures, 2004. 37(2): p. 74, DOI: 10.1007/bf02486602.

168. Coussy, O. and Monteiro, P.J.M., Poroelastic model for concrete exposed to freezing temperatures. Cement and Concrete Research, 2008. 38(1): p. 40-48, DOI: 10.1016/j.cemconres.2007.06.006.

169. Kamal, M.M., Safan, M.A., Bashandy, A.A., and Khalil, A.M., Experimental investigation on the behavior of normal strength and high strength self-curing selfcompacting concrete. Journal of Building Engineering, 2018. 16: p. 79-93, DOI: 10.1016/j.jobe.2017.12.012.

170. Ismail, S., Kwan, W.H., and Ramli, M., Mechanical strength and durability properties of concrete containing treated recycled concrete aggregates under different curing conditions. Construction and Building Materials, 2017. 155: p. 296-306, DOI: 10.1016/j.conbuildmat.2017.08.076. 
171. Escalante-García, J.I. and Sharp, J.H., Effect of temperature on the hydration of the main clinker phases in portland cements: part $i$, neat cements. Cement and Concrete Research, 1998. 28(9): p. 1245-1257, DOI: 10.1016/S0008-8846(98)00115-X.

172. Pilehvar, S., Cao, V.D., Szczotok, A.M., Carmona, M., Valentini, L., Lanzón, M., Pamies, R., and Kjøniksen, A.-L., Physical and mechanical properties of fly ash and slag geopolymer concrete containing different types of micro-encapsulated phase change materials. Construction and Building Materials, 2018. 173: p. 28-39, DOI: 10.1016/j.conbuildmat.2018.04.016.

173. Bentz, D.P., Influence of water-to-cement ratio on hydration kinetics: Simple models based on spatial considerations. Cement and Concrete Research, 2006. 36(2): p. 238244, DOI: 10.1016/j.cemconres.2005.04.014.

174. Siyal, A.A., Azizli, K.A., Man, Z., and Ullah, H., Effects of Parameters on the Setting Time of Fly Ash Based Geopolymers Using Taguchi Method. Procedia Engineering, 2016. 148: p. 302-307, DOI: 10.1016/j.proeng.2016.06.624.

175. Cao, V.D., Salas-Bringas, C., Schüller, R.B., Szczotok, A.M., Hiorth, M., Carmona, M., Rodriguez, J.F., and Kjøniksen, A.-L., Rheological and thermal properties of suspensions of microcapsules containing phase change materials. Colloid and Polymer Science, 2018. 296(5): p. 981-988, DOI: 10.1007/s00396-018-4316-9.

176. Muñiz-Villarreal, M.S., Manzano-Ramírez, A., Sampieri-Bulbarela, S., Gasca-Tirado, J.R., Reyes-Araiza, J.L., Rubio-Ávalos, J.C., Pérez-Bueno, J.J., Apatiga, L.M., Zaldivar-Cadena, A., and Amigó-Borrás, V., The effect of temperature on the geopolymerization process of a metakaolin-based geopolymer. Materials Letters, 2011. 65(6): p. 995-998, DOI: 10.1016/j.matlet.2010.12.049. 
177. Lothenbach, B., Winnefeld, F., Alder, C., Wieland, E., and Lunk, P., Effect of temperature on the pore solution, microstructure and hydration products of Portland cement pastes. Cement and Concrete Research, 2007. 37(4): p. 483-491, DOI: 10.1016/j.cemconres.2006.11.016. 


\section{Appendix}

\section{A.1. Nomenclature}

\section{A.1.1. Abbreviations}

ACI

$\mathrm{Al}$

AR

ASTM

BSE

$\mathrm{CASH}$

CEN

$\mathrm{CSH}$

CT

DVB

EDX
American Concrete Institute

Aluminum

Aspect ratio

American Society for Testing and Materials

Back scattered electrons

Calcium alumina silicate

European Committee for Standardization

Calcium silicate hydrate

Computed tomography

Divinylbenzene

Energy-dispersive X-ray spectroscopy 
EN

EVA

FA

GB

GGBFS

GPC

LFD

LOI

M

MAG

MPCM

$\mathrm{NASH}$

PCC

PCM

PE

PSD

RT27
European Standard

Ethylvinylacetate

Fly ash

Geopolymer binder

Ground granulated blast furnace slag

Geopolymer concrete

Large Field Detector

Loss on Ignition

Alkali metal

Magnification

Micro-encapsulated phase change materials

Sodium alumina silicate hydrate

Portland cement concrete

Phase change material

polyethylene

Particle size distribution

Rubitherm®RT27 
SD

SEM

St

vCD

XRD

XRF

\section{A.1.2. Symbols}

$\mathrm{A}_{\mathrm{c}}$

aq

F

$f_{c}$

mAs
Standard deviations

Scanning Electron Microscope

Styrene

Low voltage high contrast Detector

X-Ray Diffractometer

X-Ray Florescence

Cross-sectional area of the specimen (mm2)

Aqueous

Maximum load at failure

Compressive strength

Added water and the entire alkaline solution

Mass

Mass of the alkaline solution 
mGB

$\mathrm{m}_{\mathrm{L}}$

$\mathrm{m}_{\mathrm{AS} w a t e r}$

$\mathrm{m}_{\mathrm{TW}}$

$\mathrm{m}_{\text {water }}$

R

V

$\Delta \mathrm{ST}$

$\rho$

$\theta$ o

$\theta$ cycle

бo

бMPCM
Mass of the geopolymer binder

Mass of liquids

Total water in alkaline solution

Total amount of water

Mass of free water added

Ratio

Solid

volume

Difference between the initial and final setting times

Density

Mass of sample before cycle

Mass of sample after cycle

Strength without MPCM

Strength with MPCM 


\section{A.2. History of the development of alkali-activated cement and composites.}

Table A.1. Chronologically summary of some important references outlining steps in the development of alkali-activated and alkaline cements [33].

\begin{tabular}{llll}
\hline No & author & Year & significance \\
\hline 1 & Feret & 1939 & Slags used for cement \\
2 & Purdon & 1940 & Alkali-slag combinations \\
3 & Glukhovsky & 1959 & Theoretical basis and development of alkaline cements \\
4 & Glukhovsky & 1965 & First called "alkaline cements" because natural substances used as components \\
5 & Davidovits & 1979 & "Geopolymer" term - emphasizes greater polymerization \\
6 & Malinowski & 1979 & Ancient aqueducts characterized \\
7 & Forss & 1983 & F-cement (slag-alkali-superplasticizer)
\end{tabular}




\begin{tabular}{|c|c|c|c|}
\hline 8 & Langton and Roy & 1984 & Ancient building materials Characterized (Roman, Greek, Cyprus) \\
\hline 9 & Davidovits and Sawyer & 1985 & Patent leading to "Pyrament" \\
\hline 10 & Krivenko & 1986 & D.Sc. Thesis, $\mathrm{R}_{2} \mathrm{O}-\mathrm{RO}-\mathrm{R}_{2} \mathrm{O}_{3}-\mathrm{SiO}_{2}-\mathrm{H}_{2} \mathrm{O}$ \\
\hline 11 & Malolepsy and Petri & 1986 & Activation of synthetic melilite slags \\
\hline 12 & Malek et al. & 1986 & Slag cement-low level radioactive waste forms \\
\hline 13 & Davidovits & 1987 & Ancient and modern concretes compared \\
\hline 14 & Deja and Malolepsy & 1989 & Resistance to chlorides shown \\
\hline 15 & Kaushal et al. & 1989 & Adiabatic cured nuclear waste forms from alkaline mixtures including zeolite formation \\
\hline 16 & Roy and Langton & 1989 & Ancient concrete analogs \\
\hline 17 & Majumdar & 1989 & $\mathrm{C}_{12} \mathrm{~A}_{7}$ - slag activation \\
\hline 18 & Talling and Brandstetr & 1989 & Alkali-activated slag \\
\hline 19 & Wu et al. & 1990 & Activation of slag cement \\
\hline
\end{tabular}


$20 \quad$ Roy et al.

21 Roy and Silsbee

22

Palomo and Glasser

23

Roy and Malek

$24 \quad$ Glukhovsky

25

Krivenko

26 Wang and Scrivener
1991

Rapid setting alkali-activated cements

1992 Alkali-activated cements: overview

$1992 \quad$ CBC with metakaolin

$1993 \quad$ Slag cement

1994 Ancient, modern and future concretes

$1994 \quad$ Alkaline cements

1995 Slag and alkali-activated slag microstructure 


\section{A.3. Results from Chapter $\mathbf{V}$}

Table A.2. Properties of GPC mixtures containing different percentages of MPCM (PE-EVA-PCM) at $20{ }^{\circ} \mathrm{C}$.

\begin{tabular}{|c|c|c|c|c|c|c|}
\hline MPCM (vol.\%) & Slump (mm) & $\begin{array}{c}\text { Curing age } \\
\text { (days) }\end{array}$ & Density $\left(\mathrm{g} / \mathrm{cm}^{3}\right)$ & $\begin{array}{c}\text { Compressive strength } \\
\text { (MPa) }\end{array}$ & Standard deviation & Strength reduction (\%) \\
\hline \multirow{5}{*}{0} & \multirow{5}{*}{200} & 1 & 2437.1 & 39,7 & 1.6 & - \\
\hline & & 3 & 2415.6 & 50.8 & 2.1 & - \\
\hline & & 7 & 2419.3 & 66.9 & 1.4 & - \\
\hline & & 14 & 2427.5 & 77.5 & 1.3 & - \\
\hline & & 28 & 2439.5 & 93.1 & 0.8 & - \\
\hline \multirow{5}{*}{5} & \multirow{5}{*}{80} & 1 & 2365.7 & 36.3 & 0.7 & 9 \\
\hline & & 3 & 2356.3 & 45.4 & 0.4 & 11 \\
\hline & & 7 & 2360.2 & 56.2 & 0.7 & 16 \\
\hline & & 14 & 2341.4 & 66.5 & 0.8 & 14 \\
\hline & & 28 & 2333.3 & 77.8 & 0.7 & 16 \\
\hline
\end{tabular}




\begin{tabular}{|c|c|c|c|c|c|c|}
\hline \multirow{5}{*}{10} & \multirow{5}{*}{40} & 1 & 2322.9 & 28.8 & 0.2 & 27 \\
\hline & & 3 & 2346.7 & 37.3 & 0.1 & 27 \\
\hline & & 7 & 2328.1 & 46.5 & 0.9 & 30 \\
\hline & & 14 & 2267.9 & 54.4 & 1 & 30 \\
\hline & & 28 & 2283.1 & 63.1 & 1.3 & 32 \\
\hline \multirow{5}{*}{20} & \multirow{5}{*}{10} & 1 & 2260.5 & 21 & 0.8 & 47 \\
\hline & & 3 & 2220.7 & 25.1 & 0.1 & 51 \\
\hline & & 7 & 2204.9 & 30.6 & 3.8 & 54 \\
\hline & & 14 & 2241.7 & 38.3 & 0.4 & 51 \\
\hline & & 28 & 2243.1 & 44.8 & 0.6 & 52 \\
\hline
\end{tabular}


Table A.3. Properties of GPC mixtures containing different percentages of MPCM (PE-EVA-PCM) at $40{ }^{\circ} \mathrm{C}$.

\begin{tabular}{|c|c|c|c|c|c|c|}
\hline MPCM (vol.\%) & Slump (mm) & Curing age (days) & $\begin{array}{l}\text { Density } \\
\left(\mathrm{g} / \mathrm{cm}^{3}\right)\end{array}$ & $\begin{array}{c}\text { Compressive strength } \\
(\mathrm{MPa})\end{array}$ & Standard deviation & Strength reduction (\%) \\
\hline \multirow{5}{*}{0} & \multirow{5}{*}{ - } & 1 & 2419.7 & 60.5 & 0.3 & - \\
\hline & & 3 & 2418.5 & 80.8 & 1.8 & - \\
\hline & & 7 & 2406.3 & 95.5 & 1.1 & - \\
\hline & & 14 & 2431.5 & 103.9 & 1.1 & - \\
\hline & & 28 & 2417.4 & 106.8 & 1.7 & - \\
\hline \multirow{5}{*}{5} & \multirow{5}{*}{-} & 1 & 2374.5 & 52.1 & 0.9 & 14 \\
\hline & & 3 & 2368.9 & 67 & 3.1 & 17 \\
\hline & & 7 & 2365.9 & 76.9 & 1.1 & 19 \\
\hline & & 14 & 2355.5 & 86.7 & 0.6 & 17 \\
\hline & & 28 & 2348.2 & 90.1 & 0.5 & 16 \\
\hline \multirow{5}{*}{10} & \multirow{5}{*}{ - } & 1 & 2294.5 & 41.6 & 1.5 & 31 \\
\hline & & 3 & 2323.3 & 56.7 & 2.2 & 30 \\
\hline & & 7 & 2333.3 & 67.8 & 0.5 & 30 \\
\hline & & 14 & 2350.5 & 70.1 & 2.3 & 33 \\
\hline & & 28 & 2344.8 & 76.4 & 1.2 & 28 \\
\hline
\end{tabular}




\begin{tabular}{|c|c|c|c|c|c|c|}
\hline \multirow{5}{*}{20} & \multirow{5}{*}{ - } & 1 & 2252.2 & 28.4 & 0.9 & 53 \\
\hline & & 3 & 2246.5 & 36.2 & 0.5 & 55 \\
\hline & & 7 & 2265.6 & 42.8 & 1.4 & 55 \\
\hline & & 14 & 2257.7 & 44.2 & 3.4 & 57 \\
\hline & & 28 & 2240.7 & 50.2 & 1.4 & 53 \\
\hline
\end{tabular}

Table A.4. Properties of PCC mixtures containing different percentages of MPCM (PE-EVA-PCM) at $20{ }^{\circ} \mathrm{C}$.

\begin{tabular}{|c|c|c|c|c|c|c|}
\hline MPCM (vol.\%) & Slump (mm) & $\begin{array}{c}\text { Curing age } \\
\text { (days) }\end{array}$ & Density $\left(\mathrm{g} / \mathrm{cm}^{3}\right)$ & $\begin{array}{c}\text { Compressive strength } \\
(\mathrm{MPa})\end{array}$ & Standard deviation & Strength reduction (\%) \\
\hline \multirow{3}{*}{0} & & 1 & 2388,7 & 36.2 & 4 & - \\
\cline { 3 - 7 } & \multirow{3}{*}{240} & 3 & 2406.6 & 46.4 & 0.2 & - \\
\cline { 3 - 7 } & & 7 & 2384.2 & 48.5 & 1.2 & - \\
\cline { 3 - 7 } & & 14 & 2378.5 & 53.3 & & - \\
\hline
\end{tabular}




\begin{tabular}{|c|c|c|c|c|c|c|}
\hline \multirow{5}{*}{5} & \multirow{5}{*}{210} & 1 & 2359.3 & 29.5 & 0.2 & 18 \\
\hline & & 3 & 2349 & 39 & 0.1 & 16 \\
\hline & & 7 & 2353.6 & 45.5 & 1.2 & 7 \\
\hline & & 14 & 2359.6 & 50.3 & 0.8 & 6 \\
\hline & & 28 & 2361.2 & 56.5 & 1.5 & 8 \\
\hline \multirow{5}{*}{10} & \multirow{5}{*}{90} & 1 & 2316.1 & 22.6 & 0.7 & 37 \\
\hline & & 3 & 2309.8 & 32.8 & 0.4 & 30 \\
\hline & & 7 & 2319.1 & 35.2 & 3.8 & 27 \\
\hline & & 14 & 2313.1 & 43 & 0.5 & 19 \\
\hline & & 28 & 2331.4 & 50.1 & 1.2 & 18 \\
\hline \multirow{5}{*}{20} & \multirow{5}{*}{30} & 1 & 2200.7 & 14.4 & 0.7 & 60 \\
\hline & & 3 & 2231.3 & 22.7 & 1.3 & 51 \\
\hline & & 7 & 2225.2 & 26.3 & 0.9 & 45 \\
\hline & & 14 & 2225.3 & 30.1 & 2.6 & 43 \\
\hline & & 28 & 2206.9 & 35.3 & 0.2 & 42 \\
\hline
\end{tabular}


Table A.5. Properties of PCC mixtures containing different percentages of MPCM (PE-EVA-PCM) at $40{ }^{\circ} \mathrm{C}$.

\begin{tabular}{|c|c|c|c|c|c|c|}
\hline MPCM (vol.\%) & Slump (mm) & $\begin{array}{c}\text { Curing age } \\
\text { (days) }\end{array}$ & Density $\left(\mathrm{g} / \mathrm{cm}^{3}\right)$ & $\begin{array}{c}\text { Compressive strength } \\
(\mathrm{MPa})\end{array}$ & Standard deviation & Strength reduction (\%) \\
\hline \multirow{5}{*}{0} & \multirow{5}{*}{-} & 1 & 2387.7 & 40.7 & 0.8 & - \\
\hline & & 3 & 2394.3 & 47.4 & 1.4 & - \\
\hline & & 7 & 2410,1 & 53 & 4.8 & - \\
\hline & & 14 & 2387.6 & 66.3 & 2.3 & - \\
\hline & & 28 & 2396.5 & 73.1 & 3.7 & - \\
\hline \multirow{5}{*}{5} & \multirow{5}{*}{-} & 1 & 2361 & 33.7 & 0.2 & 17 \\
\hline & & 3 & 2352.1 & 39.7 & 2.1 & 16 \\
\hline & & 7 & 2341.5 & 48.2 & 3.1 & 10 \\
\hline & & 14 & 2374.5 & 56.2 & 0.3 & 15 \\
\hline & & 28 & 2320.4 & 62.9 & 0.6 & 14 \\
\hline \multirow{5}{*}{10} & \multirow{5}{*}{-} & 1 & 2272.7 & 31.1 & 0.2 & 24 \\
\hline & & 3 & 2295.7 & 34.8 & 1.1 & 26 \\
\hline & & 7 & 2292.3 & 42.6 & 1.3 & 20 \\
\hline & & 14 & 2303.7 & 47.3 & 0.9 & 28 \\
\hline & & 28 & 2278.1 & 56.3 & 0.5 & 23 \\
\hline
\end{tabular}




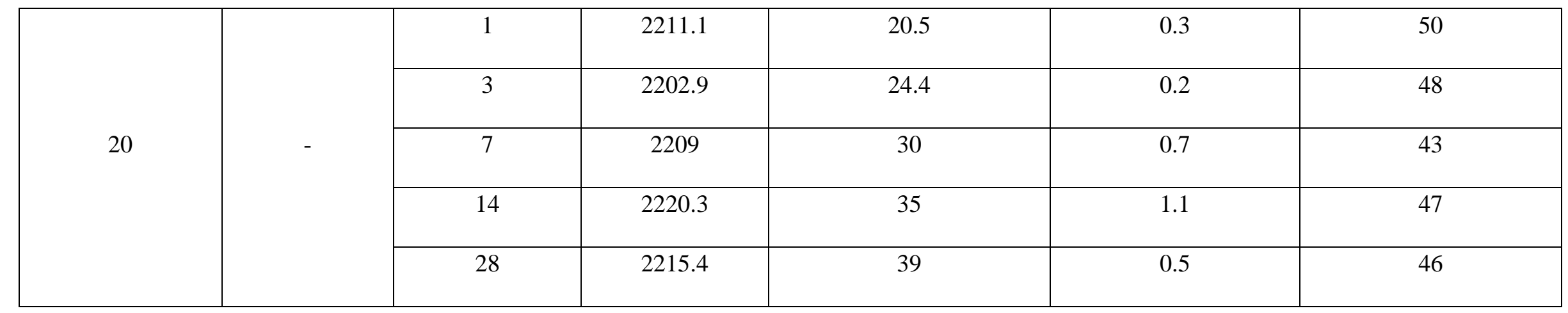




\section{A.4. Results from Chapter VII}

Table A.6. Properties of GPC mixtures containing different percentages of PE-EVA-PCM at $20{ }^{\circ} \mathrm{C}$.

\begin{tabular}{|c|c|c|c|c|c|c|c|}
\hline $\begin{array}{l}\text { MPCM } \\
(\text { vol.\%) }\end{array}$ & $\begin{array}{l}\text { Slump } \\
(\mathrm{mm})\end{array}$ & $\begin{array}{l}\text { Initial setting time } \\
\qquad(\min )\end{array}$ & $\begin{array}{l}\text { Final setting time } \\
\qquad(\mathrm{min})\end{array}$ & $\begin{array}{l}\text { Curing age } \\
\text { (day) }\end{array}$ & $\begin{array}{l}\text { Density } \\
\left(\mathrm{g} / \mathrm{cm}^{3}\right)\end{array}$ & Compressive strength (MPa) & Standard deviation \\
\hline \multirow{4}{*}{0} & \multirow{4}{*}{270} & \multirow{4}{*}{34} & \multirow{4}{*}{84.3} & 1 & 2387 & 34.3 & 0.8 \\
\hline & & & & 7 & 2391.5 & 59 & 1 \\
\hline & & & & 14 & 2380.2 & 68.3 & 0.9 \\
\hline & & & & 28 & 2369.3 & 79.4 & 0.5 \\
\hline \multirow{4}{*}{10} & \multirow{4}{*}{265} & \multirow{4}{*}{37.3} & \multirow{4}{*}{63.5} & 1 & 2274.8 & 29.3 & 0.4 \\
\hline & & & & 7 & 2273.6 & 45.4 & 0.8 \\
\hline & & & & 14 & 2282.3 & 53.6 & 1.2 \\
\hline & & & & 28 & 2292.3 & 59.4 & 1.9 \\
\hline \multirow{4}{*}{20} & \multirow{4}{*}{260} & \multirow{4}{*}{43.6} & \multirow{4}{*}{53.1} & 1 & 2219 & 22.8 & 0.6 \\
\hline & & & & 7 & 2211.4 & 33.8 & 0.9 \\
\hline & & & & 14 & 2217.2 & 40.6 & 1.3 \\
\hline & & & & 28 & 2207.5 & 47.2 & 0.4 \\
\hline
\end{tabular}


Table A.7. Properties of GPC mixtures containing different percentages of St-DVB-PCM at $20^{\circ} \mathrm{C}$.

\begin{tabular}{|c|c|c|c|c|c|c|c|}
\hline $\begin{array}{l}\text { MPCM } \\
\text { (vol.\%) }\end{array}$ & $\begin{array}{l}\text { Slump } \\
(\mathrm{mm})\end{array}$ & $\begin{array}{l}\text { Initial setting time } \\
\text { (min) }\end{array}$ & $\begin{array}{l}\text { Final setting time } \\
\text { (min) }\end{array}$ & $\begin{array}{l}\text { Curing age } \\
\text { (day) }\end{array}$ & $\begin{array}{l}\text { Density } \\
\left(\mathrm{g} / \mathrm{cm}^{3}\right)\end{array}$ & Compressive strength (MPa) & Standard deviation \\
\hline \multirow{4}{*}{0} & \multirow{4}{*}{270} & \multirow{4}{*}{34} & \multirow{4}{*}{84.3} & 1 & 2387 & 34.3 & 0.8 \\
\hline & & & & 7 & 2391.5 & 59 & 1 \\
\hline & & & & 14 & 2380.2 & 68.3 & 0.9 \\
\hline & & & & 28 & 2369.3 & 79.4 & 0.5 \\
\hline \multirow{4}{*}{10} & \multirow{4}{*}{230} & \multirow{4}{*}{44.2} & \multirow{4}{*}{59.2} & 1 & 2296.3 & 31.3 & 0.8 \\
\hline & & & & 7 & 2302.7 & 47.9 & 0.7 \\
\hline & & & & 14 & 2316.3 & 55.4 & 2.3 \\
\hline & & & & 28 & 2327 & 65.5 & 2.2 \\
\hline \multirow{4}{*}{20} & \multirow{4}{*}{190} & \multirow{4}{*}{47.2} & \multirow{4}{*}{51.1} & 1 & 2251.8 & 24.3 & 0.1 \\
\hline & & & & 7 & 2247.7 & 32.1 & 0.4 \\
\hline & & & & 14 & 2251.8 & 45.4 & 0.9 \\
\hline & & & & 28 & 2252.5 & 52.2 & 0.5 \\
\hline
\end{tabular}




\section{A.5. Results from Chapter VIII}

Table A.8. Properties of geopolymer composites containing PE-EVA-PCM and St-DVB-PCM at frost condition.

\begin{tabular}{|c|c|c|c|c|c|c|c|c|}
\hline $\begin{array}{l}\text { Mixture included } \\
(\text { vol. } \%)\end{array}$ & $\begin{array}{l}\text { Initial setting time } \\
\text { at } 0{ }^{\circ} \mathrm{C}(\mathrm{min})\end{array}$ & $\begin{array}{l}\text { Final setting time } \\
\text { at } 0{ }^{\circ} \mathrm{C}(\mathrm{min})\end{array}$ & $\begin{array}{c}\text { Freeze-thaw cycle } \\
\text { (day) }\end{array}$ & Mass loss (\%) & $\begin{array}{l}\text { Standard } \\
\text { deviation }\end{array}$ & $\begin{array}{c}\text { Compressive strength } \\
(\mathrm{MPa})\end{array}$ & $\begin{array}{l}\text { Standard } \\
\text { deviation }\end{array}$ & $\begin{array}{c}\text { Strength reduction } \\
(\%)\end{array}$ \\
\hline \multirow{4}{*}{0} & \multirow{4}{*}{12} & \multirow{4}{*}{ 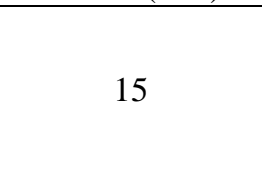 } & 1 & - & - & 77.5 & 1.3 & - \\
\hline & & & 7 & 0.15 & 0.02 & 78.9 & 2.3 & -1.8 \\
\hline & & & 14 & 0.14 & 0.01 & 77.6 & 1.5 & -0.1 \\
\hline & & & 28 & 0.12 & 0.05 & 74.2 & 0.6 & 4.2 \\
\hline \multirow{4}{*}{20 PE-EVA-PCM } & \multirow{4}{*}{10} & \multirow{4}{*}{14} & 1 & - & - & 42.3 & 2.3 & - \\
\hline & & & 7 & 0.09 & 0.03 & 42.6 & 0.9 & -0.7 \\
\hline & & & 14 & 0.11 & 0.02 & 41.1 & 1.7 & 2.8 \\
\hline & & & 28 & 0.24 & 0.03 & 43.5 & 1.2 & -2.8 \\
\hline \multirow{4}{*}{20 St-DVB-PCM } & \multirow{4}{*}{11} & \multirow{4}{*}{14} & 1 & - & - & 51.2 & 0.7 & - \\
\hline & & & 7 & 0.15 & 0.02 & 51.4 & 1.2 & -0.2 \\
\hline & & & 14 & 0.2 & 0.02 & 52 & 3.5 & -1.6 \\
\hline & & & 28 & 0.21 & 0.05 & 50 & 0.3 & 2.3 \\
\hline 0 Outside & - & - & 90 & 0.13 & 0.02 & 82.9 & 1.2 & - \\
\hline $\begin{array}{l}20 \text { PE-EVA-PCM } \\
\text { Outside }\end{array}$ & - & - & 90 & 0.77 & 0.11 & 44.6 & 0.3 & - \\
\hline $\begin{array}{c}20 \text { St-DVB-PCM } \\
\text { Outside }\end{array}$ & - & - & 90 & 0.66 & 0.03 & 53.5 & 0.7 & - \\
\hline
\end{tabular}


Table A.9. Properties of Portland cement composites containing PE-EVA-PCM and St-DVB-PCM at frost condition.

\begin{tabular}{|c|c|c|c|c|c|c|c|c|}
\hline $\begin{array}{l}\text { Mixture included } \\
\text { (vol.\%) }\end{array}$ & $\begin{array}{l}\text { Initial setting time } \\
\text { at } 0^{\circ} \mathrm{C}(\mathrm{h})\end{array}$ & $\begin{array}{l}\text { Final setting time } \\
\text { at } 0^{\circ} \mathrm{C}(\mathrm{h})\end{array}$ & $\begin{array}{l}\text { Freeze-thaw cycle } \\
\text { (day) }\end{array}$ & Mass loss (\%) & $\begin{array}{l}\text { Standard } \\
\text { deviation }\end{array}$ & $\begin{array}{c}\text { Compressive strength } \\
(\mathrm{MPa})\end{array}$ & $\begin{array}{r}\text { Standard } \\
\text { deviation }\end{array}$ & $\begin{array}{c}\text { Strength reduction } \\
(\%)\end{array}$ \\
\hline \multirow[t]{4}{*}{ (1) } & \multirow{4}{*}{10.2} & \multirow{4}{*}{22.9} & 1 & - & - & 54.8 & 1.5 & - \\
\hline & & & 7 & -0.13 & 0.08 & 50.9 & 1.6 & 7.1 \\
\hline & & & 14 & -0.16 & 0.05 & 50.3 & 2.7 & 8.2 \\
\hline & & & 28 & -0.38 & 0.03 & 43 & 1.4 & 21.5 \\
\hline \multirow{4}{*}{20 PE-EVA-PCM } & \multirow{4}{*}{10.9} & \multirow{4}{*}{18.8} & 1 & - & - & 29.7 & 0.2 & - \\
\hline & & & 7 & 0.06 & 0.02 & 30.2 & 0.4 & -1.6 \\
\hline & & & 14 & 0.11 & 0.03 & 30.4 & 0.2 & -2.3 \\
\hline & & & 28 & 0.24 & 0.02 & 30 & 0.3 & -1 \\
\hline \multirow{4}{*}{20 St-DVB-PCM } & \multirow{4}{*}{10.6} & \multirow{4}{*}{19.7} & 1 & - & - & 34.3 & 0.1 & - \\
\hline & & & 7 & 0.06 & 0.01 & 34.5 & 0.6 & -1.5 \\
\hline & & & 14 & 0.18 & 0.03 & 35.3 & 0.8 & -2.9 \\
\hline & & & 28 & 0.29 & 0.04 & 34.8 & 0.6 & -1.5 \\
\hline 0 Outside & - & - & 90 & -1.4 & 0.24 & 65.7 & 1 & - \\
\hline $\begin{array}{l}20 \text { PE-EVA-PCM } \\
\text { Outside }\end{array}$ & - & - & 90 & -1.2 & 0.21 & 35.4 & 0.6 & - \\
\hline $\begin{array}{c}20 \text { St-DVB-PCM } \\
\text { Outside }\end{array}$ & - & - & 90 & -1.1 & 0.15 & 40.6 & 0.9 & - \\
\hline
\end{tabular}




\section{A.6. Results from Chapter IX}

Table A.10. Properties of GPC mixtures containing different percentages of PE-EVA-PCM at $40{ }^{\circ} \mathrm{C}$.

\begin{tabular}{|c|c|c|c|c|c|c|c|}
\hline $\begin{array}{l}\text { MPCM } \\
\text { (vol.\%) }\end{array}$ & $\begin{array}{l}\text { Initial setting } \\
\text { time (min) }\end{array}$ & $\begin{array}{l}\text { Final setting time } \\
\text { (min) }\end{array}$ & $\begin{array}{l}\text { Curing age } \\
\quad \text { (day) }\end{array}$ & $\begin{array}{l}\text { Density } \\
(\mathrm{g} / \mathrm{cm} 3)\end{array}$ & $\begin{array}{l}\text { Compressive strength } \\
\text { (MPa) }\end{array}$ & $\begin{array}{l}\text { Standard } \\
\text { deviation }\end{array}$ & $\begin{array}{c}\text { Strength Reduction } \\
(\%)\end{array}$ \\
\hline \multirow{4}{*}{0} & \multirow{4}{*}{14} & \multirow{4}{*}{24} & 1 & 2341 & 52 & 0.3 & - \\
\hline & & & 7 & 2366.4 & 74.4 & 1.8 & - \\
\hline & & & 14 & 2357.1 & 80.4 & 0.4 & - \\
\hline & & & 28 & 2400.4 & 86.7 & 1.57 & - \\
\hline \multirow{4}{*}{10} & \multirow{4}{*}{ - } & \multirow{4}{*}{-} & 1 & 2289.4 & 40.9 & 1.1 & 21.3 \\
\hline & & & 7 & 2287.6 & 59.2 & 0.8 & 20.4 \\
\hline & & & 14 & 2292.1 & 64.3 & 0.5 & 20 \\
\hline & & & 28 & 2308.9 & 66.2 & 0.7 & 23.6 \\
\hline \multirow{4}{*}{20} & \multirow{4}{*}{13} & \multirow{4}{*}{22} & 1 & 2218.4 & 30.5 & 0.2 & 41.3 \\
\hline & & & 7 & 2231.8 & 43.9 & 0.7 & 41 \\
\hline & & & 14 & 2230.5 & 48.3 & 0.8 & 40 \\
\hline & & & 28 & 2243.5 & 49.4 & 1.4 & 43 \\
\hline
\end{tabular}


Table A.11. Properties of GPC mixtures containing different percentages of St-DVB-PCM at $40{ }^{\circ} \mathrm{C}$.

\begin{tabular}{|c|c|c|c|c|c|c|c|}
\hline $\begin{array}{l}\text { MPCM } \\
(\text { vol.\%) }\end{array}$ & $\begin{array}{l}\text { Initial setting } \\
\text { time (min) }\end{array}$ & $\begin{array}{l}\text { Final setting time } \\
\qquad \text { (min) }\end{array}$ & $\begin{array}{l}\text { Curing age } \\
\text { (day) }\end{array}$ & $\begin{array}{l}\text { Density } \\
(\mathrm{g} / \mathrm{cm} 3)\end{array}$ & $\begin{array}{l}\text { Compressive strength } \\
\text { (MPa) }\end{array}$ & $\begin{array}{l}\text { Standard } \\
\text { deviation }\end{array}$ & $\begin{array}{c}\text { Strength Reduction } \\
(\%)\end{array}$ \\
\hline \multirow{4}{*}{0} & \multirow{4}{*}{14} & \multirow{4}{*}{24} & 1 & 2341 & 52 & 0.3 & - \\
\hline & & & 7 & 2366.4 & 74.4 & 1.8 & - \\
\hline & & & 14 & 2357.1 & 80.4 & 0.4 & - \\
\hline & & & 28 & 2400.4 & 86.7 & 1.57 & - \\
\hline \multirow{4}{*}{10} & \multirow{4}{*}{ - } & \multirow{4}{*}{ - } & 1 & 2291.6 & 43.1 & 1.1 & 17.1 \\
\hline & & & 7 & 2326.3 & 63.4 & 0.2 & 14.7 \\
\hline & & & 14 & 2309.7 & 69.8 & 1.7 & 13.2 \\
\hline & & & 28 & 2305.3 & 72.6 & 1.7 & 16.3 \\
\hline \multirow{4}{*}{20} & \multirow{4}{*}{13} & \multirow{4}{*}{22} & 1 & 2229.8 & 35.2 & 0.8 & 32.3 \\
\hline & & & 7 & 2209.6 & 52.6 & 1.1 & 29.3 \\
\hline & & & 14 & 2242.9 & 56.7 & 1 & 29.5 \\
\hline & & & 28 & 2245.1 & 59.1 & 0.4 & 31.8 \\
\hline
\end{tabular}


Table A.12. Properties of PCC mixtures containing different percentages of PE-EVA-PCM at $20^{\circ} \mathrm{C}$.

\begin{tabular}{|c|c|c|c|c|c|}
\hline $\begin{array}{l}\text { MPCM } \\
\text { (vol.\%) }\end{array}$ & Curing age (day) & Density $(\mathrm{g} / \mathrm{cm} 3)$ & Compressive strength (MPa) & Standard deviation & Strength Reduction (\%) \\
\hline \multirow{4}{*}{0} & 1 & 2393 & 31.4 & 0.4 & - \\
\hline & 7 & 2390.7 & 46.2 & 2.5 & - \\
\hline & 14 & 2386.2 & 49.9 & 0.5 & - \\
\hline & 28 & 2395.7 & 57.4 & 2.6 & - \\
\hline \multirow{4}{*}{10} & 1 & 2313.1 & 22.4 & 0.5 & 20.4 \\
\hline & 7 & 2306.1 & 34.4 & 0.4 & 25.5 \\
\hline & 14 & 2306.6 & 35 & 0.5 & 29.8 \\
\hline & 28 & 2304.2 & 40.4 & 0.6 & 29.6 \\
\hline \multirow{4}{*}{20} & 1 & 2191 & 14.7 & 0.4 & 43 \\
\hline & 7 & 2199.6 & 24.5 & 0.4 & 46.7 \\
\hline & 14 & 2210.5 & 26.6 & 0.3 & 45.4 \\
\hline & 28 & 2219.3 & 30.1 & 0.5 & 47.3 \\
\hline
\end{tabular}


Table A.13. Properties of PCC mixtures containing different percentages of St-DVB-PCM at $20^{\circ} \mathrm{C}$.

\begin{tabular}{|c|c|c|c|c|c|}
\hline $\begin{array}{c}\text { MPCM } \\
\text { (vol.\%) }\end{array}$ & Curing age (day) & Density (g/cm3) & Compressive strength (MPa) & Standard deviation & Strength Reduction (\%) \\
\hline \multirow{5}{*}{0} & 1 & 2393 & 31.4 & 0.4 & - \\
\cline { 2 - 6 } & 7 & 2390.7 & 46.2 & 2.5 & - \\
\cline { 2 - 6 } & 14 & 2386.2 & 49.9 & 2.6 & 28.6 \\
\hline \multirow{5}{*}{10} & 28 & 2395.7 & 57.4 & 1.6 & 20.3 \\
\cline { 2 - 6 } & 1 & 2296.5 & 25 & 2.1 & 23.4 \\
\cline { 2 - 6 } & 14 & 2303 & 36.8 & 0.7 & 20.7 \\
\hline \multirow{3}{*}{20} & 28 & 2305.7 & 38.2 & 0.1 & 53.2 \\
\cline { 2 - 7 } & 1 & 2209.7 & 45.5 & 1.5 & 47 \\
\hline
\end{tabular}


Table A.14. Properties of PCC mixtures containing different percentages of PE-EVA-PCM at $40{ }^{\circ} \mathrm{C}$.

\begin{tabular}{|c|c|c|c|c|c|}
\hline $\begin{array}{l}\text { MPCM } \\
\text { (vol.\%) }\end{array}$ & Curing age (day) & Density $(\mathrm{g} / \mathrm{cm} 3)$ & Compressive strength (MPa) & Standard deviation & Strength Reduction (\%) \\
\hline \multirow{4}{*}{0} & 1 & 2396.1 & 37.9 & 0.8 & - \\
\hline & 7 & 2414.3 & 54 & 2 & - \\
\hline & 14 & 2421.7 & 64.8 & 0.5 & - \\
\hline & 28 & 2433.4 & 71.8 & 1.7 & - \\
\hline \multirow{4}{*}{10} & 1 & 2300 & 26.2 & 0.4 & 28.2 \\
\hline & 7 & 2301 & 40.3 & 0.4 & 25.3 \\
\hline & 14 & 2299.8 & 46 & 2.3 & 29 \\
\hline & 28 & 2297.5 & 51.8 & 2.6 & 27.8 \\
\hline \multirow{4}{*}{20} & 1 & 2198.2 & 18 & 0.3 & 52.5 \\
\hline & 7 & 2192.3 & 27.3 & 0.6 & 49.4 \\
\hline & 14 & 2182.4 & 31.4 & 0.5 & 51.5 \\
\hline & 28 & 2183.4 & 34.8 & 1.3 & 51.5 \\
\hline
\end{tabular}


Table A. 15. Properties of PCC mixtures containing different percentages of St-DVB-PCM at $40{ }^{\circ} \mathrm{C}$.

\begin{tabular}{|c|c|c|c|c|c|}
\hline $\begin{array}{l}\text { MPCM } \\
\text { (vol.\%) }\end{array}$ & Curing age (day) & Density (g/cm3) & Compressive strength (MPa) & Standard deviation & Strength Reduction (\%) \\
\hline \multirow{4}{*}{0} & 1 & 2396.1 & 37.9 & 0.8 & - \\
\hline & 7 & 2414.3 & 54 & 2 & - \\
\hline & 14 & 2421.7 & 64.8 & 0.5 & - \\
\hline & 28 & 2433.4 & 71.8 & 1.7 & - \\
\hline \multirow{4}{*}{10} & 1 & 2294.4 & 27.2 & 0.7 & 30.8 \\
\hline & 7 & 2291 & 39.6 & 1 & 26.7 \\
\hline & 14 & 2307 & 49.2 & 1.2 & 24.1 \\
\hline & 28 & 2303.3 & 55.9 & 2.5 & 22.1 \\
\hline \multirow{4}{*}{20} & 1 & 2238.3 & 20.9 & 0.3 & 44.8 \\
\hline & 7 & 2233.9 & 31.8 & 0.6 & 41.1 \\
\hline & 14 & 2205.8 & 38.1 & 1 & 41.2 \\
\hline & 28 & 2223.9 & 43.5 & 0.8 & 39.4 \\
\hline
\end{tabular}

